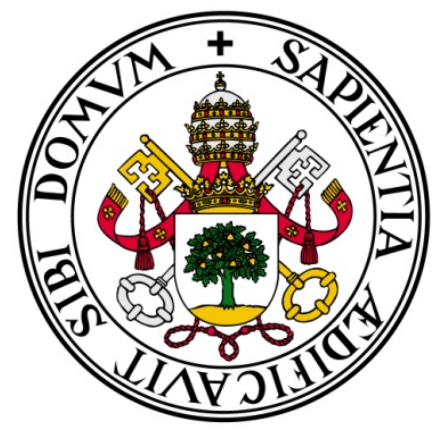

UNIVERSIDAD DE VALLADOLID

FACULTAD DE CIENCIAS

DEPARTAMENTO DE QUÍMICA ANALÍTICA

TESIS DOCTORAL

\title{
METODOLOGÍA MULTIRESIDUO PARA ANALISIS DE RODENTICIDAS EN MUESTRAS AMBIENTALES
}

Alma María Hernández Bahillo 



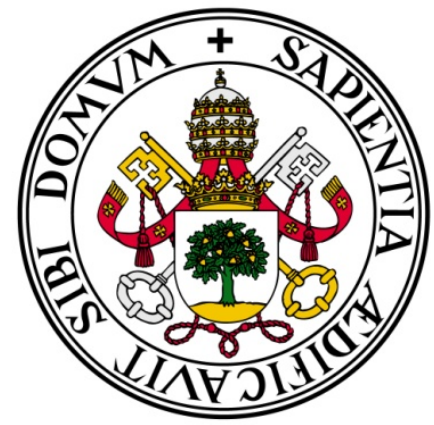

UNIVERSIDAD DE VALLADOLID

FACULTAD DE CIENCIAS

DEPARTAMENTO DE QUÍMICA ANALÍTICA

\section{TESIS DOCTORAL}

\section{METODOLOGÍA MULTIRESIDUO PARA ANALISIS DE RODENTICIDAS EN MUESTRAS AMBIENTALES}

Presentada por Alma María Hernández Bahillo para optar al grado de doctora por la Universidad de Valladolid

Dirigida por los Dres. María Jesús del Nozal Nalda y José Luis Bernal Yagüe 



\section{AUTORIZACIÓN DEL DEPARTAMENTO O COMISIÓN ACADÉMICA RESPONSABLE DEL PROGRAMA DE DOCTORADO A LA PRESENTACIÓN DE TESIS DOCTORAL}

(Art. 2.1. c de la Normativa para la presentación y defensa de la Tesis Doctoral en la UVa)

La Comisión Académica del Doctorado en QUIMICA ANALITICA APLICADA. CONTAMINACION Y MEDIO AMBIENTE en su reunión de fecha 2 de Mayo de 2014, acordó autorizar la presentación de la siguiente Tesis Doctoral, al considerar que cumple todos los requisitos establecidos en la legislación vigente:

Título: Metodología multirresiduo para análisis de rodenticidas en muestras ambientales

Autora: Da Alma María Hernández Bahillo

con D.N.I. n ${ }^{\circ} 71135217 \mathrm{~N}$

Directores:

Dr. José Luis Bernal Yagüe ( DNI: 13042484N)

Dra. María Jesús del Nozal Nalda (DNI: 12205076B)

Valladolid, 5.de Mayo de 2014

El Presidente Comisión Académica

Fdo.: José Luis Bernal Yagüe 



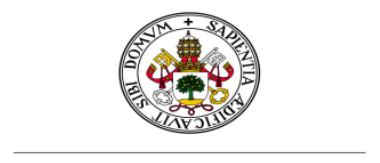

Universidad deValladolid

Impreso $2 \mathrm{~T}$

\section{AUTORIZACIÓN DE LOS DIRECTORES DE TESIS}

((Art. 21 del R.D. 1393/2007 del 29 de octubre y Art. 4 c) de la Normativa para la defensa de la Tesis Doctoral)

D José Luis Bernal Yagüe con D.N.I. no 1304248 N, Profesor del Departamento de Química Analítica, Facultad de Ciencias, Universidad de Valladolid, como coDirector de la Tesis Doctoral titulada:

Metodología multirresiduo para análisis de rodenticidas en muestras ambientales presentada por $D^{a}$ Alma María Hernández Bahillo, alumna del Programa de Doctorado QUIMICA ANALITICA APLICADA.CONTAMINACIÓN Y MEDIO AMBIENTE impartido por el DEPARTAMENTO de QUÍMICA ANALÍTICA, autoriza la presentación de la misma, considerando que cumple todos los requisitos establecidos en la legislación vigente.

Valladolid, 5 de Mayo de 2014

El Director de la Tesis,

Fdo.: José Luis Bernal Yagüe

SR. PRESIDENTE DE LA COMISIÓN DE DOCTORADO 



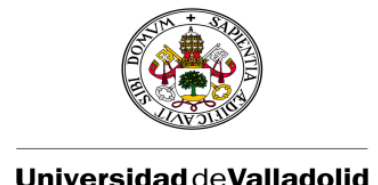

Impreso 2T

\section{AUTORIZACIÓN DEL DIRECTOR DE TESIS}

(Art. 2.1. c de la Normativa para la presentación y defensa de la Tesis Doctoral en la UVa)

Da Maria Jesús del Nozal Nalda con D.N.I. no 12205076 B, Profesora del Departamento de Química Analítica, Facultad de Ciencias, Universidad de Valladolid como co- Directora de la Tesis Doctoral titulada:

Metodología multirresiduo para análisis de rodenticidas en muestras ambientales

presentada por $\mathrm{D}^{\mathrm{a}}$ Alma María Hernández Bahillo, alumna del Programa de Doctorado QUIMICA ANALITICA APLICADA.CONTAMINACIÓN Y MEDIO AMBIENTE impartido por el DEPARTAMENTO de QUÍMICA ANALÍTICA, autoriza la presentación de la misma, considerando que cumple todos los requisitos establecidos en la legislación vigente.

Valladolid, 5 de Mayo de .2014

La Directora de la Tesis,

Fdo.: María Jesús del Nozal Nalda

SR. PRESIDENTE DE LA COMISIÓN DE DOCTORADO 

La experimentación recogida en esta Memoria ha sido llevada a cabo en los laboratorios del grupo TESEA en el Instituto CINQUIMA de la Universidad de Valladolid.

Las muestras analizadas han sido suministradas por el Instituto Tecnológico Agrario de la Junta de Castilla y León (ITACyL) que también ha contribuido a la financiación parcial de la experimentación

A todos ellos mi más sincero agradecimiento. 

"La formulación de un problema es más importante que su solución" (Albert Einstein)

"Todo parece imposible hasta que se hace" (Nelson Mandela)

"La disciplina es la parte más importante del éxito" (Truman capote) 

AGRADECIMIENTOS 

Ya hace cuatro años que comencé este duro y a la vez gratificante camino, el cual ha estado lleno de una mezcla de distintos estados emocionales que me han hecho madurar y sobretodo aprender. Por todo ello, y a todos los que han participado en este camino de superación y aprendizaje, les doy las gracias.

\section{GRACIAS a:}

Mis tutores y directores de tesis, José Luis Bernal Yagüe y María Jesús del Nozal Nalda por su ayuda en mi formación, por compartir su sabiduría conmigo y permitirme formar parte de su grupo de investigación.

Maite Martín Gómez y Laura Toribio, por formar parte de mi trabajo, las cuales han estado apoyándome con palabras de ánimo, por preocuparse de cómo avanzaba, y por prestarme su ayuda desinteresada siempre que lo he necesitado.

Luis Debán y Rafael Pardo, profesores del departamento de Química Analitica, los cuales han formado parte de mi vida universitaria con sus clases y su ayuda igualmente desinteresada.

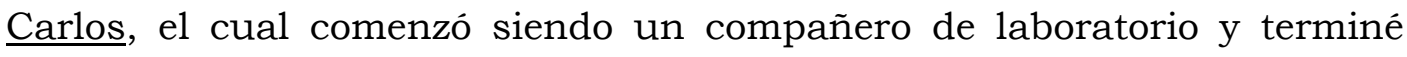
descubriendo que es una gran persona. Gracias por enseñarme a superar momentos duros, por tus sabios consejos y sobre todo por enseñarme tus amplios conocimientos. Eres un gran profesional y gran amigo.

Pili, con la que comencé esta aventura universitaria, y con la que me une una gran y profunda amistad que espero que dure PARA SIEMPRE. Hemos compartido muchos momentos felices, tristes, y siempre ha estado ahí apoyándome y levantándome el ánimo en los muchos momentos de "bajón". Por todo lo que nos ha unido y nos une, tanto en la carrera y en este período doctoral como en lo personal, MUCHAS GRACIAS AMIGA!

Karen, también hemos compartido momentos dulces y amargos juntas, de los cuales hemos podido aprender mucho. De ella aprendi otros puntos de 
vista de la analítica. Me enseñó a ver la vida de otra manera, a luchar. Gracias por tus consejos tanto científicos como personales. Es bonito saber que los $\mathrm{km}$ no son un obstáculo cuando se trata de personas de verdad. Gracias chilena. Y gracias también a Marcelo, su marido.

Ernestina, Esther y Ana, que se han preocupado por mí y por mi trabajo. Por esos momentos vividos tanto en el laboratorio como fuera de él, gracias.

Joana, "ayudante de laboratorio" durante un año. Gracias, creo que aprendimos mucho la una de la otra.

A todos los compañeros que han estado conmigo en el laboratorio, Pepe, Yolanda, Ester, César, Marcia, etc. No quiero que se me olvide ninguno, así que gracias a todos.

Y por supuesto a las últimas incorporaciones, mis compañeras Deamelys y Laura. Aunque el tiempo que hemos compartido haya sido corto, creo que ese compañerismo se ha convertido en amistad.

Mis padres, Goyo y Pili, a ellos un ENORME GRACIAS que nunca llegará a ser suficiente por todo lo que han hecho por mí. Sin ellos yo no sería nadie. Me lo han dado todo, me han ayudado en todo lo posible y se han sacrificado por mí. Gracias por aguantar mis lágrimas, enfados, desesperaciones, etc. Ahora comparto mis alegrias con ellos, que espero que también las sientan como propias.

A $\underline{\text { Nacho, }}$ por su apoyo incondicional y sus palabras de ánimo cuando lo necesitaba.

A mis abuelos, Pili y Nicanor. También les debo mucho.

A mi abuela Asunción por su preocupación, y a mi abuelo Gregorio, que está en el cielo. 
A mis amigos y demás familia que se han interesado por este período de mi vida.

A todos ellos, GRACIAS. 

"Una experiencia nunca es un fracaso, pues siempre viene a demostrar algo" (Thomas Alva Edison)

"El que ha llegado tan lejos que ya no se confunde, ha dejado también de trabajar" (Max Plank)

"El destino es el que baraja las cartas, pero nosotros somos los que jugamos" (William Shakespeare) 

INDICE 



\section{INTRODUCCIÓN}

II. ANTECEDENTES Y ESTADO ACTUAL DEL TEMA

III. OBJETIVOS

IV. MATERIALES Y REACTIVOS

IV.1 Instrumentación

IV.2 Equipo adicional

IV.3 Reactivos y disolventes

IV 4 Columna analítica

V. DETERMINACIÓN DE CP, BD, DF Y BF EN SUELOS

V.1 Disoluciones

V.2 Condiciones cromatográficas

V.2.1 Condiciones para la detección

V.2.2 Composición de la fase móvil

V.3 Tratamiento de muestra

V.4 Validación del método analítico

V.5 Aplicación del método propuesto

a muestras de suelo

VI. DETERMINACIÓN DE CP, BD, DF Y BF EN AGUA

VI.1 Tratamiento de muestra

VI.1.1 Extracción en fase sólida

VI.1.2 Extracción líquido-líquido

VI.2 Validación del método

VI.3 Aplicación del método propuesto

a muestras de agua

VI.4 Liberación al agua de BD y CP

V.2.1 Liberación de BD

V.2.2 Liberación de CP

VII. DETERMINACIÓN DE CP, BD, DF Y BF EN TEJIDOS

VII.1 Tratamiento de muestra

VII.2 Validación de la metodología analítica pág. 5

pág. 11

pág. 39

pág. 43

pág. 45

pág. 47

pág. 47

pág. 48

pág. 49

pág. 51

pág. 51

pág. 52

pág. 59

pág. 67

pág. 72

pág. 81

pág. 87

pág. 89

pág. 89

pág. 97

pág. 112

pág. 125

pág. 126

pág. 126

pág. 131

pág. 137

pág. 139

pág. 147 
VII.3 Aplicación del método de análisis de muestras de hígado, músculo e intestino pág. 157

VIII. ANÁLISIS MULTIRESIDUO DE 9 RODENTICIDAS EN MUESTRAS DE SUELO Y AGUA pág. 159

VIII.1 Condiciones cromatográficas pág. 161

VIII. 1.1 Condiciones de detección pág. 162

VIII. 1.2 Composición de la fase móvil pág. 166

VIII.2 Determinación de nueve rodenticidas en suelo pág. 173 VIII.2.1 Validación del método pág. 180

VIII.2.2 Aplicación del método de análisis a muestras de suelo pág. 183 VIII.3 Determinación de nueve rodenticidas en agua pág. 183

VIII.3.1 Validación de la metodología analítica pág. 188

VIII.3.2 Aplicación del método pág. 192

IX. CONCLUSIONES pág. 193

X. BIBLIOGRAFÍA pág. 199 
I.- INTRODUCCIÓN 

En la mayoría de los países, incluyendo España, se emplean los rodenticidas anticoagulantes para control de la población de roedores y reducir el daño asociado a las cosechas, particularmente aquellos problemas ocasionados por el topillo campesino (Microtus arvalis) en cuyo ciclo reproductivo, condicionado entre otros factores por la climatología, se producen periódicamente picos demográficos que alteran la dinámica de las poblaciones. En Castilla y León vienen apareciendo de manera cíclica esas plagas lo cual ha motivado la implantación de estrategias y campañas para su control, teniendo como última opción el empleo de los rodenticidas. En los últimos años, esas campañas se han visto incrementadas en respuesta a la situación planteada por las recientes plagas.

En la campaña agrícola 2006/2007, las condiciones meteorológicas, caracterizadas por temperaturas suaves y ausencia de lluvias intensas, facilitaron la multiplicación de dicho roedor en amplias zonas de Castilla y León, con una virulencia tal que no hubo más remedio que recurrir finalmente al empleo amplio de rodenticidas. A tal fin se aplicó, con no demasiada fortuna, granos de cereal impregnados de clorofacinona. Posteriormente, se aplicó en cebo parafinado y ante la no remisión de la plaga se pasó al empleo de la bromadiolona, primero en grano y luego en cebo parafinado, incluidos directamente en la hura o protegidos en tubos de $50 \mathrm{~cm}$, para evitar el acceso de otros animales, consiguiéndose un drástica reducción del número de roedores y por tanto la erradicación de la plaga.

No obstante, se planteó una situación hasta entonces no considerada puesto que esa acción tan enérgica aplicando cebo en base cereal, a veces coloreados en azul, rojo o verde para hacerlos más apetitosos para los roedores, parece ser que provocó una elevada mortandad de 
especies no diana, lo que derivó en la selección de otro rodenticida y sobre todo varió su forma de aplicación. Obviamente, esos compuestos altamente tóxicos están en el medio ambiente pudiendo entrar directamente en la cadena alimentaria o pasar a los ríos y lagos u otros cursos de agua.

Ante el conocimiento de fenómenos de resistencia ya probados para clorofacinona e incluso apuntados para la bromadiolona, nos planteamos incluir otros posibles rodenticidas a fin de considerar posibles tratamientos alternativos en el futuro puesto que las plagas se repiten. Hubo un repunte en 2012 que se consiguió frenar y en estos momentos están observándose parámetros que hacen sospechar la repetición de la virulencia de la de 2007, por lo que se está comenzando a tratar con bromadiolona determinadas zonas de la Comunidad. Ante ello y desde el punto de vista analítico, creemos necesario disponer de métodos sensibles para evaluar los residuos de esos compuestos en diferentes matrices.

Las matrices que se han considerado han sido prioritariamente suelos y agua para conocer el efecto de la aplicación de esos compuestos en el campo. Se planteó el caso inicial de los compuestos entonces autorizados, aunque actualmente clorofacinona ya no es aplicable, y se desarrollaron métodos multirresiduo, incluyendo los compuestos de las familias de las hidroxicumarinas y las indandionas. Al mismo tiempo, se pensó en conocer cómo los distintos cebos liberaban los principios activos al agua.

Finalmente se pudieron conseguir cadáveres de topillos, que fueron diseccionados, y en sus vísceras y tejidos se realizó un análisis aplicando métodos que previamente hubieron de desarrollarse. Con ello, puede tenerse una idea básica acerca de la repercusión medioambiental de las aplicaciones en campo y sobre todo tener datos para tratamientos de futuras plagas.

Para desarrollar los métodos, y teniendo en cuenta las características físico-quimicas de los compuestos, se ha elegido la cromatografia líquida 
de alta resolución, empleando columnas de mayor versatilidad y tratando de proponer fases móviles que permitieran el trabajo con los detectores de UV-visible y fluorescencia y que a su vez fueran compatibles con los de espectrometría de masas.

Se han buscado procedimientos lo más sencillos, rápidos y económicos posibles para aislar y concentrar los analitos en las diferentes matrices ensayadas.

La metodologia desarrollada ha sido aplicada a diferentes muestras recogidas en las distintas Provincias de la Comunidad, teniendo en cuenta zonas sin tratamiento, con tratamiento leve, medio e intenso.

Como etapa final, la metodología desarrollada se ha transferido a la Junta de Castilla y León a fin de que sus laboratorios la implanten, validen y acrediten de modo que estén preparados para futuras apariciones de la plaga. 

II. ANTECEDENTES Y ESTADO ACTUAL DEL TEMA 

El artículo 2 de la Ley 43/2002, de 20 de Noviembre, de Sanidad Vegetal, define en su letra e) como plaga al "organismo nocivo de cualquier especie, raza o biotipo vegetal o animal o agente patógeno dañino para los vegetales o los productos vegetales“. Es en este contexto donde se encuadra la investigación que se presenta.

El topillo campesino (Microtus arvalis) es un roedor en cuyo ciclo reproductivo, condicionado entre otros factores por la climatologia, se producen periódicamente picos demográficos que alteran la dinámica de las poblaciones, causando afección en las parcelas y cultivos donde se asientan, además de otros perjuicios que se comentarán en otro apartado.

En España, la distribución del topillo campesino se limitaba hasta hace 20 años a los sistemas montañosos de la mitad norte (Cordillera Cantábrica, Sistema Central, Sistema Ibérico y Pirineos). Sin embargo, los ciclos poblacionales que ha experimentado esta especie a partir de 1980, con explosiones demográficas cada tres o cuatro años, han propiciado la colonización de nuevas áreas, ocupando en la actualidad prácticamente la totalidad de la Meseta Norte.

En la campaña agrícola 2006/2007, las condiciones meteorológicas caracterizadas por temperaturas suaves y ausencia de lluvias intensas facilitaron la multiplicación de dicho roedor en amplias zonas de Castilla y León. La imposibilidad de control por parte de los agricultores con acciones individuales y los elevados daños ocasionados en las parcelas agrícolas en dicha campaña determinaron que por orden AYG/556/2007 de 19 de Febrero se declarara oficialmente en el territorio de Castilla y León la existencia de plaga de topillo campesino, declarando asimismo de utilidad pública y urgente ejecución las medidas fitosanitarias dirigidas a su control, de conformidad con lo dispuesto en el artículo 15 de la Ley 43/2002. 
Mediante resolución de 19 de Julio de 2007 de la Consejería de Agricultura y Ganadería se autorizó como medida fitosanitaria para la lucha contra dicha plaga el arado profundo tras la recolección de la cosecha en las explotaciones agricolas afectadas por dicha plaga. Posteriormente por Orden AYG/1469/2007 de 14 de Septiembre se declaró como medida fitosanitaria para la lucha contra la plaga la quema de rastrojos en las mencionadas explotaciones. Asimismo, mediante la Orden AYG /1765/2007 de 5 de Noviembre, se declaró como medida fitosanitaria para la lucha contra dicha plaga la quema de cunetas, linderos y desagües de parcelas en determinadas comarcas y municipios de la Comunidad Autónoma.

El Ministerio de Agricultura, Alimentación y Medio Ambiente consciente de la especial dificultad que reviste el control de las poblaciones de estos roedores, exige actuar preventivamente en situaciones y épocas en las que no existe una relación directa con los daños que aparecerán posteriormente en periodos en los cuales el agricultor no tiene directa responsabilidad, así como la situación catastrófica que se produce cíclicamente en los cultivos agrícolas de aquellas regiones geográficas en las que estas plagas son endémicas, y las especiales circunstancias de su control. Por todo lo que esto conlleva, el Ministerio aconseja la integración de un conjunto de medidas fitosanitarias necesarias para prevenir y controlar sus explosiones demográficas naturales. Además, se aprobó el Real Decreto 409/2008, de 28 de Marzo, por el que califica de utilidad pública la prevención y lucha contra las plagas del topillo de campo, "Microtus arvalis" (Pallas) y otros microtinos, y se establece el programa nacional de control de los mismos, de acuerdo con lo dispuesto en el artículo 15 de la Ley 43/2002.

De acuerdo con el mencionado Real Decreto, se adoptan como medidas fitosanitarias de prevención y control del desarrollo de las poblaciones de topillo de campo las siguientes: 
a) Prácticas culturales limitantes para el desarrollo de las poblaciones de topillo, relativas al laboreo del terreno, rotaciones con cultivos poco favorables a la plaga, planificación adecuada de las siembras otoñales, y control de la cubierta vegetal en los lugares que son reservorios de las poblaciones. A los efectos previstos, las quemas de los lugares que son reservorios de poblaciones de topillo se considerarán técnicas de control de la cubierta vegetal.

b) Promoción del control biológico de la plaga mediante el fomento de los vertebrados depredadores.

c) Utilización de sistemas de trampeo de la plaga en las zonas en las que se detecte actividad de los topillos.

d) Reducción de las poblaciones de plaga mediante tratamientos bajo control oficial con productos rodenticidas, cuando se superen los umbrales que para cada zona determine la Comunidad Autónoma, mediante controles localizados, según las circunstancias, en toperas, zonas de refugio o en grandes superficies.

e) Cualquier otra medida distinta de las anteriores, que se justifique técnica o científicamente como necesaria para prevenir y controlar el desarrollo de las poblaciones de las plagas de topillos.

En el caso concreto de la plaga mencionada, no cabe duda que la virulencia con que apareció pilló quizás por sorpresa a toda la Comunidad, la cual se veía impotente a hacerla remitir por los medios habituales habiéndose de recurrir, en última instancia, al empleo de rodenticidas. La creación de un comité asesor a este respecto (Comité Científico de Lucha Contra Plagas Agrícolas en Castilla y León, Decreto 11/ 2008 de 14 de Febrero, BOCyL n 35 de 20 de Febrero) creemos contribuyó a poner las cosas en su sitio y a establecer un plan director (PLAN DIRECTOR DE LUCHA CONTRA PLAGAS AGRÍCOLAS EN CASTILLA Y LEÓN 2008-2011) para futuras actuaciones. 
La información pormenorizada que se recoge $\mathrm{y}$ analiza ha constituido desde entonces una medida sumamente útil ante nuevas situaciones de crisis o pre-crisis, como pudo suceder a finales de 2012 y más recientemente en los primeros meses de 2014. Como medidas preventivas, lo primero que se ha hecho a través del Plan Director de Plagas es intentar conseguir un censo fiable de las poblaciones. Una vez conocido es posible prever que pueda repuntar y entonces, a partir de ahí, pueden comenzar a aplicarse medidas preventivas, principalmente en las zonas más prolificas las cuales deben ser conocidas.

Esta situación no es exclusiva de España como se puso de manifiesto en el European Vertebrate Pest Management Conference celebrada en Turku, Finlandia en Septiembre de 2013 ( EUPMC9).Por ejemplo Jens Jacob en su comunicación sobre plagas en Alemania, indicó que en 2012 hubo otra explosión demográfica del topillo campesino que causó daños en más de 650.000ha con pérdidas económicas superiores a los 150 millones de euros.

\section{Los rodenticidas}

Son compuestos ampliamente usados para controlar especies de roedores que pueblan el entorno molestando a los humanos y dañando diferentes tipos de bienes. Esta práctica es muy común en granjas para prevenir el deterioro y consumo de piensos y granos almacenados, el daño a edificaciones y la transmisión de enfermedades (Shore, 2006; Tosh, 2011). Algunas especies de roedores, con ciclos marcados de población, pueden dañar grandes extensiones de cosechas han sido controladas por el empleo de este tipo de compuestos (Olea, 2009). Los roedores también pueden usar y cubrir otros entornos humanos como ciudades y vertederos con el consiguiente riesgo de transmisión de zoonosis (Semenza, 2009; Vidal 2009). Por ello, el tratamiento con rodenticidas se lleva a cabo regularmente bajo condiciones muy controladas, como productos para protección de las plantas o biocidas (Berny, 2010), también se emplean 
para conservar las especies nativas en islas donde los roedores has sido introducidos, si bien pueden originar efectos adversos sobre especies no diana (Eason, 2002).

Sin lugar a dudas, los compuestos hoy día más empleados son los anticoagulantes que tienen una acción inhibitoria sobre el enzima epoxireductasa de la Vitamina $\mathrm{K}$.

La Warfarina fue el primer rodenticida antocoagulante introducido en el mercado. Su descubrimiento fue fruto de la investigación de las intoxicaciones observadas en ganado durante la década de los 20 en Wisconsin. Estas intoxicaciones, caracterizadas por una alta mortalidad y sangrado, se relacionaban con el consumo de pasto en mal estado. Posteriormente, se descubrió que se debía a la transformación de la cumarina, presente en el trébol dulce (Meliotus alba) del pasto, en dicumarol, un potente anticoagulante, por fermentación fúngica (Last, 2002). Unos años más tarde, hacia 1931, un veterinario de Dakota del Norte llamado L. M. Roderick demostró que la hemorragia se producía cuando había un déficit de protrombina en la sangre por debajo del 10\%, lo que impedía la coagulación de la sangre. Gracias al descubrimiento de las propiedades anticoagulantes del dicumarol y su aplicación en la prevención de formación de trombos en humanos, se sintetizó la Warfarina, una sustancia estable, incolora, inodora, y básicamente insipida y con mayor actividad anticoagulante cuyo nombre se debe a que fue patentada por la "Wisconsin Alumni Research Foundation". Con el nombre de warfarin, esta sustancia empezó a utilizarse como raticida hacia 1940; le siguieron otros productos de primera generación (coumarin, indandiona), caracterizados por tener corta vida media y requerir de dosis repetidas para producir los mismos efectos en la lucha contra los roedores. Este compuesto químico también se utiliza como medicamento anticoagulante en humanos. 
Todos los rodenticidas anticoagulantes orales son compuestos derivados de la 4-hidroxicumarina o de la indandiona (Ecobichon, 2001). Se han clasificado en anticoagulantes de primera o de segunda generación, según su eficacia contra roedores resistentes a la warfarina (Ishizuka, 2008). Por definición, los ingredientes activos con efecto tóxico contra roedores "resistentes a la warfarina" se denominan rodenticidas anticoagulantes de segunda generación, generalmente más tóxicos y bioacumulables (Thomas, 2011) aunque ya se citan también fenómenos de resistencia a estos de segunda generación (Vien, 2011).

Actualmente la warfarina es muy poco utilizada como rodenticida y en cambio, hay una mayor oferta de rodenticidas de segunda generación. La característica es que los de primera generación se consideran que no son suficientemente tóxicos para causar la muerte de los roedores con una simple exposición y requieren dosis adicionales. Dentro de estos rodenticidas encontramos ingredientes activos derivados de la indandiona, como: Pindona, Difacinona y Clorofacinona. También se encuentran aquellos derivados de la 4-hidroxicumarina, como: Warfarina, Coumachlor, Cumafuryl y Cumatetralilo (Racumin). Los de segunda generación se diferencian de los anteriores en que para lograr el efecto letal en la rata, es necesario que ingiera una sola dosis, produciéndose la muerte algunos días después. Esto se debe a la gran potencia rodenticida del ingrediente activo. Dentro de estos compuestos están: Brodifacum, Flocumafen, Bromadiolona, Difetialona. Según (Brooks y Rowe, 1979), Brodifacum es el más tóxico de este grupo, por lo tanto, se emplea en una sola dosis en una concentración de $0.005 \%$. Suelen tener una alta estabilidad para su almacenaje $\mathrm{y}$, dada su baja volatilidad, las concentraciones en el aire son muy bajas, lo que les da un alto nivel de seguridad. 
Los tipos de rodenticidas más usados y algunos de sus nombres comerciales se muestran en la Tabla 1.

Tabla 1: Principio activo y nombre del producto comercial

\begin{tabular}{cc}
\hline PRINCIPIO ACTIVO & NOMBRE COMERCIAL \\
\hline Brodifacum & Klerat, Talon \\
Bromadiolona & Contrac, Lanirat, Ratex, \\
Clorofacinona & Ratomet, Ramucide \\
Coumatetralilo & Racumin \\
Difacinona & Matex Rodenticida, Ramix \\
Flocumafen & Pellet, Liquatox, P.C.Q. \\
Warfarina & Storm, Stratagem \\
Difenacum & Ratoxin, Raticin, Rodex, \\
Pindona & Warfatodo \\
& Ratak \\
\hline
\end{tabular}

Los anticoagulantes y sus derivados se absorben por vía oral y también por la piel y el sistema respiratorio, teniendo como órgano diana al hígado. Alli interfieren competitivamente el metabolismo de la vitamina $\mathrm{K}$, la cual es producida ya sea por vegetales (vitamina $\mathrm{K} 1=$ fitoquinona), o por microorganismos intestinales (vitamina $\mathrm{K} 2=$ menaquinona). Cualquiera sea su forma, la vitamina se inactiva ("vitamina K epóxido") tras ser utilizada por los hepatocitos para la síntesis de factores de la coagulación II, VII, IX y X (Figura 2). Se reactiva nuevamente mediante un proceso en el cual el enzima "vitamina $\mathrm{K}$ epóxido reductasa" desempeña un rol clave. La vitamina es almacenada por el hígado en forma de vitamina $\mathrm{K}$ activa, con lo cual, reanuda su ciclo. Los rodenticidas anticoagulantes inactivan al enzima antes señalado, con lo cual la vitamina no puede ser reactivada y 
deriva de ello una grave hemorragia interna. El esquema se muestra en la Figura 1:

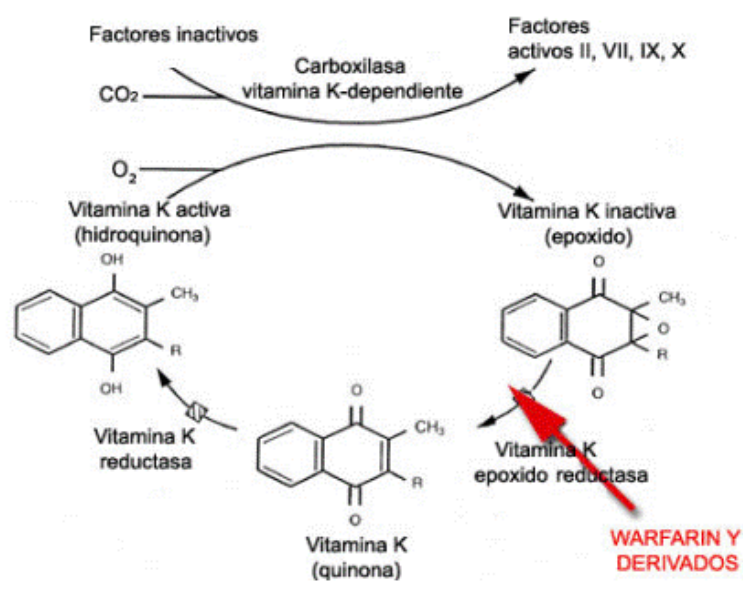

Figura 1: Metabolismo de la vitamina $\mathrm{K}$

El efecto antiprotrombina es el más conocido y proporciona la base para detectar y evaluar el envenenamiento clínico, pero también aumenta la permeabilidad de los capilares a través del cuerpo, predisponiendo al animal a una hemorragia interna masiva, debido a la larga vida-media que tienen los factores anticoagulantes dependientes de la vitamina $\mathrm{K}$ (Mack, 1994; Katona, 1989), aunque después de la ingestión de pequeñas dosificaciones de los compuestos modernos más tóxicos puede presentarse una hemorragia letal (Litovitz, 1997).

Estos biocidas atacan al hígado, al corazón y los pulmones, provocando sintomas neurológicos y hemorragias internas, como se ha comentado anteriormente. Los topillos suelen morir lejos del comedero, generalmente en sus madrigueras y sin mostrar señales de dolor ni agonía; sus congéneres no son capaces de relacionar la muerte con el lugar preparado para atraer a los roedores y éste sigue siendo frecuentado bastante tiempo. El problema es que también pueden morir en la superficie, quedando su cadáver a disposición de animales carnívoros (intoxicación de animales no-diana). 
Son numerosos los autores que a partir del año 1958 han descrito la existencia de poblaciones de ratas resistentes a rodenticidas anticoagulantes como la warfarina. En muchos estudios se ha encontrado resistencia individual no sólo a la warfarina, sino también a otros compuestos derivados de la hidroxicumarina y de la indandiona, exceptuando los anticoagulantes de segunda generación (Brooks, 1979) en los que como se ha comentado ya se describen también fenómenos de resistencia. Según Wallace y Macswinnery (1976), el mecanismo de resistencia en el ratón casero se debe a la existencia de un gen dominante. En el caso de la rata noruega, éste estaría determinado por un solo gen autosomal resistente (Greaves, 1984).

La resistencia a rodenticidas anticoagulantes en ratas y ratones es heredable, trasmitiéndose de generación en generación y no como resultados de la ingestión de pequeñas cantidades de cebo. Dicha resistencia se manifiesta siempre y cuando el gen respectivo esté presente en poblaciones de ratas sometidas a programas intensivos de control, que hayan empleado los productos de primera generación durante varios años (Litovitz, 1997). Además está demostrado que la flora bacteriana intestinal de los roedores sintetiza vitamina $\mathrm{K}$, para evitar este efecto, algunos laboratorios agregan a sus fórmulas sulfaquinoxalina y antibióticos como la tetraciclina, eliminando así la flora bacteriana.

Aunque en principio los tratamientos se realizaron con clorofacinona y bromadiolona, en la actualidad solo es posible el uso de la bromadiolona, que también está en aras de ser prohibida, por lo que quizás se autoricen otros compuestos dentro de estas familias o se propongan otros nuevos por lo que se han considerado los compuestos de ambas familias, cuyas características básicas se resumen a continuación.

Warfarina: (Cumafeno, zoocumarina, warfarin), $\mathrm{C}_{19} \mathrm{H}_{16} \mathrm{O}_{4}$. (RS)-4-hidroxi-3(1-fenil-3-oxo-butil)- cumarina) Su solubilidad en agua es igual a $17 \mathrm{mg} / \mathrm{L}$ 
a $20^{\circ} \mathrm{C}$. Es soluble en acetona y dioxano, ligeramente soluble en metanol, etanol e isopropanol y prácticamente insoluble en benceno y ciclohexano. DL50 oral: en rata de alcantarilla $58 \mathrm{mg} / \mathrm{kg}$.

Clorofacinona: (Chlorophacinone, $\mathrm{C}_{23} \mathrm{H}_{15} \mathrm{ClO}_{3} \quad$ (2-(2-(4-clorofenil)-2fenilacetil)indan-1, 3-diona). Se trata de un derivado de la indandiona creado por los laboratorios franceses Lipha SA. Considerado como el de acción más rápida, puede provocar una mortalidad hasta del $96 \%$ con una sola ingestión (con varias se puede llegar al 100\%), mientras que en el resto de los anticoagulantes son necesarias varias ingestiones para llegar a un porcentaje alto de mortalidad. Poco soluble en agua $(100 \mathrm{mg} / \mathrm{l} \mathrm{a}$ $20^{\circ} \mathrm{C}$ ), soluble en aceite, acetona, etanol y metanol. Tiene baja toxicidad en aves salvajes (DL50 $430 \mathrm{mg} / \mathrm{kg}$ ). Solubilidad a $25^{\circ} \mathrm{C}$ en etanol $(0,7$ $\mathrm{mg} / 1)$, metanol (0,47 mg/1), hexano (0,2 mg/1), cloroformo (40,8 mg/1) y acetona $(4,3 \mathrm{mg} / 1)$. DL50 oral: en rata $2 \mathrm{mg} / \mathrm{kg}$, en ratón $1 \mathrm{mg} / \mathrm{kg}$. Presenta varios máximos de absorción en el ultravioleta cercano.

Bromadiolona: (Bromadiolone, $\mathrm{C}_{30} \mathrm{H}_{23} \mathrm{BrO}_{4}$. (3-[3-(4-bromodifenil-4-il)-3hidroxi-1-fenilpropil]-4-hidroxicumarina). Rodenticida anticoagulante derivado de la cumarina creado por los laboratorios franceses Lipha SA y presentado en 1976. Una sola ingestión de $50 \mathrm{mg} / \mathrm{kg}$ es suficiente para matar al cabo de 5 días a una rata de alcantarilla. Es eficaz contra las ratas y ratones resistentes a la warfarina y al cumatetralilo. Es soluble en agua, etanol, acetona, acetato de etilo y dimetilformida. Habitualmente la concentración del ingrediente activo que hay en los cebos es muy baja, por lo que se asume que deben consumirse normalmente varias dosis para que resulte eficaz. DL50 oral: en rata de alcantarilla $1,125 \mathrm{mg} / \mathrm{kg}$. Presenta absorción en el ultravioleta cercano y fluorescencia.

Difenacum (Difenacoum, $\mathrm{C}_{31} \mathrm{H}_{24} \mathrm{O}_{3}$. (3-(3-bifenil-4-il-1,2,3,4-tetrahidro-1naftil)-4-hidroxicumarina). Primer rodenticida de segunda generación, desarrollado en 1972 por Sorex Limited de Londres y comercializado en 
1975. Poco soluble en agua a $20^{\circ} \mathrm{C} 1,7 \mathrm{mg} / 1 \mathrm{PH} 7$. Soluble a $20^{\circ} \mathrm{C}$ en acetona (7,6 g/1), propanol (1,5 g/1), tolueno (1,2 g/1), methanol: $(1,2 \mathrm{~g} / 1)$, hexano $(12,1 \mathrm{~g} / 1)$, diclorometano $(19,6 \mathrm{~g} / 1)$. DL50 oral: en rata de alcantarilla $1,8 \mathrm{mg} / \mathrm{kg}$. Presenta absorción en el ultravioleta cercano y fluorescencia.

Brodifacum: (Brodifacoum, $\mathrm{C}_{31} \mathrm{H}_{23} \mathrm{BrO}_{3}$. (4-hidroxi-3-(3-(4'-bromo-4bifenilil)-1,2,3,4-tetrahidro-1-naftil)cumarina. Sorex Ltd de Londres comercializó en 1977 un raticida con esta sustancia que fue desarrollada en 1974 por Imperial Chemical Industries PLC. Se trata de un anticoagulante derivado de la cumarina, de segunda generación. Es de los más activos. Es muy poco soluble en agua (menos de $10 \mathrm{mg} / 1$ a $20^{\circ} \mathrm{C}$ y PH7). Poco soluble en alcoholes y benceno, soluble en acetona. Se trata de un biocida de ingesta única. DL50 oral: en rata de alcantarilla 0,27 $\mathrm{mg} / \mathrm{kg}$, en ratón doméstico $0,40 \mathrm{mg} / \mathrm{kg}$. Presenta absorción en el ultravioleta cercano y fluorescencia.

Cumatetralilo: (Coumatetralyl, $\mathrm{C}_{19} \mathrm{H}_{16} \mathrm{O}_{3}$. Desarrollado por Bayer AG en 1956 y conocido con el nombre de Racumin. Solubilidad en agua $(10 \mathrm{mg} / 1$ a $\left.20^{\circ} \mathrm{C}\right)$, diclorometano $(75 \mathrm{~g} / 1)$, isopropanol $(35 \mathrm{~g} / 1)$. DL50 oral: en rata de alcantarilla $16,5 \mathrm{mg} / \mathrm{kg}$.

Difacinona: (diphacinone, diphenadione), $\mathrm{C}_{23} \mathrm{H}_{16} \mathrm{O}_{3}$. (2-difenilacetil-1,3indandiona). Indandiona desarrollada en Estados Unidos. Las características de este anticoagulante fueron descritas en 1952. Poco soluble en agua (0,3 mg/1), soluble en acetona (29 g/1) y en tolueno (73 g/1). Se descompone rápidamente en agua por la acción del sol. DL50 oral: en rata de alcantarilla $3 \mathrm{mg} / \mathrm{kg}$.

Pindona: (pival, pivaldiona, pindone), $\mathrm{C}_{14} \mathrm{H}_{14} \mathrm{O}_{3}$. (2-(2,2-Dimetil-1oxopropil)-1H-indeno-1,3 (2H)-diona). Indandiona sintetizada en $1937 \mathrm{y}$ desarrollada como insecticida. Fue creado como una alternativa a las piretrinas. En 1953 se estudió su uso como raticida anticoagulante. 
Solubilidad en agua a $25^{\circ} \mathrm{C}: 18 \mathrm{mg} / 1$. Soluble en alcohol, éter y acetona. DL50 oral: en rata de alcantarilla $50 \mathrm{mg} / \mathrm{kg}$.

Flocumafen:(Flocoumafen, $\mathrm{C}_{33} \mathrm{H}_{25} \mathrm{~F}_{3} \mathrm{O}_{4}$ (2-Hydroxy-3-[3-[4-([4trifluoromethyl) phenyl] methoxy) phenyl]- 1,2,3,4 -tetrahydronaphthalen1-yl] chromen-4-one). Coumarina fluorado. Rodenticida de alta toxicidad, intermedia entre Bromadiolona y Brodifacum. Es estable a hidrólisis a $50^{\circ} \mathrm{C}$ y pH $7-9$. Se utiliza para el control de roedores en arroz, caña, piña, melón, palma aceitera y cacao, en centros urbanos e industriales y en granos almacenados. DL50/CL50 oral (ratas): 0,25 mg/kg; inhalación (ratas): 0,00008 mg/L. Extremadamente peligroso (OMS). Altamente tóxico (formulación) (EPA).

Las estructuras químicas de los compuestos se muestran en la Figura 2. 


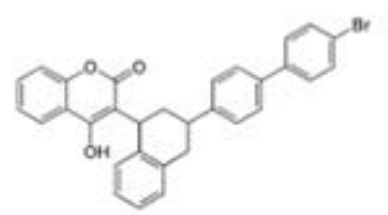

Brodifacum (BF)

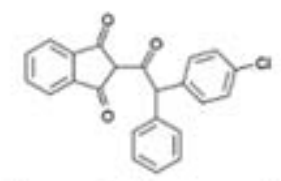

Clorofacinona (CP)

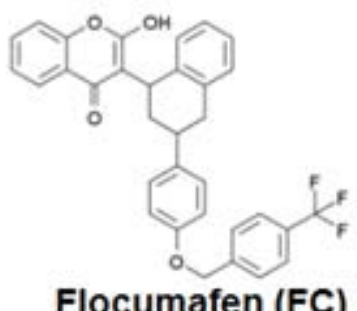

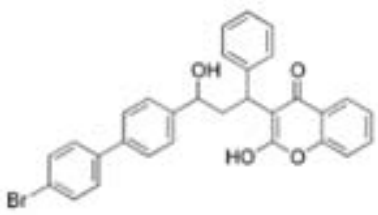

Bromadiolona (BD)

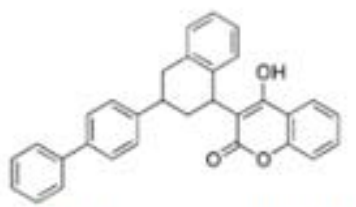

Difenacum (DF)

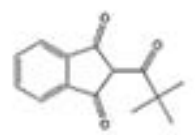

Pindona (PD)

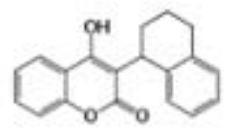

Cumatetralilo (CT)

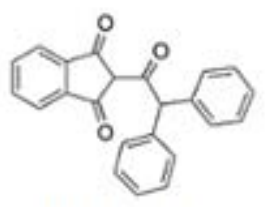

Difacinona (DP)

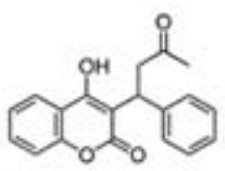

Warfarina (W)

Figura 2: Estructura química de los rodenticidas

\section{Efectos secundarios}

El problema colateral que plantea el empleo masivo de rodenticidas se relaciona con la persistencia de esos productos en el campo, y en particular en los suelos agrícolas, lo cual puede condicionar su posterior uso así como generar toxicidad secundaria en otras especies ya sea por acceso directo al veneno como por su actividad predadora (Lemus, 2011, Witmer,2011). Dentro de las informaciones, de muy diferente sesgo y derivadas después de la lucha contra la plaga de 2007, queremos señalar un estudio realizado (Sánchez-Barbero, 2012) sobre unas 400 muestras de animales, domésticos y silvestres, encontrados muertos en España, con posible evidencia de envenenamiento por anticoagulantes, tratando de explicar un envenenamiento primario y secundario de animales no diana. Sin ahondar en el muestreo, factor clave para la deducción de cualquier 
conclusión, sí que es interesante indicar que se detectaron residuos en casi un 40\% de las muestras, pensándose que un 34,9\% podía haber muerto por anticoagulantes, basado en que los sospechosos tendrían del orden de $0,005 \mu \mathrm{g} / \mathrm{g}$, mientras que los positivos estarian del orden de 0,706 $\mu \mathrm{g} / \mathrm{g}$ del peso global. Las rapaces nocturnas y los carnívoros estarian entre los consumidores secundarios con mayor prevalencia a la exposición a los anticoagulantes, especialmente a los de segunda generación. Por otra parte, las aves granivoras fueron las más afectadas por la clorofacinona en el episodio de 2007, posiblemente porque este producto en grano fue lo que en principio fue empleado, para posteriormente pasar a cebo y más tarde sustituirlo por la bromadiolona. No quisiéramos dejar este apartado sin hacer mención que esos fueron los productos recomendados por la Junta De Castilla y León, lo cual no es impedimento para que los agricultores adquieran y apliquen otros productos, cuestión que debería siempre ser muy tenida en cuenta.

No obstante creemos de sumo interés se conozca la permanencia de los productos tras su aplicación puesto que en muchas ocasiones las condiciones para su biodegradación no están siempre presentes e incluso el propio compuesto es resistente a la degradación. Ello, unido a posibles fenómenos de resistencia de las especies diana a ciertos compuestos, puede orientar a tratamientos con compuestos alternativos que con eficacia similar o mayor se apliquen en las condiciones adecuadas para minimizar la cantidad de residuos y su vida media en condiciones reales de campo. No obstante, ambos compuestos se han empleado conjuntamente para combatir plagas en otros lugares hace ya bastante tiempo (Askham, 1985), donde también se han comentado efectos adversos sobre otras especies no diana. Ello ha motivado que diversas agencias establezcan regulaciones acerca de su empleo (WHO, 1995; WHO/FAO 1996; US EPA, 2011) por citar algunas relacionadas con bromadiolona y otros rodenticidas. 
La clorofacinona es un compuesto perteneciente a la denominada primera generación y se sintetizó a partir del compuesto cumarinico quizás más conocido, la warfarina. Estos rodenticidas de primera generación son los predecesores de una segunda generación tales como difenacum, bromadiolona, brodifacum y flocumafen, que son tóxicos más agudos. En España, el empleo de cebos con compuestos de la primera generación está menos regulado y se permite su empleo en campañas extensivas de control por su efecto bioacumulativo, aunque clorofacinona a pesar de pertenecer a este grupo ha mostrado toxicidad secundaria para búhos, mustélidos y zorros (Albert, 2010, Fournier, 2004), mientras que los de segunda generación tienen un uso más restrictivo debido a su efecto letal con una sola dosis ingerida (Buckle,1994). En nuestro país y como fitosanitarios están comercializándose, entre otros, Brodifacum, Bromadiolona, Difenacum y Clorofacinona y se sigue empleando Warfarina. Revisando compendios de plaguicidas y bibliografia reciente hemos encontrado que en otros lugares se emplean para roedores también otros compuestos, quizás más efectivos, que se encuadran dentro del grupo conocido como superwarfarinas, podiamos destacar por su cita frecuente a cumafuril, cumatetralilo, así como la difacinona y la pindona. Por supuesto que se emplean otros compuestos de muy diversa naturaleza, no obstante del examen de sus propiedades y acción, caso de tetramina o fluoroacetamida, no creemos deban considerarse como alternativas próximas. En cuanto a los venenos inorgánicos, el único autorizado es el fosfuro de aluminio (lo hay también de cinc) y no creemos adecuado su ensayo por la alta peligrosidad que conlleva, incluso para los manipuladores, y más si tenemos en cuenta que en este caso no se trataría en general de aplicación por expertos.

Otro aspecto que debería tenerse en cuenta sobre el uso masivo de rodenticidas es que ya se están comentando episodios de aparición de resistencia como comentan en Francia (Vein, 2011) después del tratamiento de la plaga de ratón de campo (Arvicola terrestres scherman) 
con bromadiolona. Se intentó primeramente un control físico con trampas, control biológico con predadores, mostrándose como insuficientes por si solos y muy lentos por lo que al final se optó por el anticoagulante. Se trató con grano y también se detectó mortandad, en particular del zorro rojo. Examinando la actuación sobre esa plaga cíclica se ha detectado también un hecho sorprendente: la bromadiolona es más persistente en el grano de lo estimado originalmente (Sage, 2007). Esta aparición de resistencia ha sido también observada en otros lugares de Europa, Norteamérica, Asia y Australia (Greaves, 1994; Pelz, 2005; Ishizuka, 2008) y ya se había descrito para warfarina (Kohn, 2000; Markussen, 2008). Sobre este compuesto también cabe mencionar otros aspectos significativos tales como la aparición de sus residuos en suelos y cebadas después de su aplicación a cosechas cerealistas (Lakticova, 2009,) incluso tres años después del tratamiento, donde se detectaron hasta 0,072ppm, lo cual está motivando estudios acerca de su degradación enantioselectiva en suelos (Lao, 2012), teniendo en cuenta que está considerado como un contaminante emergente. Este hecho es escasamente considerado y sin embargo ya hace bastante tiempo (Ogilvie, 1997), en relación a tratamiento con Brodifacum para erradicar plagas de ratas en algunas Islas de Nueva Zelanda, observan que cuando los cebos quedan en el suelo se degradan muy lentamente con vidas medias superiores a los 160 días. Destacan la fuerte adsorción al suelo donde permanece prácticamente inmóvil con lo que es más probable que pueda persistir, lo cual se incrementa con la presencia de ácidos húmicos aumentando su toxicidad (André, 2005;Wong, 2013). Como consecuencia general se puede señalar que: los productos quimicos usados en la agricultura entran en la cadena alimentaria más frecuentemente a través de su aplicación al suelo o a los cultivos, y la penetración de sustancias en el suelo y su permanencia pueden afectar a las plantas, vida animal, medio ambiente y biodiversidad en general.

Como resumen podría señalarse: 
- en Castilla y León vienen apareciendo plagas de topillo campesino (en estos momentos, Enero 2014, existen algunos datos que señalan un aumento nuevo de poblaciones de roedores).

- Las virulencias con que aparecen hacen necesario recurrir como vía última al empleo de rodenticidas autorizados.

- El empleo de esos anticoagulantes debe tener en cuenta los efectos colaterales sobre otras especies, lo cual condiciona el modo de aplicación.

- No se conoce nada acerca de qué pasa con los rodenticidas que se depositan en superficie ni en huras, su persistencia y degradación en los principales tipos de suelo de la Comunidad.

En cuanto a la metodología empleada es muy dispar puesto que el número de matrices a abordar es tremendamente diferente y al mismo tiempo se pueden considerar diversos compuestos, bien aislados o agrupados entre sí o con otros, generalmente pesticidas. Por ello, en este apartado se va a tratar de presentar los trabajos que fueron pioneros y en los que posteriormente se han basado la mayoría de los autores, así como una visión más reciente a la luz del estado actual de la metodología analítica empleada en el tema que nos ocupa, destacando aquellos aspectos más significativos que nos han ayudado a establecer las pautas a seguir en los diferentes casos que se presentan, sin tratar de presentar una relación bibliográfica exhaustiva.

Con relación al aislamiento de los analitos, las dos opciones más utilizadas son las extracciones líquido-líquido y sólido líquido, obviamente condicionados por el estado físico de la matriz. Los disolventes utilizados son muy diversos empleándose bien aislados: metanol, diclorometano, acetonitrilo, acetato de etilo, acetona, cloroformo; o bien en mezclas de ellos (Langset, 1991) realizándose normalmente varias extracciones, como ya indicaba Hunter en 1983 en 
sus primeros trabajos sobre determinación de residuos de rodenticidas cumarínicos en tejidos animales, en los que también sugería realizar una concentración en columnas de permeación por gel proponiendo distintas estrategias para abordar la determinación y confirmación de varios de ellos (Hunter, 1985) o de alguno en particular como en el caso de la bromadiolona (Hunter, 1988), ideas asimiladas posteriormente por muchos autores (Groboscht, 2006). Otras opciones para alimentos y fluidos biológicos apuntan a las ventajas del empleo de la extracción acelerada con disolventes (ASE) que parece funciona con éxito en la aplicación para analizar cuatro rodenticidas en arroz, maíz y sangre (Hao,2014)

Los extractos son purificados y concentrados a través de minicolumnas y cartuchos con diferentes sorbentes, predominan los de C18 y poliméricos, aunque recientemente algunos grupos tratan de adecuar metodología QuEChERS, quizá por estar de moda.

Para la preparación de muestra en el análisis de tejidos, la mayoría de los autores emplean el método inicialmente propuesto por Berny y colaboradores en 1995, tratando varias veces con acetona, eliminando las proteínas con éter dietílico, centrifugando, evaporando a sequedad y redisolviendo en la fase móvil. Sin embargo, otros prefieren atacar la muestra con acetonitrilo (Marek, 2007) y posteriormente purificar en cartuchos de alúmina, mientras que para las muestras liquidas recomiendan extracción con diclorometano y concentración en cartuchos de cianopropil (Primus, 2006).

En algunos casos introducen un patrón interno tal como dimetilcoumarina (Vanderbrouke, 2008) u otro rodenticida como difenacum (Sage, 2007) que a veces añaden sobre la muestra original y otras veces solo emplean en la etapa de determinación. No es una práctica muy frecuente y más si se tiene en cuenta que una enorme cantidad de trabajos son desarrollados por investigadores que no son 
químicos y menos químico analíticos. Raramente se sugiere que la calibración se realice sobre matriz, cuando la mayoría constata que esta influye notablemente.

En cuanto a las técnicas empleadas, la mayor parte de los investigadores se decanta por el empleo de HPLC con detectores que van desde los iniciales UV-visible (Hunter, 1985) y Fluorescencia (Lawrence, 1991), a las modernas hibridaciones con diferentes detectores principalmente de masas. Creemos que la detección a ionización negativa en electrospray da suficiente sensibilidad como ya se indicó en su momento (Letta, 2007; Jin, 2007; Yan, 2012), ahora bien, dicen que la recuperación no era tan buena como se deseaba (Jin, 2008) y por eso proponen masas en tándem. No creemos que ello implique una mejora en la recuperación como señalan otros autores (Cai, 2009).

Desde tiempos pasados, se han propuesto obviamente numerosas alternativas, como la cromatografia en fase gaseosa con derivatización previa (Bullard, 1976), la cual proporciona buena selectividad y sensibilidad si bien el procedimiento parece no suministraba buenas recuperaciones y además era demasiado lento.

Se han sugerido también técnicas espectrofotométricas (Kawano, 1980) que posiblemente sigan siendo útiles para análisis en formulados pero que presentan problemas de selectividad al tratar de aplicarlas a multirresiduo, no obstante quizá con la actuales herramientas quimiométricas podría resolverse ese aspecto aunque pensamos que para nivel de traza seguiría habiendo dificultades. Esos niveles también dificultan el empleo de la cromatografia en capa fina en sus distintas modalidades (Opong, 1988; Berny, 1995), por lo que como se ha comentado, la mayoría de los autores se han inclinado por el empleo de la cromatografia líquida en fase inversa. En el caso de los trabajos iniciales de Hunter también se proponía fase normal, la 
técnica proporcionaba sensibilidad adecuada pero inicialmente daba resoluciones muy pobres para las indandionas (Addison, 1982; Reynolds,1980; Mura,1992), por lo que a veces se ha recurrido a la formación de pares iónicos, generalmente con tetrabutilamonio, con lo que se facilitaba el análisis de clorofacinona y difacinona (Vigh, 1981; Hunter, 1985) con detección fluorescente, con mejor selectividad y buena sensibilidad. Pero existía un problema: el acortamiento de la vida útil de la columna por la adsorción del reactivo sobre la fase estacionaria (Jin, 2007b, Guan, 1999), pero no obstante se sigue empleando (Vudathala, 2010, Giorgi, 2010). A pesar de las diferentes alternativas, la mayoría de los trabajos actuales se centran en el empleo de la fase inversa. Debe tenerse en cuenta que las columnas han evolucionado enormemente y los detectores actuales han mejorado ostensiblemente desde las primeras propuestas de análisis para los anticoagulantes.

La separación generalmente se hace sobre columnas con $\mathrm{C} 18$ como fase estacionaria, aunque a veces se sugiere el C8 (Marek, 2007).

Las fases móviles empleadas son muy variadas, en algunos casos son válidas para trabajo con detectores UV-visible o fluorescente, en otros solo se desarrollan para detectores de masas. Se emplean generalmente en gradiente, algunos realmente complicados (Giorgi, 2010). Lo más común es el empleo de acetato amónico-agua-metanol (Marek, 2007), metanol-fosfato di ácido de potasio (Sage, 2007), formiato amónico-agua (Vandenbroucke, 2008), fosfato diácido con tetrabutilamonio (Primus, 2006), incluso con regeneración del eluyente (Jin, 2008). Obviamente todo ello depende del tipo de matriz y sobretodo del compuesto o compuestos a determinar. Hablariamos de métodos de residuo simple o de métodos multirresiduo.

La determinación de clorofacinona y difacinona en formulados, así como los otros rodenticidas en su caso, se suele abordar por 
cromatografia líquida con detectores de UV-visible o fluorescencia puesto que se trata habitualmente de cantidades apreciables. Los métodos, ya clásicos, para grano y cebos suelen implicar extracciones repetidas, limpieza-concentración y empleo de amplios tamaños de muestra (Yuen, 1978; Bland, 1983). Ahora bien, cuando el tamaño de muestra es reducido no queda más opción que ir a técnicas más sensibles como puede ser la detección por espectrometría de masas (Mesmer, 2000).

No hay demasiados trabajos dedicados a la determinación de residuos de rodenticidas en suelos y en su caso se dirigen a algún compuesto en concreto. Quizás el más buscado y del que más literatura se encuentra sea la warfarina que habitualmente se medía por HPLCDAD después de una extracción sólido líquido asistida por ultrasonidos o bien empleando Soxhlet con metanol como extractante, encontrando numerosas interferencias debidas a la matriz (Medvedovici, 1997), posiblemente debidas a la interacción entre los complejos solubles de ácidos húmicos en el agua y suelo, a los cuales los rodenticidas se unen con alta afinidad (André, 2005) y que facilitan la movilización y transporte de los compuestos hidrofóbicos en el medio ambiente. La extracción de warfarina en suelos en los que se había aplicado un formulado para combatir una plaga de ratón de campo, se suele hacer por extracción repetida con cloroformo-acetona, posterior evaporación del disolvente, centrifugado en presencia de nhexano, utilizando C18 y detección UV (Lakticova, 2009). Estos autores detectan residuos en cebada y trigo y en el suelo hasta tres años después de la aplicación de diferentes dosis.

La determinación de trazas de anticoagulantes en muestras líquidas, tales como bebidas de frutas y similares, suele llevarse a cabo por extracciones repetidas con diclorometano, evaporando el extracto y reconstituyendo en metanol al que se adiciona acetato amónico para posteriormente analizarlo por LC-ESI/MS/MS (Marek, 2007). En aguas 
prácticamente no hay bibliografia salvo la relativa a algunos episodios esporádicos como la pérdida desde un helicóptero de un contenedor con cebos de Brodifacum (Fisher, 2012) y caída en una lago. Parece ser que al cabo de dos semanas no se detectaba el compuesto en el agua atribuyéndolo a su reducida solubilidad, que además es muy dependiente del $\mathrm{pH}$, se hace hincapié en que se adhiere mucho más a la materia orgánica presente tanto en los cebos como en su aplicación sobre grano (World Health Organization, 1995).

La mayor parte de la literatura más reciente se centra en la metodología multirresiduo para solventar problemas de envenenamiento de humanos o para ayudar al análisis forense. Se incluyen más de un compuesto, generalmente anticoagulantes, aunque frecuentemente se seleccionan algunos rodenticidas y se añaden algunos plaguicidas, habitualmente herbicidas, para abordar distintas situaciones. Por lo general, estas metodologias buscan inicialmente la confirmación de la existencia de trazas en alguno de los compuestos y raramente incluyen aspectos cuantitativos. El órgano diana empleado suele ser el hígado por almacenar preferentemente los compuestos. La metodología es muy dispar aunque generalmente coinciden en emplear HPLC, la diferencia suele estribar en el tratamiento de la muestra. Generalmente se emplea una extracción con disolventes orgánicos y un clean-up con cartuchos de extracción en fase sólida. Esa limpiezaconcentración de los extractos no solo es esencial para conseguir adecuada sensibilidad en el caso de empleo de detectores convencionales, sino que es imprescindible en orden a minimizar el efecto matriz cuando se utiliza el acoplamiento a masas, al mismo tiempo que se mantiene al detector en condiciones óptimas de operación (Berny, 1995; Mesmer, 2000; Guermouche, 2008; Vanderbrouke, 2009; Vudathala, 2010).

Los detractores del clean-up con los cartuchos de extracción en fase sólida argumentan que suele implicar tiempo y volúmenes grandes de 
disolvente para activar, lavar y eluir la muestra, aunque todo es discutible pues se pueden lograr concentraciones elevadas. Como alternativa, a veces no tan eficaz como se preveía, se suele optar por la metodología QuEChERS (Anastassiades, 2003) inicialmente propuesta para fruta y vegetales, es decir, para muestras con alto contenido en agua, se hace una extracción con acetonitrilo y una etapa de limpieza mezclando el extracto con amina primaria secundaria (PSA), sulfato de magnesio, C18 y/o carbón grafitizado (GCB). Su aplicación a muestras con alto contenido en grasa y poca humedad plantea bastantes problemas, de hecho son muy pocos los trabajos que lo recomiendan, por ejemplo, en el análisis de residuos de fármacos en el hígado (Kinsella, 2009; Ploss1, 2006). Para la determinación de algunos rodenticidas se propone una notable modificación incluyendo una reextracción con acetonitrilo y un sorbente múltiple en el que a los ya clásicos se agregan florilsil y alúmina básica, se hace una posterior formación de pares iónicos (Vudathala, 2010) y detección UV-FLD, lo que a nuestro juicio no muestra por ningún lado ni la economía de tiempo ni de reactivos.

Aunque no es objeto de nuestro estudio, parece que el análisis de suero y plasma plantea menos dificultades y como resulta que quizás el interés en abordarlo es más grande, pues suele tratarse de envenenamientos en humanos, no se suelen escatimar medios y es más que frecuente el uso de LC-ESI/MS/MS (Zuo,2010, Yan,2012), trampa de iones (Chen, 2009) o modificaciones para técnicas convencionales como puede ser la sensibilización de la luminiscencia en presencia de Ytrio (Jin, 2011).

No cabe duda pues que la técnica habitualmente empleada es la cromatografía líquida en la que se siguen utilizando los detectores UVvisible (Ring, 2000, Vudathala, 2010) y fluorescencia (Armentano, 2012) o combinación de ambos; y en el caso de la espectrometría de masas existen distintas opciones, desde el cuadrupolo a las 
hibridaciones más actuales (Vandenbrouke, 2008; Zuo, 2010; Yan, 2012). En muy contadas ocasiones se emplean separaciones quirales previa a la detección por masas, lo más común ha sido estudiar los enantiómeros de la warfarina (Zuo, 2010), si bien dependiendo del selector quiral y el modo de operar se han propuesto también detectores UV (Locatelli, 2005) solos o acoplados en línea con detector de fluorescencia y dicroísmo circular (Takahshi, 1997), el empleo de la electroforesis capilar (Zhou, 2003), o la alternancia de columnas (Uno, 2007).

Por último, y en relación a otras matrices, hay que tener en cuenta, como se ha comentado anteriormente, que el empleo de los rodenticidas puede implicar riesgos en especies no diana ( Vyas, 2012; Langford, 2013; Hernández Moreno, 2013) bien por exposición primaria (consumo directo) o secundaria (los predadores que consumen roedores), por lo que se ha regulado ampliamente su venta y empleo ( WHO, 1996; USEPA ,2011). En cuanto a sus efectos, hay numerosos estudios tratando de comprobar y explicar las posibles intoxicaciones. En nuestro País se ha estudiado la presencia de rodenticidas en hígado de avutardas recogidas entre 1991-2010, encontrándose que 10 de las 71 muestras examinadas contenían clorofacinona y una de ellas flocumafen; parece que también existía una correlación con la cantidad de patógenos en las aves intoxicadas (Lemus, 2011), si bien las opiniones son contradictorias con estudios realizados en otros lugares. Así en Inglaterra, un estudio sobre la incidencia de los anticoagulantes de segunda generación sobre las mofetas indicaba que no había efectos secundarios (Shore ,2003). En esta línea y realizando un seguimiento sobre las lechuzas (Gray, 1994) y el empleo de brodifacum, difenacum y flocumafen que se administraron durante 15 días vía ratón alimentado con rodenticida para simular condiciones de campo, se encontró que las lechuzas sobrevivian a una dosis, acumulada durante esos dias, de cada 
rodenticida de al menos 1,9 mg / kg. Ello equivale al consumo diario de dos ratones de $25 \mathrm{~g}$ con un residuo de $1 \mathrm{mg} / \mathrm{kg}$ cada uno. Obviamente se observó que el hígado era el órgano que más retenía el rodenticida ingerido. Este mismo grupo investigador (Gray, 1994b) propone el estudio del regurgitado para tener un procedimiento no invasivo, señalando que un $25 \%$ del rodenticida consumido es regurgitado.

También se ha observado que muchos invertebrados consumen parte de los cebos, tanto en los lugares de almacenado como en los suelos de áreas tratadas (Dunlevy, 2000). Esos invertebrados pueden ser alimento posterior de las aves y traspasar los rodenticidas. Por ello, hay diversos estudios relativos a la determinación de distintos anticoagulantes en especies tales como caracoles, babosas, etc (Primus, 2006) detectándose valores del orden de $4 \mathrm{mg} / \mathrm{kg}$, que son muy elevados si los compara con los valores encontrados en cadáveres de animales expuestos al cebo como pueden ser ratas, ratones $\mathrm{y}$ ardillas. Creemos que la cuestión no es tan simple pues se ha demostrado que la presencia de bromadiolona en cebos de trigo depende no solo del medio ambiente sino también del comportamiento de los ratones, describiendo como una cinética de primer orden, la cual no tiene que ver con el almacenamiento prolongado en las huras (Sage, 2007), aunque tenemos la duda de que los resultados sean válidos puesto que extrae con metanol y esas no son las condiciones reales de campo. Esa cinética es en cierto modo similar a la observada para estudios de bromadiolona en huevos de gallina (Giorgi, 2010), aunque estos autores realizan una cromatografia realmente extraña pues la fase móvil es muy compleja (tres disoluciones diferentes con mezclas de varios componentes) para luego emplear detección UV.

Como resumen pueden indicarse los siguientes aspectos: 
- Prácticamente no hay bibliografia acerca de la determinación multicomponente en suelos y agua, y en la existente se indican problemas de estabilidad y recuperación.

- Donde más información se encuentra es en la determinación de diversos grupos de compuestos en hígado, en ese caso la preparación de muestra es tremendamente variada, en muchas ocasiones se emplean disolventes clorados cuyo uso está prohibido o en vías de restricción, la purificación de los extractos se realiza por extracción en fase sólida siendo los sorbentes más habituales los de $\mathrm{C} 18$ y poliméricos.

- Con respecto a la separación se suele emplear mayoritariamente la cromatografia líquida, en general sobre columnas de octadecilsilano, ahora bien las fases móviles propuestas, a veces muy complicadas, son prácticamente diseñadas para un detector específico y son de difícil empleo con otros detectores.

- La detección suele ser por UV- visible con detectores que van desde los de longitud de onda variable a los de diodos alineados, en otras ocasiones y frecuentemente después de generar pares iónicos se opta por la detección fluorescente. Ambas situaciones no llegan a resolver bien problemas de trazas o multicomponente. El detector obviamente más preferido es el espectrométrico de masas desde el cuadrupolo, que se muestra muy eficaz, a las modernas hibridaciones. 


\section{II.- OBJETIVOS}



El objetivo final es llegar a conocer la incidencia que, sobre los suelos y aguas del entorno, ha tenido el tratamiento intensivo con rodenticidas de amplias extensiones agrarias de la Comunidad con motivo de la erradicación de la plaga de topillo campesino que apareció en la campaña agrícola de 2006/2007.

Para ello, se han planteado una serie de objetivos intermedios:

- Desarrollo de metodología analítica para determinación de clorofacinona, bromadiolona, difenacum y brodifacum en suelos agrícolas.

- Desarrollo de metodología analítica para determinación de clorofacinona, bromadiolona, difenacum y brodifacum en agua.

- Estudio de la liberación de rodenticida por cebos con clorofacinona o bromadiolona en agua.

- Desarrollo de metodología analítica para determinación de clorofacinona, bromadiolona, difenacum y brodifacum en tejidos de topillo campesino.

- Desarrollo de metodología multirresiduo para nueve rodenticidas en suelo y agua.

- Aplicación de los métodos desarrollados a la determinación de residuos de rodenticidas en muestras seleccionadas de suelos, aguas y cadáveres de topillo. 

IV.-INSTRUMENTACIÓN Y REACTIVOS 



\section{IV.1.- Instrumentación}

Durante la experimentación se han utilizado tres equipos de cromatografia de líquidos de alta resolución. A continuación se describen brevemente las características generales de los mismos.

- Cromatógrafo de líquidos de alta resolución de Agilent Technologies (Palo Alto, CA, EE.UU.), series 1050 que consta de un depósito de disolventes, un desgasificador, una bomba cuaternaria, un inyector automático con bandeja muestreadora de 100 viales, compartimento termostatado de columnas, detector de fluorescencia (FLD) y espectrofotométrico de longitud de onda variable.

- Cromatógrafo de líquidos de alta resolución de Agilent Technologies (Palo Alto, CA, EE.UU.), series 1100 que consta de un depósito de disolventes, un desgasificador, una bomba cuaternaria, un inyector automático con bandeja muestreadora de 100 viales, compartimento termostatado de columnas, detector de fluorescencia (FLD) y diodos alineados (DAD), todo ello controlado por el software ChemStation Rev. A. 06.03.

- Cromatógrafo de líquidos de alta resolución de Agilent Technologies (Palo Alto, CA, EE.UU.), series 1100 que consta de un depósito de disolventes, un desgasificador, bomba cuaternaria, un inyector automático con bandeja muestreadora de 100 viales, compartimento termostatado de columnas y detector de espectrometría de masas (MSD) con analizador cuadrupolar, todo controlado por el software HPLC/MSD Chemstation Rev. A.10.02. Este detector está equipado con dos fuentes de ionización, electrospray (ESI) e ionización química 
- presión atmosférica (APCI). Son dos interfases pertenecientes a la familia de técnicas denominadas ionización a presión atmosférica las cuales tienen como objetivo y finalidad eliminar la fase móvil utilizada para la separación por HPLC y transformar los analitos que se encuentran en disolución en iones en estado gaseoso, realizándose la transformación a presión atmosférica.

- Los campos de aplicación de ambas fuentes de ionización se muestran en la Figura 3, dependiendo de la polaridad y el peso molecular de los analitos.

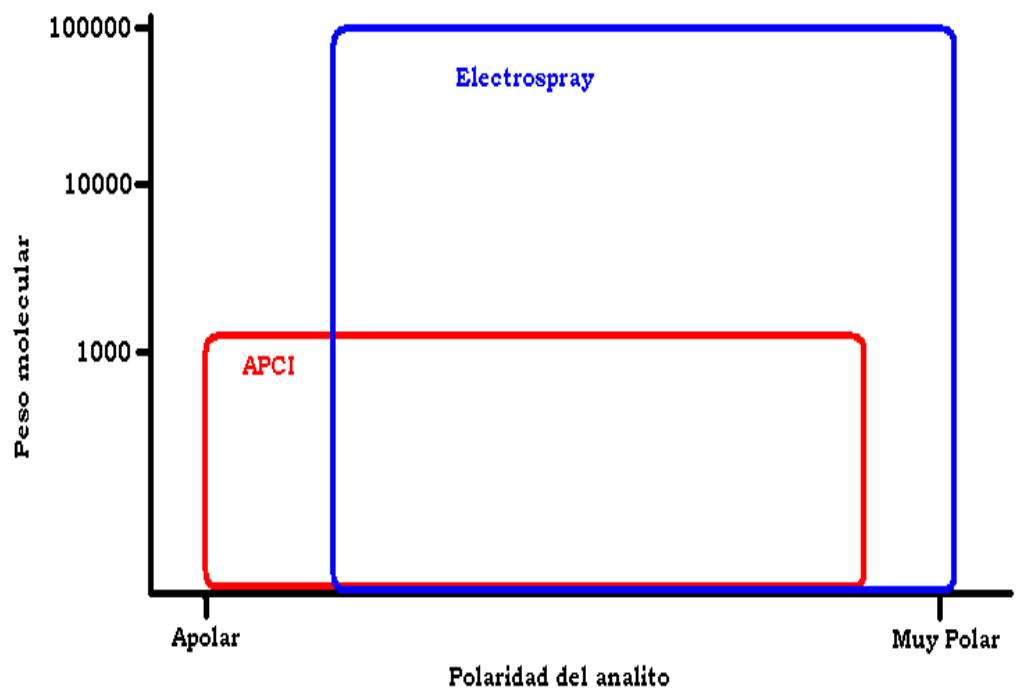

Figura 3: Campos de aplicación de la fuente de ionización.

Como se puede observar en la Figura ambas interfases son complementarias, sirviendo APCI para analitos de baja a mediana polaridad, y ESI para analitos de mediana a alta polaridad. 


\section{IV.2.- Equipo adicional y reactivos}

El material adicional utilizado se detalla a continuación:

- Agitador Vibromatic de J.P. Selecta SA (Barcelona, España).

- IKA $^{\circledR}$ Ultraturrax $^{\circledR}$ T18 basic de IKA-Werke GmbH \& Co.KG (Staufen, Alemania).

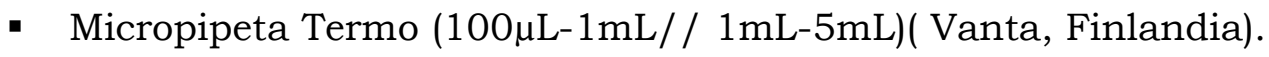

- Baño de ultrasonidos de J.P. Selecta SA (Barcelona, España)..

- Balanza analítica de precisión EA-240 de Mettler Toledo, (Darmstadt, Alemania).

- Centrífuga 5810R de Eppendorf (Hamburg, Alemania).

- Cartuchos de extracción Oasis ${ }^{\circledR}$ HLB (60 mg/3mL), Waters (Milford, MA, USA).

- Equipo de extracción en fase sólida con sistema de vacío Visiprep ${ }^{\mathrm{TM}}$ de Supelco (St. Louis, MO, USA).

- Filtros de jeringa con membrana de nylon $0.45 \mu \mathrm{m}$ x $13 \mathrm{~mm}$ de Advantec MFS (Dublín, CA, USA).

- pH-metro MicropH 2001 de Crison (Barcelona, España).

- Rotavapor R- 210/215 de Büchi (Flawil, Suiza).

- Equipo de filtración, Phenomenex (Torrance, CA, USA).

- Filtros de jeringa de Nylon (17 mm, 0,45 $\mu \mathrm{m})$ de Nalgene (Rochester, NY, USA)

- Material de uso general de laboratorio.

\section{Reactivos y disolventes}

- Patrones rodenticidas: clorofacinona (CP, 96\%), bromadiolona (BD, 98\%), difenacum (DF, 97\%), brodifacum (BF, 96\%), flocumafen (FC, $96,5 \%)$ utilizado como patrón interno para el análisis por LC-MS y analito, warfarina (W, 99.9\%), coumatetralil (CT, 97\%), difacinona (DP, 
99\%), pindona (PD, 98,5\%) suministrados por Dr. Ehrenstofer Gmbh (Augsburg, Germany).

- Metanol y Acetonitrilo, gradiente HPLC, de PANREAC (Barcelona, España).

- Formiato amónico grado reactivo, 97\% de Sigma-Aldrich (Madrid, España)

- Ácido fórmico de Sigma-Aldrich (Madrid, España)

- Acetato de etilo, Labscan (Dublin, Ireland).

- Sulfato de aluminio 18-hidrato, PANREAC (Barcelona, España).

- Di-n-butilamina para análisis de PANREAC (Barcelona, España).

- Cloruro amónico de Carlo Erba (Milan, Italia).

- Ácido etilendiamino tetracético sal disódica de AnalytiCals Carlo Erba (Milan, Italia).

- Solución de amoníaco 32\% purísimo de Scharlab (Barcelona, España).

- Agua ultrapura procedente de un equipo compacto que consta de dos unidades de purificación (Milli- RO y Milli- Q) de Millipore (Bedford, MA, USA).

\section{Columna Analitica}

Fase inversa Gemini de Phenomenex (Torrance, CA, USA) cuyas características son:

Longitud

Diámetro Interno

Tamaño partícula

Mecanismo de separación

Soporte

Fase estacionaria

Tamaño de poro

Área superficial

Carga de $\mathrm{C}$

Intervalo de $\mathrm{pH}$

- Precolumna:
$150 \mathrm{~mm}$

$4.6 \mathrm{~mm}$

$5 \mu \mathrm{m}$

Fase inversa

Organosílica porosa

$\mathrm{C}_{18}$, recubrimiento Trimetilsililo

$110 \AA$

$375 \mathrm{~m}^{2} / \mathrm{g}$

$14 \%$

1-12

Gemini $\mathrm{C}_{18}$ 
V.- DETERMINACIÓN DE CLOROFACINONA, BROMADIOLONA, DIFENACUM Y BRODIFACUM EN SUELOS 

Como ya se ha indicado anteriormente en la memoria, para combatir la plaga de topillos la Junta de Castilla y León autorizó tratamientos con clorofacinona y bromadiolona, sin embargo, sospechando que se habian podido utilizar otros rodenticidas no autorizados, en un principio se

abordó el desarrollo de un método analítico para la determinación de cuatro rodenticidas en suelos, clorofacinona, bromadiolona, difenacum y brodifacum. A continuación se detallan las etapas llevadas a cabo para la determinación de los compuestos.

\section{V.1.- Disoluciones}

Se prepararon por pesada disolviendo aproximadamente $10 \mathrm{mg}$ de cada compuesto en $10 \mathrm{~mL}$ de metanol para obtener una concentración del orden $1000 \mathrm{mg} / 1$. La concentración de estas disoluciones fue corregida de acuerdo con su pureza. A partir de las disoluciones de patrones individuales se obtuvieron las disoluciones de trabajo por dilución en metanol. Fueron almacenadas a $4^{\circ} \mathrm{C}$ y protegidas de la luz para evitar la posible fotodegradación. Estas disoluciones se mantuvieron estables por un período de 1 mes.

\section{V.2.- Condiciones cromatográficas}

Según la revisión bibliográfica realizada, el mecanismo más utilizado para la separación de este tipo de compuestos es el reparto en fase inversa, utilizando como fases móviles disoluciones de diferentes tampones y como modificador orgánico acetonitrilo o metanol. Estas condiciones se tomaron como punto de partida para encontrar las condiciones óptimas de determinación de los cuatro compuestos en suelo. Se realizaron estudios acerca de la influencia que las distintas variables cromatográficas podrian ejercer sobre la separación con la finalidad de encontrar las condiciones óptimas que permitieran realizar una correcta determinación de los analitos. Para la realización de este estudio se procedió a modificar una 
variable manteniendo las demás constantes con el fin de comprobar el efecto que produce cada una de ellas en los parámetros cromatográficos. A continuación, se describe de manera detallada este proceso para cada una de las variables estudiadas.

\section{V.2.1.- Condiciones para la detección}

El empleo de detectores acoplados se debe en primer lugar a que la clorofacinona, al no ser una molécula fluorescente, se debe de detectar por absorción molecular; mientras que los otros tres compuestos, al presentar fluorescencia, proporcionan una señal más intensa que por absorción, consiguiéndose unos límites de detección y cuantificación más bajos que se podrian reducir aún más, caso de que fuera necesario, con el empleo de la espectrometría de masas como sistema de detección. Se creyó interesante desarrollar el método de análisis utilizando detección DAD-FLD, a pesar del inconveniente de su menor sensibilidad frente al MSD, pues sería aplicable en los laboratorios donde no se dispusiera de detectores de masas.

Debido a que se utilizaron tres tipos de detectores, DAD, FLD y MS, se tuvieron que establecer las condiciones para cada uno de ellos. Las pruebas se hicieron con una fase móvil binaria compuesta por metanol/formiato de amonio $20 \mathrm{mM}$ en agua (70:30, v/v) a $\mathrm{pH} 6.5$ con una columna Gemini $5 \mu \mathrm{C}_{18}$ a un flujo de fase móvil de $1 \mathrm{~mL} \mathrm{~min}^{-1}$ en régimen isocrático, manteniendo la temperatura del compartimiento de 
columna a $25^{\circ} \mathrm{C}$ e inyectando $20 \mu \mathrm{L}$ de mezcla de patrones, salvo cuando se realizó el FIA para el MS donde no se empleó columna y el flujo fue de $0.3 \mathrm{~mL} \mathrm{~min}^{-1}$.

\section{Absorción molecular UV-Visible (DAD)}

Con las condiciones cromatográficas iniciales seleccionadas e inyectando un patrón de clorofacinona de concentración de $5 \mathrm{mg} \mathrm{L}^{-1}$ en metanol, se obtuvo el espectro de absorción molecular en el intervalo de 200 a 400 nm. El espectro obtenido se presenta en la Figura 4:

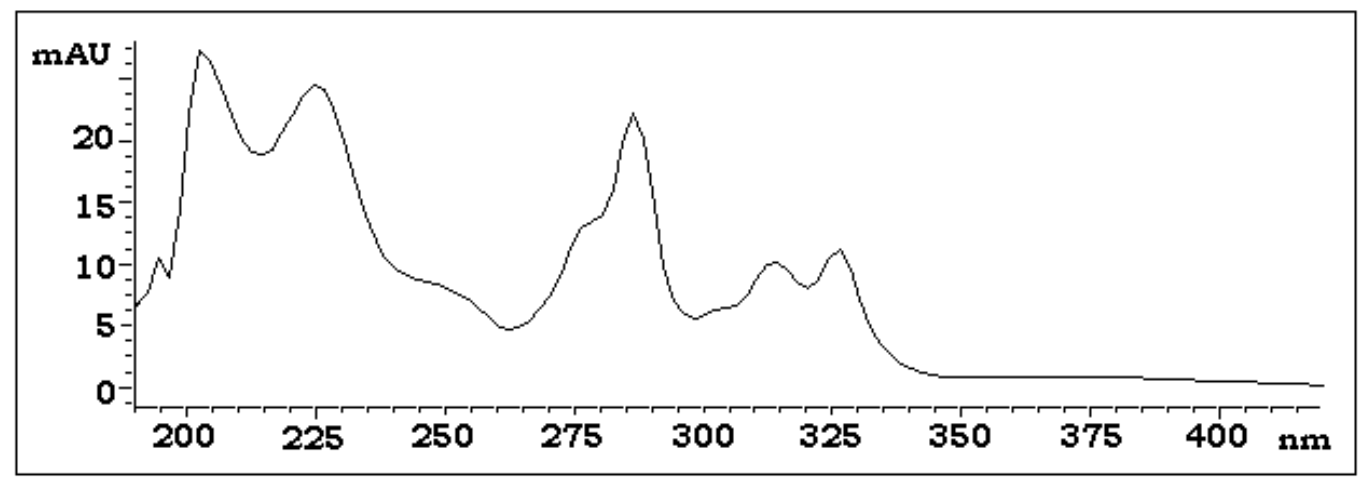

Figura 4: Espectro de absorción molecular.

Como se puede observar, la clorofacinona (CP) presenta máximos de absorción a las longitudes de onda de 224, 285, 313 y $325 \mathrm{~nm}$. Tras comparar la intensidad obtenida con cada uno de ellos se concluyó que la mayor sensibilidad se obtendría utilizando la longitud de onda de $285 \mathrm{~nm}$ para la detección.

\section{- Fluorescencia molecular (FLD)}

De igual manera se procedió para la obtención de los espectros de excitación y emisión de bromadiolona, difenacum y brodifacum (BD, DF y $\mathrm{BF}$, respectivamente). Dichos compuestos presentaron todos ellos espectros muy similares. En la Figura 5, a modo de ejemplo, se muestran los espectros obtenidos para la BD. 

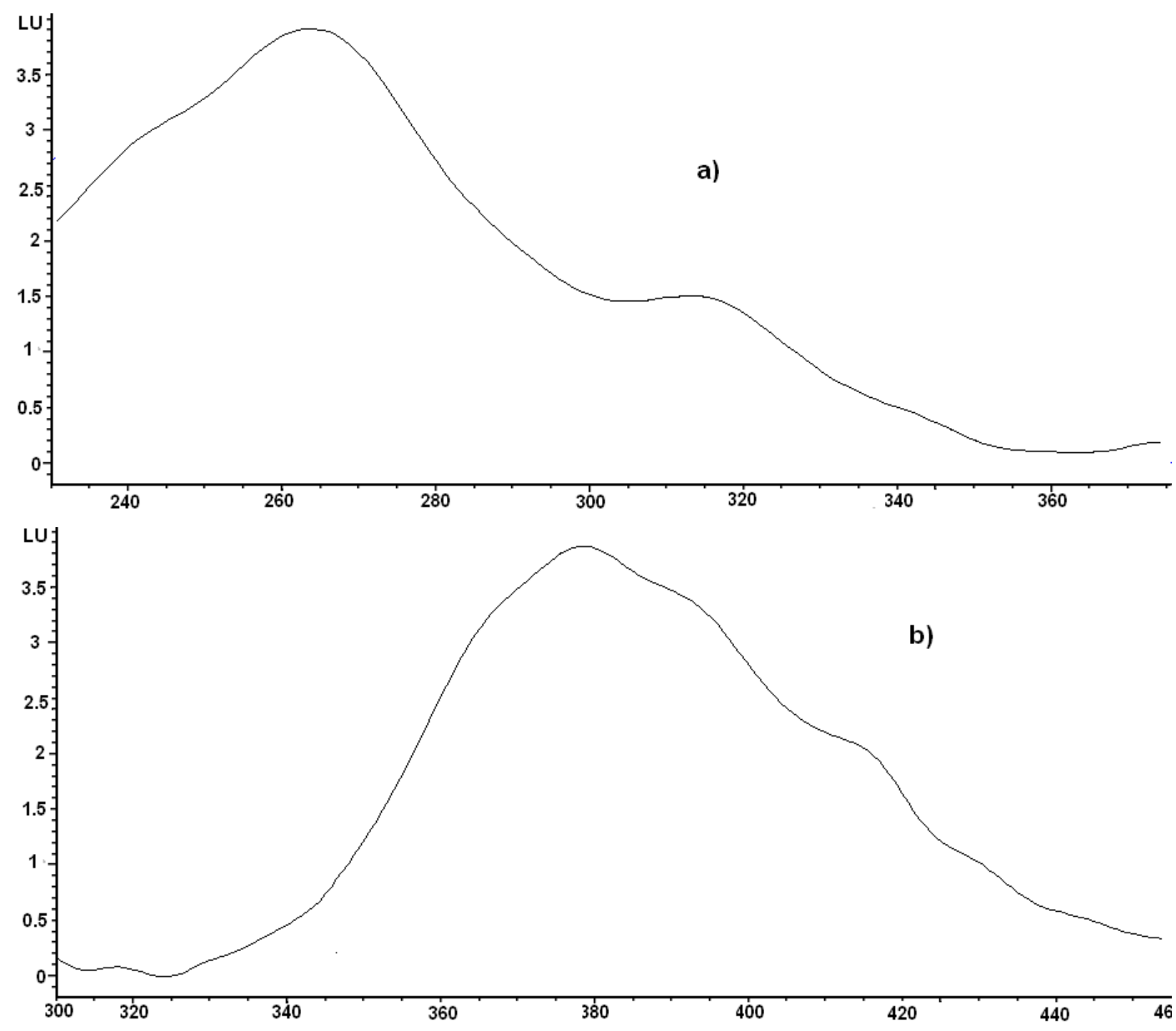

Figura 5: a) Espectro de excitación y b) de emisión de la BD

Como se puede observar el máximo de excitación se sitúa en torno a 263 $\mathrm{nm}$ y el máximo de emisión a $390 \mathrm{~nm}$. La cuantificación de estos analitos se llevó a cabo con la señal de FLD debido a la mayor selectividad y sensibilidad de este detector frente a la que se obtuvo por absorción molecular.

De este modo en el método analítico, en el que se combinan la detección DAD/FLD, quedó establecida la longitud de onda de $285 \mathrm{~nm}$ para determinar la CP en la señal de absorción molecular y $263 \mathrm{~nm}$ de 
excitación y $390 \mathrm{~nm}$ de emisión para la señal de fluorescencia con la que se cuantificaron BD, DF y BF.

\section{Espectrometria de masas (MSD)}

El tercer sistema que se empleó para la detección de los analitos fue un espectrómetro de masas cuadrupolar equipado con dos fuentes de ionización, electrospray (ESI) e ionización química a presión atmosférica (APCI). Dadas las características de los compuestos objeto de estudio (polaridad y masas moleculares medias), se realizaron pruebas con ambas fuentes, probando tanto la ionización positiva como negativa, obteniéndose que la que proporcionaba mayores señales era la fuente de iones ESI en modo negativo, por lo que se seleccionó este modo de ionización para continuar con el trabajo. Elegida la fuente de ionización y la polaridad de trabajo se procedió a obtener las condiciones de detección para alcanzar la máxima sensibilidad. Las experiencias se llevaron a cabo mediante un análisis por inyección en flujo (FIA), utilizando un flujo de $0.3 \mathrm{~mL} / \mathrm{min}$ y un volumen de inyección de $5 \mu \mathrm{L}$. Los factores que afectan a la respuesta del detector se estudiaron de manera individual. Como resultado de los estudios realizados, se establecieron como condiciones más adecuadas para realizar la detección de los compuestos, las que se indican en las Tabla 2.

Tabla 2: Parámetros de MS-ESI en modo negativo.

\begin{tabular}{lcc}
\hline \multicolumn{1}{c}{ Parámetro } & Intervalo & Valor \\
\hline Voltaje del fragmentador $(\mathrm{V})$ & $20-380$ & $*$ \\
Voltaje del capilar $(\mathrm{V})$ & $2000-5500$ & 3500 \\
$\begin{array}{l}\text { Flujo gas secante }\left(\mathrm{N}_{2},\right. \\
\mathrm{mL} / \mathrm{min})\end{array}$ & $2-12$ & 10 \\
Temperatura gas secante $\left(\mathrm{N}_{2}\right.$, & $100-350$ & 350 \\
$\left.{ }^{\circ} \mathrm{C}\right)$ & $10-60$ & 50 \\
Presión del nebulizador (psig) & $5-20$ & 10 \\
Ganancia & & \\
\hline
\end{tabular}




\begin{tabular}{lc}
\hline \multicolumn{1}{c}{ Compuesto } & *Voltaje del Fragmentador \\
\hline CP, BD, DF & 180 \\
BF & 220 \\
\hline
\end{tabular}

Con las condiciones de detección seleccionadas se realizó un barrido (modo SCAN) entre 100 y 700 unidades de relación masa/carga con el fin de establecer los iones más abundantes y utilizarlos para trabajar en modo SIM, lo que proporcionaria la máxima sensibilidad en el análisis cuantitativo. Los espectros de masas se muestran en la Figura 6:
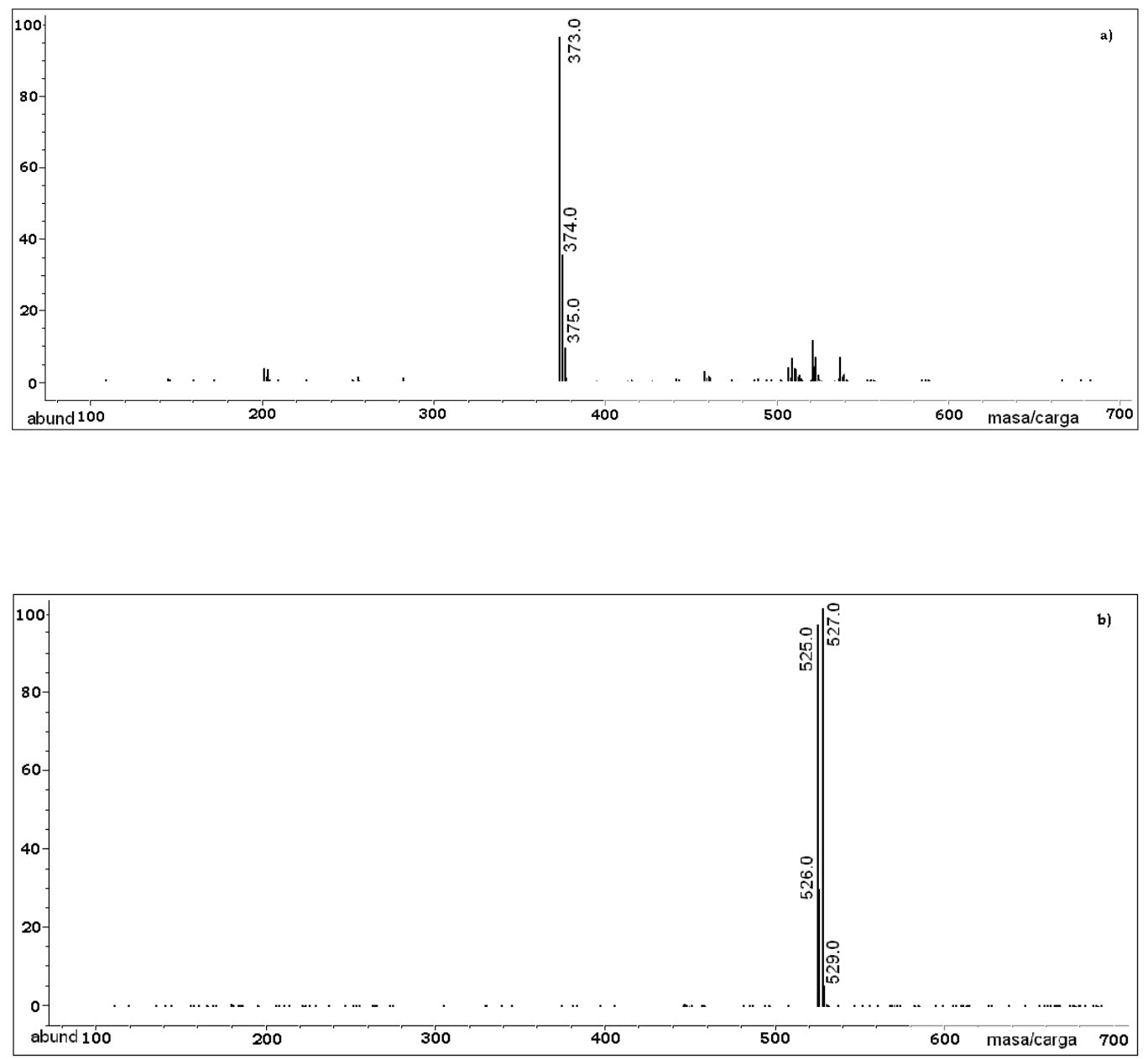

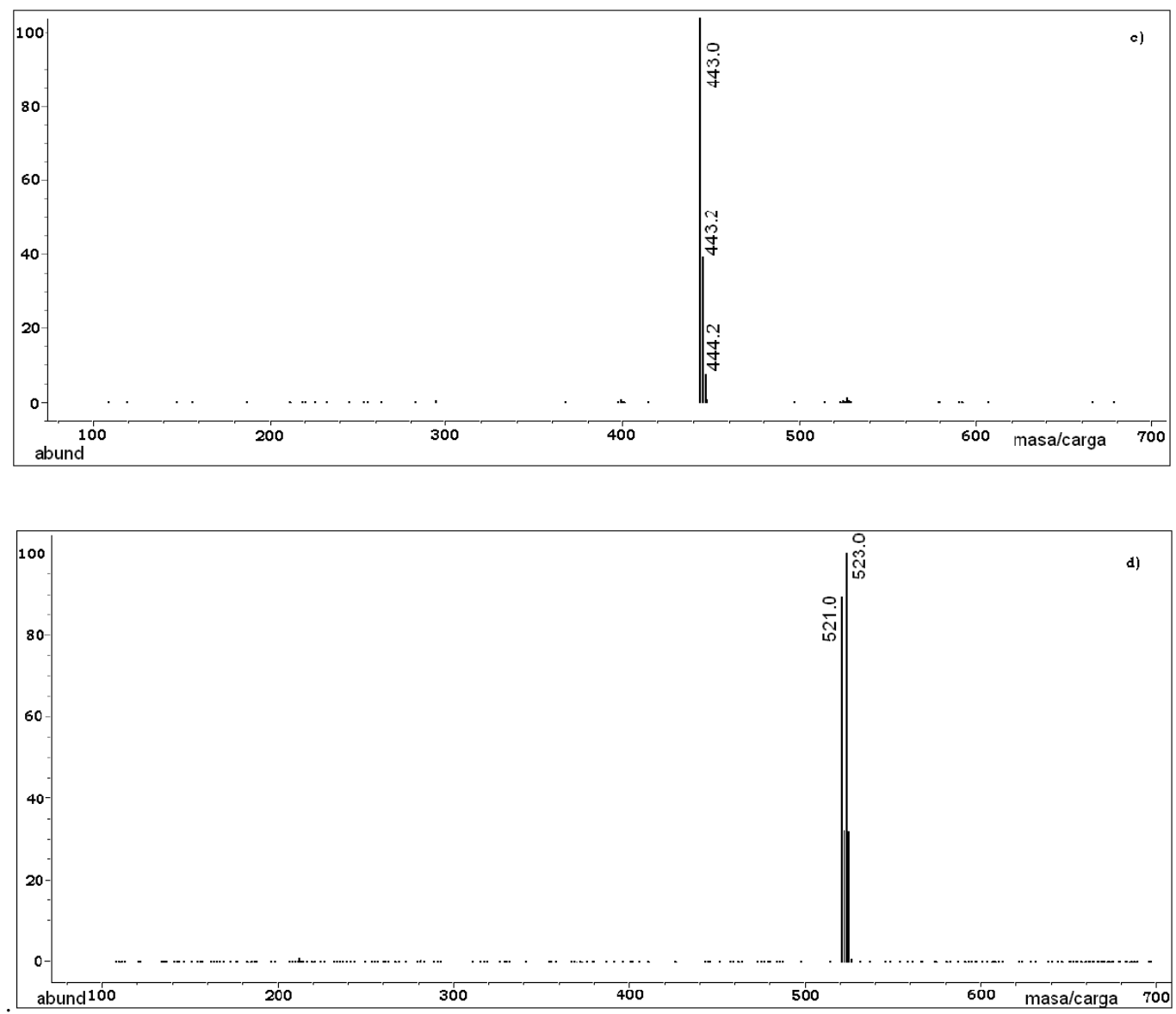

Figura 6: Espectros de MS-ESI modo negativo de disoluciones en metanol de cada patrón en concentración de 100 mg/L., a) Clorofacinona; b) Bromadiolona; c) Difenacum; d) Brodifacum,

El espectro de masas de cada analito muestra que existe un ion mayoritario $(\mathrm{m} / \mathrm{z})$ que corresponde al ion $[\mathrm{M}-\mathrm{H}]^{-}$el cual se utilizará para la cuantificación de cada compuesto, y uno o varios de confirmación.

En la Tabla 3 se presentan los iones usados para la cuantificación y confirmación de los compuestos. 
Tabla 3: Iones $(\mathrm{m} / \mathrm{z})$ para la cuantificación y confirmación por MS-ESI

\begin{tabular}{ccc}
\hline Compuesto & Ion cuantificación & Ion detección \\
\hline CP & 373 & 374,375 \\
BD & 527 & 525,526 \\
DF & 443 & 443,444 \\
BF & 523 & 521,524 \\
\hline
\end{tabular}

Ante la posible falta de reproducibilidad en la detección, se pensó en la posibilidad de utilizar un patrón interno. Para la selección del compuesto a utilizar a tal fin se realizaron ensayos con compuestos pertenecientes a distintas familias de rodenticidas. Estos compuestos se inyectaron en el equipo cromatográfico en las mismas condiciones. De los compuestos que se ensayaron, el único que eluía en una zona vacía del cromatograma era el flocumafen $(\mathrm{FC})$, por lo que se optó por seleccionarlo como patrón interno.

El espectro de masas se muestra a continuación en la Figura 7:

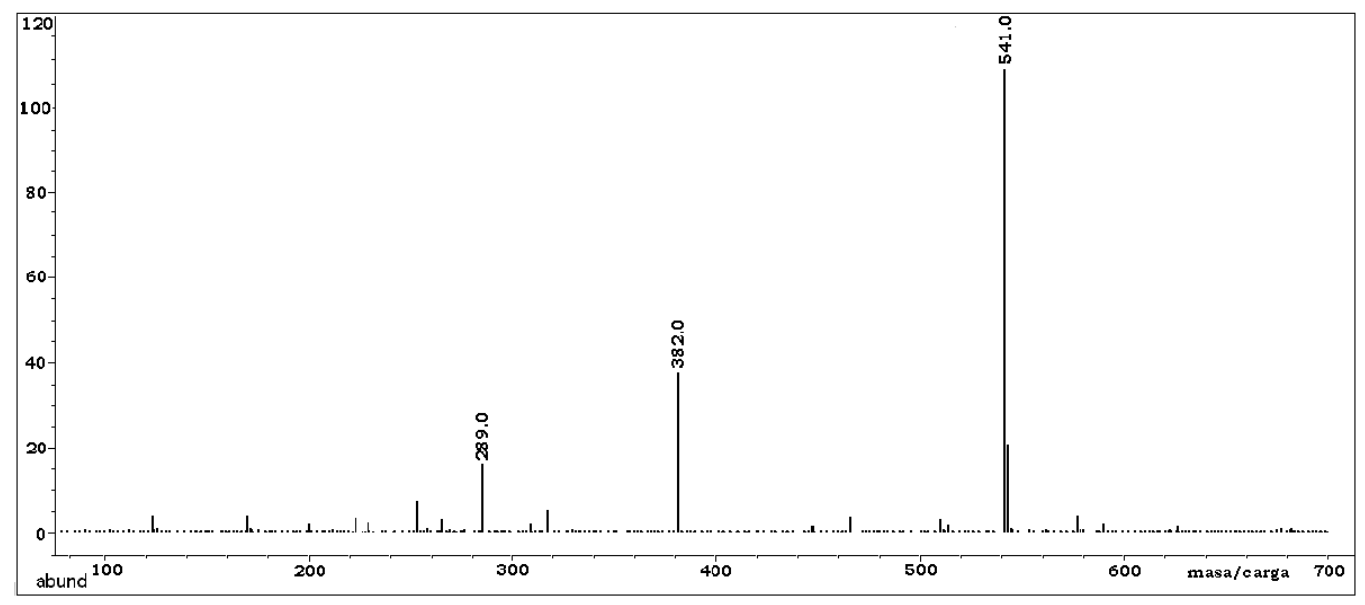

Figura 7: Espectro de MS-ESI modo negativo de un patrón de Flocumafen de 100 mg/L.

Como se puede observar en el espectro de masas obtenido con las condiciones establecidas para los otros compuestos, el ion mayoritario que aparece a una relación $\mathrm{m} / \mathrm{z}$ de 541 y correspondiente al ion $[\mathrm{M}-\mathrm{H}]^{-}$, es el 
ion que se utilizó para cuantificar, siendo los iones de confirmación los de $\mathrm{m} / \mathrm{z} 382$ y 289.

\section{V.2.2.- Composición de la fase móvil}

\section{Naturaleza y porcentaje del modificador orgánico}

En primer lugar se estudió el efecto que ejercía sobre la separación la naturaleza del modificador orgánico, sustituyendo el Metanol por Acetonitrilo, manteniendo la composición de la fase móvil, ya comentada, compuesta por modificador orgánico/formiato de amonio $20 \mathrm{mM}$ en agua (70:30; v/v) a pH 6.7 en régimen isocrático. Los resultados de dichos ensayos fueron negativos, ya que su utilización provocaba una deformación en los picos correspondientes a los compuestos, fundamentalmente el correspondiente al BF, por lo que se estableció la utilización del Metanol como componente orgánico.

Por otro lado, con la composición de la fase móvil inicial se producía una fuerte retención del $\mathrm{BF}$, el compuesto más retenido, por lo que se realizaron una serie de experiencias consistentes en variar el porcentaje del metanol para reducirla. El resultado de las mismas indicó, como era de esperar, que al aumentar el porcentaje se producía una disminución en la retención, no solo para el BF sino también para los otros compuestos. A la vista de los resultados que se obtuvieron y que aparecen señalados para el BF en los datos de la Tabla 4, se estableció un porcentaje de Metanol del 73\%, pues porcentajes mayores provocaban el solapamiento entre los picos correspondientes a la BD y DF. 
Tabla 4: Efecto de variación porcentaje de metanol sobre el $t_{r}$ del BF .

\begin{tabular}{|c|c|}
\hline \% MeOH/ \%HCOONH 420 mM pH 6.5 & $\mathrm{t}_{\mathrm{r}} \mathrm{BF}(\mathrm{min})$ \\
\hline $70 / 30$ & 28.3 \\
\hline $71 / 29$ & 25.6 \\
\hline $73 / 27$ & 19.9 \\
\hline $75 / 25$ & 14.5 \\
\hline
\end{tabular}

Como ya se ha comentado en la memoria, inicialmente se realizaron una serie de ensayos previos en los que se utilizaba como fase móvil una mezcla o bien de agua-Metanol $(25: 75 ; \mathrm{v} / \mathrm{v})$ o formiato amónico-Metanol en la misma proporción, en régimen isocrático. De la observación de los cromatogramas que se obtuvieron al inyectar los compuestos se desprendía que la utilización del formiato en lugar de agua, aparte de ser beneficioso para realizar la detección por MS, también mejoraba la simetría de los picos, por lo que se seleccionó este compuesto como componente de la fase móvil.

Una vez seleccionado el porcentaje del modificador orgánico se procedió a estudiar la influencia que la fuerza iónica ejercía sobre la separación. Para ello se varió en un intervalo de 10 a $50 \mathrm{mM}$, manteniendo constante el porcentaje de modificador orgánico e inyectando para cada concentración el mismo volumen de la disolución patrón de los rodenticidas.

De los resultados que se obtuvieron, se puso de manifiesto que al aumentar la fuerza iónica se producía una disminución en la anchura de los picos mejorándose notablemente la forma de estos, fundamentalmente el pico correspondiente al $\mathrm{BF}$, hasta una concentración de formiato de 30 $\mathrm{mM}$, lo cual se puede apreciar en los cromatogramas obtenidos con detección DAD/ FLD, que se muestran en la siguiente Figura 8: 

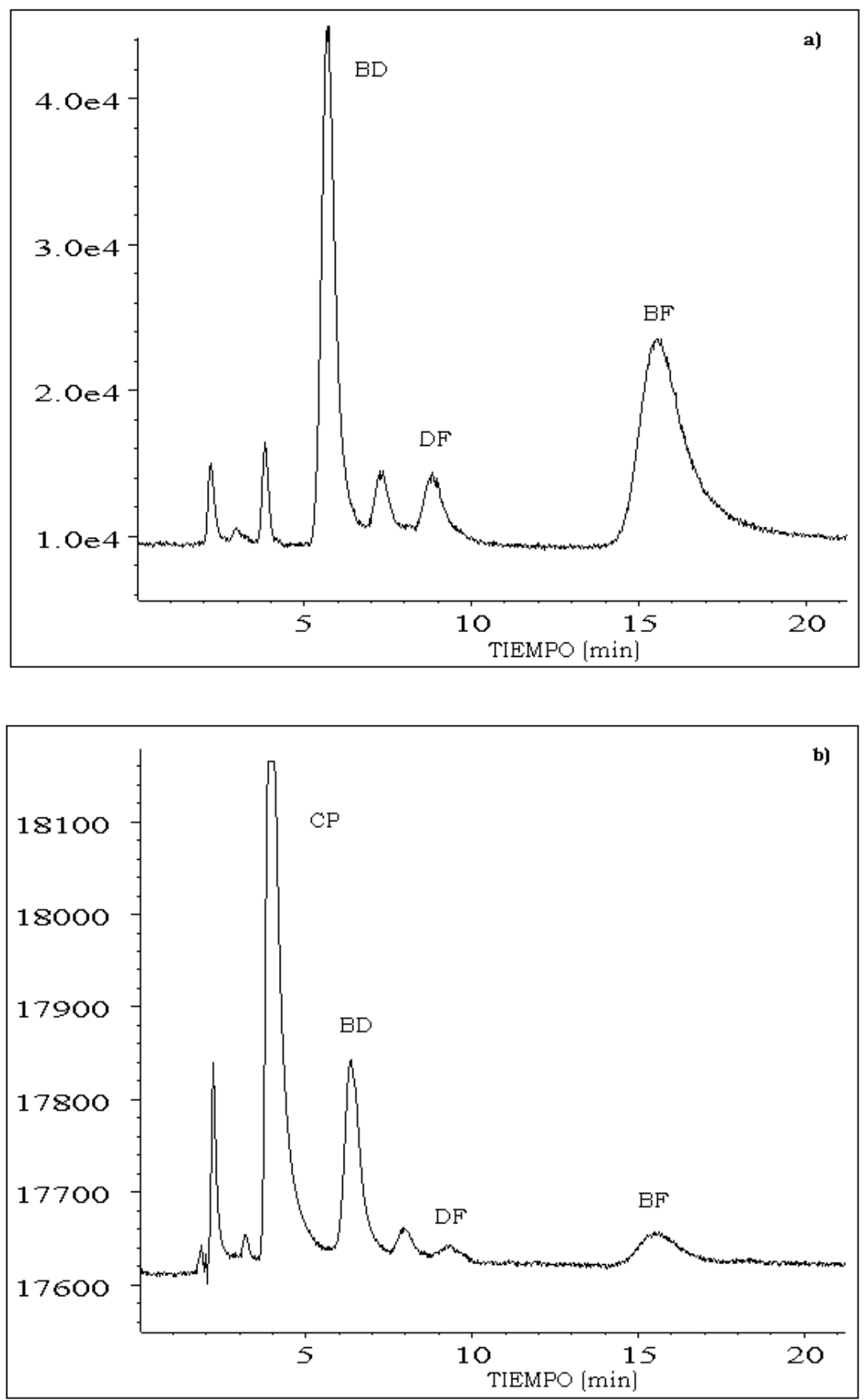

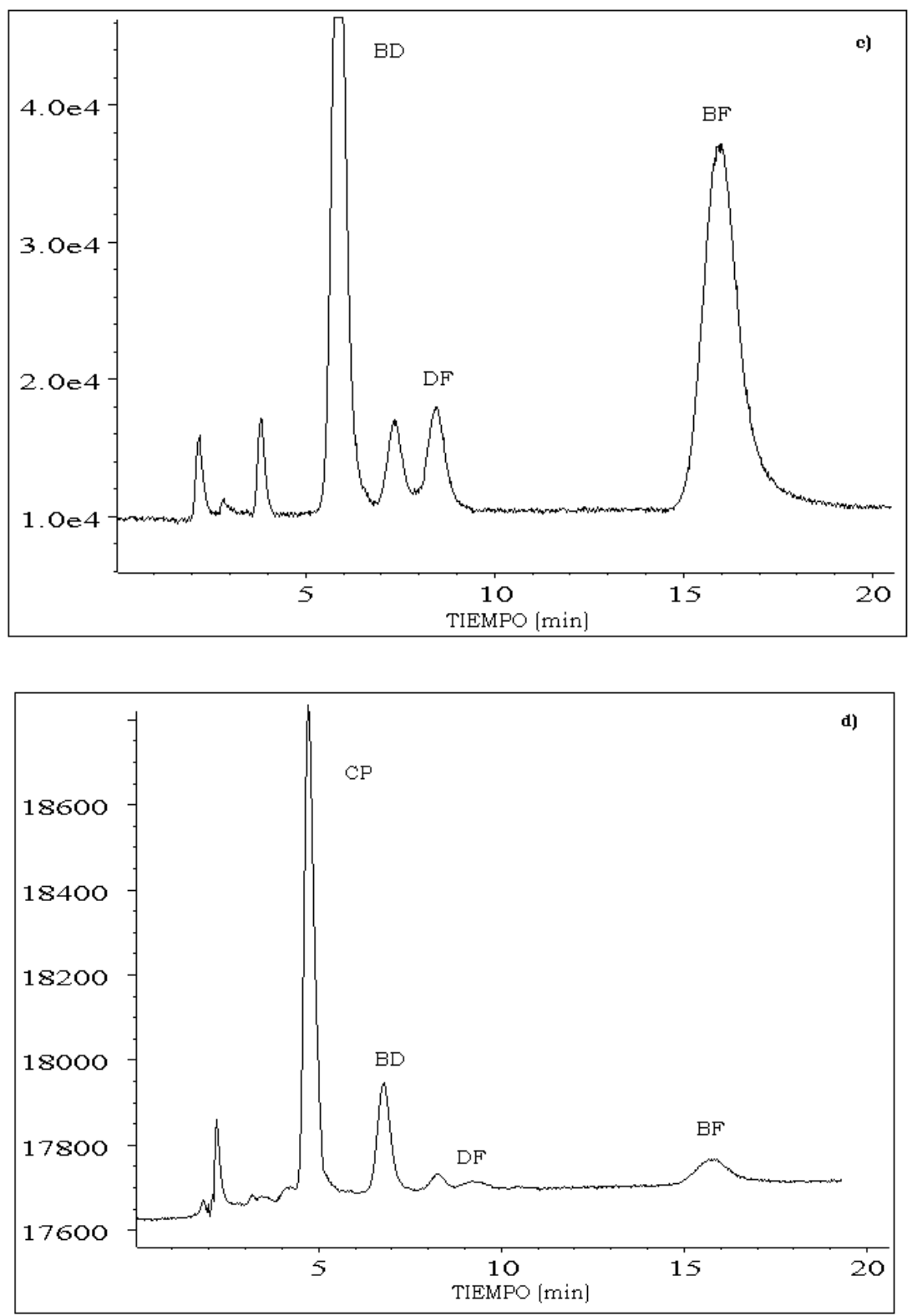

Figura 8: Cromatogramas de una mezcla patrón de los analitos en concentración de $10 \mathrm{mg} / \mathrm{L}$, con detección por FLD, utilizando como componente de la fase móvil formiato amónico $10 \mathrm{mM}$ (a) y $30 \mathrm{mM}$ (c). Y con detección por DAD, utilizando formiato amónico $10 \mathrm{mM}$ (c) y $30 \mathrm{mM}$ (d).

También se puede observar una disminución en la retención para todos los compuestos a medida que aumenta la fuerza iónica. Concentraciones de formiato superiores a $30 \mathrm{mM}$ no provocaban mejoras apreciables, por lo que se decidió fijar la concentración en $30 \mathrm{mM}$. 
Aunque inicialmente se trabajó con el pH 6.5, que era el que proporcionaba la solución de formiato amónico, posteriormente se procedió a estudiar la influencia que pudiera ejercer la variación del mismo sobre la retención y señal de los compuestos. Se varió el pH entre 2.5 y 9.0 mediante la adición de ácido fórmico o de hidróxido amónico.

De los resultados que se obtuvieron se dedujo que la utilización de $\mathrm{pH}$ ácidos provocaba un aumento considerable en la retención del BF, el cual eluía a tiempos superiores a los 30 minutos, y CP provocando también un cambio en la selectividad para este compuesto que eluía más tarde que la BD y DF, como se puede observar en los cromatogramas de la siguiente Figura 9, razón por la cual se desestimó la utilización de pH ácidos.
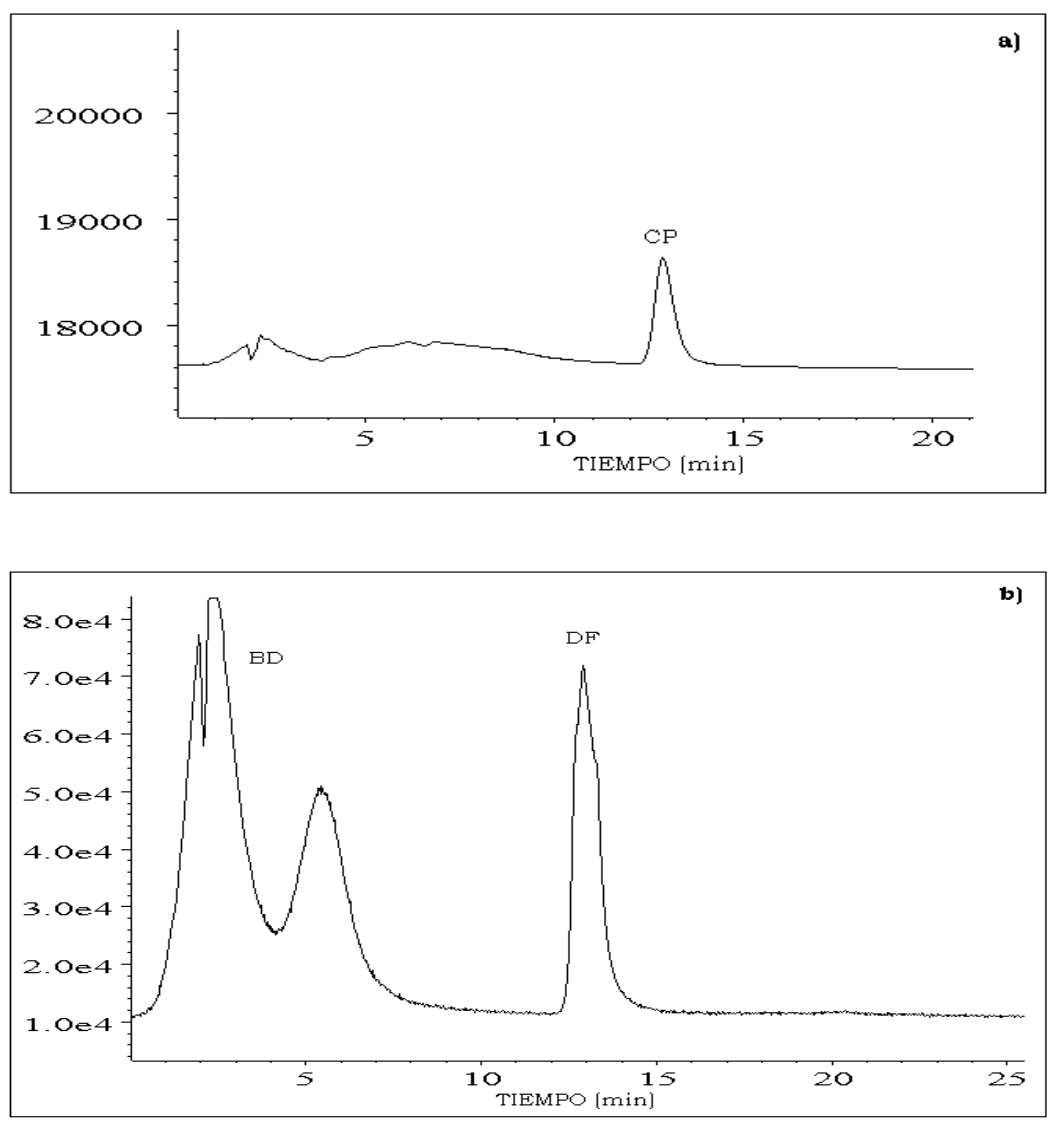

Figura 9: Cromatograma de una mezcla patrón de los analitos en concentración de $10 \mathrm{mg} / \mathrm{L}$, obtenidos en DAD (a) y FLD (b) a pH ácido. 
En cuanto a los resultados que se obtuvieron al utilizar $\mathrm{pH}$ básicos cabe destacar que prácticamente la retención para los compuestos no variaba pero si provocaba un pérdida considerable en la simetría de pico correspondiente a la CP que incluso llega a solaparse ligeramente con el pico correspondiente a la $\mathrm{BD}$, lo cual se puede observar en el cromatograma que aparece en la siguiente Figura 10:

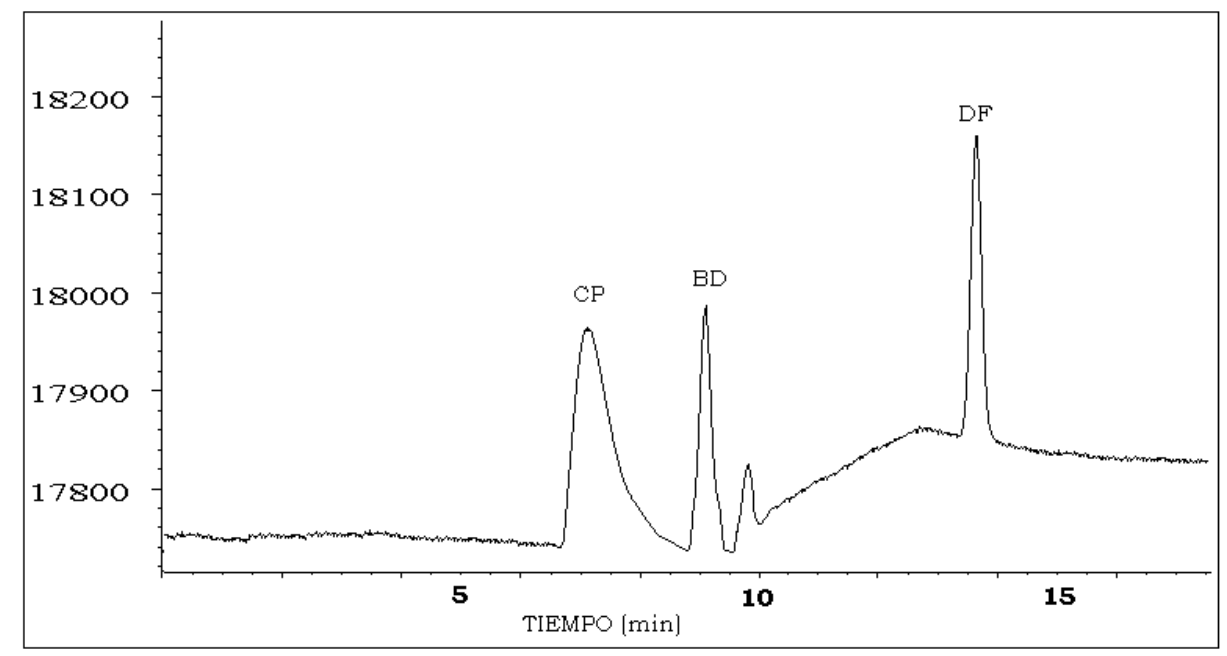

Figura 10: Cromatograma de una mezcla patrón de los cuatro analitos en concentración de $10 \mathrm{mg} / \mathrm{L}$, obtenidos en DAD, utilizando formiato amónico a pH 9.

Por todo esto se fijó el pH de la fase móvil en 6.5.

Se estudió el efecto que la temperatura ejercía sobre la separación, para lo cual se realizaron una serie de experiencias variándola en un intervalo de $20-50^{\circ} \mathrm{C}$ a intervalos de $5^{\circ} \mathrm{C}$. De los cromatogramas que se obtuvieron se observó, como cabía esperar, que el aumento de la temperatura provocaba una disminución en la retención de todos los compuestos, disminución que era más acusada cuanto mayor era la retención. La mejor resolución se alcanzaba cuando dicha separación se realizaba a $30^{\circ} \mathrm{C}$ pues, aunque temperaturas superiores conducian a una reducción en el tiempo de análisis, se perdía resolución en la separación entre la BD y el DF. Por lo cual, se eligió como temperatura de separación $30^{\circ} \mathrm{C}$. 
Por último, se trató de establecer el volumen máximo de muestra que se podría inyectar con el fin de obtener límites de detección y cuantificación menores sin pérdida de resolución. Se probaron diferentes volúmenes comprendidos entre 10 y $100 \mu \mathrm{L}$ comprobándose que, con muestras patrón de hasta $10 \mathrm{mg} / \mathrm{L}$, la inyección de $20 \mu \mathrm{l}$ proporcionaba buenas resoluciones que permitian tanto la identificación como la cuantificación de los compuestos.

Como resultado de los estudios realizados se propone para la separación de la clorofacinona, bromadiolona, difenacum y brodifacum la utilización de una columna Gemini $\mathrm{C}_{18}, 110 \AA$ (150x4.6 mm, $\left.5 \mu \mathrm{m}\right)$ y una fase móvil compuesta por metanol y formiato amónico $30 \mathrm{mM}$ a $\mathrm{pH} 6.5$ en agua (73:27, v/v), en régimen isocrático, con un flujo de fase móvil de $1 \mathrm{~mL}$ min $^{-1}$, utilizando un volumen de inyección de $20 \mu \mathrm{L}$ y una temperatura de separación de $30^{\circ} \mathrm{C}$. En la Figura 11 se muestran los cromatogramas correspondientes a la inyección de $20 \mu \mathrm{L}$ de una disolución patrón de los cuatro anticoagulantes obtenidos por los tres sistemas de detección empleados.

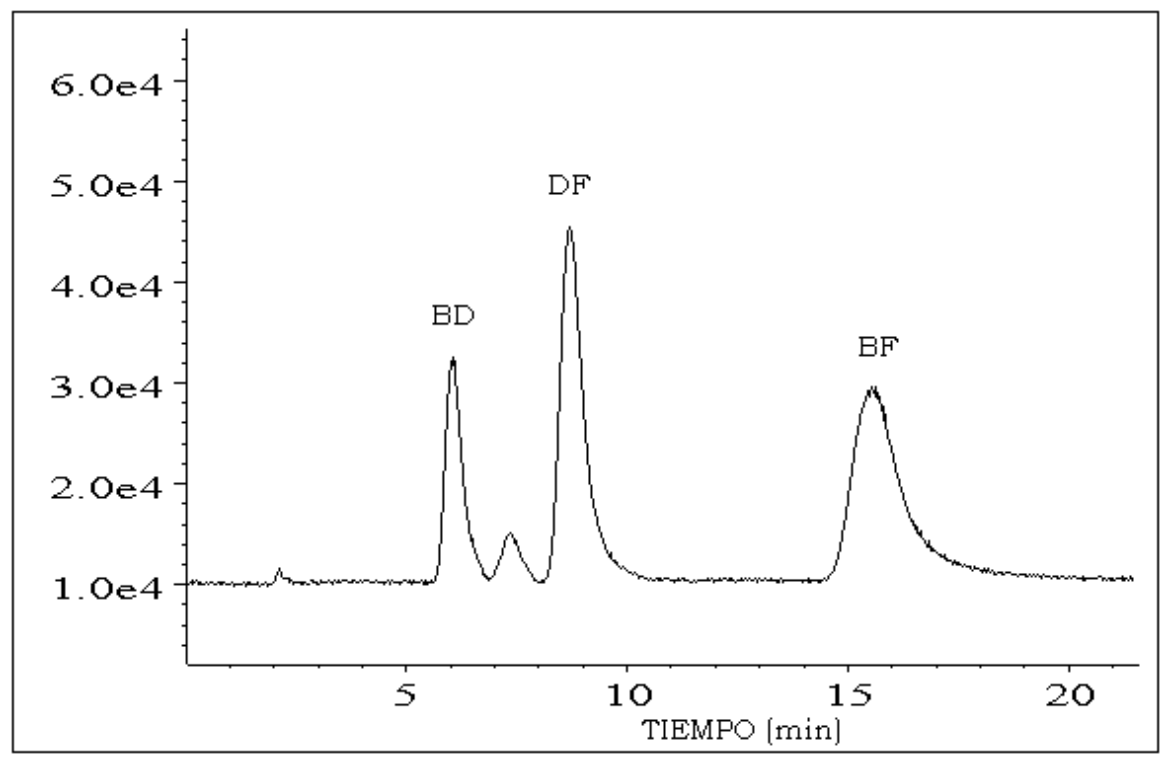



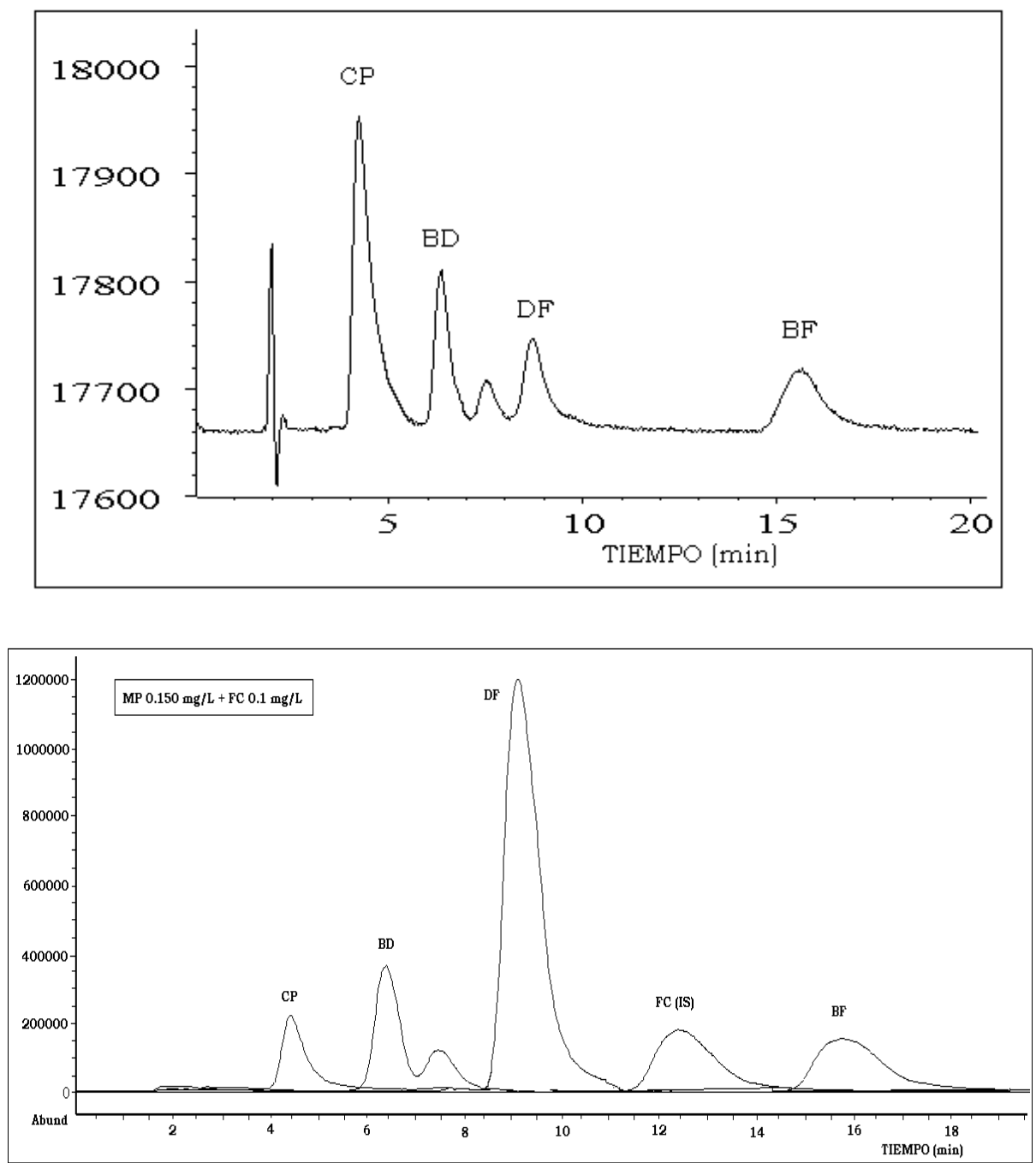

Figura 11: Cromatograma de una mezcla patrón de los cuatro analitos en concentración de 1.25 $\mathrm{mg} / \mathrm{L}$, obtenidos en FLD, DAD y MS, respectivamente.

En las condiciones cromatográficas establecidas, los tiempos de retención de los compuestos son los que se muestran en la Tabla 5:

Tabla 5: Tiempos de retención de cada analito

\begin{tabular}{cc}
\hline Compuesto & $\mathbf{t}_{\mathbf{r}}(\mathbf{m i n})$ \\
\hline CP & 4.4 \\
BD & 6.4 \\
DF & 9.4 \\
FC & 12.4 \\
BF & 15.7 \\
\hline
\end{tabular}




\section{V.3.- Tratamiento de muestra}

Una vez seleccionadas las condiciones cromatográficas, el siguiente estudio que se realizó tuvo como finalidad desarrollar un procedimiento que nos permitiera realizar el análisis de estos compuestos en suelos. Como paso previo era necesario aislarlos de la matriz por lo que se pensó en utilizar la extracción sólido- líquido.

Se dispuso de suelo agrícola proporcionado por el ITACyL, el cual no había estado en contacto con ningún rodenticida. La muestra fue triturada, tamizada y finalmente secada en estufa hasta pesada constante. Posteriormente, se almacenó en desecador hasta su utilización.

Para el desarrollo del método fue necesario establecer un procedimiento que permitiera adicionar a la muestra de suelo una cantidad exactamente conocida de los compuestos objeto de estudio. Se probaron tres maneras de llevarlo a cabo, las cuales se detallan a continuación:

1.- Se introdujo la muestra de suelo en un tubo de centrífuga de plástico. A continuación, se añadieron $10 \mathrm{~mL}$ de una disolución patrón de los 4 compuestos de concentración $1 \mathrm{mg} / \mathrm{L}$ en metanol. Se agitó durante 20 minutos en un vibromatic para que la distribución fuese homogénea y se introdujo en una estufa a $80^{\circ} \mathrm{C}$ hasta la evaporación completa del disolvente. Previamente se realizaron ensayos para conocer la estabilidad térmica de los compuestos, manteniéndolos en estufa a diferentes temperaturas, en un intervalo de $40^{\circ} \mathrm{C}$ hasta $90^{\circ} \mathrm{C}$, a intervalos de $10^{\circ} \mathrm{C}$. Como resultado de dichos ensayos se observó que los compuestos eran estables hasta $80^{\circ} \mathrm{C}$, siendo por lo tanto esta temperatura la que se utilizó por requerir un menor tiempo para la evaporación del disolvente.

2.- Para disminuir el tiempo necesario para la evaporación del disolvente se pensó en aumentar la superficie, por lo que se depositó el mismo peso de suelo en un erlenmeyer y se añadió el mismo volumen de la solución 
metanólica de los compuestos en la misma concentración. A continuación, se realizaba la agitación y evaporación como en el primer procedimiento.

3.- El mismo peso aproximado de suelo se depositó en un vidrio de reloj y se le añadió un volumen determinado de la solución patrón de los analitos intentando mezclar bien la muestra con la disolución patrón para que se produjera su completa adsorción. Este volumen se estableció en $0.5 \mathrm{~mL}$ después de una serie de pruebas y por último se dejó secar al aire.

Con los dos primeros procedimientos se comprobó que los compuestos quedaban retenidos en las paredes del tubo de centrífuga y también en las del erlenmeyer. Esto no ocurría con el tercer procedimiento, por lo que se optó por este para realizar el dopado de la muestra.

Una vez elegida la forma de dopado de la muestra, para el establecimiento del procedimiento de extracción de los compuestos de la matriz sólida se operó, en todas los ensayos efectuados, de la misma manera: se pesaba $1 \mathrm{~g}$ de suelo seco sin dopar para que actuara como blanco y el mismo peso de suelo dopado con una concentración conocida de los compuestos en tubos de centrifuga. A continuación, se añadió un volumen de extractante, el cual inicialmente se estableció en $10 \mathrm{~mL}$. Dada la poca solubilidad de estos compuestos en agua y la elevada solubilidad en alcoholes y acetato de etilo, se probó la utilización de etanol, metanol y acetato de etilo. A continuación, la mezcla se sometió a agitación mecánica durante 15 minutos, se decantó y el líquido fue concentrado a sequedad en rotavapor $\left(40^{\circ} \mathrm{C}\right)$. El residuo se reconstituyó con $1 \mathrm{ml}$ de metanol y previa filtración se introdujo en un vial para su análisis en las condiciones cromatográficas establecidas.

De los cromatogramas que se obtuvieron se dedujo que el metanol era el extractante que proporcionaba mayores recuperaciones, por lo que fue el disolvente seleccionado, además se pudo comprobar que en el 
cromatograma correspondiente a la muestra sin adicionar no aparecian picos al tiempo de retención de los compuestos objeto de estudio.

A continuación, se pasó a establecer el volumen de metanol a emplear como extractante, para lo cual se realizaron una serie de experiencias en las que se añadieron, a la muestra blanco y muestra dopada, volúmenes de metanol comprendidos entre 5 y $25 \mathrm{~mL}$, manteniendo el tiempo de agitación, velocidad de centrifugación, concentración a sequedad y reconstitución del residuo en las mismas condiciones que en los ensayos previos. Además, para cada volumen ensayado se inyectaba paralelamente una mezcla patrón de los 4 compuestos de la misma concentración que la adicionada al suelo para evaluar la recuperación.

De los resultados que se obtuvieron se dedujo que el porcentaje de recuperación aumentaba a medida que lo hacía el volumen de extractante hasta $15 \mathrm{ml}$ y que la utilización de volúmenes superiores no mejoraba la recuperación así como tampoco lo hacia la realización de una extracción sucesiva con el mismo volumen de extractante. Por lo cual, se seleccionó la utilización de $15 \mathrm{ml}$ de metanol en una única extracción.

El siguiente estudio que se realizó tuvo como finalidad establecer el tiempo de agitación, para lo cual éste se varió entre 5 y 30 minutos, a intervalos de 5 minutos. Los resultados se muestran en la Tabla 6:

Tabla 6: Influencia del tiempo de agitación (min) sobre el porcentaje de recuperación

\begin{tabular}{l|lllll}
\hline Analito & 5 & 10 & 15 & 20 & 30 \\
\hline$\%$ CP & 89.0 & 90.3 & 91.4 & 89.5 & 90.2 \\
$\%$ BD & 90.0 & 91.6 & 89.6 & 91.5 & 89.9 \\
$\%$ DF & 97.0 & 96.5 & 96.0 & 98.2 & 97.5 \\
$\%$ BF & 95.5 & 94.2 & 97.0 & 97.5 & 95.1 \\
\hline
\end{tabular}

Como se puede observar en los valores de la Tabla, los porcentajes de recuperación que se obtuvieron fueron muy similares para todos los 
tiempos de contacto entre las fases, por lo que se seleccionó un tiempo de agitación de 5 minutos, lo cual permitía reducir el tiempo de análisis.

Por último, se realizaron ensayos para establecer tanto la naturaleza del disolvente empleado para la reconstitución del residuo obtenido en la concentración a sequedad, como el volumen necesario para lograrla. Se realizaron pruebas con fase móvil (metanol: formiato, 73:27, v/v) y metanol, obteniéndose los mejores resultados con metanol ya que se conseguía la solubilización completa del residuo. En cuanto al volumen, se realizaron pruebas adicionando de 1 en $1 \mathrm{ml}$ hasta $3 \mathrm{ml}$, por triplicado. De los resultados que se obtuvieron se pudo observar que la utilización de $1 \mathrm{ml}$ era lo más adecuado, pues nos permitiría la obtención de los límites de detección y cuantificación menores, ya que la utilización de un segundo mililitro sólo implicaba un incremento inferior al $1 \%$ y en el tercer mililitro no se recuperaba nada.

Por lo tanto el tratamiento de muestra que se propone para la determinación de $\mathrm{CP}, \mathrm{BD}, \mathrm{DF}$ y $\mathrm{BF}$ es el que se indica y esquematiza a continuación:

En tubo de centrifuga se pesa $1 \mathrm{~g}$ de suelo previamente tamizado y seco. Se añaden $15 \mathrm{ml}$ de metanol y se somete a agitación mecánica durante 5 minutos. Posteriormente se centrifuga a 9000 rpm durante 5 minutos y se decanta el líquido en un matraz donde se concentra a sequedad en rotavapor a $40^{\circ} \mathrm{C}$ y al residuo seco se le añade $1 \mathrm{ml}$ de metanol y se lleva a un baño de ultrasonidos para disolver el posible residuo que quedara en las paredes. A continuación, se filtra con un filtro de jeringa de nylon sobre un vial topacio y finalmente una alícuota de $20 \mu \mathrm{l}$ se inyecta en el sistema cromatográfico. El esquema se presenta en la Figura 12: 


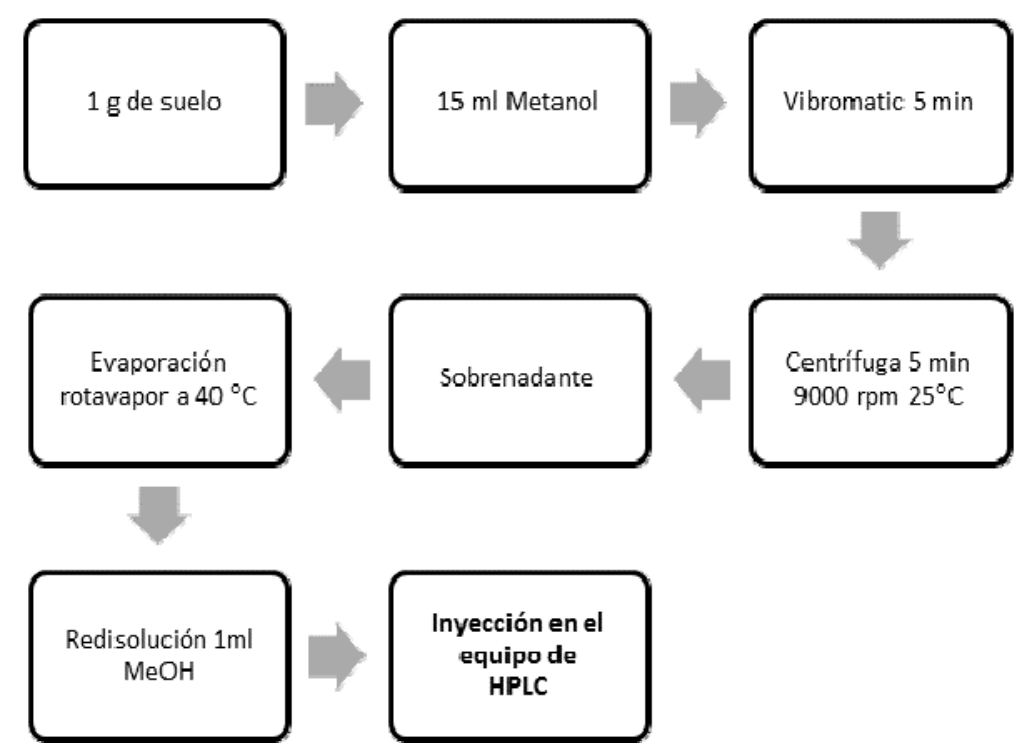

Figura 12: Esquema del tratamiento de muestra

Los porcentajes de recuperación para los cuatro compuestos y la eficacia del método desarrollado se determinaron en 6 réplicas a tres niveles de concentración y aparecen reflejados en la siguiente Tabla 7 :

Tabla 7: Porcentajes de recuperación a tres niveles de concentración $(n=6)$ y \% RSD

\begin{tabular}{clc}
\hline Compuesto & \multicolumn{1}{c}{$\begin{array}{c}\text { Concentración } \\
(\boldsymbol{\mu g} / \mathbf{k g} \text { de suelo) }\end{array}$} & \%Recuperación \pm \% RSD \\
\hline \multirow{2}{*}{ CP } & 3 & $91 \pm 5$ \\
& 250 & $93 \pm 5$ \\
& 1000 & $90 \pm 5$ \\
\hline \multirow{2}{*}{ BD } & 2 & $90 \pm 6$ \\
& 250 & $92 \pm 5$ \\
& 1000 & $92 \pm 6$ \\
\hline \multirow{2}{*}{ DF } & 0.7 & $97 \pm 6$ \\
& 250 & $99 \pm 5$ \\
& 1000 & $98 \pm 6$ \\
\hline \multirow{2}{*}{ BF } & 0.7 & $97 \pm 6$ \\
& 250 & $99 \pm 6$ \\
& 1000 & $95 \pm 6$ \\
\hline
\end{tabular}




\section{V.4.- Validación de la metodologia analitica}

La validación del método se llevó a cabo siguiendo las directrices marcadas por el informe técnico de la IUPAC (2002) y el documento SANCO/12571/2013. Se evaluó la selectividad, límites de detección y cuantificación, precisión, linealidad y exactitud para la metodología analítica propuesta, con los tres detectores que se han empleado.

\section{Selectividad}

Para comprobar la selectividad, se inyectaron en el equipo cromatográfico dos extractos de suelo, uno correspondiente al blanco y el otro al de una muestra de suelo a la que se le adicionó los compuestos objeto de estudio. En las Figuras 13 y 14 se muestran los cromatogramas correspondientes obtenidos con los tres sistemas de detección, para un blanco y una muestra a la que se le había añadido los compuestos en concentración conocida y fueron tratados según el método que se propone.

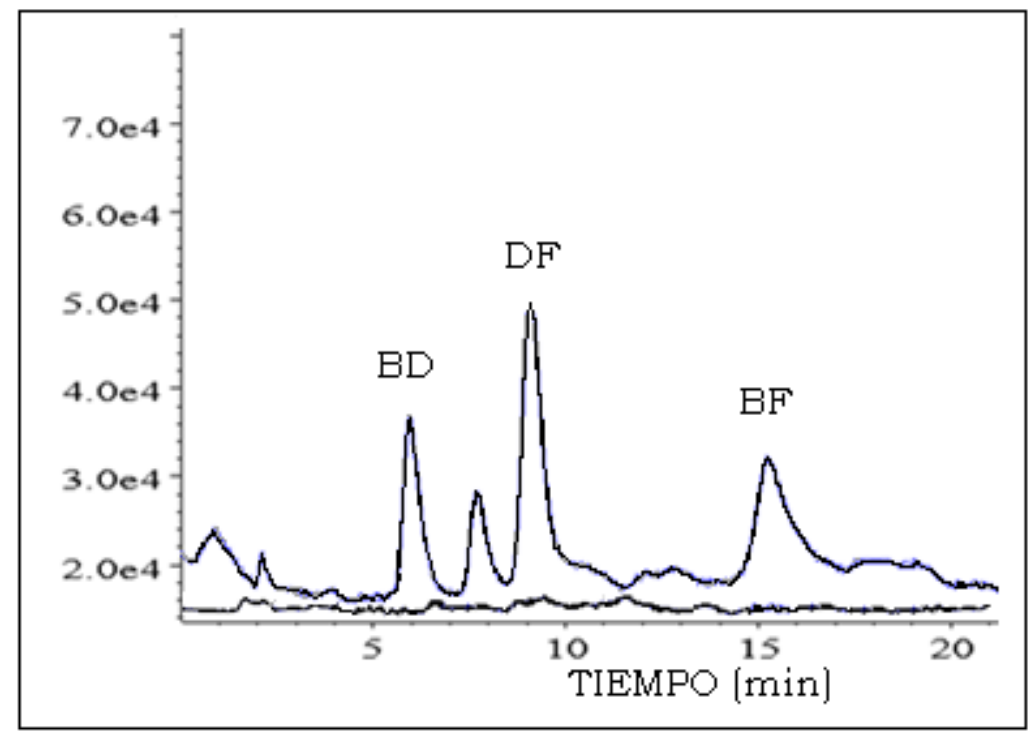




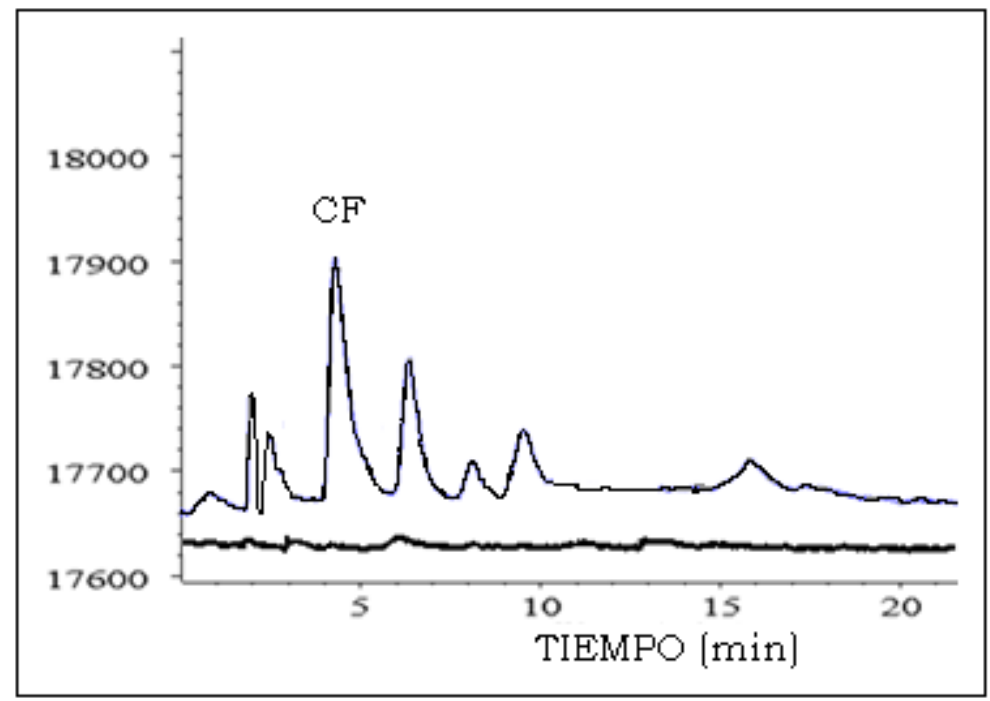

Figura 13: Cromatogramas superpuestos de muestras de suelo blanco y adicionado $(1.24 \mathrm{mg} / \mathrm{kg})$ tratadas según el procedimiento que se propone con los detectores FLD y DAD.

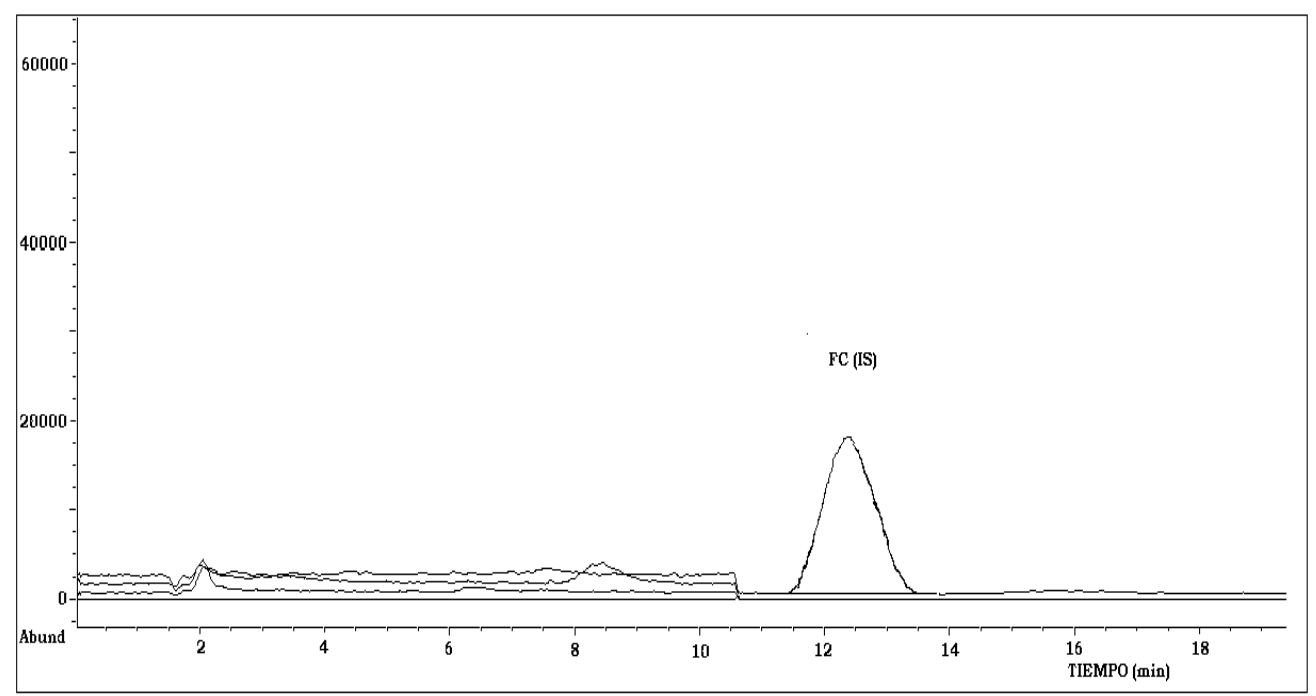




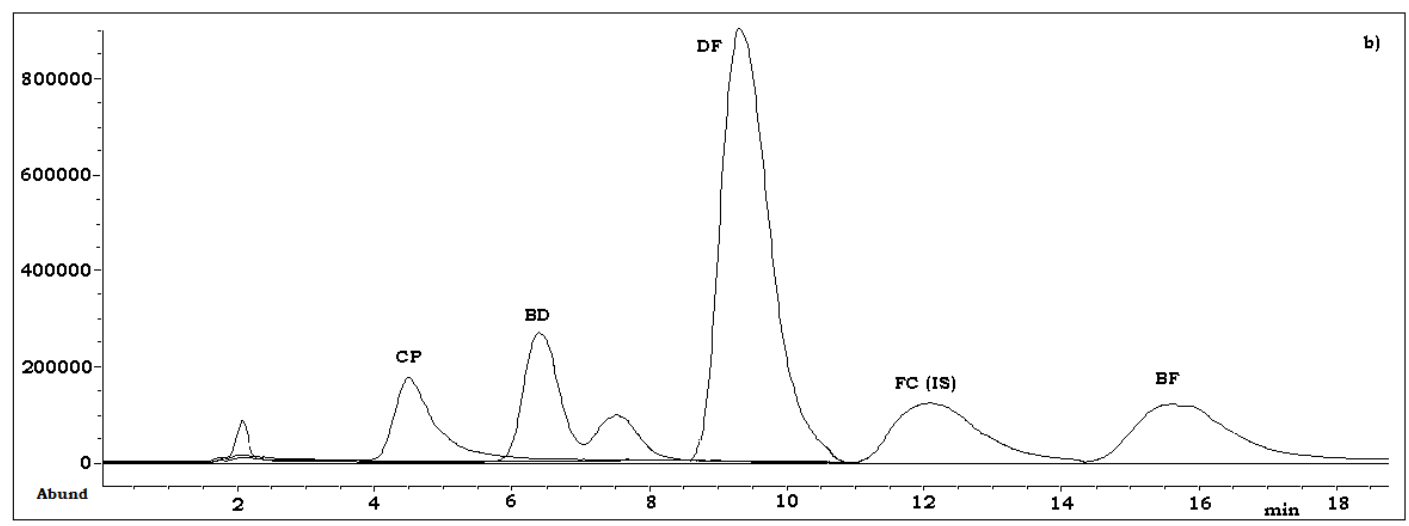

Figura 14: a) Cromatograma de un blanco de suelo tratado al que se adicionó el patrón interno (FC) en concentración $0.10 \mu \mathrm{g} / \mathrm{g}$. b) Cromatograma de una muestra dopada con una concentración de los rodenticidas con una cantidad de $0.15 \mu \mathrm{g} / \mathrm{g}$ y patrón interno, obtenidos por MS en modo SIM

Como se puede apreciar en las Figuras anteriores, no se observó, en los cromatogramas correspondientes a los blancos de muestra, ningún pico a los tiempos de retención de los anticoagulantes, comprobándose así la selectividad del método desarrollado.

\section{Limite de detección y de cuantificación}

Los límites de detección (LOD) y de cuantificación (LOQ) se determinaron de manera experimental mediante la inyección de una serie de muestras de suelo tratadas que no contenían ninguno de los analitos de interés, que hemos llamado blancos, midiéndose el valor de la señal analítica al tiempo de retención que eluían los analitos (ruido).

A continuación, se inyectaron extractos de muestras de suelo a las que si se les había adicionado una cantidad conocida de los 4 rodenticidas, realizando diluciones sucesivas hasta obtener una señal de 3 y 10 veces superior al ruido el LOD y LOQ, respectivamente.

Los valores obtenidos para los diferentes detectores utilizados se muestran en la siguiente Tabla 8. 
Tabla 8: LOD y LOQ, expresados en $\mu \mathrm{g} / \mathrm{kg}$ de suelo para los distintos sistemas de detección.

\begin{tabular}{ccccc}
\hline & \multicolumn{2}{c}{ FLD-DAD } & \multicolumn{2}{c}{ MSD-ESI } \\
\hline Compuesto & LOD & LOQ & LOD & LOQ \\
\hline CP & 78 & 210 & 0.6 & 1.8 \\
BD & 48 & 120 & 0.5 & 1.3 \\
DF & 35 & 98 & 0.1 & 0.3 \\
BF & 52 & 135 & 0.2 & 0.5 \\
\hline
\end{tabular}

De la observación de los datos de la Tabla se desprende que los valores obtenidos para los LOD y LOQ en ESI-MSD son mucho más bajos que en DAD-FLD, siendo de interés este detector para la determinación de residuos de estos compuestos cuando se encuentren a bajos niveles de concentración.

\section{Precisión}

Para llevar a cabo el estudio de precisión se sometió a la metodología desarrollada a réplicas de suelo adicionado con los analitos en tres niveles de concentración $(\mu \mathrm{g} / \mathrm{kg})$, en el caso de la repetibilidad durante el mismo día y de la precisión intermedia en 3 días consecutivos. Se inyectaron los diferentes extractos de suelo evaluando los coeficientes de variación (\%CV) del área (A) de los picos. En las Tabla 9 y 10 se presentan los resultados obtenidos para los niveles de concentración ensayados con DAD/FLD y MSD respectivamente. 
Tabla 9: Valores de los coeficientes de variación en el estudio de precisión para la detección DAD/FLD $(n=3)$

\begin{tabular}{|c|c|c|c|}
\hline \multirow[t]{2}{*}{ Compuesto } & \multirow{2}{*}{$\begin{array}{c}\text { Concentración } \\
\left(\mu \mathrm{gkg}^{-1}\right)\end{array}$} & \multirow{2}{*}{$\begin{array}{c}\text { Repetibilidad } \\
\% \mathbf{C V}\end{array}$} & \multirow{2}{*}{$\begin{array}{c}\text { Precisión } \\
\text { intermedia } \\
\% \mathbf{C V}\end{array}$} \\
\hline & & & \\
\hline \multirow[t]{3}{*}{$\mathbf{C P}$} & 625 & 2.6 & 3.1 \\
\hline & 2500 & 2.1 & 2.3 \\
\hline & 10000 & 2.4 & 2.7 \\
\hline \multirow[t]{3}{*}{ BD } & 625 & 3.7 & 4,0 \\
\hline & 2500 & 3.1 & 3.4 \\
\hline & 10000 & 3.3 & 3.6 \\
\hline \multirow[t]{3}{*}{ DF } & 625 & 3.0 & 3.2 \\
\hline & 2500 & 2.2 & 2.5 \\
\hline & 10000 & 2.8 & 3.0 \\
\hline \multirow[t]{3}{*}{ BF } & 625 & 3.5 & 3.7 \\
\hline & 2500 & 3.0 & 3.3 \\
\hline & 10000 & 3.2 & 3.4 \\
\hline
\end{tabular}

Tabla 10: Valores de los coeficientes de variación en el estudio de precisión para la detección MSD (n= 3)

\begin{tabular}{lcccc}
\hline Compuesto & $\begin{array}{c}\text { Concentración } \\
\left(\boldsymbol{\mu g k g}^{-1}\right)\end{array}$ & $\begin{array}{c}\text { Repetibilidad } \\
\text { \%CV }\end{array}$ & $\begin{array}{c}\text { Precisión } \\
\text { intermedia }\end{array}$ \\
${$\cline { 3 - 3 }$} }$ & 19 & 2.4 & \%CV \\
& 156 & 1.9 & 2.9 \\
& 1250 & 2.3 & 2.2 \\
BD & 19 & 3.6 & 2.6 \\
& 156 & 3.0 & 3.8 \\
& 1250 & 3.1 & 3.1 \\
DF & 19 & 2.9 & 3.4 \\
& 156 & 2.0 & 3.0 \\
& 1250 & 2.7 & 2.1 \\
BF & 19 & 3.4 & 2.8 \\
& 156 & 3.0 & 3.5 \\
& 1250 & 3.1 & 3.0 \\
\hline
\end{tabular}


Del análisis de los valores obtenidos se observa que el método desarrollado es preciso dado que los \%CV son inferiores al 4\% para los sistemas de detección utilizados.

\section{Linealidad y efecto matriz}

Para realizar la cuantificación de los analitos en los tres detectores, se realizó un calibrado utilizando el método de patrón externo para DADFLD y patrón interno para MS, cuantificando cada compuesto en base al área del pico. Para realizar el estudio de linealidad, se preparó una mezcla de los cuatro rodenticidas en metanol, a partir de ésta se realizaron las correspondientes diluciones en un intervalo de concentración desde LOQ hasta $10 \mathrm{mg} / \mathrm{L}$ para FLD-DAD y desde LOQ hasta $1000 \mu \mathrm{g} / \mathrm{L}$ para MSD. En la Tabla 11 se recogen los parámetros estadísticos de las líneas obtenidas por LC-DAD-FLD y MS.

Se aplicó la prueba $t$ para verificar la tendencia de la regresión y para asumir una tendencia lineal se ha de cumplir que $t_{\exp }$ sea superior a la $t_{\text {tab, }}$ obteniéndose la texp mediante el cociente entre el valor de la pendiente (b) de la recta y la desviación estándar de la misma $\left(\mathbf{s}_{\mathrm{b}}\right)$. La $\mathrm{t}_{\text {tab }}$ es la $t$-Student obtenida para $n$ - 2 grados de libertad y una probabilidad de 0.95. En todos los casos se cumple que la $t_{\text {exp }}>t_{\text {tab }}$, por lo tanto se acepta que el método es lineal y la ausencia de bias. Los valores del coeficiente de determinación $\left(R^{2}\right)$ eran para todos los casos mayores de 0.99 , lo que indica la bondad del ajuste del calibrado. 


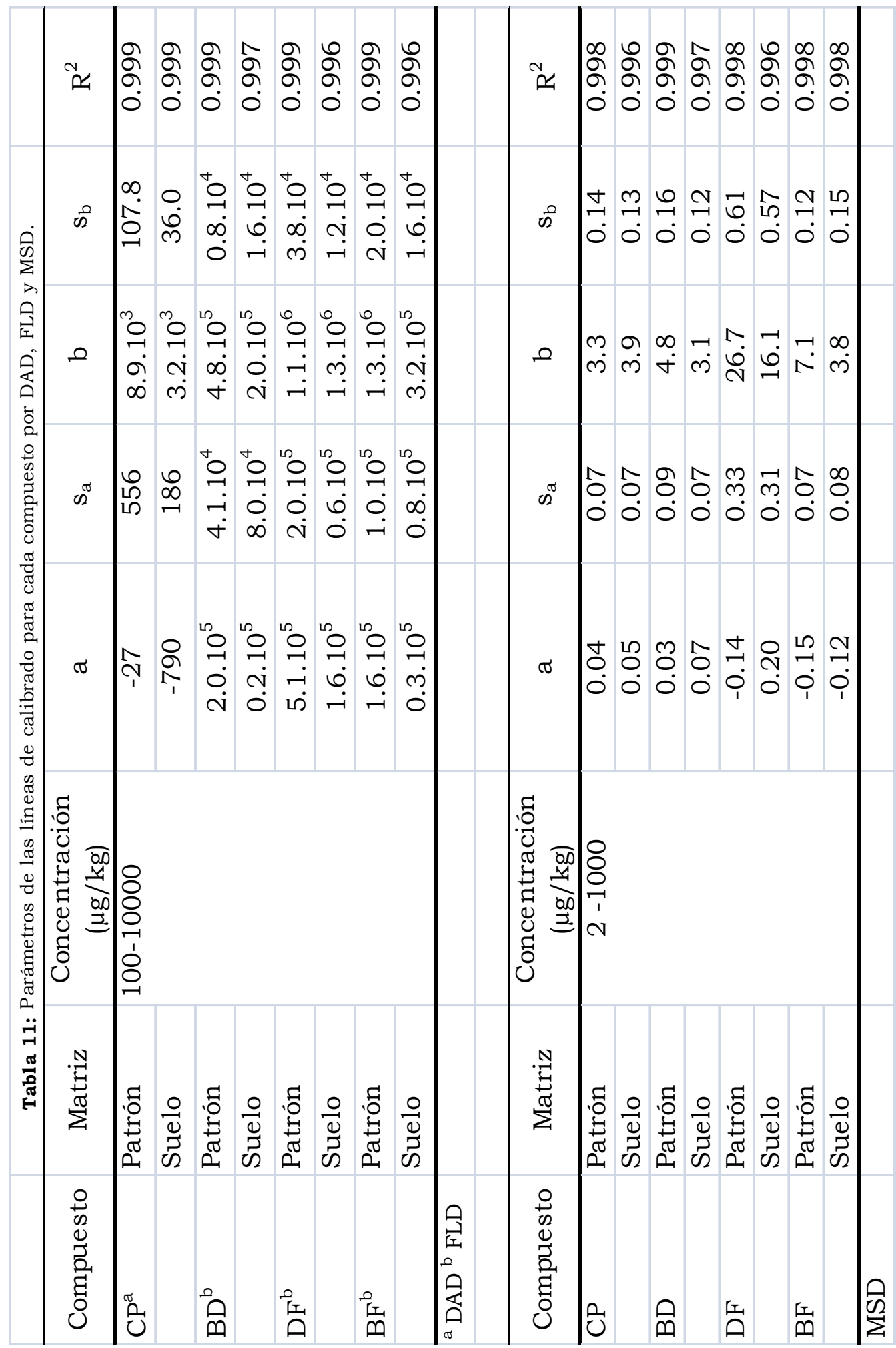


Por otra parte, para verificar el efecto matriz se realizó la comparación de las pendientes del calibrado de patrones en metanol y en suelo, observándose que las pendientes del calibrado entran dentro del intervalo de confianza.

\section{Exactitud}

La determinación de este parámetro se realizó mediante el cálculo del porcentaje de error relativo (\%RE). Para lo cual, se analizaron réplicas de extractos de suelos dopados con patrones a tres niveles de concentración durante tres días consecutivos.

Las concentraciones experimentales se determinaron a partir de la correspondiente línea de calibrado en matriz. En la Tabla 12 se presentan los valores calculados para DAD/FLD y en la Tabla 13 se presentan los valores de error relativo calculados para ESI-MS modo SIM.

Tabla 12: Porcentaje de error relativo obtenido para la detección DAD-FLD

\begin{tabular}{ccc}
\hline Compuesto & $\begin{array}{c}\text { Concentración añadida } \\
(\boldsymbol{\mu g} / \mathbf{k g})\end{array}$ & \% RE \\
\hline CP & 100 & 3.9 \\
& 2500 & 2.8 \\
BD & 10000 & 1.9 \\
& 100 & 5.7 \\
& 2500 & 5.6 \\
DF & 10000 & 4.4 \\
& 100 & 3.9 \\
& 2500 & 4.8 \\
BF & 10000 & 2.7 \\
& 100 & 5.2 \\
& 2500 & 4.1 \\
& 10000 & 3.2 \\
\hline
\end{tabular}


Tabla 13: Porcentaje de error relativo obtenido para la detección MSD- ESI

\begin{tabular}{ccc}
\hline Compuesto & $\begin{array}{c}\text { Concentración añadida } \\
(\boldsymbol{\mu g} / \mathbf{k g})\end{array}$ & \% RE \\
\hline CP & 19 & 6.8 \\
& 156 & 5.3 \\
BD & 1250 & 5.8 \\
& 19 & 5.6 \\
& 156 & 4.7 \\
DF & 1250 & 5.9 \\
& 19 & 4.4 \\
& 156 & 4.2 \\
BF & 1250 & 4.6 \\
& 19 & 6.1 \\
& 156 & 5.2 \\
\end{tabular}

Se observa en ambas Tablas que el \%RE para todos los analitos es inferior al 6\% para DAD/FLD y al 7\% para MS, valor considerado adecuado para la exactitud en el caso del análisis con este tipo de detectores. 


\section{V.5.- Aplicación a muestras de suelo}

El método propuesto se aplicó a muestras que presumiblemente habían tenido contacto con este tipo de compuestos, en concreto con clorofacinona y bromadiolona que fueron los dos únicos rodenticidas autorizados por la Junta de Castilla y León para la eliminación de la plaga de topillos.

El Instituto Tecnológico de Castilla y León (ITACyL) nos proporcionó una serie de muestras de suelo agrícola las cuales habían estado en contacto con los tratamientos efectuados con los 2 compuestos autorizados, y se habian tomado en diferentes zonas de nuestra Comunidad, concretamente en las provincias de Burgos, Palencia y Valladolid, así como también algunas procedentes de las provincias de Zamora y León. Las zonas de recogida se muestran en el siguiente mapa de la comunidad de Castilla y León

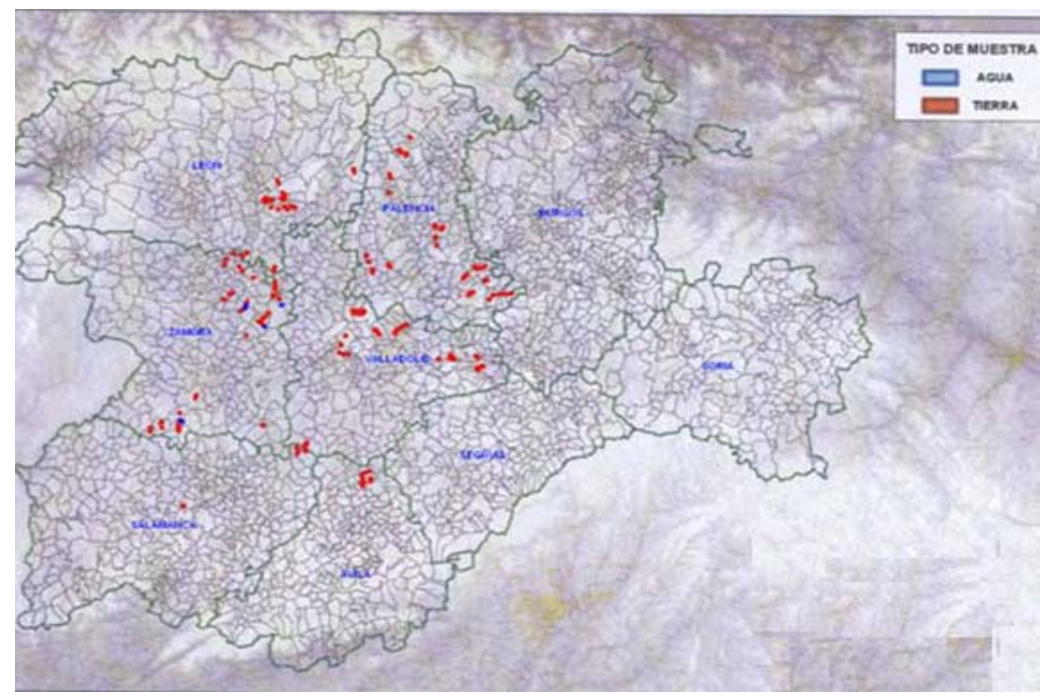

Figura 15: Mapa mostrando los puntos de recogida de muestra 
Las muestras se entregaron agrupadas en lotes dependiendo de si el tratamiento en la zona fue nulo, bajo, medio o alto. En total fueron 134 muestras divididas en 6 lotes.

Se aplicó el método que se propone para el análisis de los 4 rodenticidas y para la cuantificación se realizó un calibrado en matriz, dopando con concentraciones conocidas de $\mathrm{CP}$ y $\mathrm{BD}$ un suelo proporcionado por el ITACyL que no contenía ningún residuo de rodenticidas, y que fue tomado como blanco, según el procedimiento establecido.

Los resultados que se obtuvieron se muestran, a modo de ejemplo, en la siguiente Tabla 14, para algunas de las muestras pertenecientes a diferentes lotes:

Tabla 14: Ejemplo de algunos datos obtenidos de muestras reales sometidas al tratamiento de muestra propuesto.

\begin{tabular}{lcl}
\hline PROCEDENCIA & TRATAMIENTO & RESULTADO \\
\hline Alfaráz de Sayago & Nulo & $\operatorname{tr}=6.6$ \\
Alfaráz de Sayago & Nulo & - \\
Peñasuende & Nulo & - \\
Pereruela & Nulo & - \\
Carbellino & Nulo & $\operatorname{tr}=6.7$ \\
Fresno de Sayago & Nulo & - \\
Aldeaseca & Medio & $\operatorname{tr}=6.6$ \\
Langa & Medio & $\operatorname{tr}=6.6$ \\
Sinlabajos & Medio & - \\
Villanueva del Alderal & Medio & - \\
Abarca & Medio & $\operatorname{tr}=6.6$ \\
Amusco & Medio & - \\
Piña de Campos & Alta & $\operatorname{tr}=6.6$ \\
Población de campos & Alta & $\operatorname{tr}=6.6$ \\
\hline
\end{tabular}


Tabla 14: continuación

\begin{tabular}{lll}
\hline PROCEDENCIA & TRATAMIENTO & RESULTADO \\
\hline Autillo & Alta & - \\
Frechilla & Alta & - \\
Frómista & Alta & - \\
Fuentes de Nava & Alta & $\operatorname{tr}=6.9$ \\
Abarca & Medio & $\operatorname{tr}=6.6$ \\
Amusco & Medio & $\operatorname{tr}=6.6$ \\
Piña de Campos & Alta & - \\
Población de campos & Alta & $\operatorname{tr}=4.2$ \\
Autillo & Alta & - \\
Frechilla & Alta & - \\
Frómista & Alta & - \\
Fuentes de Nava & Alta & $\operatorname{tr}=6.9$ \\
Abarca & Medio & $\operatorname{tr}=6.6$ \\
Amusco & Medio & $\operatorname{tr}=6.6$ \\
Autillo & Alta & $\operatorname{tr}=6.6$ \\
Frechilla & Alta & $\operatorname{tr}=6.6$ \\
Frómista & Alta & $\operatorname{tr}=6.6$ \\
Fuentes de Nava & Alta & $\operatorname{tr}=6.6$ \\
Abarca & Medio & - \\
Amusco & Medio & $\operatorname{tr}=6.6$ \\
\hline
\end{tabular}

Como se puede observar en los resultados hay una serie de muestras en las que aparece un pico a un tiempo de retención de 6.6, tiempo próximo al pico de elución de la bromadiolona, y que podría deberse a la existencia de residuos del compuesto en el suelo. 
Para comprobar si se trataba o no de dicho compuesto, se añadieron a las muestras que habían dado ese pico, una cantidad conocida de BD y se volvieron a inyectar en los equipos LC-FLF/DAD y LC-MS.ESI.

Los resultados que se obtuvieron descartaron la existencia de dicho compuesto, como se demuestra en el cromatograma que se muestra en la Figura 16:

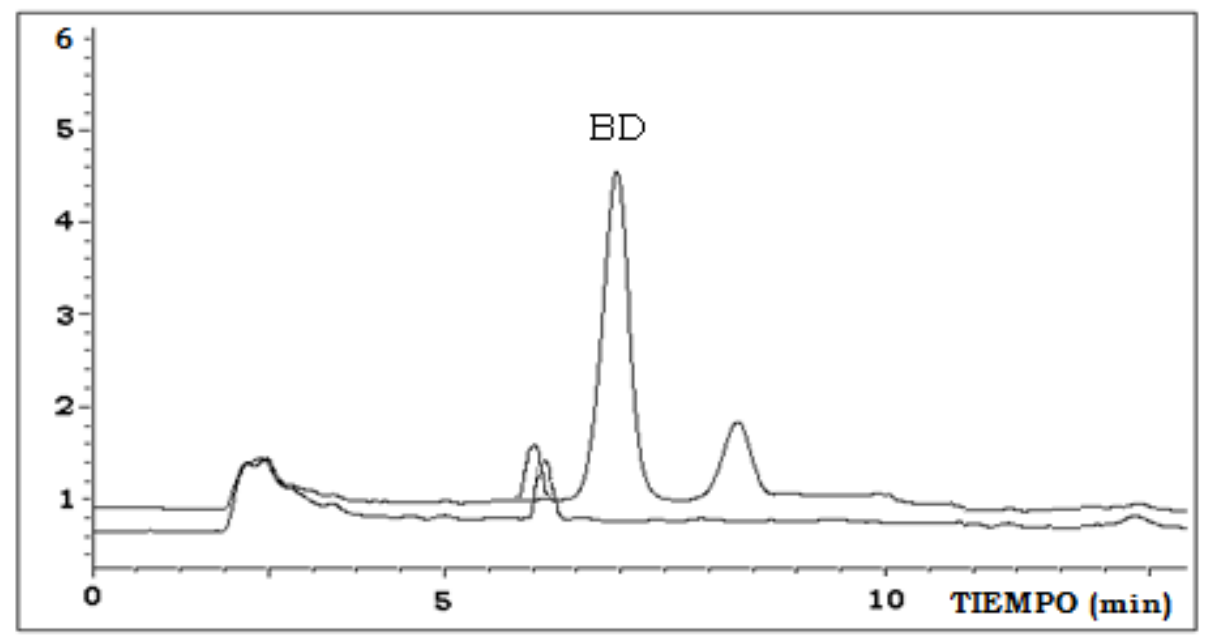

Figura 16: Cromatograma de una muestra real de suelo y de la misma muestra a la que se le añadió una pequeña cantidad de patrón de BD.

En la anterior Figura se muestran los cromatogramas superpuestos de una de las muestras y el obtenido cuando se adicionó una cantidad de $\mathrm{BD}$, como se puede observar la adición de $\mathrm{BD}$ implicaba la aparición de los 2 picos correspondientes a dicho compuesto, y que tenían tiempos de retención distintos al del compuesto existente en la muestra, hecho que descartaba la posibilidad de existencia de BD en las muestras.

Este hecho se corroboró también utilizando el sistema LC-ESI MS, ya que al inyectar las muestras adicionadas en modo SCAN, se obtenían, para el pico con tiempo de retención de 6.6 minutos, unos iones que no se correspondian con los de la BD. 
De modo análogo se demostró que el pico que aparecía en alguna de las muestras a un tiempo de retención de aproximadamente 4.2 minutos, próximo al tiempo de retención de la Clorofacinona, no se trataba de la existencia de este compuesto en la misma.

Se trató de establecer la naturaleza de estos compuestos a través de sus espectros de masas, puesto que existía la posibilidad de que se tratara de productos de degradación o metabolitos pero no se pudo llegar a establecer con la instrumentación disponible.

Cabe destacar el hecho que solo en 3 de las muestras analizadas se detectaron residuos de $\mathrm{BD}$, en una de las muestras en concentración inferior al LOD y en las otras dos muestras se encontraron cantidades de 3 y $6 \mu \mathrm{g} / \mathrm{kg}$. Clorofacinona se detectó en 2 muestras, en una de ellas en concentración inferior al LOD y en la otra el residuo era de $5 \mu \mathrm{g} / \mathrm{kg}$, cantidades que solo se pudieron determinar por ESI-MS en modo SIM. 

VI.- DETERMINACIÓN DE CLOROFACINONA, BROMADIOLONA, DIFENACUM Y BRODIFACUM EN AGUA 

Debido a la necesidad de realizar tratamiento con rodenticidas para detener la plaga de topillos, se pensó que cabía la posibilidad de que estos compuestos fuesen arrastrados por el agua de lluvia y pudieran llegar a los cursos de agua desconociéndose cuál es la persistencia de estos compuestos en esta matriz. Siendo esta la razón por la que se pensó en desarrollar un método que permitiera realizar la determinación de $\mathrm{CP}, \mathrm{BD}$, DF y BF en agua.

Como ya se ha indicado, en la consulta bibliográfica se encontraron descritos métodos para la determinación de este tipo de compuestos, fundamentalmente en matrices biológicas, pero no se encontró ningún trabajo en el que se abordara la determinación en agua.

\section{VI.1.- Tratamiento de muestra}

Para el desarrollo del método se pensó en dos posibilidades para conseguir su extracción-concentración de la matriz: extracción en fase sólida y la extracción líquido-líquido. Una vez establecido el tratamiento, sería necesario comprobar si las condiciones cromatográficas propuestas para el análisis de estos compuestos en suelo eran válidas para los extractos de agua.

\section{V1.1.1.- Extracción en fase sólida (SPE)}

Debido a la polaridad de los compuestos se pensó en utilizar cartuchos con relleno poco polar $\left(\mathrm{C}_{18}\right)$ seleccionando los cartuchos Oasis HLB (60 $\mathrm{mg} / 3 \mathrm{cc}$ ) con relleno polimérico, los cuales en ensayos previos realizados mostraron una buena retención de los compuestos.

Una vez seleccionado el tipo de cartucho, se procedió a la optimización de las etapas del procedimiento de extracción en fase sólida, con la finalidad de conseguir las condiciones más adecuadas para cada etapa que nos condujera a la máxima recuperación de los compuestos. 


\section{Etapa de activación}

Para la activación de los cartuchos se empleó metanol, de modo análogo se empleó metanol para la etapa de solvatación y agua para la de equilibración, estableciendo para ambos disolventes un volumen de $5 \mathrm{~mL}$.

\section{Cantidad de muestra}

Se realizaron ensayos para establecer el máximo volumen de muestra que se podría pasar, lo que permitiría conseguir la máxima concentración y alcanzar menores límites de detección y cuantificación, sin sobrepasar la capacidad del sorbente.

Para ello, se hicieron distintas pruebas con diferentes volúmenes de agua desionizada, a los que previamente se había adicionado la misma concentración de los compuestos de estudio. Los volúmenes de agua fueron 20,50,100, 250 y $500 \mathrm{~mL}$, realizándose la posterior elución de los compuestos con $5 \mathrm{~mL}$ de metanol, que fueron posteriormente concentrados a sequedad en rotavapor, y después el residuo seco se disolvió con $1 \mathrm{~mL}$ de metanol, $20 \mu \mathrm{L}$ de los cuales se inyectaron en el cromatógrafo utilizando las condiciones establecidas para la determinación en suelos.

De los cromatogramas que se obtuvieron se dedujo que hasta volúmenes de muestra de $250 \mathrm{~mL}$ no se sobrepasaba la capacidad del cartucho, por lo que se seleccionaron los volúmenes de 100 y $250 \mathrm{~mL}$, ya que serian estos volúmenes los que nos permitirian obtener una mayor concentración.

Los porcentajes de recuperación fueron buenos para los tres primeros compuestos en eluir (clorofacinona, bromadiolona, difenacum) pero no para el brodifacum, que se recuperaba en bajo porcentaje. 
Se comprobó, como era de esperar, que no era necesaria la utilización de la etapa de lavado.

\section{Etapa de elución}

Dado que empleando como disolvente para la elución metanol no se conseguía recuperar más que un pequeño porcentaje del brodifacum, se ensayaron diferentes disolventes así como la adición de ácidos y bases al mismo. En primer lugar, se empleó acetonitrilo no mejorando los porcentajes de recuperación para ningún analito, por lo que se pensó en estudiar si la adición al metanol de ácido o base lograba mejorarlos. Se ensayaron como soluciones para esta etapa: 10\% $\mathrm{HCl} 1 \mathrm{M}, 10 \% \mathrm{NaOH} 1$ M y $10 \% \mathrm{NH}_{3} 1 \mathrm{M}$ en metanol. Los mejores porcentajes se obtuvieron utilizando $\mathrm{NH}_{3}$, por lo que a continuación se procedió a variar su concentración, observándose que a medida que aumentaba su concentración se incrementaba la recuperación, siendo esta máxima cuando se empleaba concentrado.

Posteriormente, se procedió a establecer el porcentaje de amoniaco en la mezcla. Se realizaron diferentes ensayos en los que se pudo observar que el aumento del mismo provocaba un aumento en la recuperación, sobre todo para el brodifacum, de hasta un 20\% ya que porcentajes superiores prácticamente no los modificaban. Por lo que se estableció para la elución de los analitos la utilización de metanol con un $20 \% \mathrm{NH}_{3}$ concentrado.

Se ensayaron diferentes volúmenes de la mezcla seleccionada para la elución en el intervalo de 1 hasta $15 \mathrm{~mL}$, ya que volúmenes mayores no mejoraban el porcentaje de recuperación. Inicialmente se hicieron pasar 2 $\mathrm{mL}$, se recogió el extracto y se inyectó, posteriormente se pasó $1 \mathrm{~mL}$ más y se inyectó, comprobándose que aún seguía habiendo compuestos retenidos en el sorbente. Se continuaron estas pruebas haciendo pasar mayor cantidad de metanol, deduciéndose que a partir de $10 \mathrm{~mL}$ no se lograba arrastrar una cantidad apreciable de los compuestos, por lo que 
se seleccionó como volumen más adecuado el de $10 \mathrm{~mL}$. A continuación, se pasó a establecer cómo se debían de utilizar estos $10 \mathrm{~mL}$, si de una vez o realizando la elución con volúmenes más pequeños. De los resultados que se obtuvieron se pudo comprobar que los porcentajes de recuperación mayores se obtenían cuando se realizaban 5 eluciones con $2 \mathrm{~mL}$ cada vez.

La evaporación del eluyente se realizó utilizando rotavapor a una temperatura de $40^{\circ} \mathrm{C}$. Y para la reconstitución del residuo seco se utilizó metanol, siendo necesario establecer el volumen a emplear que permitiera por un lado la disolución total del residuo seco y por otro no incrementar los límites de detección. Los volúmenes variaron desde 0.5 hasta $2 \mathrm{~mL}$, observándose a partir de $1 \mathrm{~mL}$ la redisolución total del residuo. En la Tabla 15 se muestran los porcentajes de recuperación obtenidos:

Tabla 15: \% Recuperación SPE para volúmenes de $100 \mathrm{~mL}$ y $250 \mathrm{~mL}$ de agua desionizada

\begin{tabular}{ccc}
\hline Compuesto & \multicolumn{2}{c}{ \%Recuperación } \\
\cline { 2 - 3 } & $\mathbf{1 0 0} \mathbf{~ m L}$ & $\mathbf{2 5 0} \mathbf{~ m L}$ \\
CP & 87,0 & 74,0 \\
BD & 93.8 & 82.8 \\
DF & 87.3 & 80.1 \\
BF & 77.9 & 70.9 \\
\hline
\end{tabular}

\section{Tratamiento de muestra propuesto}

Después de estas experiencias el proceso de extracción en fase sólida con cartucho $\mathrm{C}_{18}$ polimérico Oasis HLB (60 mg/ $3 \mathrm{cc}$ ), quedó establecido con las condiciones que se resumen en la Figura 17: 


\section{Concentración SPE Oasis HLB (60 mg/ 3 cc)}

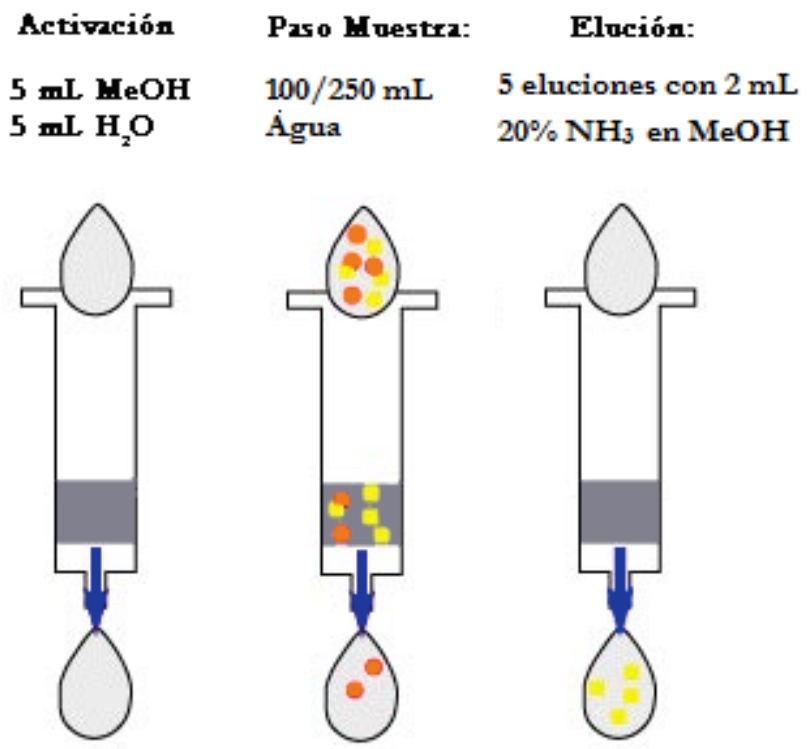

Concentración: Evaporación en Rotavapor

Evporar a sequedad a $40^{\circ} \mathrm{C}$

Redisolver con $1 \mathrm{~mL}$ de $\mathrm{MeOH}$

Figura 17: Esquema del tratamiento de muestra.

Se realizaron calibrados para los dos volúmenes de muestra estudiados, utilizando el método de patrón externo, cuantificándose en base al área del pico. Para realizar el estudio de linealidad, se preparó una mezcla de los diferentes compuestos en metanol, a partir de ésta se realizaron las correspondientes diluciones en un intervalo de concentración de 0.25 a 2 $\mathrm{mg} / \mathrm{L}$ para el DAD-FLD, las mismas que se utilizaron para añadir al agua. En la Tabla 16 se recogen los parámetros estadísticos de las líneas obtenidas por LC-DAD/FLD para los volúmenes de agua de 100 y $250 \mathrm{~mL}$. 


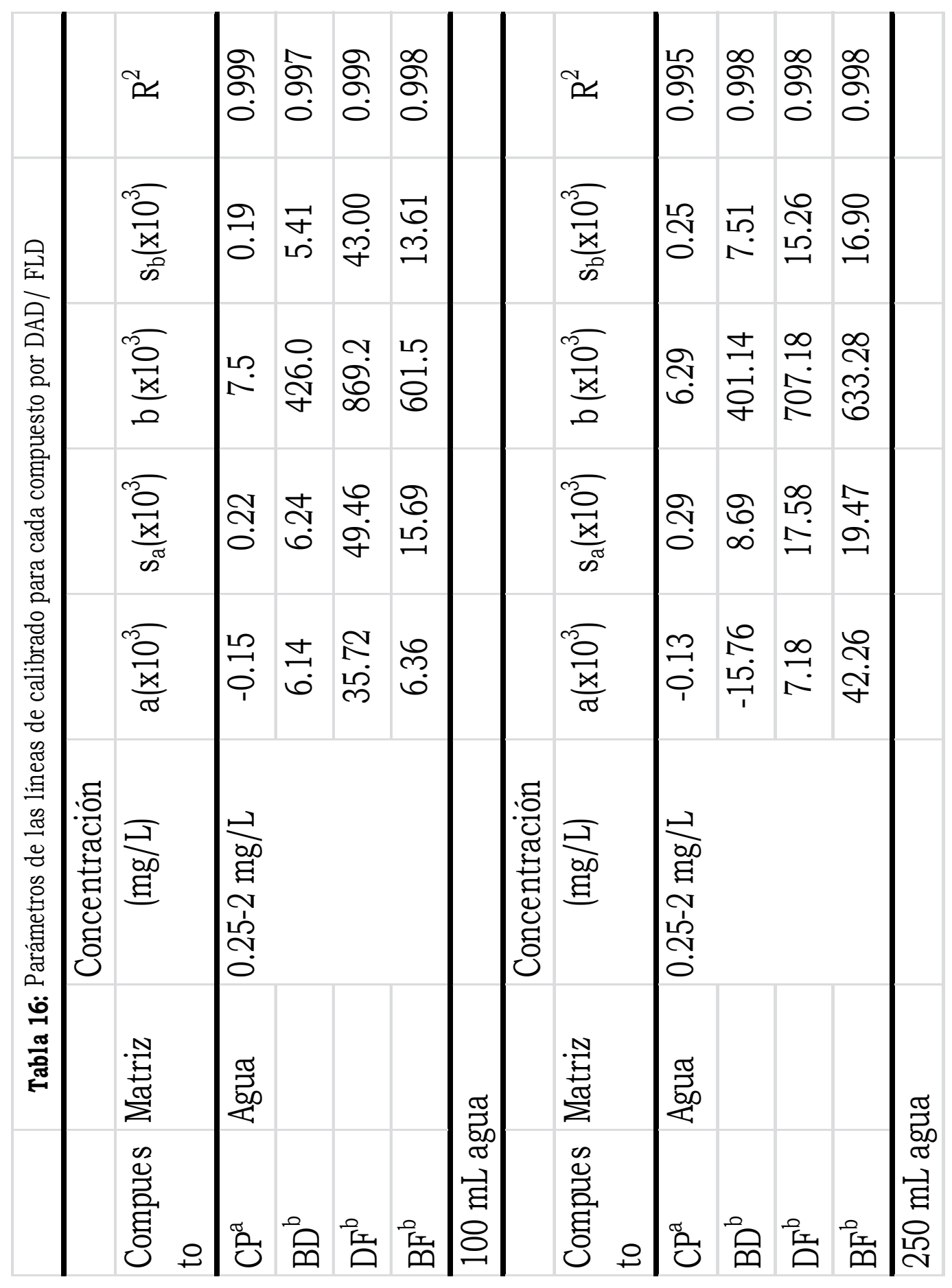


Se aplicó la prueba $t$ para verificar la tendencia de la regresión y para asumir una tendencia lineal y en todos los casos se cumple que la $t_{\text {exp }}>t_{\text {tab, }}$ por lo tanto se acepta que el método es lineal. Los valores del coeficiente de determinación $\left(\mathrm{r}^{2}\right)$ fueron mayores de 0.99 , lo que indica la bondad del ajuste del calibrado.

Una vez desarrollado el tratamiento de muestra, para realizar la determinación de los cuatro compuestos en agua desionizada, se procedió a aplicarlo a muestras de agua procedentes de la red urbana, a las que previamente se le había adicionado los compuestos. Los resultados que se obtuvieron fueron negativos ya que los porcentajes de recuperación eran muy inferiores a los obtenidos con el agua inicialmente tomada y además muy poco reproducibles.

A partir de estos resultados, se pensó en que una posible causa de la disparidad de los resultados podría deberse a la diferencia del valor del $\mathrm{pH}$ entre el agua desionizada, el cual tenía un valor de aproximadamente 6.1, y el del agua de la red urbana, que era del orden de 7.8. Se realizaron distintas pruebas, variando el $\mathrm{pH}$ del agua de la red urbana, comprobándose que efectivamente, los resultados en cuanto a la recuperación de los compuestos variaban considerablemente dependiendo del pH de la misma. Por lo que el siguiente paso consistió en llevar el pH de agua a un valor próximo a 6, para posteriormente tratarla según el método establecido. Los resultados que se obtuvieron no mejoraban ni las recuperaciones ni la reproducibilidad de las mismas.

Dada la gran influencia que el $\mathrm{pH}$ parecía ejercer se pensó en comprobar la estabilidad de los compuestos al $\mathrm{pH}$ del agua de red y compararla con la estabilidad en agua. Para ello, se prepararon una serie de disoluciones de los compuestos, a dos niveles de concentración, 0.1 y $1 \mathrm{mg} / \mathrm{L}$, en agua de red a su $\mathrm{pH}$ y llevada a un $\mathrm{pH}$ de aproximadamente 6.1, y la mismas concentraciones en agua desionizada. 
Estas disoluciones fueron inyectadas en el equipo cromatográfico durante varios días. Los resultados que se obtuvieron no permitieron obtener ninguna conclusión, ya que el comportamiento de los compuestos, tanto en los dos tipos de agua ensayada como a los dos $\mathrm{pH}$, era similar. A modo de ejemplo en la siguiente Figura 18, se muestran los resultados para la concentración de $1 \mathrm{mg} / \mathrm{L}$.

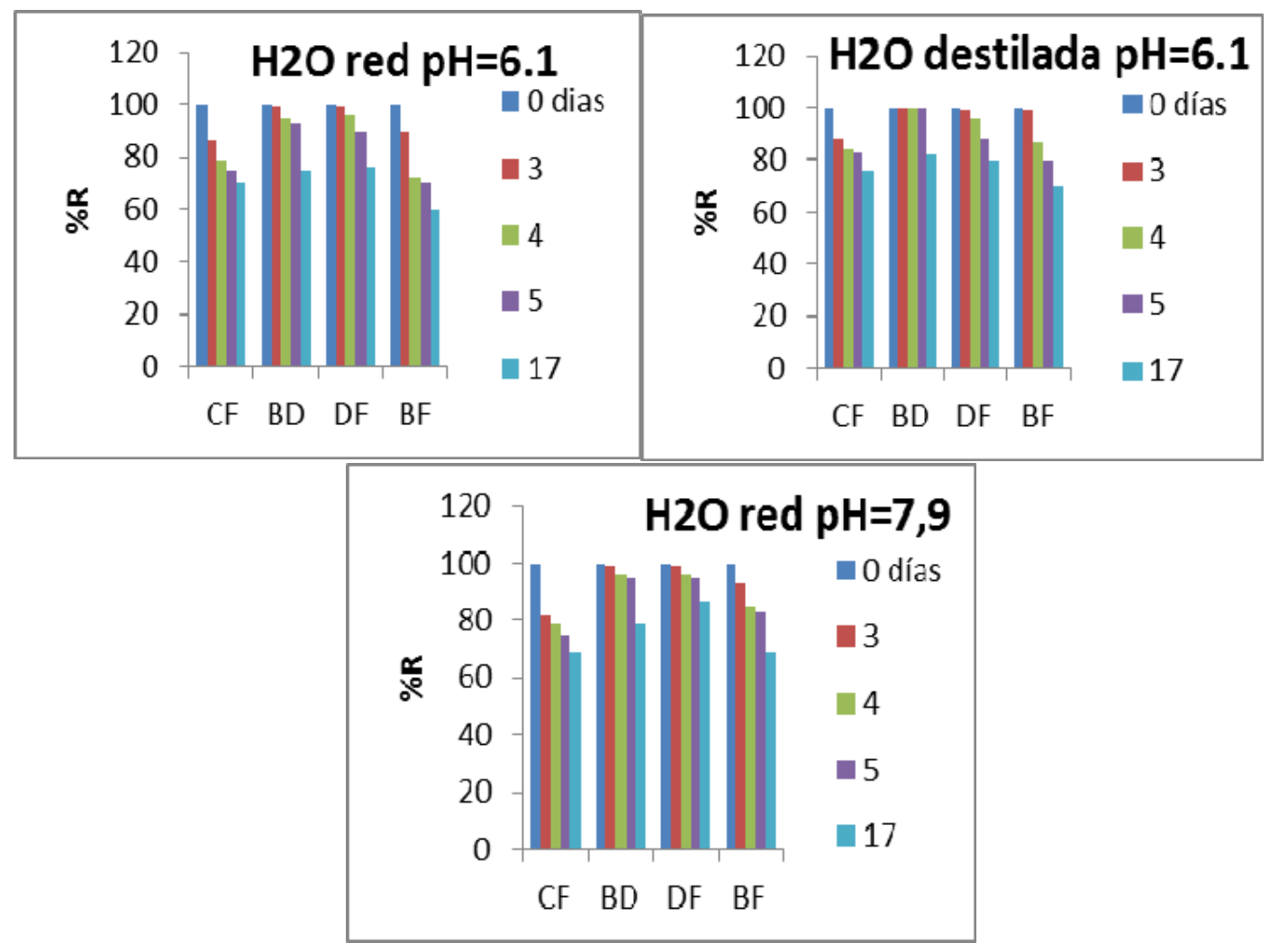

Figura 18: Estabilidad de los analitos en agua de red y desionizada a diferentes $\mathrm{pH}$

Como se puede observar en la Figura anterior, donde se representa el porcentaje de cada compuesto en función de los días, la estabilidad de los compuestos es muy similar en los dos tipos de agua y también para la misma agua a distinto $\mathrm{pH}$. La única diferencia que se podría apreciar sería que en general es menor la estabilidad en agua de red frente al agua desionizada. 
Dado que se comprobó que no era el pH la causa de la falta de reproducibilidad encontrada en los resultados del tratamiento desarrollado para aislar/concentrar los compuestos del agua de la red urbana por SPE, se pensó que la única otra posibilidad se debiera a la saturación del sorbente, a pesar de que no se habian detectado los compuestos en el eluido del paso de muestra. Por ello, se realizaron nuevos tratamientos disminuyendo el volumen de muestra a tratar llegando hasta los $10 \mathrm{~mL}$ y aunque con este último volumen los resultados fueron reproducibles y los porcentajes de recuperación adecuados, del orden del $75 \%$, este tratamiento de muestra se desechó debido a que se lograba una baja concentración lo que conduciría a límites de detección y cuantificación elevados. En la Tabla 17 se muestran los porcentajes de recuperación obtenidos:

Tabla 17: \% Recuperación SPE para volumen de $10 \mathrm{ml}$ de agua de red urbana adicionada

\begin{tabular}{cc}
\hline Compuestos & \% Recuperación \\
\hline CP & 65 \\
BD & 72 \\
DF & 74 \\
BF & 79 \\
\hline
\end{tabular}

En este punto se pensó en desarrollar el tratamiento de muestra utilizando la extracción líquido- líquido.

\section{VI.1.2.- Extracción liquido-liquido}

Según la bibliografia consultada, uno de los disolventes más utilizado para la extracción de este tipo de compuestos en otras matrices era el 
acetato de etilo, razón por la cual se pensó en utilizar este disolvente como extractante para los cuatro rodenticidas.

Para comprobar el poder de extracción del acetato de etilo, para los compuestos objeto de estudio del agua se realizaron unos ensayos previos en los que se utilizó $100 \mathrm{~mL}$ de agua de red urbana $(\mathrm{pH}=7.8)$ a la que se había adicionado una cantidad conocida de una mezcla patrón de los cuatro rodenticidas. Se realizaron 3 extracciones sucesivas con $10 \mathrm{~mL}$ de acetato de etilo, con agitación mecánica en cada extracción, durante 10 minutos. A continuación, se recogian los extractos por separado para concentrarlos en rotavapor y los residuos secos se disolvieron con $1 \mathrm{~mL}$ de metanol. Por último, los extractos reconstituidos fueron inyectados en el cromatógrafo en las condiciones establecidas.

A continuación, en las Figuras 19 y 20 se muestran los cromatogramas correspondientes a las tres extracciones obtenidos con detección DAD y FLD:

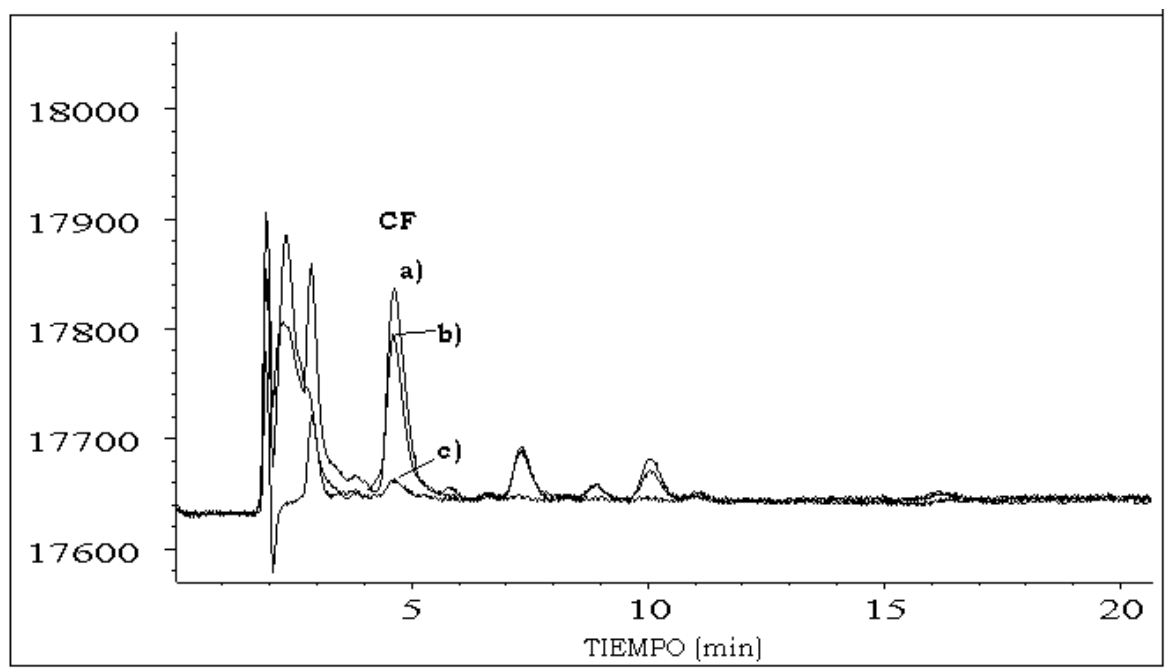

Figura 19: Superposición de tres cromatogramas correspondientes a a) $1^{\text {a }}$ extracción; b) 2a extracción; c) $3^{a}$ extracción. Detección por DAD. 


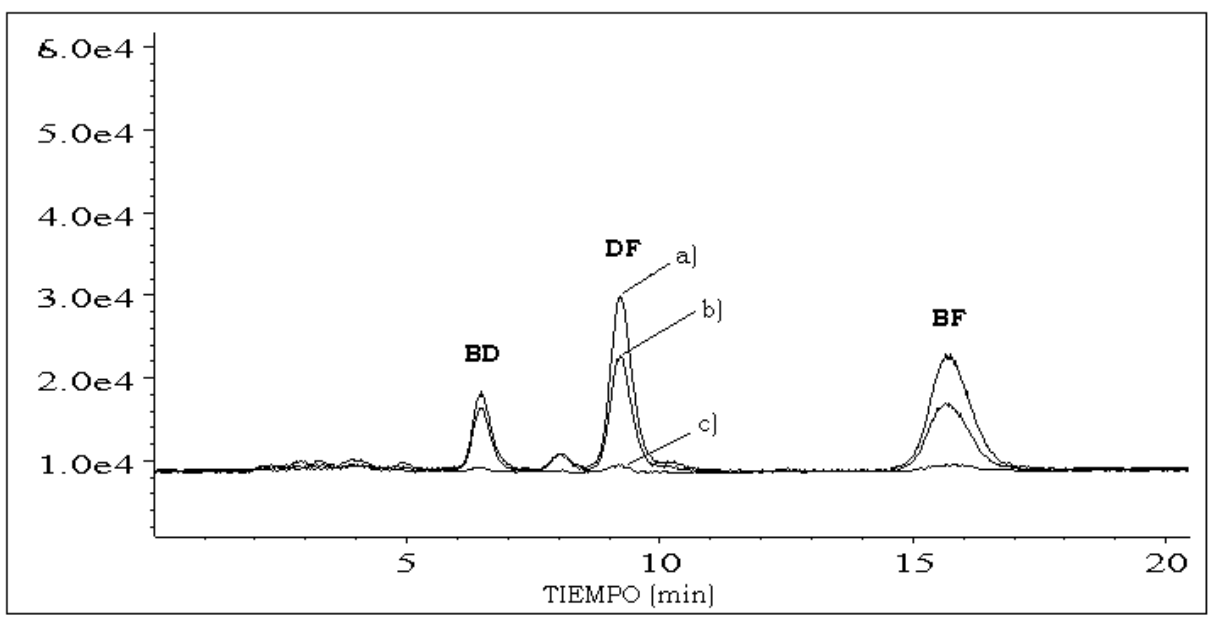

Figura 20: Superposición de tres cromatogramas correspondientes a a) $1^{\text {a }}$ extracción; b) $2^{a}$ extracción; c) $3^{a}$ extracción. Detección por FLD.

Como se puede observar, la intensidad de los picos correspondientes a los compuestos va disminuyendo con cada extracción, siendo con las dos primeras extracciones donde se recupera la mayor parte de los analitos, entre un $65-75 \%$, y en la tercera extracción lo que se recuperaba era inferior al 5\%. Comprobado que efectivamente el acetato de etilo se podía utilizar para la extracción de estos rodenticidas, se pensó en estudiar todos los factores que podían influir en el proceso, con el fin de establecer los valores más adecuados que nos condujeran a las máximas recuperaciones.

\section{Influencia del pH}

En primer lugar y debido a que anteriormente ya se habian tenido problemas con el $\mathrm{pH}$ que tenía el agua de red urbana, y el efecto que éste podría producir en la extracción de nuestros analitos, se procedió a realizar varias pruebas manteniendo las dos extracciones sucesivas con $10 \mathrm{~mL}$ de acetato de etilo y variando el $\mathrm{pH}$ del agua, en un intervalo de $3 \mathrm{a}$ 10, mediante la adición de ácido fórmico o hidróxido amónico. En la Tabla 18, que se muestra a continuación, aparecen los porcentajes de 
recuperación totales, en las dos extracciones, que se obtuvieron para los distintos $\mathrm{pH}$ ensayados.

Tabla 18: Porcentajes de recuperación de cada compuesto en función del pH.

\begin{tabular}{lllllllll}
\hline \multicolumn{10}{c}{ \% Recuperación } \\
\hline & pH 3 & pH 4 & pH 5 & pH 6 & pH 7 & pH 8 & pH 9 & pH 10 \\
\cline { 2 - 9 } & - & - & - & 48 & 56 & 70 & 82 & 85 \\
BD & 5 & 8 & 9 & 53 & 68 & 78 & 84 & 88 \\
DF & 22 & 37 & 26 & 66 & 74 & 82 & 88 & 99 \\
BF & 39 & 57 & 36 & 69 & 75 & 84 & 90 & 98 \\
\hline
\end{tabular}

Como se puede observar en la Tabla, el pH ejerce una notable influencia en el proceso de extracción de los compuestos, ya que a $\mathrm{pH} \leq 5$ la $\mathrm{CP}$ no se extrae y la recuperación de los otros compuestos es baja. Las mayores recuperaciones se obtienen a partir de $\mathrm{pH} \mathrm{9,} \mathrm{por} \mathrm{lo} \mathrm{que} \mathrm{se} \mathrm{estableció} \mathrm{como}$ pH más adecuado el de 10. Para conseguir ese valor de $\mathrm{pH}$, aunque se probaron distintos tampones, se seleccionó el tampón $\mathrm{NH}_{4}{ }^{+} / \mathrm{NH}_{3}$.

Como era lógico, al llevar el agua a este pH se observó la aparición de una turbidez, la cual podría atribuirse a la precipitación de calcio al tratarse de aguas duras, por lo que se añadió un complejante para eliminarla. Se utilizó para este fin el AEDT estableciéndose, después de realizar algunas pruebas, que la adición de $1 \mathrm{~mL}$ de AEDT $0.1 \mathrm{M}$ era suficiente, añadiendose antes de ajustar el pH con el tampón.

\section{Volumen de extractante}

Para seleccionar el volumen de extractante más adecuado se tomaron varias muestras de $100 \mathrm{~mL}$ de agua a las que se les había añadido unas cantidades conocidas de los cuatro analitos. Posteriormente, se les ajusto el $\mathrm{pH}$ a un valor próximo a 10 mediante la adición de $1 \mathrm{~mL}$ de AEDT $0.1 \mathrm{M}$ y $0.5 \mathrm{~mL}$ del tampón $\mathrm{NH}_{4}+\mathrm{NH}_{3}$, y a continuación se realizaron extracciones con diferentes volúmenes de acetato de etilo entre 10 y 50 
$\mathrm{mL}$ a intervalos de $10 \mathrm{~mL}$, manteniendo una agitación constante durante 10 minutos. Los extractos se concentraron a sequedad en rotavapor reconstituyendo el residuo con $1 \mathrm{~mL}$ de metanol. Los resultados se muestran en la siguiente Tabla 19:

Tabla 19: Porcentajes de recuperación en función del volumen de extractante

\begin{tabular}{lccccc}
\hline \multirow{2}{*}{ Compuesto } & \multicolumn{5}{c}{ Volumen de acetato de etilo (mL) } \\
\cline { 2 - 6 } CP & $\mathbf{1 0}$ & $\mathbf{2 0}$ & $\mathbf{3 0}$ & $\mathbf{4 0}$ & $\mathbf{5 0}$ \\
BD & 63 & 78 & 92 & 90 & 91 \\
DF & 70 & 80 & 95 & 94 & 93 \\
BF & 71 & 83 & 98 & 95 & 94 \\
\hline
\end{tabular}

Como se puede observar en la Tabla la recuperación para todos los compuestos aumentaba a medida que se incrementaba el volumen de extractante hasta $30 \mathrm{~mL}$, mientras que la utilización de volúmenes superiores no la mejoraban. Se realizaron otros ensayos empleando 20, 25 y $30 \mathrm{~mL}$ de acetato de etilo y los resultados que se obtuvieron se detallan en la siguiente Tabla 20.

Tabla 20: Porcentajes de recuperación en función del volumen de extractante

\begin{tabular}{lccc}
\hline \multirow{2}{*}{ Compuesto } & \multicolumn{3}{c}{ Volumen de extractante $\mathbf{~ m L}$} \\
\cline { 2 - 4 } & $\mathbf{2 0}$ & $\mathbf{2 5}$ & $\mathbf{3 0}$ \\
\hline CP & 78 & 91 & 90 \\
BD & 80 & 96 & 95 \\
DF & 83 & 99 & 98 \\
BF & 81 & 97 & 97 \\
\hline
\end{tabular}


A la vista de los datos de la Tabla se seleccionó un volumen de $25 \mathrm{~mL}$, ya que la utilización de volúmenes superiores no mejoraba el porcentaje de recuperación.

Se probó a realizar una segunda extracción, utilizando el mismo volumen de extractante y tiempo de agitación, pero se desestimó ya que el incremento en la recuperación era inferior al 5\% para la CP, y menor para el resto de los compuestos.

\section{Tiempo de agitación}

Por último se estudió la influencia que el tiempo de agitación ejercía sobre el proceso. Para lo cual, se tomaron varias muestras de $100 \mathrm{~mL}$ agua a las que se había adicionado cantidades conocidas de los compuestos y a las que se había ajustado el $\mathrm{pH}$ según lo establecido, y a las que se les añadió el volumen de extractante seleccionado, sometiendo a cada una a un tiempo de agitación mecánico distinto, en un intervalo de entre 5-20 minutos, a intervalos de 5 minutos. Los resultados obtenidos se detallan en la Tabla 21:

Tabla 21: Porcentajes de recuperación en función del tiempo de agitación

\begin{tabular}{lcccc}
\hline \multirow{2}{*}{ Compuesto } & \multicolumn{4}{c}{ Tiempo de Agitación (min) } \\
\cline { 2 - 5 } & $\mathbf{5}$ & $\mathbf{1 0}$ & $\mathbf{1 5}$ & $\mathbf{2 0}$ \\
\hline CP & 67 & 91 & 89 & 92 \\
BD & 79 & 96 & 95 & 94 \\
DF & 71 & 99 & 97 & 93 \\
BF & 79 & 97 & 98 & 95 \\
\hline
\end{tabular}

Los datos de la Tabla 21 mostraron que el tiempo de 10 minutos de agitación era suficiente, ya que tiempos superiores no incrementaban la recuperación y por el contrario incrementaría el tiempo de análisis. 
Por último, se comprobó que con $1 \mathrm{~mL}$ de metanol se conseguía la disolución completa del residuo seco obtenido en la concentración a sequedad del extracto.

Como resumen el procedimiento de separación líquido- líquido con acetato de etilo de estos cuatro rodenticidas que se propone quedó establecido de la siguiente manera: a muestras de $100 \mathrm{~mL}$ de agua de red urbana se le añadió, por triplicado, $1 \mathrm{~mL}$ de una mezcla patrón de concentración conocida de los analitos, $1 \mathrm{~mL}$ de AEDT 0.1 M y se ajustó el pH a un valor cercano a 10 con la adición de $0.5 \mathrm{~mL} \mathrm{NH}{ }_{4} \mathrm{Cl} / \mathrm{NH}_{4} \mathrm{OH}$. A continuación, las muestras se trasvasaron a un embudo de decantación y se les añadió 25 $\mathrm{mL}$ de acetato de etilo. La mezcla se agitó durante 10 minutos mediante un agitador mecánico. Transcurridos 10 minutos de agitación, las muestras permanecieron en reposo hasta que se separaron las fases y la fase orgánica se concentró a sequedad en rotavapor a $40^{\circ} \mathrm{C}$. El residuo seco se reconstituyó en $1 \mathrm{~mL}$ de metanol. Una alícuota de $20 \mu \mathrm{L}$ se inyectó en el sistema cromatográfico en las mismas condiciones que las establecidas para la determinación en suelos. La Figura 21 muestra el esquema del tratamiento: 


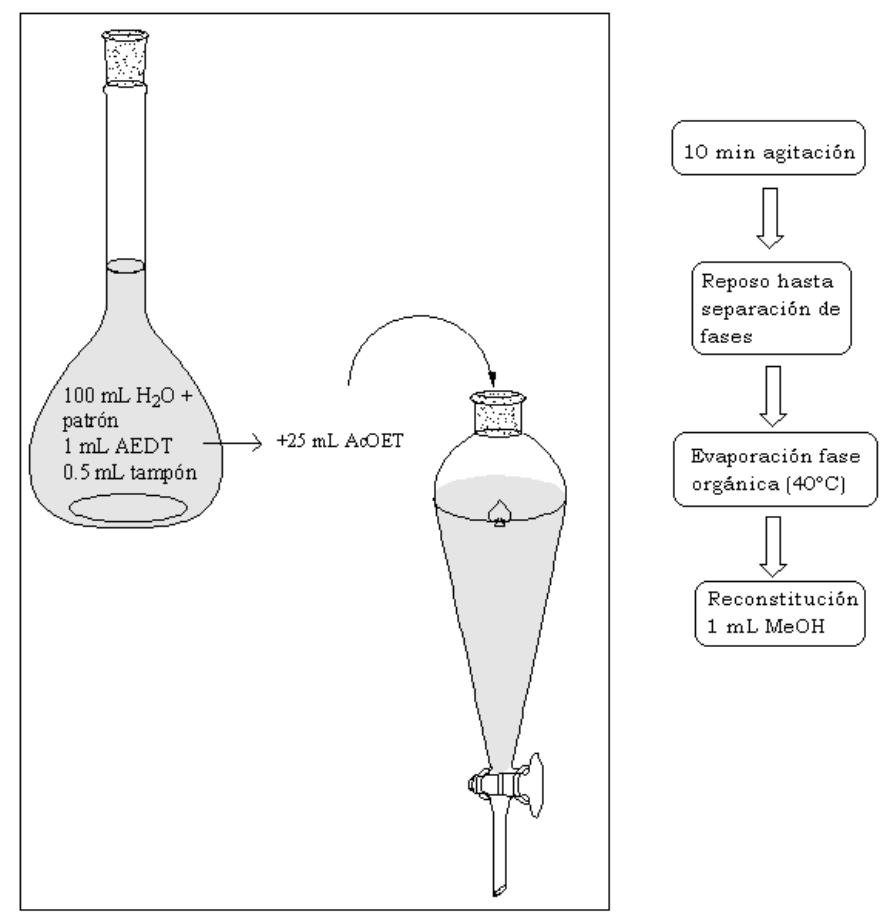

Figura 21: Tratamiento de muestra.

Los porcentajes de recuperación para los cuatro compuestos y la eficacia del método desarrollado se determinaron en 6 réplicas a tres niveles de concentración. Se comparó el área de los picos correspondientes a los compuestos en los cromatogramas de muestras de agua dopadas con una concentración determinada de los analitos y tratadas según el procedimiento descrito, con el área de los picos de muestras de agua sin dopar tratadas según el mismo procedimiento y posteriormente dopadas con la misma concentración de los rodenticidas al redisolver el residuo después de la evaporación a sequedad. Los porcentajes de recuperación obtenidos se recogen a continuación en la Tabla 22: 
VI.- Determinación de $C F, B D, D F$ y $B F$ en agua

Tabla 22: Porcentajes de recuperación a tres niveles de concentración $(n=6)$ y \% RSD

\begin{tabular}{|c|c|c|}
\hline Compuesto & $\begin{array}{c}\text { Concentración } \\
(\mu \mathrm{g} / \mathrm{L})\end{array}$ & $\%$ Recuperación \pm \% RSD \\
\hline \multirow{3}{*}{$\mathbf{C P}$} & 100 & $92 \pm 6$ \\
\hline & 250 & $88 \pm 5$ \\
\hline & 1000 & $86 \pm 6$ \\
\hline \multirow{3}{*}{ BD } & 100 & $95 \pm 6$ \\
\hline & 250 & $92 \pm 4$ \\
\hline & 1000 & $91 \pm 4$ \\
\hline \multirow{3}{*}{ DF } & 100 & $97 \pm 6$ \\
\hline & 250 & $99 \pm 5$ \\
\hline & 1000 & $90 \pm 4$ \\
\hline \multirow{3}{*}{ BF } & 100 & $98 \pm 6$ \\
\hline & 250 & $96 \pm 5$ \\
\hline & 1000 & $95 \pm 5$ \\
\hline
\end{tabular}

Como se puede ver, el método desarrollado proporciona elevadas recuperaciones para todos los compuestos.

En la Figura 22 se muestran los cromatogramas superpuestos, obtenidos con detección DAD y FLD, correspondientes a la inyección de un patrón y una muestra de agua tratada, según el procedimiento que se propone, de la misma concentración.

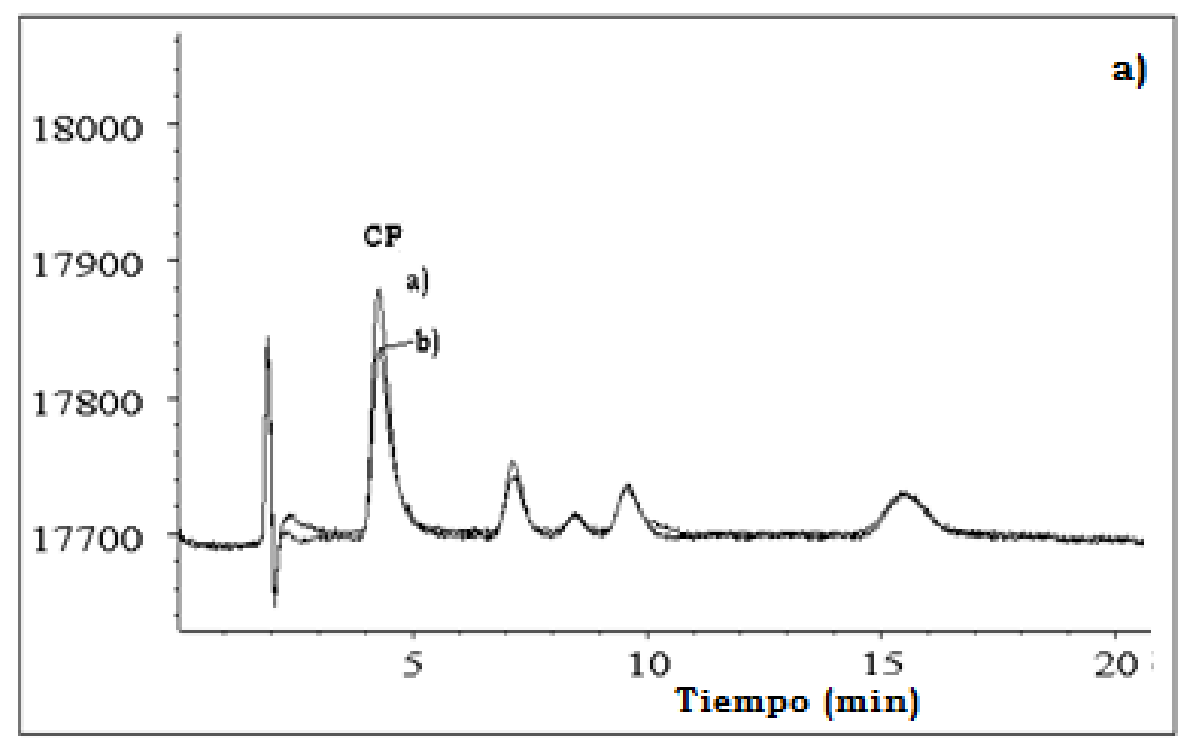




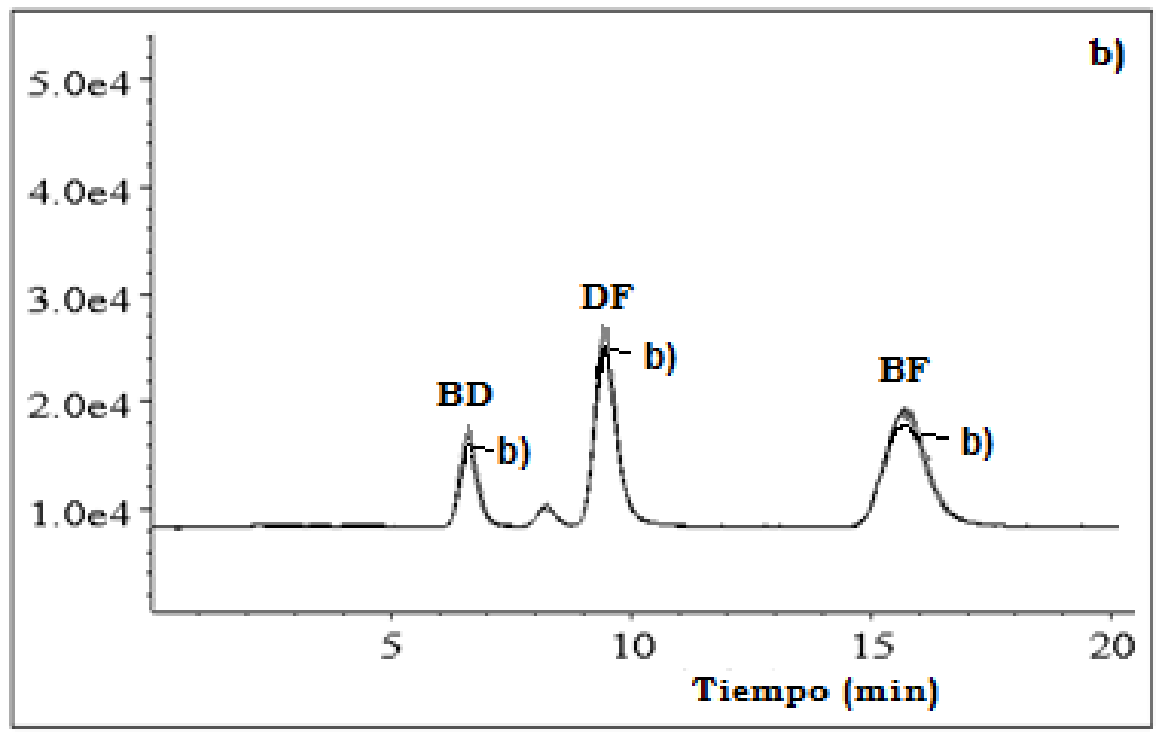

Figura 22: a) Cromatograma superpuestos correspondientes a) mezcla patrón sin tratar en concentración de $500 \mathrm{mg} / \mathrm{L}$. DAD. b) $100 \mathrm{~mL}$ muestra de agua dopada con los analitos en concentración de $500 \mathrm{mg} / \mathrm{L}$, FLD, tratada según el método desarrollado.

En el caso de utilizar la detección por masas, para mejorar la reproducibilidad en la detección se decidió utilizar un patrón interno, al igual que para la detección de estos compuestos en muestras de suelo. El patrón interno que se utilizó volvió a ser flocumafen, ya que eluía a un tiempo intermedio y no se solapaba con ningún analito de interés. La detección de los analitos se realizó en modo SIM.

Utilizando las mismas condiciones seleccionadas para el análisis en suelos, se creó una tabla de tiempos para poner las condiciones del MS seleccionadas para la detección de cada compuesto.

En la Figura 23 se muestran los cromatogramas de un patrón y una muestra de agua tratada de la misma concentración, $500 \mu \mathrm{g} / \mathrm{L}$. 

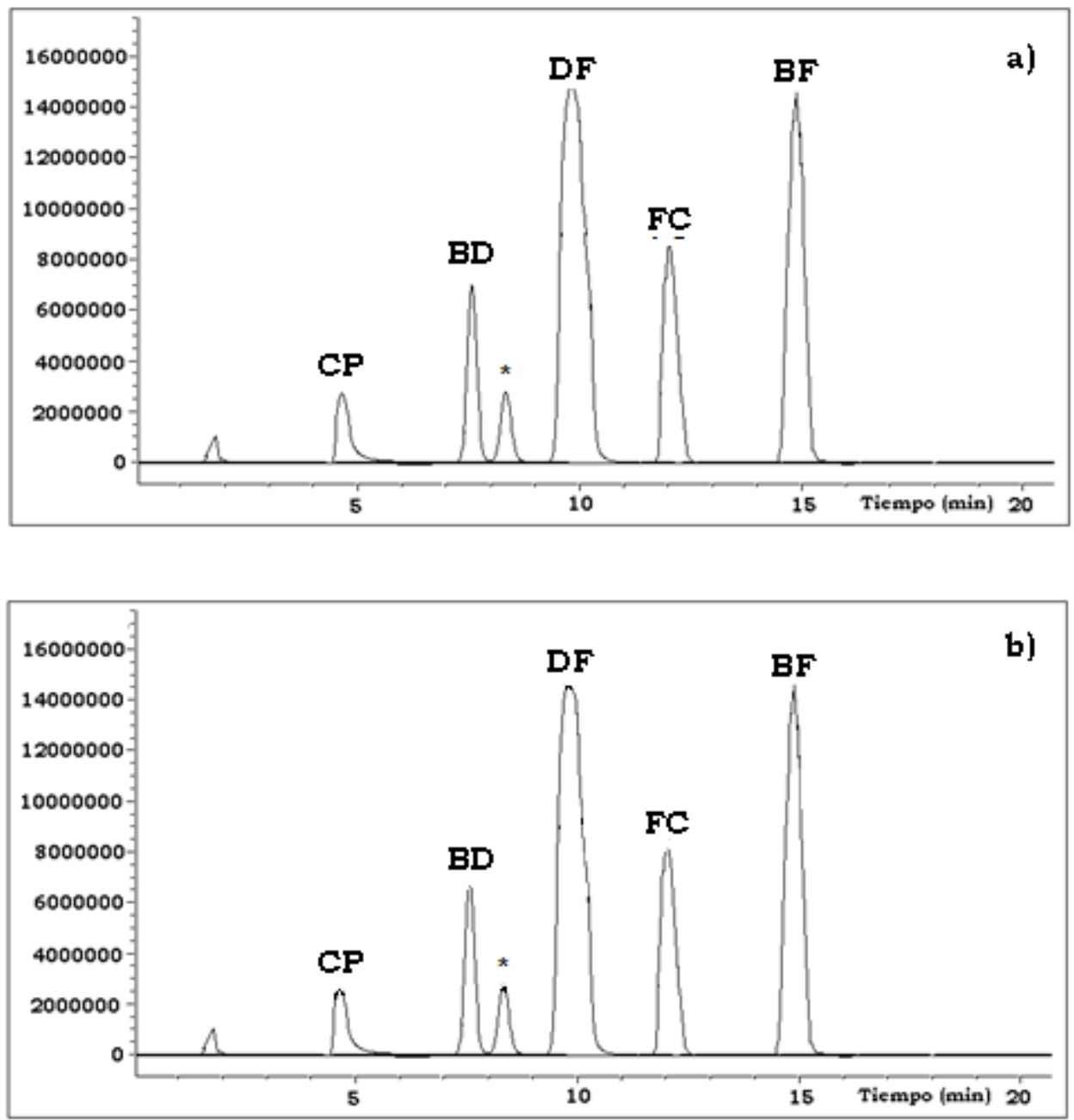

Figura 23: Cromatogramas (a). mezcla patrón $500 \mu \mathrm{g} / \mathrm{L}$ y (b). $100 \mathrm{~mL}$ agua dopada con la misma concentración de los rodenticidas y tratada con detección ESI-MS modo SIM.

Con el fin de disminuir los límites de cuantificación y de detección, se pensó en aumentar el volumen de agua a tratar a $250 \mathrm{~mL}$. Al aumentar el volumen de muestra se tuvieron que seleccionar de nuevo las variables que influían en el proceso de separación-concentración.

En primer lugar, para el establecimiento del volumen de extractante se probaron volúmenes comprendidos entre 25 y 50 , a intervalos de $5 \mathrm{~mL}$, manteniendo la agitación mecánica constante durante 10 minutos. 
Tabla 23: porcentajes de recuperación según el volumen de extractante para un volumen de $250 \mathrm{~mL}$

\begin{tabular}{lcccccc}
\hline \multirow{2}{*}{ Compuesto } & \multicolumn{6}{c}{ Volumen de acetato de etilo (mL) } \\
\cline { 2 - 7 } CP & $\mathbf{2 5}$ & $\mathbf{3 0}$ & $\mathbf{3 5}$ & $\mathbf{4 0}$ & $\mathbf{4 5}$ & $\mathbf{5 0}$ \\
BD & 43 & 52 & 60 & 85 & 81 & 80 \\
DF & 20 & 35 & 65 & 82 & 83 & 80 \\
BF & 39 & 59 & 75 & 90 & 89 & 85 \\
\hline
\end{tabular}

De los resultados que se obtuvieron y que se muestran en la anterior Tabla 23 se seleccionó un volumen de extractante de $40 \mathrm{~mL}$, ya que la utilización de volúmenes superiores mantenía prácticamente iguales las recuperaciones para todos los compuestos.

En cuanto al tiempo de agitación, se realizaron una serie de experiencias en las que se varió entre 10 y 30 minutos. Se seleccionó un tiempo de agitación de 25 minutos ya que para tiempos inferiores se obtenían recuperaciones menores y la utilización de mayores tiempos no las mejoraba.

También, en este caso se comprobó que $1 \mathrm{~mL}$ de metanol era suficiente para la disolución completa del residuo seco obtenido en la concentración a sequedad del extracto.

Con lo que el procedimiento para la extracción de los cuatro rodenticidas del agua dopada quedó establecido como se indica a continuación:

Se toman $250 \mathrm{~mL}$ de agua de red urbana a la que se adiciona $1 \mathrm{~mL}$ de una mezcla patrón de concentración conocida de los cuatro analitos. A continuación, se añaden $2.5 \mathrm{~mL}$ de AEDT $0.1 \mathrm{M}$ y la cantidad necesaria de la solución reguladora $\mathrm{NH}_{4} \mathrm{Cl}(2 \mathrm{M}) / \mathrm{NH}_{4} \mathrm{OH}$ para la obtención de un $\mathrm{pH}$ cercano a 10. La muestra se trasvasa a embudo de decantación y se añade $40 \mathrm{~mL}$ de acetato de etilo. Se somete posteriormente a 25 minutos 
de agitación mecánica y una vez separadas las fases, la fase orgánica se evapora hasta sequedad en rotavapor a $40^{\circ} \mathrm{C}$ y el residuo seco se reconstituye en $1 \mathrm{~mL}$ de metanol. Alícuotas de $20 \mu \mathrm{L}$ fueron inyectadas en el equipo cromatográfico en las mismas condiciones ya citadas.

En la Figura 24 se muestran los cromatogramas superpuestos de un patrón y una muestra de agua tratada, dopada con la misma concentración que la mezcla patrón, para los 3 sistemas de detección empleados.
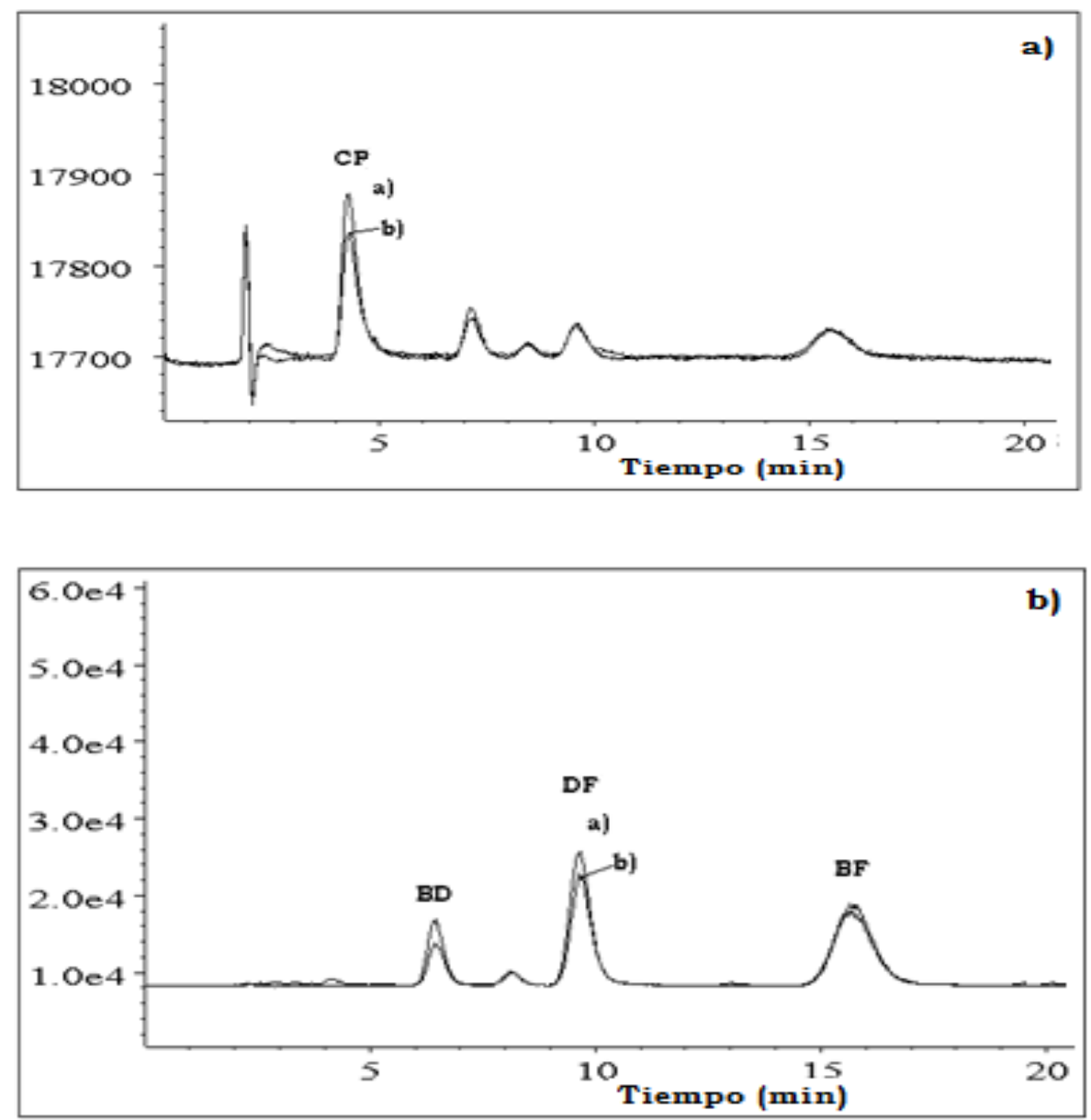


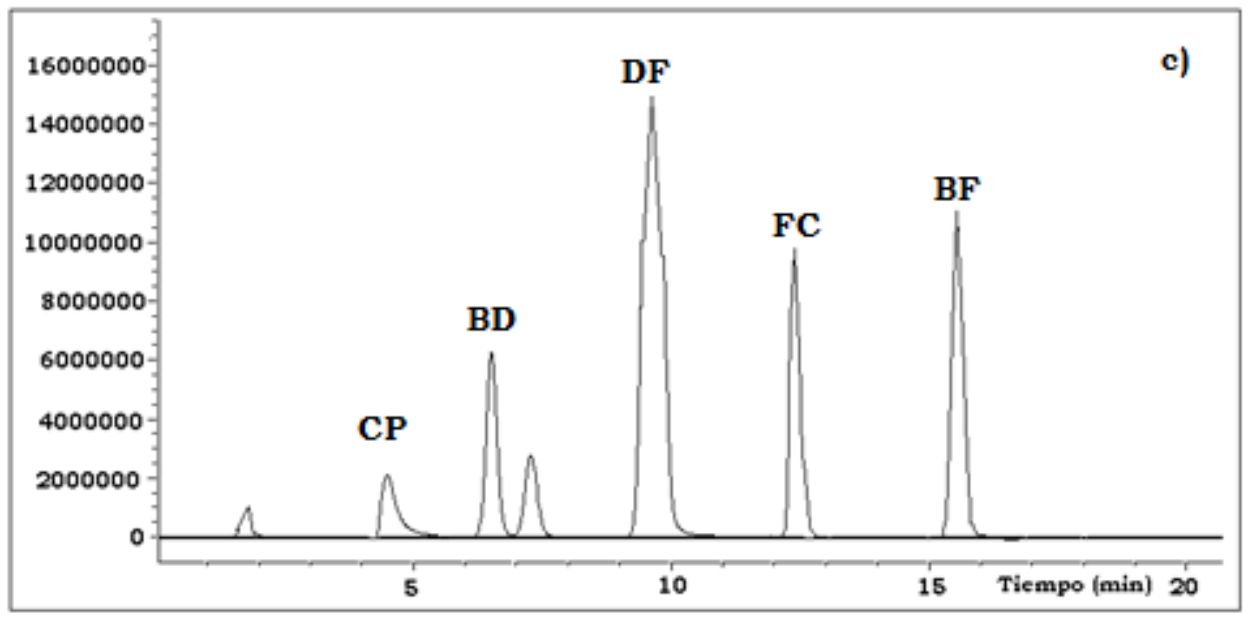

Figura 24: Cromatogramas superpuestos a) correspondiente a una mezcla patrón de los cuatro analitos en concentración $500 \mu \mathrm{g} / \mathrm{L}$. DAD. b) correspondiente a una muestra de agua dopada con la misma concentración de los compuestos y tratada según el método que se propone. FLD. c) cromatograma de la muestra adicionada con detección ESI-MS modo SIM.

Los porcentajes de recuperación obtenidos al tratar $250 \mathrm{~mL}$ de agua según el método desarrollado se determinaron en 6 réplicas a tres niveles de concentración, se muestran en la Tabla 24:

Tabla 24: Porcentajes de recuperación a tres niveles de concentración $(n=6)$ y \% RSD

\begin{tabular}{clc}
\hline Compuesto & \multicolumn{1}{c}{$\begin{array}{c}\text { Concentración } \\
(\boldsymbol{\mu g} / \mathbf{L})\end{array}$} & \%Recuperación \pm \% RSD \\
\hline \multirow{2}{*}{ CP } & 100 & $85 \pm 6$ \\
& 250 & $82 \pm 5$ \\
\multirow{2}{*}{ BD } & 1000 & $80 \pm 6$ \\
& 100 & $82 \pm 6$ \\
& 250 & $83 \pm 4$ \\
\multirow{2}{*}{ DF } & 1000 & $84 \pm 4$ \\
\hline \multirow{2}{*}{ BF } & 100 & $87 \pm 6$ \\
& 250 & $89 \pm 5$ \\
& 1000 & $88 \pm 4$ \\
\hline & 100 & $87 \pm 6$ \\
& 250 & $93 \pm 5$ \\
\end{tabular}

Aunque las recuperaciones obtenidas para volúmenes de muestra de 250 $\mathrm{mL}$ son algo inferior que los que se obtuvieron para $100 \mathrm{~mL}$ de muestra, 
siguen siendo adecuados para poder realizar la determinación permitiendo alcanzar LOD y LOQ algo inferiores. 


\section{VI.2.- Validación del método}

La validación del método se realizó, evaluando los mismos parámetros que se hizo en suelo, para los métodos desarrollados utilizando los dos volúmenes de muestra (100 y $250 \mathrm{~mL}$ de agua).

\section{Selectividad}

Aplicando el método analítico desarrollado se comprobó que en la zona de elución de los analitos de interés no eluía ningún compuesto que pudiera interferir en su cuantificación. Para ello, se inyectaron en el equipo cromatográfico muestras blanco de agua y muestras de agua a las que se le había adicionado los cuatro rodenticidas en concentración conocida y que fueran tratadas según el método establecido.

En la Figura 25 se muestran los cromatogramas que se obtuvieron, para un blanco de $250 \mathrm{~mL}$ de agua y una muestra de $500 \mu \mathrm{g} / \mathrm{L}$, con los tres sistemas de detección empleados.

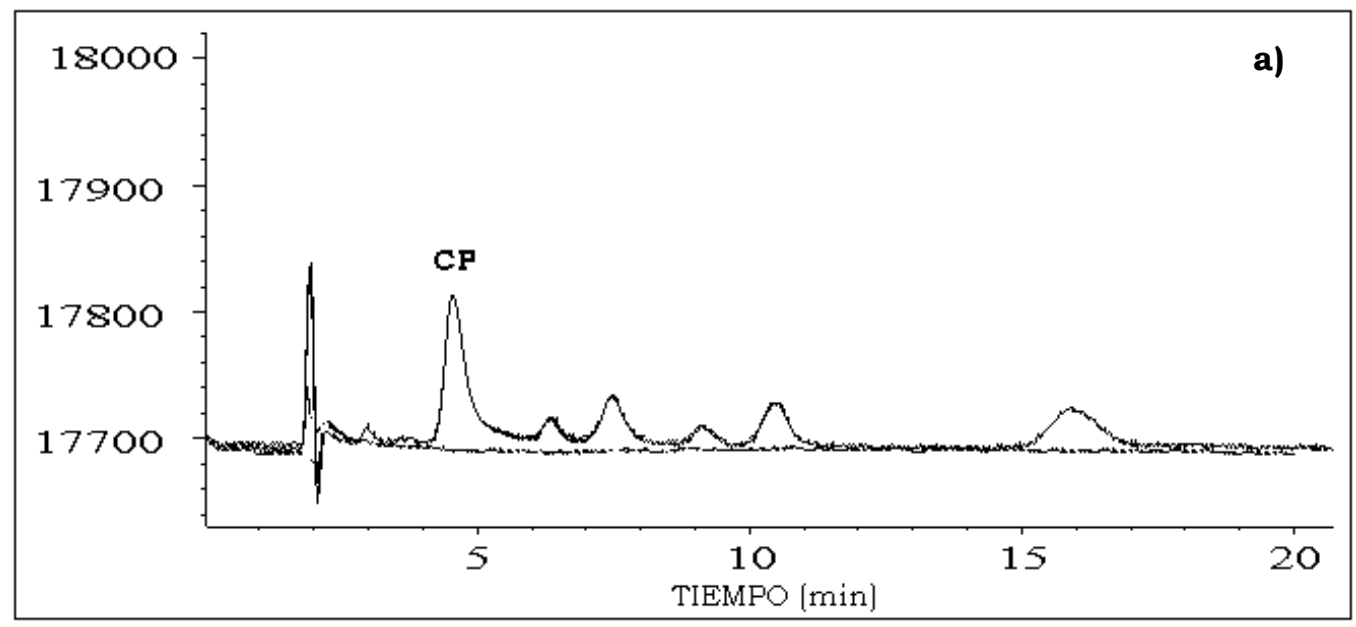



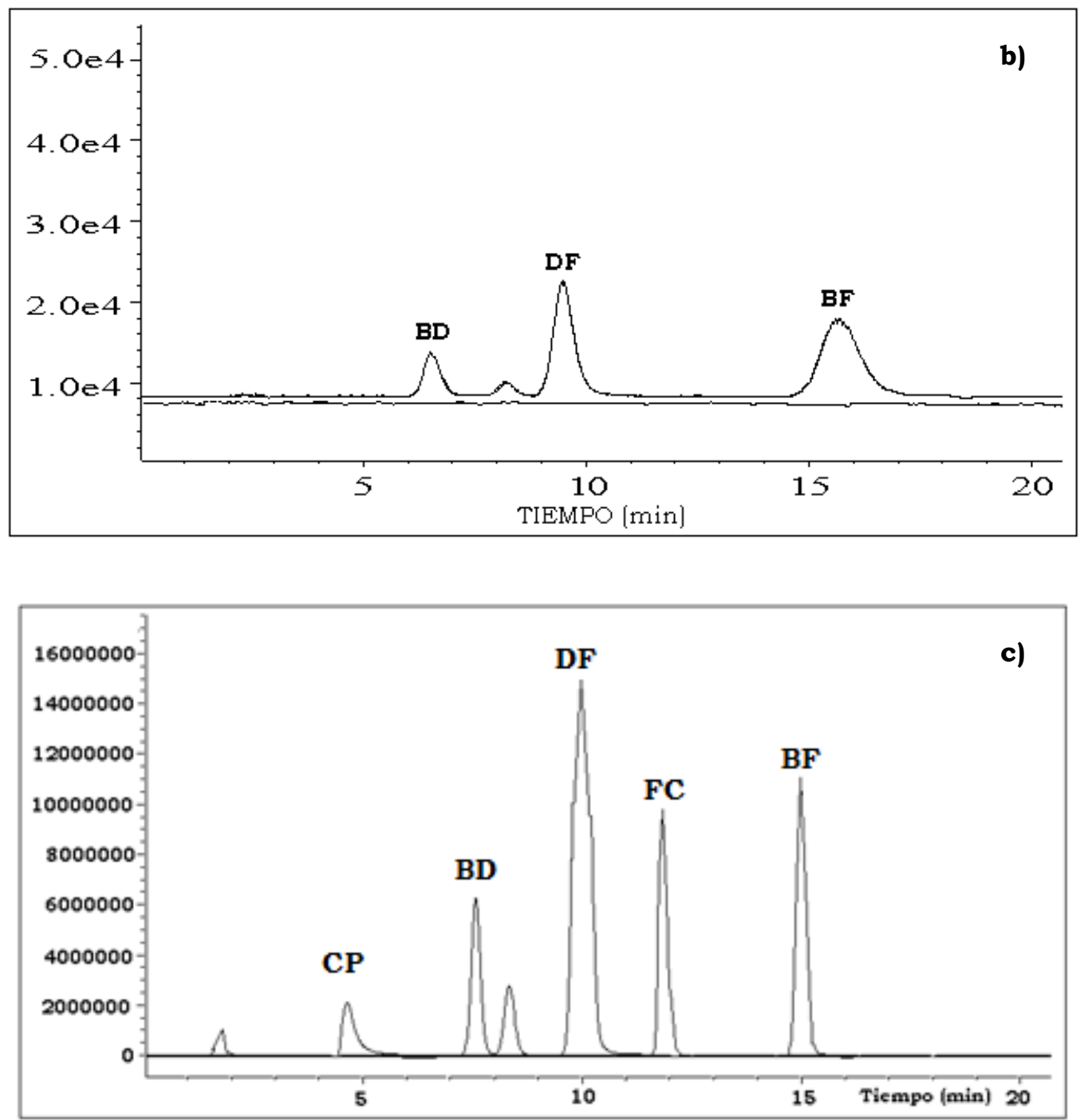

Figura 25: Cromatograma de un blanco de $250 \mathrm{~mL}$ agua. a) DAD, b) FLD y c) MSD modo SIM.

Como se puede apreciar en los cromatogramas de los blancos, para los dos volúmenes de muestra utilizados, no aparece ningún pico al tiempo de retención de los compuestos de interés, por lo que queda demostrada la selectividad del método. 


\section{Limites de detección y cuantificación}

Se fijaron los limites de detección (LOD) y de cuantificación (LOQ) de forma experimental, de manera análoga a como se establecieron en el estudio anterior de las muestras de suelo.

En las siguientes Tablas 25 y 26, se muestran los resultados obtenidos tanto para la detección DAD/FLD como MSD expresados en $\mu \mathrm{g} / \mathrm{L}$, para los dos volúmenes de muestra.

Tabla 25: LOD y LOQ $(\mu \mathrm{g} / \mathrm{L})$ para DAD/FLD y $100 \mathrm{~mL}$ de agua

\begin{tabular}{ccccc}
\hline & \multicolumn{2}{c}{ FLD-DAD } & \multicolumn{2}{c}{ MSD-ESI } \\
\hline Compuesto & LOD & LOQ & LOD & LOQ \\
\hline CP & 40 & 100 & 0,5 & 1.3 \\
BD & 30 & 50 & 0.2 & 0.8 \\
DF & 30 & 50 & 0.1 & 0.3 \\
BF & 30 & 60 & 0.1 & 0.4 \\
\hline
\end{tabular}

Tabla 26: LOD, LOQ para $250 \mathrm{~mL}$ de agua. FLD-DAD-MSD.

\begin{tabular}{ccccc}
\hline & \multicolumn{2}{c}{ FLD-DAD } & \multicolumn{2}{c}{ MS-ESI } \\
\hline Compuesto & LOD & LOQ & LOD & LOQ \\
\hline CP & 29 & 89 & 0.2 & 0.8 \\
BD & 19 & 33 & 0.2 & 0.5 \\
DF & 20 & 30 & 0.07 & 0.2 \\
BF & 22 & 35 & 0.09 & 0.2 \\
\hline
\end{tabular}

En la Tablas se puede observar que los valores obtenidos de LOD y LOQ en DAD/FLD son superiores a los obtenidos por MS-ESI-, siendo el uso de aquellos detectores una alternativa más económica cuando no se requiere mucha sensibilidad. 


\section{Precisión}

La precisión se determinó en muestras de agua a las que se le había añadido los compuestos de interés, en tres niveles de concentración, y que posteriormente habian sido sometidas al tratamiento de muestra desarrollado. Posteriormente, se inyectaron en el equipo cromatográfico por triplicado durante el mismo día. Y para evaluar la precisión intermedia, esas mismas muestras se inyectaron durante tres dias consecutivos. En las Tablas 27, 28, 29 y 30 se muestran los valores obtenidos para los sistemas de detección empleados:

Tabla 27: \%RSD obtenidos para la evaluación de la precisión para un volumen de agua de $100 \mathrm{~mL}$ utilizando detección DAD- FLD.

\begin{tabular}{|c|c|c|c|}
\hline \multirow[t]{2}{*}{ Compuesto } & \multirow{2}{*}{$\begin{array}{c}\text { Concentración } \\
(\mu g / L)\end{array}$} & $\begin{array}{l}\text { Precisión } \\
\text { en el dia }\end{array}$ & \multirow{2}{*}{$\begin{array}{c}\begin{array}{c}\text { Precisión } \\
\text { intermedia }\end{array} \\
\% \text { RSD } \\
\end{array}$} \\
\hline & & \%RSD & \\
\hline \multirow[t]{3}{*}{$\mathbf{C P}$} & 100 & 4.4 & 4.9 \\
\hline & 1000 & 2.1 & 3.2 \\
\hline & 5000 & 3.7 & 4.1 \\
\hline \multirow[t]{3}{*}{ BD } & 100 & 4.8 & 5.2 \\
\hline & 1000 & 2.9 & 3.5 \\
\hline & 5000 & 3.6 & 4.2 \\
\hline \multirow[t]{3}{*}{ DF } & 100 & 3.7 & 3.9 \\
\hline & 1000 & 3.2 & 4.1 \\
\hline & 5000 & 2.8 & 3.4 \\
\hline \multirow[t]{3}{*}{ BF } & 100 & 4.7 & 5.3 \\
\hline & 1000 & 5.1 & 5.6 \\
\hline & 5000 & 3.3 & 3.9 \\
\hline
\end{tabular}


Tabla 28: \%RSD obtenidos para la evaluación de la precisión para un volumen de agua de $100 \mathrm{~mL}$ utilizando detección ESI-MS.

\begin{tabular}{|c|c|c|c|}
\hline \multirow[t]{2}{*}{ Compuesto } & \multirow{2}{*}{$\begin{array}{c}\text { Concentración } \\
(\mu \mathrm{g} / \mathrm{L})\end{array}$} & \multirow{2}{*}{$\begin{array}{c}\text { Precisión } \\
\text { en el dia } \\
\text { \%RSD }\end{array}$} & \multirow{2}{*}{$\begin{array}{c}\text { Precisión } \\
\text { intermedia } \\
\% \text { RSD }\end{array}$} \\
\hline & & & \\
\hline \multirow[t]{3}{*}{$\mathbf{C P}$} & 50 & 6.1 & 6.5 \\
\hline & 500 & 5.2 & 5.7 \\
\hline & 1000 & 4.9 & 4.2 \\
\hline \multirow[t]{3}{*}{ BD } & 50 & 5.6 & 5.9 \\
\hline & 500 & 4.6 & 5.0 \\
\hline & 1000 & 3.7 & 4.6 \\
\hline \multirow[t]{3}{*}{$\mathbf{D F}$} & 50 & 4.8 & 5.6 \\
\hline & 500 & 4.1 & 4.8 \\
\hline & 1000 & 3.7 & 4.5 \\
\hline \multirow[t]{3}{*}{ BF } & 50 & 5.1 & 5.6 \\
\hline & 500 & 4.2 & 5.2 \\
\hline & 1000 & 3.9 & 4.4 \\
\hline
\end{tabular}

Tabla 29: \%RSD obtenidos para la evaluación de la precisión para un volumen de agua de $250 \mathrm{~mL}$ utilizando detección DAD- FLD.

\begin{tabular}{lcccc}
\hline \multirow{2}{*}{ Compuesto } & $\begin{array}{c}\text { Concentración } \\
(\boldsymbol{\mu g} / \mathbf{L})\end{array}$ & $\begin{array}{c}\text { Precisión } \\
\text { en el dia }\end{array}$ & & $\begin{array}{c}\text { Precisión } \\
\text { intermedia }\end{array}$ \\
\cline { 3 - 4 } & 100 & \%RSD & \%RSD \\
\hline CP & 1000 & 3.4 & 4.8 \\
BD & 5000 & 5.5 & 4.3 \\
& 100 & 5.7 & 6.0 \\
& 1000 & 5.2 & 4.9 \\
DF & 5000 & 3.9 & 4.7 \\
& 100 & 3.5 & 4.2 \\
& 1000 & 5.0 & 4.0 \\
BF & 5000 & 4.3 & 4.6 \\
& 100 & 3.9 & 4.2 \\
& 1000 & 3.6 & 4.7 \\
\hline
\end{tabular}


VI.- Determinación de $C F, B D, D F$ y $B F$ en agua

Tabla 30: \%RSD obtenidos para la evaluación de la precisión para un volumen de agua de $250 \mathrm{~mL}$ utilizando detección ESI-MS.

\begin{tabular}{lcccc}
\hline Compuesto & $\begin{array}{c}\text { Concentración } \\
(\boldsymbol{\mu g} / \mathbf{L})\end{array}$ & $\begin{array}{c}\text { Precisión } \\
\text { en el dia }\end{array}$ & & $\begin{array}{c}\text { Precisión } \\
\text { intermedia }\end{array}$ \\
\cline { 3 - 3 } & 50 & \%CV & \%CV \\
\hline BP & 500 & 5.1 & 4.8 \\
& 1000 & 6.7 & 3.4 \\
& 50 & 5.7 & 5.3 \\
DF & 500 & 3.5 & 4.3 \\
& 1000 & 4.7 & 3.3 \\
& 50 & 4.2 & 5.0 \\
BF & 500 & 5.9 & 3.9 \\
& 1000 & 6.7 & 6.2 \\
& 50 & 7.0 & 5.5 \\
& 500 & 5.1 & 6.5 \\
\hline
\end{tabular}

Como se puede ver en las Tablas 27-30, el método cromatográfico cumple los requisitos de precisión porque en todos ellos los \% CV son inferiores al $7 \%$. 


\section{Linealidad}

Con el fin de llevar a cabo la determinación cuantitativa de los analitos para los tres detectores, se realizó un calibrado utilizando el método de patrón externo, para DAD-FLD y patrón interno para MSD, cuantificándose en base al área del pico. Para realizar el estudio de linealidad, se preparó una mezcla de los diferentes compuestos en metanol, a partir de ésta se realizaron las correspondientes diluciones en un intervalo de concentración que variaba dependiendo del volumen de muestra que se tratara y del sistema de detección empleado, las cuales se utilizaron para añadirlas a las aguas, y después sometidas al tratamiento de muestra desarrollado. En las Tablas 31 y 32 se recogen los parámetros estadísticos de las líneas obtenidas por LC-DAD/FLD y LC-MSD para un volumen de muestra de $100 \mathrm{~mL}$. En las Tablas 33 y 34 se muestran los resultados correspondientes a un volumen de muestra de $250 \mathrm{~mL}$.

Se aplicó la prueba $t$ para verificar la tendencia de la regresión y en todos los casos se cumple que la $t_{\exp }>t_{\text {tab}}$, por lo tanto se acepta que el método es lineal y la ausencia de bias. Los valores del coeficiente de determinación $\left(\mathrm{R}^{2}\right)$ eran para todos los casos mayores de 0.99 , lo que indica la bondad del ajuste del calibrado.

Por otra parte, para verificar el efecto matriz se realizó la comparación de las pendientes del calibrado de patrones en metanol con la de las aguas adicionadas y tratadas, cuyos resultados indicaron que los valores de las pendientes en agua se encuentran dentro del intervalo de confianza de la pendiente en fase metanol. 


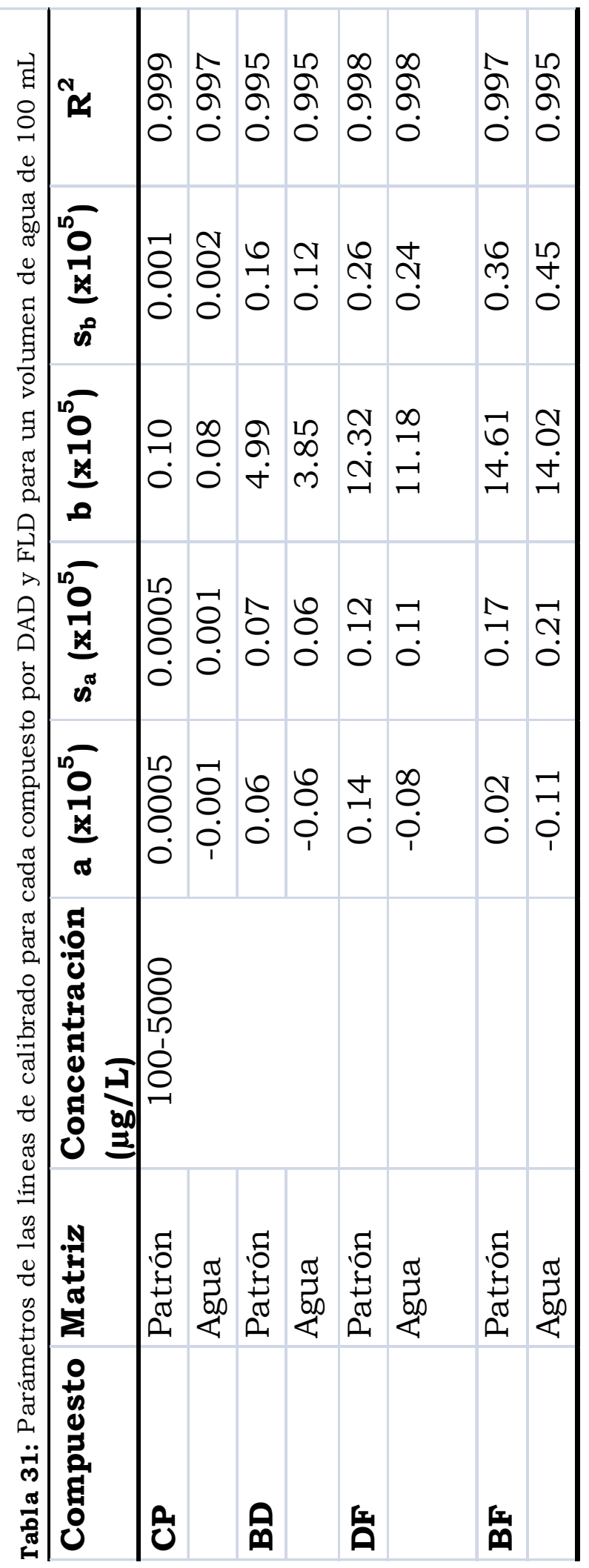




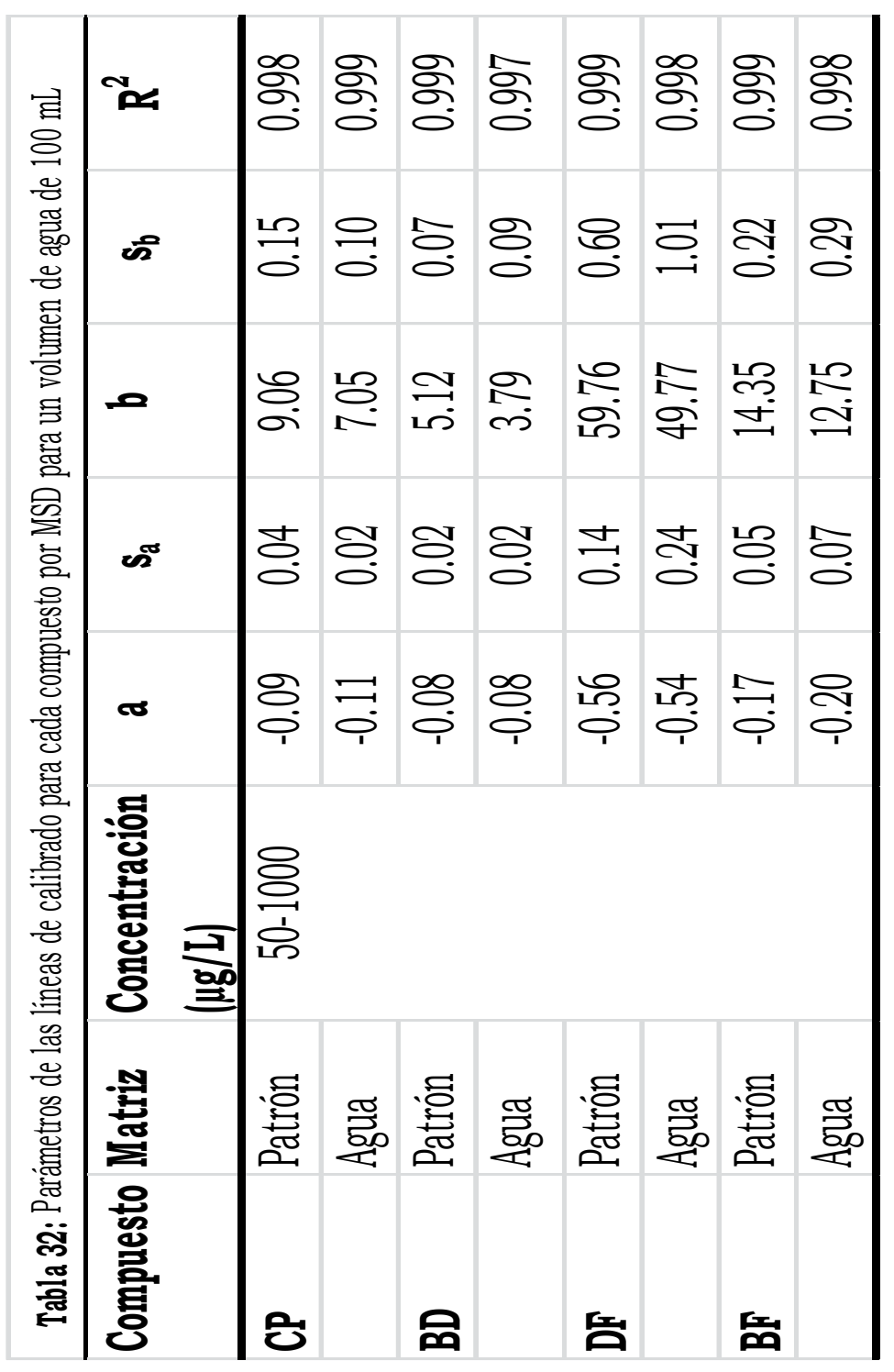




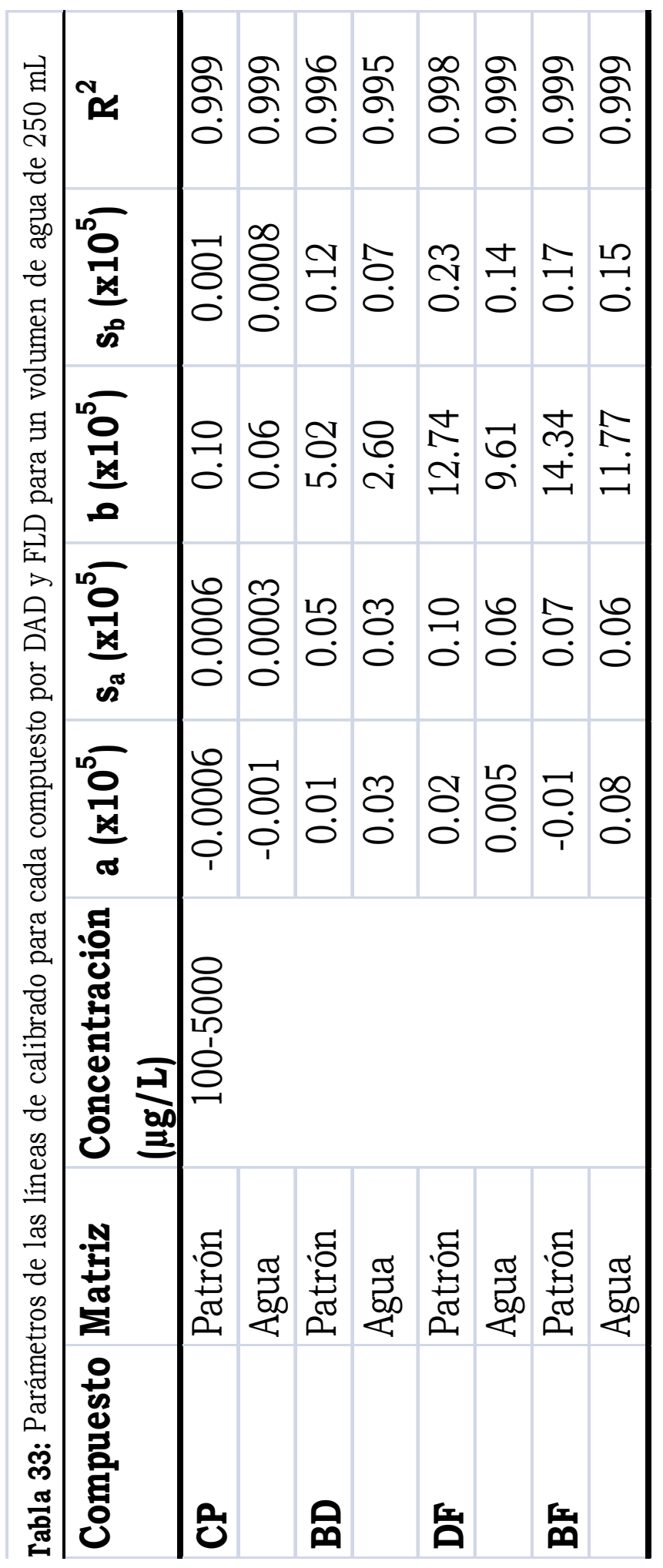




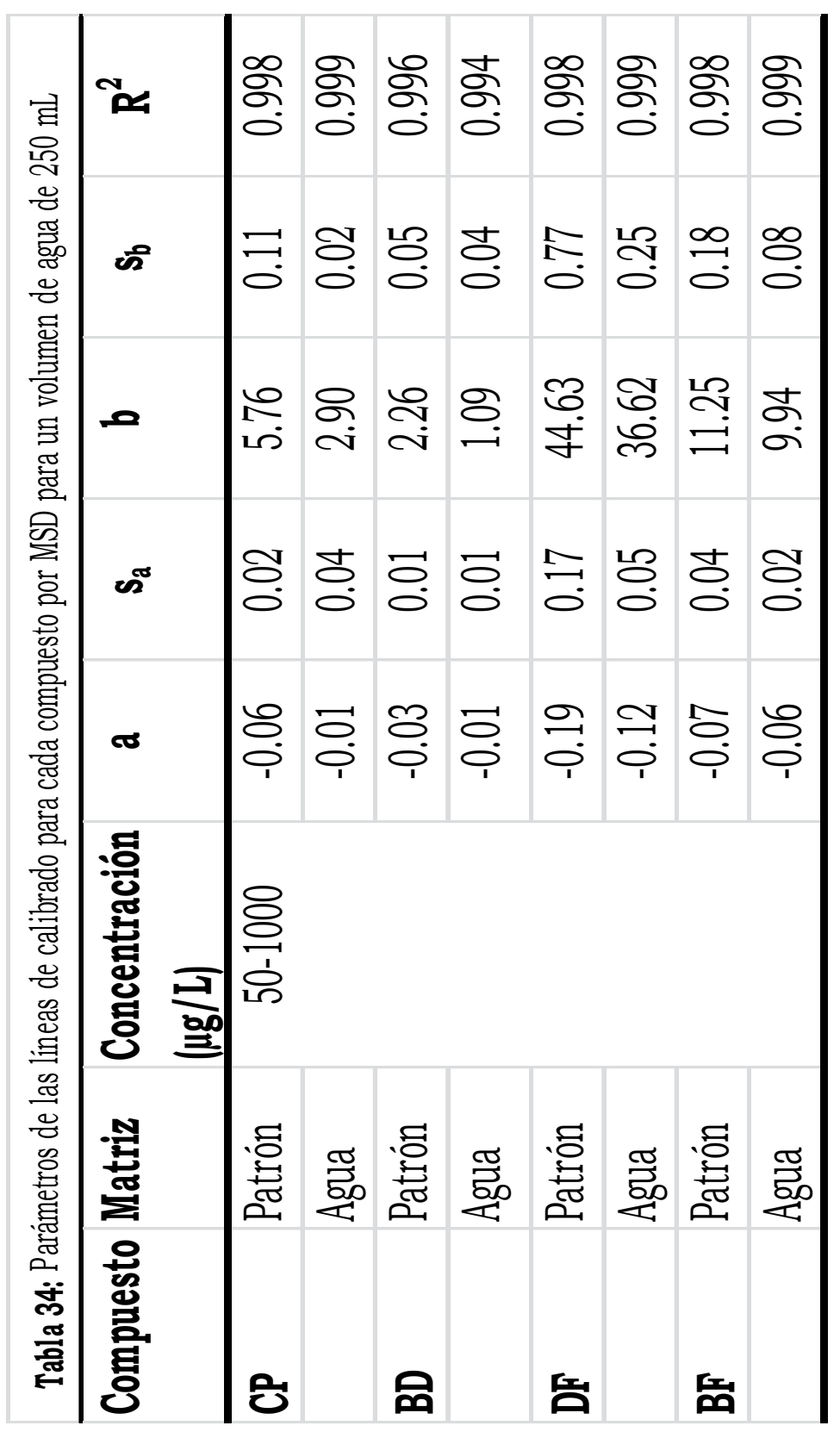




\section{Exactitud}

La determinación de la exactitud se realizó mediante el cálculo del porcentaje de error relativo ( $\% \mathrm{RE})$, para lo cual se analizaron réplicas de extractos de agua adicionada con patrones a tres niveles de concentración durante tres días consecutivos.

Las concentraciones experimentales se determinaron a partir de la correspondiente línea de calibrado. En las Tablas 35 y 36 se presentan los valores calculados para DAD/FLD/MSD para volúmenes de agua de $100 \mathrm{y}$ $250 \mathrm{~mL}$ respectivamente

Tabla 35: Porcentaje de error relativo para el estudio de exactitud. FLD-DAD-MSD para VM de $100 \mathrm{~mL}$.

\begin{tabular}{cccc}
\hline Compuesto & $\begin{array}{c}\text { Concentración } \\
\text { añadida }(\boldsymbol{\mu g} / \mathbf{L})\end{array}$ & $\begin{array}{c}\text { \% RE } \\
\text { DAD/FLD }\end{array}$ & $\begin{array}{c}\text { \% RE } \\
\text { MSD }\end{array}$ \\
\hline CP & 0.03 & 6.5 & 4.9 \\
& 0.13 & 5.9 & 6.5 \\
BD & 1.00 & 4.9 & 7.0 \\
& 0.03 & 5.5 & 5.5 \\
& 0.13 & 6.7 & 5.9 \\
DF & 1.00 & 6.9 & 6.3 \\
& 0.03 & 5.6 & 6.8 \\
& 0.13 & 6.0 & 6.5 \\
BF & 1.00 & 6.3 & 6.9 \\
& 0.03 & 6.8 & 5.8 \\
& 0.13 & 6.3 & 6.4 \\
& 1.00 & 6.4 & 6.8 \\
\hline
\end{tabular}


Tabla 36: Porcentaje de error relativo para el estudio de exactitud. FLD-DAD-MSD para $V_{M}$ de $250 \mathrm{~mL}$.

\begin{tabular}{cccc}
\hline Compuesto & $\begin{array}{c}\text { Concentración } \\
\text { añadida }(\boldsymbol{\mu g} / \mathbf{L})\end{array}$ & $\begin{array}{c}\text { \% RE } \\
\text { DAD/FLD }\end{array}$ & $\begin{array}{c}\text { \% RE } \\
\text { MSD }\end{array}$ \\
\hline CP & 15.6 & 6.8 & 5.9 \\
& 62.5 & 5.6 & 4.4 \\
BD & 500.0 & 6.3 & 3.9 \\
& 15.6 & 6.6 & 3.8 \\
& 62.5 & 4.9 & 4.5 \\
DF & 500.0 & 3.5 & 3.1 \\
& 15.6 & 6.9 & 4.3 \\
& 62.5 & 4.0 & 4.5 \\
BF & 500.0 & 4.5 & 4.9 \\
& 15.6 & 5.1 & 5.1 \\
& 62.5 & 3.8 & 4.9 \\
& 500.0 & 3.2 & 4.2 \\
\hline
\end{tabular}

Se observa en ambas Tablas que el \%RE para todos los analitos es inferior al $7 \%$, en todos los casos para los distintos detectores utilizados, valor considerado adecuado para la exactitud en el caso del análisis con este tipo de detectores. 


\section{VI.3.- Aplicación del método propuesto a muestras de agua}

Como ya se ha comentado, la Junta de Castilla y León autorizó el uso de bromadiolona para combatir la plaga de topillos y el ITACyL nos proporcionó 7 muestras de agua procedentes de pequeños cursos de agua próximos a campos de cultivo que habian sido tratados con dicho compuesto para así poder determinar los posibles residuos de bromadiolona. La recogida se realizó en las provincias de Valladolid y Palencia.

Para su análisis se seleccionó como volumen de muestra a tratar $250 \mathrm{~mL}$. Las muestras primero fueron filtradas para eliminar todas las partículas en suspensión. Posteriormente, se las sometió al tratamiento de muestra según el método que se propone para este volumen de muestra.

En la Figura 26 se muestran los cromatogramas superpuestos correspondientes a un patrón de bromadiolona y al de una muestra de las aguas estudiadas tratadas, ambos obtenidos con detección FLD:

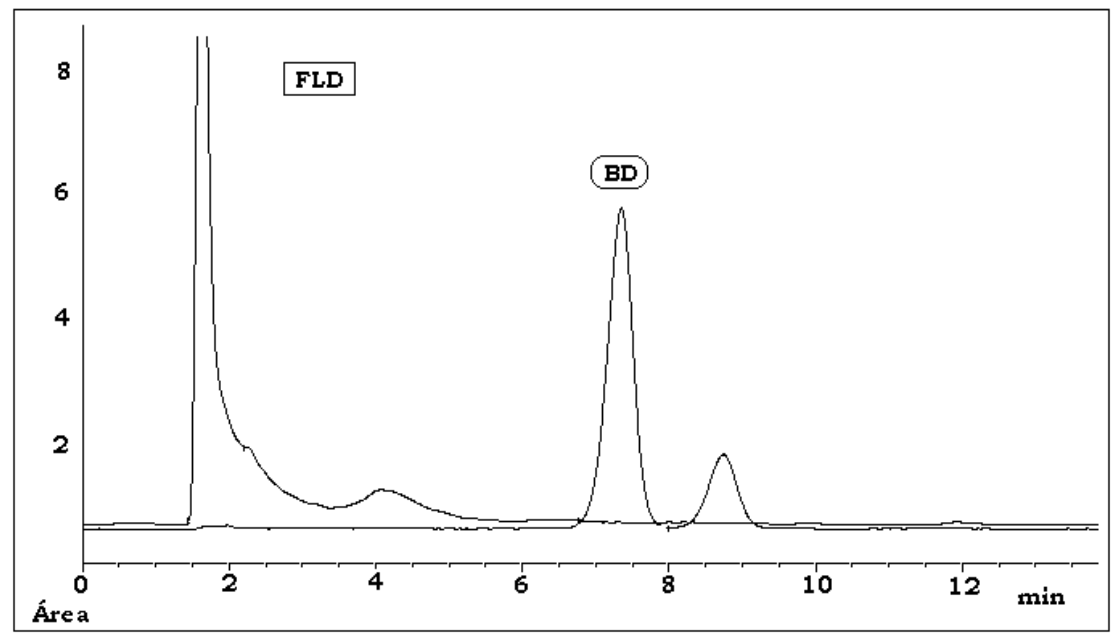

Figura 26: Cromatograma de una patrón de Bromadiolona de $0.75 \mathrm{mg} / \mathrm{L}$ y de una muestra de agua procedente de un arroyo cercano a una zona de cultivo tratada.

Como se puede observar en la Figura, no aparece ninguna señal diferenciable del ruido al tiempo de retención del compuesto de interés, 
por lo que se puede afirmar que esa muestra no contiene residuos de bromadiolona en cantidades superiores al límite de detección. Los mismos resultados se obtuvieron para las 6 muestras restantes de agua analizadas.

Estas muestras se analizaron también por espectrometría de masas por si existía algún compuesto producto de la degradación de la bromadiolona.

\section{VI.4.- Liberación al agua de Bromadiolona y Clorofacinona}

Como ya se ha comentado se autorizó el tratamiento primero con clorofacinona y después con bromadiolona, como última solución, para acabar con la plaga de topillos y dado que se carece de datos acerca de la liberación al agua, se planteó realizar su estudio.

Los rodenticidas se presentan en distintos formatos comerciales, en este caso se nos proporcionó, por el Instituto Tecnológico Agrario de Castilla y León (ITACyL), dos de los formatos en los que se aplicaron ambos compuestos: uno en forma de semillas, que son cereales impregnados; y el otro en pastillas, que son bloques parafinados extrusionados con un alto contenido en cereales y bajo contenido en parafina.

\section{VI.4.1.- Liberación de Bromadiolona}

Para la realización de este estudio se dispusieron en cada uno de 4 vasos de precipitados $2 \mathrm{~L}$ de agua para en dos de ellos añadir una cantidad determinada del formato en pastilla y en los otros dos del formulado en semilla. Inicialmente se realizaron una serie de ensayos en los que se variaron las cantidades tanto de semillas como de pastillas, se llegaron a ensayar cantidades de hasta $25 \mathrm{~g}$ de semillas y 4 pastillas (peso 
aproximado $4 \mathrm{~g}$ ), pero las semillas fermentaban y con las pastillas la parafina que se liberaba era elevada y en ambos casos se dificultaba enormemente la toma de muestra. Por lo que se optó por utilizar para el caso de semillas un peso de 6.0191 y 12.0316 g; y para el formato pastilla, 1 y 2 pastillas cuyos pesos fueron 1.1710 y $2.0146 \mathrm{~g}$, respectivamente. Los cuatro recipientes se mantuvieron con agitación constante a una velocidad de $500 \mathrm{rpm}$ y a una temperatura de $20{ }^{\circ} \mathrm{C}$. El volumen de muestra se estableció en $100 \mathrm{ml}$.

En un principio se aplicó el método desarrollado para la determinación de los cuatro rodenticidas en agua, pero al hacerlo aparecía un coloide que era imposible de separar y que impedía realizar la extracción con acetato de etilo. Tras varios ensayos, el problema se pudo solucionar mediante la adición a las muestras de un aglutinante como el sulfato de aluminio.

El procedimiento que se siguió para poder determinar la concentración de BD liberada se detalla a continuación: a los $100 \mathrm{~mL}$ de muestra se les añadió $0.1 \mathrm{~g}$ de sulfato de aluminio el cual se disolvió con ayuda de un baño de ultrasonidos, $1 \mathrm{~mL}$ de AEDT $0.1 \mathrm{M}$ y se ajustó el $\mathrm{pH}$ a un valor próximo a 10 mediante la adición del tampón de $\mathrm{NH}_{4} \mathrm{Cl} / \mathrm{NH}_{3}$. A continuación, se centrifugó a $5000 \mathrm{rpm}$ durante 5 minutos a $10^{\circ} \mathrm{C}$ y el sobrenadante se filtró, con papel de filtro, recogiendo el líquido filtrado en un embudo de decantación. Se añadieron $25 \mathrm{~mL}$ de acetato de etilo y se agitó la muestra durante 10 minutos. Se separaron las fases y la fase orgánica se concentró a sequedad en rotavapor a $40^{\circ} \mathrm{C}$ y el residuo seco se reconstituyó con $1 \mathrm{~mL}$ de metanol, se filtró con filtro de muestras de Nylon y $20 \mu \mathrm{L}$ fueron inyectados en el equipo cromatográfico en las condiciones ya establecidas, realizándose en este caso sólo detección fluorescente. E1 porcentaje de recuperación para la BD fue del $83 \%$.

Una vez establecido el tratamiento de muestra, se procedió a realizar el calibrado que permitiera cuantificar la cantidad de analito que se liberaba. 
Para realizarlo a $1 \mathrm{~L}$ de agua de red se le añadió $1 \mathrm{~g}$ de sulfato de aluminio, $10 \mathrm{~mL}$ de AEDT $0.1 \mathrm{M}$ y una cantidad de tampón $\mathrm{NH}_{4} \mathrm{Cl} / \mathrm{NH}_{3}$ para alcanzar el $\mathrm{pH}$ cercano a 10, tomándose alícuotas de $100 \mathrm{~mL}$. Por otra parte se preparó, por pesada, una solución patrón de BD de 1000 $\mathrm{mg} / \mathrm{L}$, a partir de esta se realizaron las correspondientes diluciones en metanol, en un intervalo de concentración de 0.02-3 mg/L, las que se utilizaron para añadir $1 \mathrm{~mL}$ a cada una de las alícuotas y posteriormente se procedió a realizar el tratamiento descrito anteriormente.

En la Tabla 37 se muestran los parámetros estadísticos de las líneas obtenidas por LC-FLD.

Tabla 37: Parámetros de las líneas de calibrado para BD por FLD

\begin{tabular}{llcllllll}
\hline Compuesto & Matriz & $\begin{array}{c}\text { Concentración } \\
(\mathbf{m g} / \mathbf{L})\end{array}$ & $\mathbf{a}$ & $\mathbf{s}_{\mathbf{a}}$ & $\mathbf{b}$ & $\mathbf{s}_{\mathbf{b}}$ & $\mathbf{R}^{\mathbf{2}}$ \\
& & & & & & & \\
\hline BD $^{\mathbf{a}}$ & Patrón & $0.02-3 \mathrm{mg} / \mathrm{L}$ & 0.06 & 4.58 & 158.47 & 2.95 & 0.999 \\
& Agua & & 6.33 & 2.21 & 132.80 & 1.43 & 0.999
\end{tabular}

Se aplicó la prueba $t$ para verificar la tendencia de la regresión cumpliéndose que la $t_{\text {exp }}>t_{\text {tab }}$, por lo tanto se acepta que el método es lineal y la ausencia de bias. te. El valor del coeficiente de determinación $\left(R^{2}\right)$ era mayor de 0.99, lo que indica la bondad del ajuste del calibrado.

Una vez establecido el método se añadieron a los vasos de precipitados, en los cuales se habian vertido $2 \mathrm{~L}$ de agua, las cantidades anteriormente citadas de semillas y pastillas. Los cuatro recipientes se mantuvieron con agitación constante a una velocidad de $500 \mathrm{rpm}$ y a una temperatura de $20^{\circ} \mathrm{C}$, realizándose la primera toma de muestra a los 4 dias del comienzo del estudio, y las siguientes muestras se tomaron a lo largo de mes y medio. Cada vez que se realizaba la toma de muestra se reponía el volumen tomado con agua, manteniendo siempre el volumen en $2 \mathrm{~L}$. 
En la Figura 27 se muestran los cromatogramas superpuestos obtenidos para una de las dos tomas de muestra de agua con semillas y agua con pastilla con el de un patrón de BD.
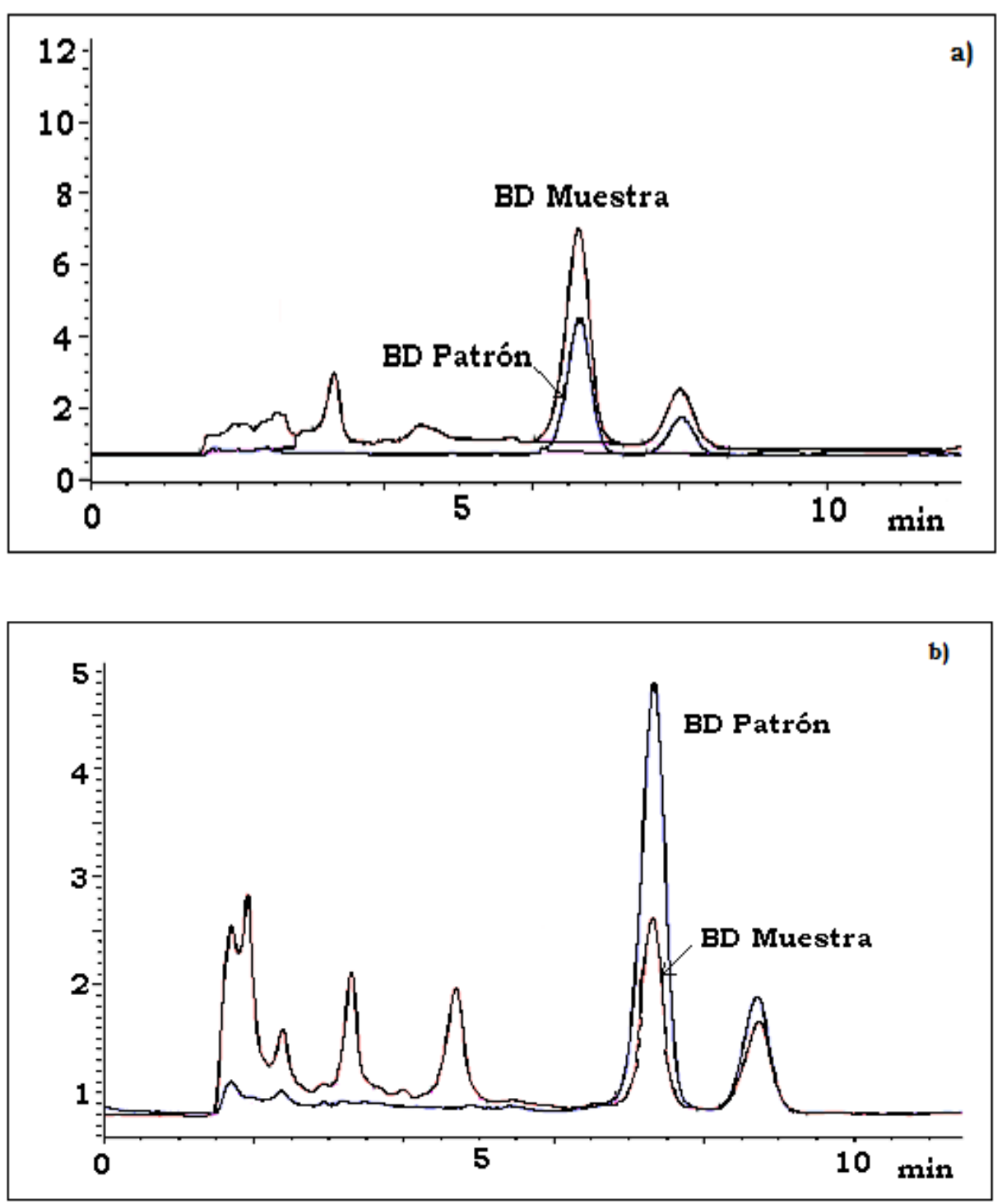

Figura 27: Cromatogramas superpuestos de un patrón de Bromadiolona en concentración 0.75mg/L con (a) muestra con $12 \mathrm{~g}$ de semillas y (b) muestra con 2 pastillas.

Los resultados de liberación de $\mathrm{BD}$ al agua que se obtuvieron aparecen resumidos en la siguiente Figura 28. 

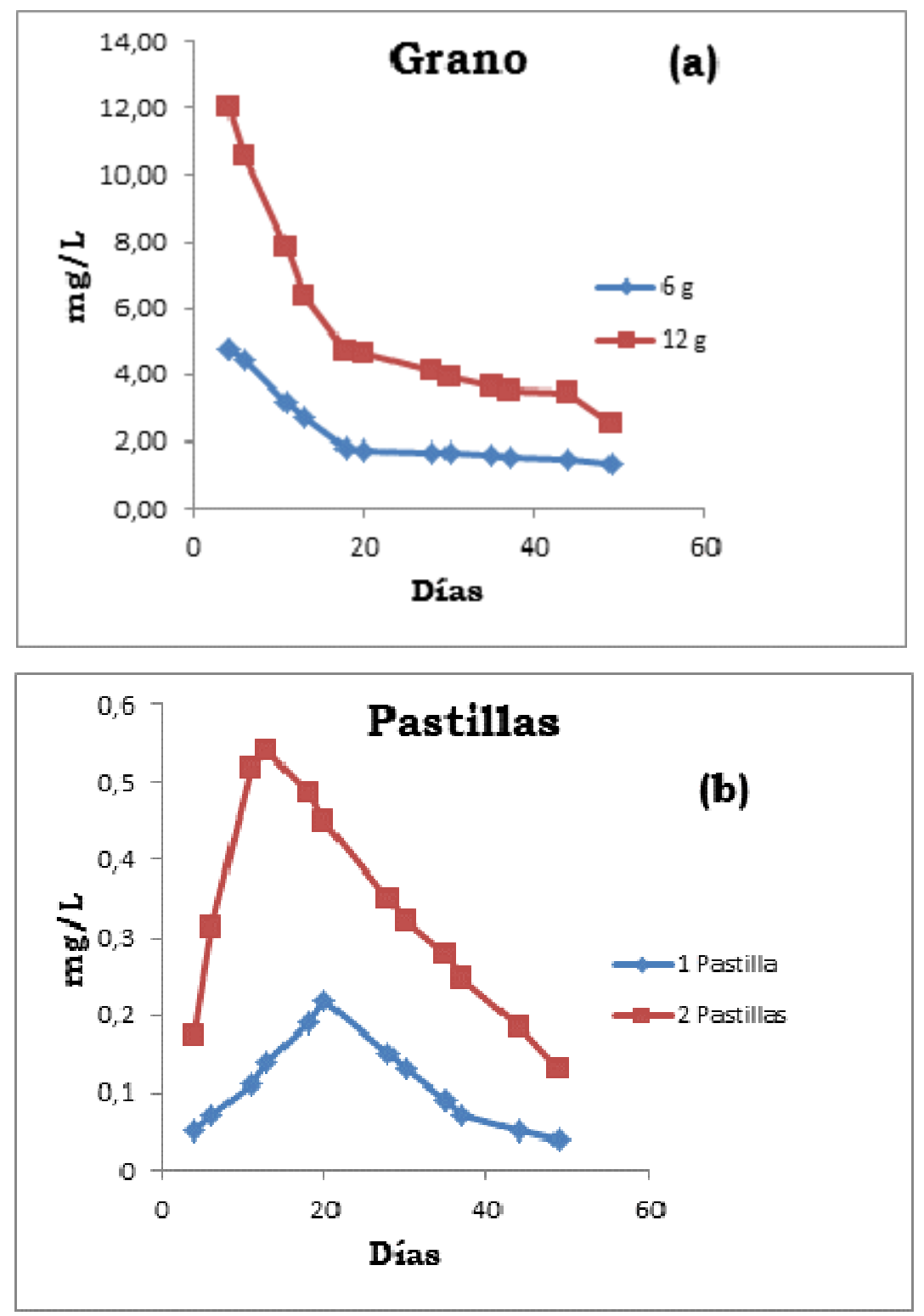

Figura 28: Liberación de BD al agua utilizando a) semillas y b) pastillas.

A la vista de los resultados obtenidos parece ser que la liberación de BD por las semillas se produce rápidamente al ponerlas en contacto con el agua para posteriormente ir disminuyendo su concentración, quedando cantidades apreciables después de 50 días, mientras que las pastillas 10 libera más lentamente, debido probablemente al recubrimiento de parafina, alcanzándose la máxima concentración al cabo de los 13 y 20 días respectivamente, para luego disminuir alcanzándose niveles similares 
de concentración de $\mathrm{BD}$ en agua en la última toma de muestra realizada a los 50 días. Lógicamente las cantidades liberadas son superiores cuanto mayor es la cantidad de producto activo utilizado.

\section{VI.4.2.- Liberación de Clorofacinona}

Para la realización de este estudio, se comprobó que el procedimiento desarrollado para determinar la liberación al agua del otro rodenticida estudiado era válido también para determinar la $\mathrm{CP}$, la única diferencia es que para la detección, en este caso, se utilizó un detector de diodos alineados en las mismas condiciones cromatográficas, ya que este compuesto, como ya se ha mencionado en la memoria, no es fluorescente.

En la Figura 29 se muestran los cromatogramas correspondientes a la inyección de una muestra de agua, a la cual se adicionó una concentración de $\mathrm{CP}$ y se trató según el método que se propone, y el correspondiente a un blanco de agua tratada.

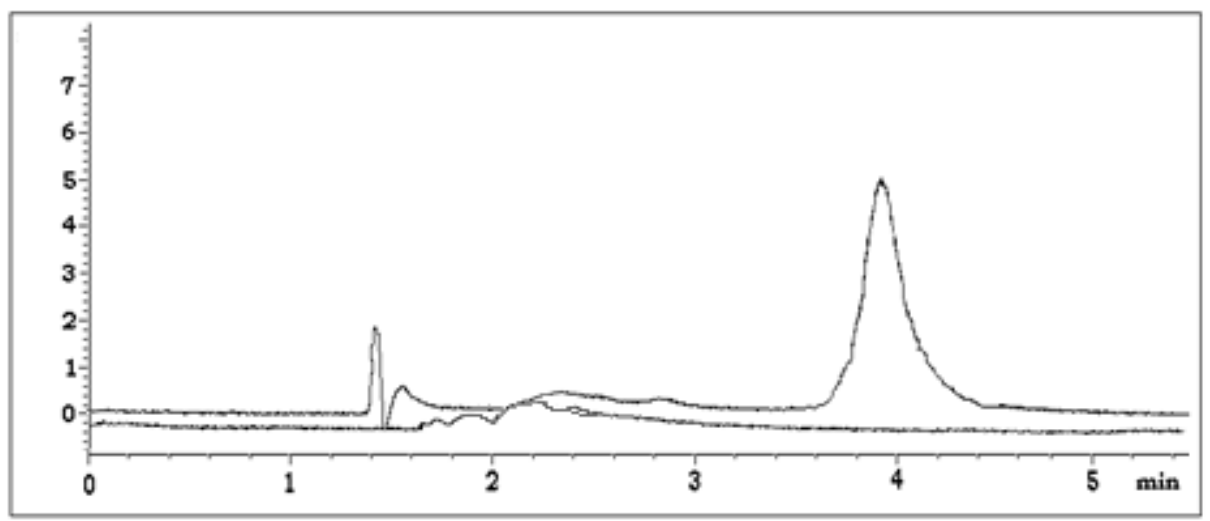

Figura 29: Cromatogramas superpuestos de un blanco y una muestra de agua adicionada con una concentración de CP de $0.60 \mathrm{mg} / \mathrm{L}$ tratadas, DAD.

Como se puede ver en la anterior Figura, no se observa la elución de ningún compuesto al tiempo de elución de la $\mathrm{CP} \mathrm{t}_{\mathrm{r}}=4.0$ minutos, por lo que queda demostrada la selectividad del método. 
Los porcentajes de recuperación que se obtuvieron se resumen en la siguiente Tabla 38:

Tabla 38: Porcentajes de recuperación a cuatro niveles de concentración $(n=6)$ y \% CV

\begin{tabular}{ccc}
\hline Compuesto & $\begin{array}{c}\text { Concentración } \\
\text { (mg/L) }\end{array}$ & \%Recuperación \pm \% CV \\
\hline \multirow{2}{*}{ CP } & 0.313 & $88 \pm 3$ \\
& 0.625 & $84 \pm 3$ \\
& 1.25 & $84 \pm 4$ \\
2.50 & $82 \pm 5$ \\
\hline
\end{tabular}

Como se puede observar, los porcentajes de recuperación son mayores del $80 \%$ y los coeficientes de variación inferiores al $5 \%$, por lo que el método es reproducible.

Una vez comprobada la validez del método se preparó, por pesada, una disolución de $1000 \mathrm{mg} / \mathrm{L}$ en metanol, a partir de la cual se realizaron diluciones sucesivas en metanol, con finalidad de realizar el estudio de linealidad en matriz en un intervalo de concentraciones de entre 0.325-2.5 $\mathrm{mg} / \mathrm{L}$. A continuación, a cada $100 \mathrm{~mL}$ de agua tratada se le añadió $1 \mathrm{~mL}$ de solución patrón de $\mathrm{CP}$ de concentración conocida, y posteriormente se trataron según el método establecido. La cuantificación se realizó por el método del patrón externo en base al área del pico y en la Tabla 39 se muestran las características de las líneas obtenidas por LC-DAD. 
Tabla 39: Parámetros de las lineas de calibrado para CP por LC- DAD

\begin{tabular}{llclllll}
\hline Compuesto & Matriz & $\begin{array}{c}\text { Concentración } \\
(\mathbf{m g} / \mathbf{L})\end{array}$ & $\mathbf{a}$ & $\mathbf{s} \mathbf{s}_{\mathbf{a}}$ & $\mathbf{b}$ & $\mathbf{s}$ b & $\mathbf{R}^{\mathbf{2}}$ \\
& & & & & & & \\
\hline CP & Patrón & $0.3-2.5$ & -6.06 & 2.58 & 104.10 & 1.00 & 0.999 \\
& Agua & & 1.97 & 0.89 & 78.01 & 0.62 & 0.999 \\
& & & & & & & \\
\hline
\end{tabular}

En ambos casos se cumple que la $t_{\text {exp }}>t_{t a b}$, por lo tanto se acepta que el método es lineal y los $\mathrm{R}^{2}$ mayores de 0.99 lo que indica la bondad del ajuste del calibrado.

Por otra parte, la comparación de las pendientes del calibrado de patrones en metanol y en agua tratados indicaron que los valores de pendiente en agua se encuentran fuera del intervalo de confianza de la pendiente $(p=0.95)$ en metanol por lo que se hace necesario, para su correcta cuantificación, realizar el calibrado sobre patrones en agua tratados.

El procedimiento que se siguió fue el mismo que se utilizó para la $\mathrm{BD}$, detallado anteriormente, es decir, se pusieron 2 L de agua de red en 4 vasos de precipitados para en dos de ellos añadir una cantidad determinada del formato en pastilla y en los otros dos del formulado en semilla. Las cantidades utilizadas, después de realizar una serie de ensayos previos, fueron: $6.1636 \mathrm{~g}$ y $12.0281 \mathrm{~g}$ para la semilla y de la pastilla $2.7529 \mathrm{~g}$ y $4.9523 \mathrm{~g}$. Los cuatro recipientes se mantuvieron con agitación constante y también se estableció como volumen de muestra $100 \mathrm{~mL}$, que se reponían con agua cada vez que se realizaba la toma de muestra, para mantener constante el volumen durante todo el estudio.

Una vez establecido el método se aplicó a una serie de muestras recogidas a lo largo de un mes. En la siguiente Figura 30 se muestran los cromatogramas obtenidos al inyectar unas de las muestras tomadas de semillas y de pastilla. 

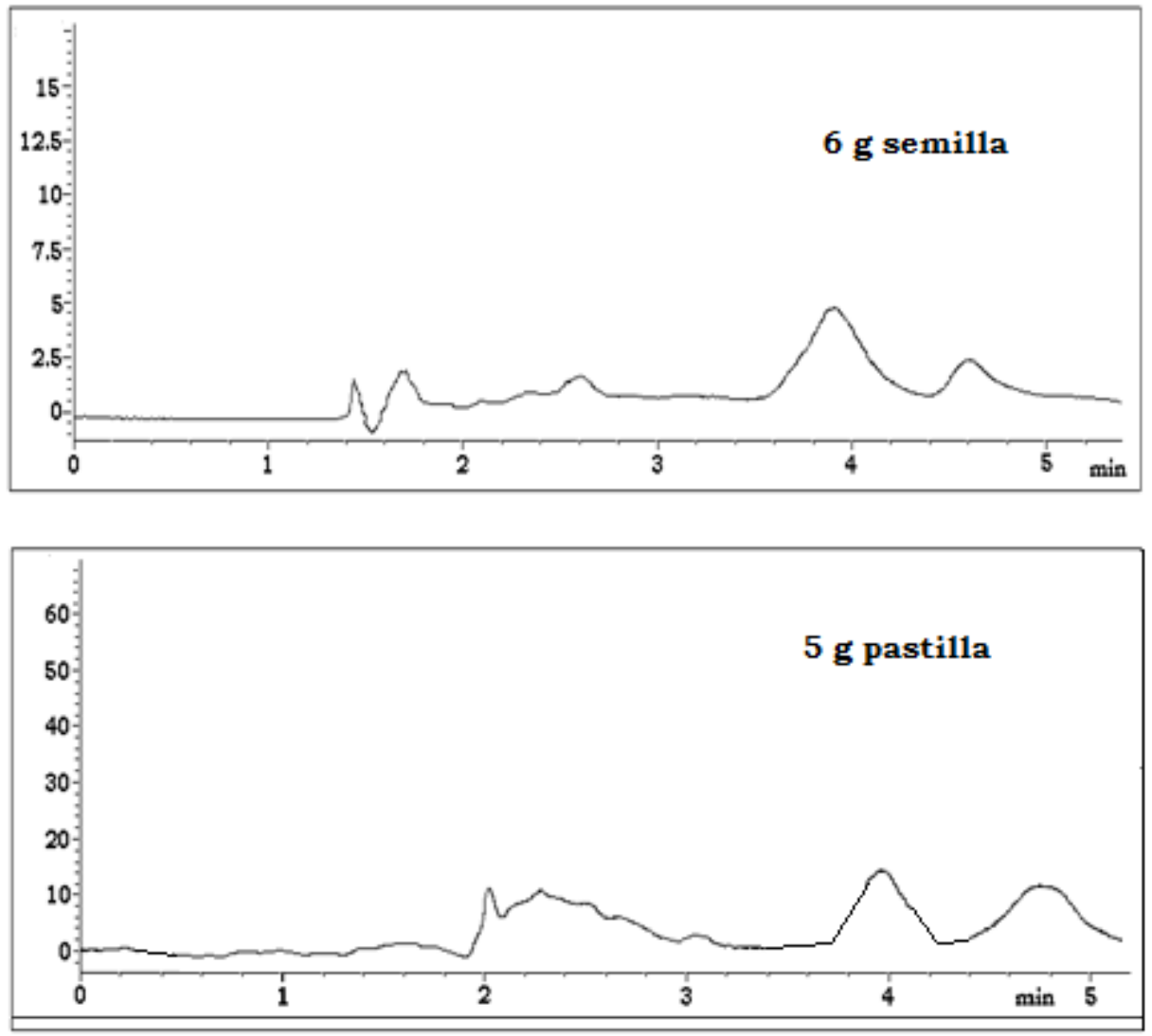

Figura 30: Cromatogramas obtenidos en la inyección de una de las tomas de muestra realizada en el caso de utilizar semillas y pastilla

Los resultados medios del estudio realizado durante 50 días se muestran en la siguiente Figura 31, donde se representa la concentración expresada en $\mathrm{mg} / \mathrm{L}$ en función de los dias, para los dos formatos de principio activo estudiados. 

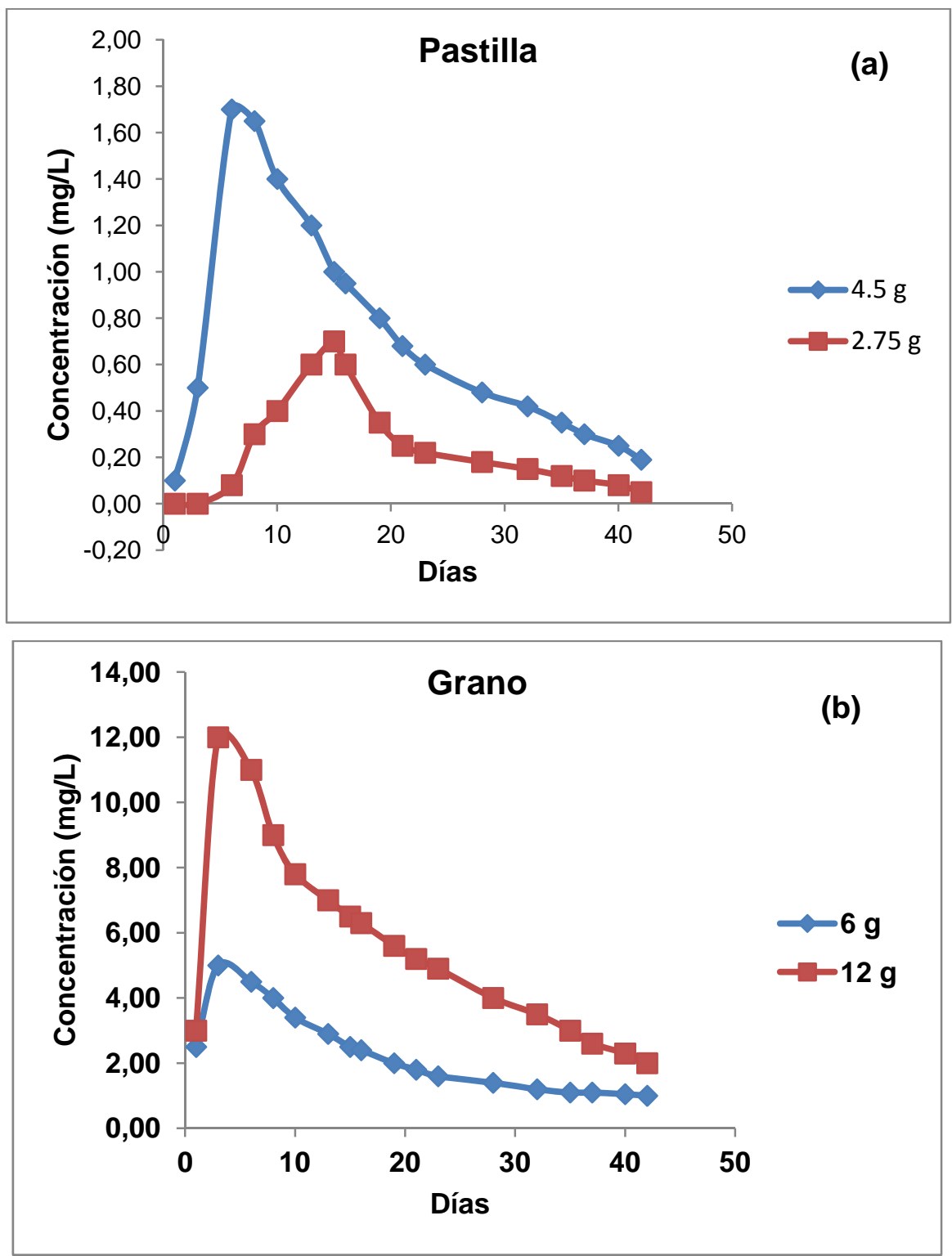

Figura 31: Liberación de $\mathrm{CP}$ al agua a) pastilla y b) grano 



\section{VII.- DETERMINACION DE CLOROFACINONA, BROMADIOLONA, DIFENACUM Y BRODIFACUM EN TEJIDOS}



El objetivo de este apartado fue el desarrollo de un método de análisis sobre distintas partes de la anatomía del topillo, cuyo estudio se centrara en el tratamiento de limpieza-concentración que permitiese eliminar por un lado las posibles interferencias de la matriz y al mismo tiempo realizar una concentración de los analitos. Ya que las condiciones cromatográficas en principio ya estaban seleccionadas, se intentó que este método fuera válido para cualquier tipo de tejido del animal objeto de estudio.

Para realizar dicho tratamiento se pensó en la utilización de la extracción sólido-líquido. Nos fueron proporcionadas muestras de hígado, intestino y músculo por el ITACyL correspondientes a 30 topillos (Microtus arvalis) de las provincias de Valladolid y Palencia, los cuales nunca habian estado en contacto con los compuestos de estudio. Una vez extraídos sus órganos, se liofilizaron y se trituraron en un mortero de vidrio para obtener una mayor homogeneidad en el tamaño de muestra y fueron almacenadas protegidas de la luz a $-20^{\circ} \mathrm{C}$.

\section{VII.1.- Tratamiento de muestra}

Antes de iniciar el desarrollo del método, se comprobó la ausencia de rodenticidas, en las muestras procedentes de áreas geográficas en las que no se había aplicado tratamiento con ningún rodenticida, por LC-ESI-MS, por lo que se podrian utilizar como blancos para el desarrollo del método y validación así como para preparar el calibrado en matriz.

Para el desarrollo del método lo primero que se tuvo que establecer fue la forma de adicionar los compuestos a los tejidos, para lo cual se pensó en la utilización del mismo procedimiento utilizado en las muestras de suelo. La forma en la que se operó fue siempre la misma y consistió en pesar 2 muestras de $50 \mathrm{mg}$ del tejido en vidrio de reloj, a una de las cuales se le adicionaba un volumen de una mezcla patrón de concentración conocida en metanol y a la otra muestra el mismo volumen de metanol. En el caso 
de las muestras que se fueran a analizar por MS el metanol que se adicionaba contenía una concentración de FC (PI) correspondiente a 150 $\mu \mathrm{g} / \mathrm{Kg}$. Se estableció el peso de $50 \mathrm{mg}$ pues proporcionaba buenos resultados y sensibilidad.

Fue necesario establecer el volumen que se debía adicionar para impregnar toda la muestra, realizándose distintas pruebas con volúmenes comprendidos entre 100 y $500 \mu \mathrm{L}$. Como resultado de dichos ensayos se puso de manifiesto que la adición de $100 \mu \mathrm{L}$ era suficiente independientemente del tipo de tejido, por lo que se estableció este valor para adicionar a las muestras, añadiendo el mismo volumen solamente de metanol a la muestra que se utilizó como blanco.

Una vez adicionada la mezcla patrón se dejaba evaporar el disolvente introduciéndolas en estufa a $45^{\circ} \mathrm{C}$, o al aire. A continuación, se transferian a un tubo de centrifuga con tapón, recipiente donde se realizó la extracción.

Para la optimización de todas las etapas necesarias en el proceso de extracción sólido-líquido se operó siempre tratando la muestra adicionada y blanco de la misma manera, variando únicamente el parámetro a estudiar y manteniendo constantes el resto. Inicialmente todos los ensayos se realizaron sobre muestras de hígado.

\section{Naturaleza y volumen de extractante}

En primer lugar se procedió a seleccionar el disolvente a emplear como extractante así como el volumen a emplear del mismo. Se empezó empleando el mismo extractante utilizado para los suelos, es decir, metanol, y como se obtuvieron buenos resultados fue el seleccionado.

Se procedió entonces a establecer el volumen a utilizar, realizándose una serie de ensayos en los que se varió entre 2 y $10 \mathrm{~mL}$ de metanol, puesto 
que inicialmente se realizaron pruebas utilizando volúmenes entre 10 y 15 $\mathrm{mL}$ y no se observaron diferencias en las recuperaciones para los compuestos con el aumento en el volumen de extractante. A continuación, se agitaron mecánicamente durante 10 minutos y se centrifugaron otros 10 minutos a una velocidad de $9000 \mathrm{rpm} \mathrm{y} 10^{\circ} \mathrm{C}$. Seguidamente se decantaron y los líquidos fueron concentrados a sequedad en rotavapor a $40^{\circ} \mathrm{C}$, disolviéndose el residuo seco con $1 \mathrm{~mL}$ metanol, introduciéndose seguidamente en un baño de ultrasonidos para favorecer su solubilización. Se filtraron a través de filtros de Nylon en viales topacio y $20 \mu \mathrm{L}$ se inyectaban en el sistema cromatográfico en las condiciones establecidas, además de inyectar una mezcla patrón de la misma concentración que la adicionada a la muestra para el cálculo de las recuperaciones. Los resultados que se obtuvieron se muestran en la siguiente Tabla 40:

Tabla 40: Porcentajes de recuperación para los rodenticidas estudiados en muestras de hígado en función del volumen de extractante

\begin{tabular}{lccccccc}
\hline & \multicolumn{8}{c}{ \% Recuperación } \\
\hline Compuesto & $\mathbf{2}$ & $\mathbf{3}$ & $\mathbf{4}$ & $\mathbf{5}$ & $\mathbf{6}$ & $\mathbf{8}$ & $\mathbf{1 0}$ \\
CP & 41 & 64 & 85 & 99 & 98 & 99 & 97 \\
BD & 38 & 60 & 80 & 97 & 96 & 95 & 94 \\
DF & 35 & 57 & 82 & 93 & 94 & 93 & 92 \\
BF & 36 & 59 & 80 & 91 & 90 & 89 & 91 \\
\hline
\end{tabular}

De los resultados que se obtuvieron se estableció como volumen más adecuado el de $5 \mathrm{~mL}$, ya que se obtuvieron buenas recuperaciones y la utilización de volúmenes superiores no las mejoraban, como ya se había puesto de manifiesto en los ensayos previos.

El tiempo de agitación que se estableció inicialmente de 10 minutos resultó ser el adecuado, ya que se realizaron una serie de experiencias en las que se varió entre 5 y 20 minutos a intervalos de 5 minutos y los resultados que se obtuvieron mostraron que tiempos de agitación inferiores conducian a recuperaciones de los compuestos menores 
mientras que la utilización de mayores tiempos de agitación no las mejoraban, como se puede apreciar en los datos de la siguiente Tabla 41.

Tabla 41: Porcentajes de recuperación para los anticoagulantes en hígado en función del tiempo de agitación

\begin{tabular}{lcccc}
\hline & \multicolumn{4}{c}{ \% Recuperación } \\
\hline Compuesto & $\mathbf{5}$ & Tiempo de agitación (min) & $\mathbf{2 0}$ \\
CP & 80 & $\mathbf{1 0}$ & $\mathbf{1 5}$ & 97 \\
BD & 75 & 98 & 96 & 94 \\
DF & 78 & 95 & 96 & 92 \\
BF & 76 & 94 & 93 & 90 \\
\hline
\end{tabular}

En cuanto al tiempo de centrifugación, 10 minutos fueron suficientes para lograr la separación de las fases y se realizó a $10^{\circ} \mathrm{C}$ para evitar la posible evaporación del extractante.

Finalmente, se realizaron ensayos con el objetivo de establecer tanto la naturaleza como el volumen a emplear para reconstituir el residuo seco obtenido en la etapa de concentración a sequedad, que se realizó con el fin de poder concentrar y de esta forma alcanzar límites de detección y cuantificación más bajos.

El disolvente a emplear en esta etapa en principio fue el metanol, y en cuanto al volumen se estableció en $1 \mathrm{~mL}$ ya que la utilización de volúmenes inferiores no logró la solubilización completa del residuo y volúmenes superiores provocaban una dilución innecesaria. Sin embargo, aunque en principio la solubilización era completa, al cabo de poco tiempo se observó la aparición de partículas sólidas lo que implicó su trasvase a tubos eppendorf para de nuevo centrifugar para eliminarlas.

El procedimiento se desarrolló de la forma descrita para los tres tejidos, pero en el caso del intestino y músculo se observó en los cromatogramas correspondientes a los blancos de estos tejidos la aparición de picos a tiempos de retención análogos a los de los compuestos de interés. Se comprobó, mediante la detección por espectrometría de masas, que no se 
trataban de rodenticidas por lo que se debían a componentes de las matrices que impedian su correcta cuantificación.

Para eliminar dichas interferencias se pensó que la forma más fácil de realizarlo sería cambiando la naturaleza del disolvente empleado para la reconstitución del residuo obtenido en la etapa de concentración. Se probaron mezclas de agua-metanol con diferentes porcentajes y la propia fase móvil (73\% metanol/27\% formiato amónico $30 \mathrm{mM} \mathrm{pH}$ 6.5), manteniendo en $1 \mathrm{~mL}$ el volumen empleado.

De los cromatogramas que se obtuvieron se pudo deducir que era la composición de la fase móvil la que proporcionaba los cromatogramas más limpios no apareciendo picos interferentes a los tiempos de retención de los analitos.

Con lo que el tratamiento de muestra que se propone para los tres tejidos se resume en la siguiente Figura 32:

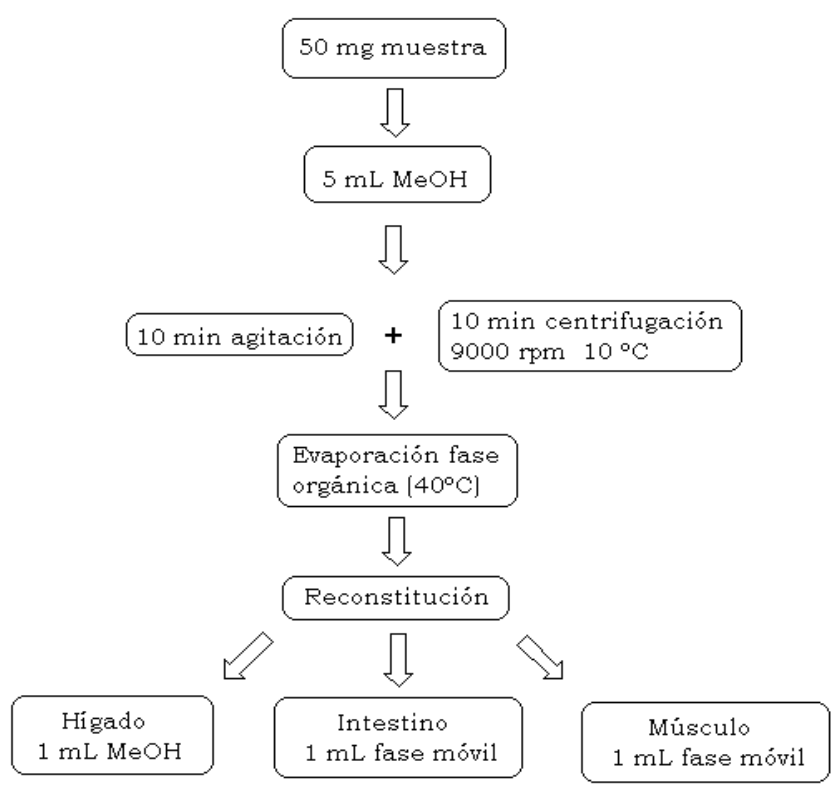

Figura 32: Esquema del tratamiento de muestra. 
En las siguientes Figuras 33, 34 y 35 se muestran los cromatogramas correspondientes a la inyección de blancos y muestras adicionadas tratadas según el procedimiento desarrollado, para los tres tejidos analizados con los tres sistemas de detección empleados.
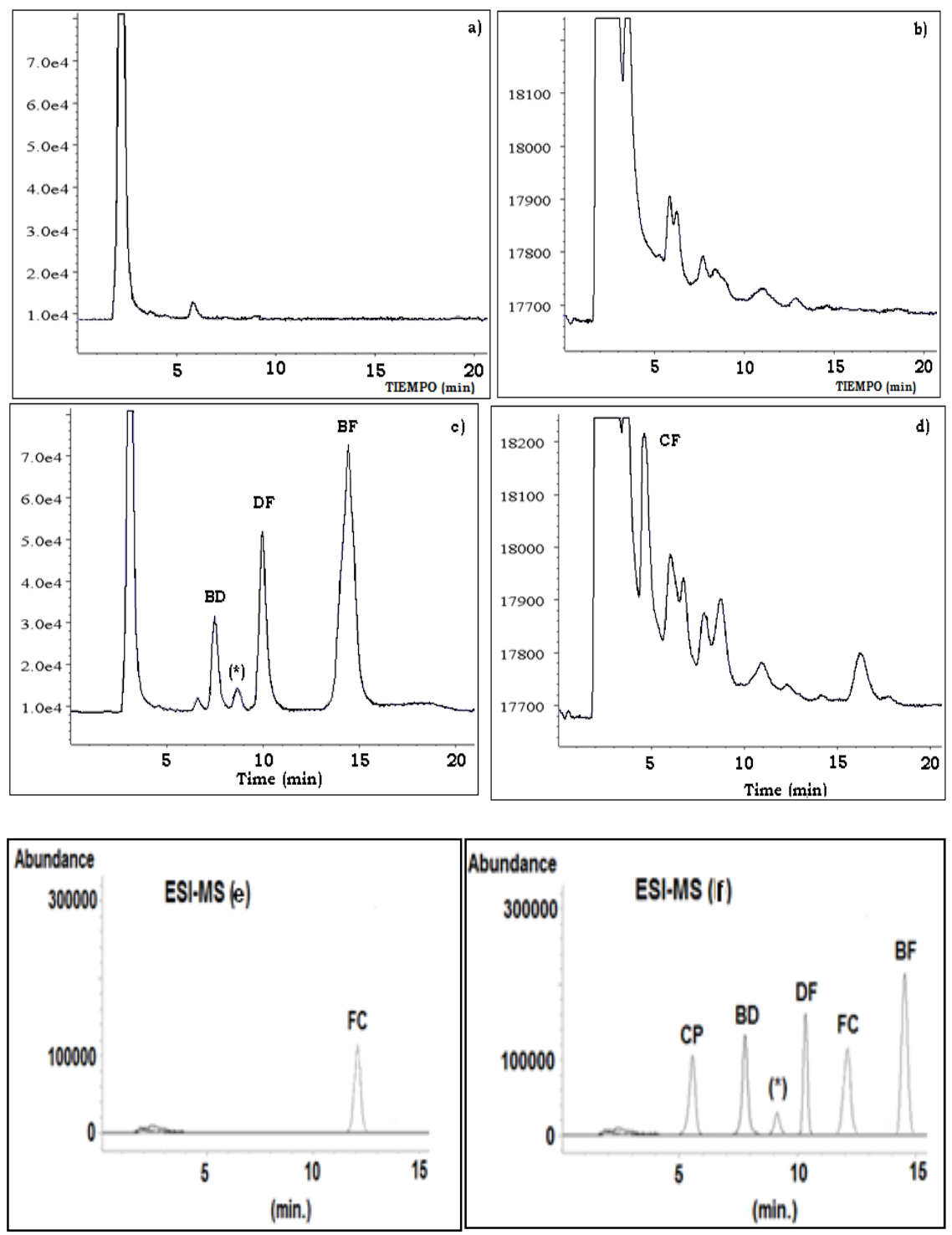

Figura 33: Cromatogramas correspondiente a muestras de intestino : blancos en FLD (a) y DAD (b); muestra tratada, adicionada con los 4 compuestos en concentración de $250 \mu \mathrm{g} / \mathrm{kg}$, sin patrón interno, para FLD (c) y DAD (d), (e) blanco para la detección por MS al que se le adicionó el patrón interno en concentración de $150 \mu \mathrm{g} / \mathrm{kg}$ y (f) muestra adicionada para MS con analitos en concentración de 150 $\mu \mathrm{g} / \mathrm{kg}$. (*) Isómero Bromadiolona. 

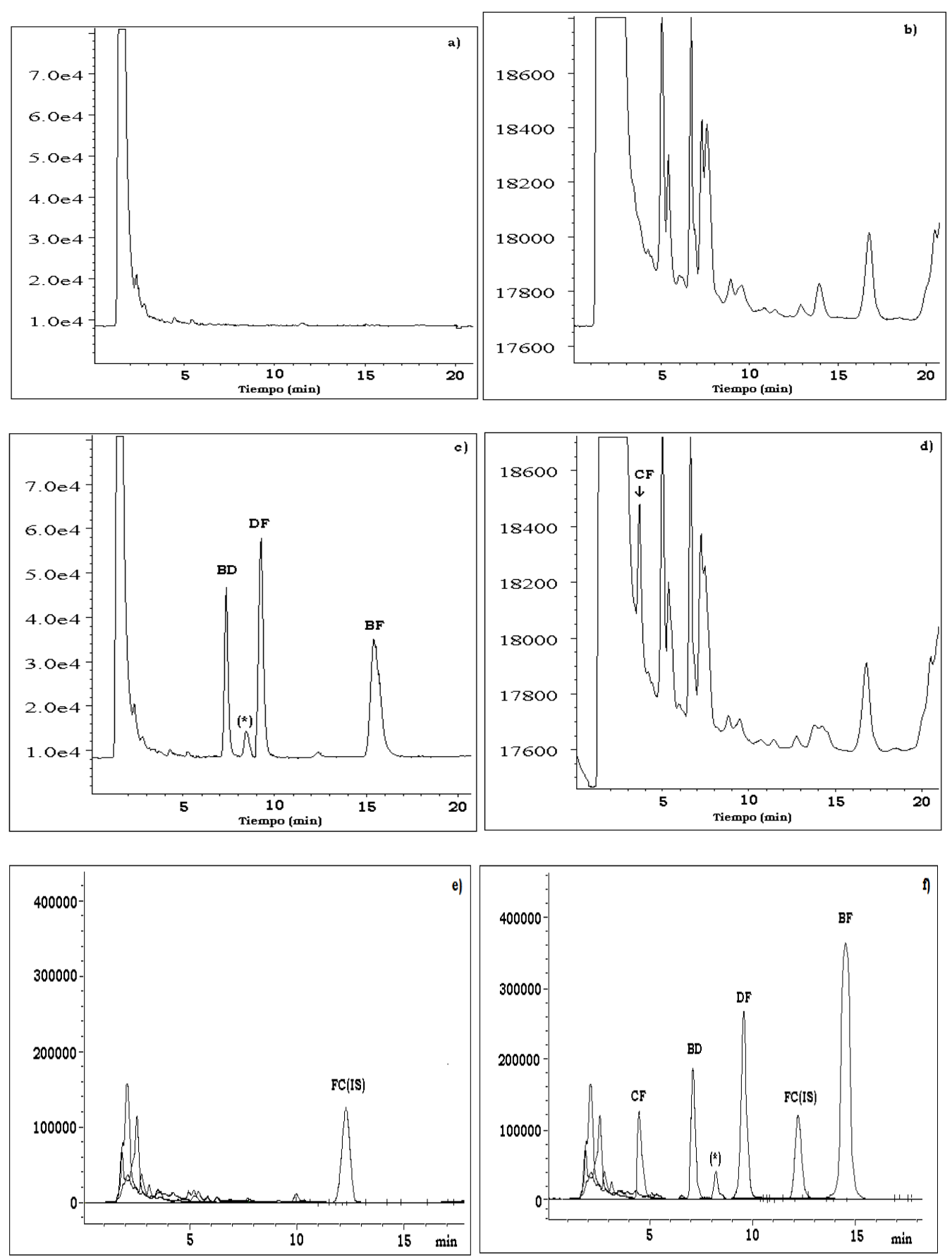

Figura 34: Cromatogramas correspondiente a muestras de hígado: blancos en FLD (a) y DAD (b); muestra tratada, adicionada con los 4 compuestos en concentración de $250 \mu \mathrm{g} / \mathrm{kg}$, sin patrón interno, para FLD (c) y DAD (d), (e) blanco para la detección por MS al que se le adicionó el patrón interno en concentración de $150 \mu \mathrm{g} / \mathrm{kg}$ y (f) muestra adicionada para MS con analitos en concentración de 150 $\mu \mathrm{g} / \mathrm{kg} \cdot$ ( $^{*}$ Isómero Bromadiolona. 

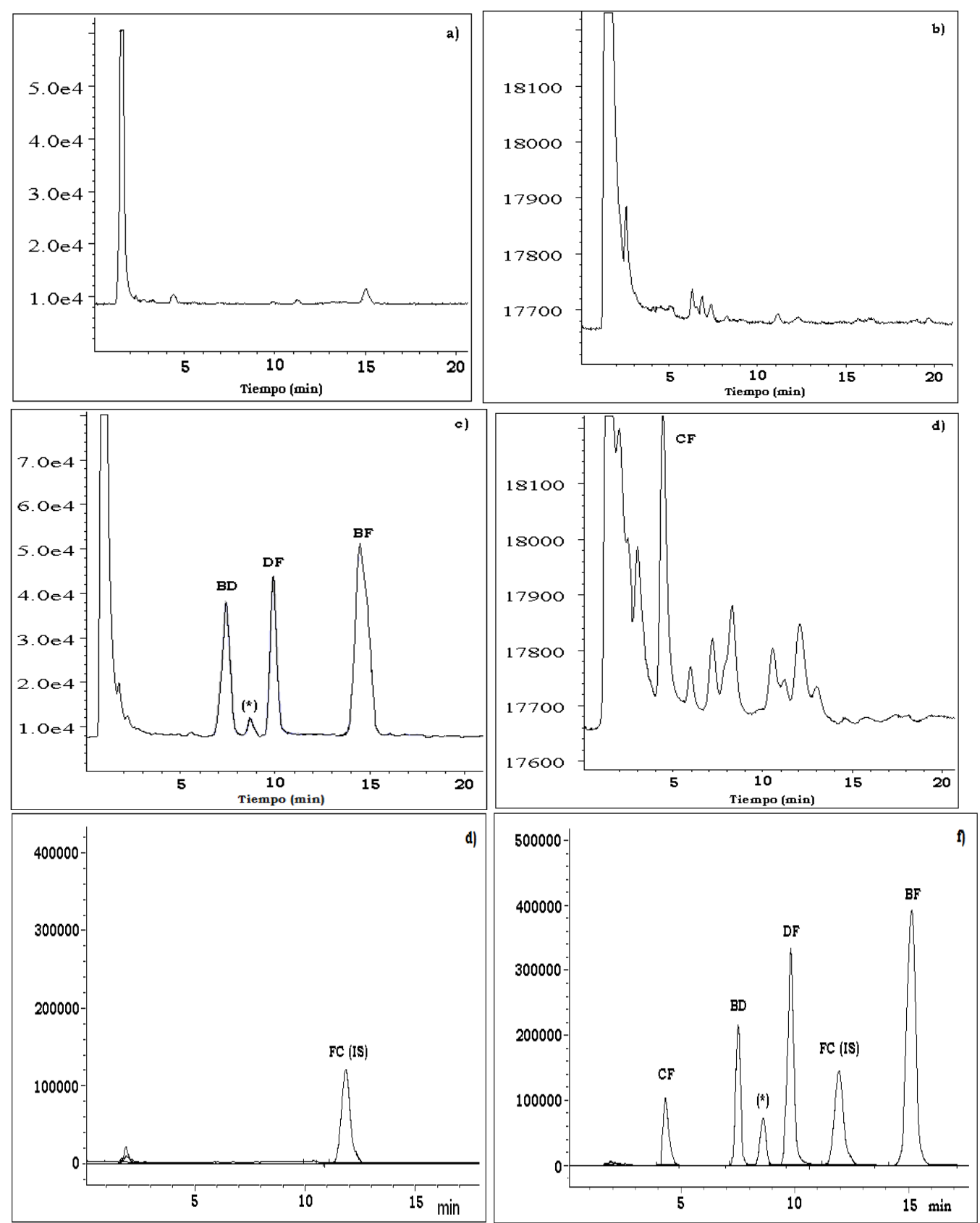

Figura 35: Cromatogramas correspondiente a muestras de músculo blancos en FLD (a) y DAD (b); muestra tratada, adicionada con los 4 compuestos en concentración de $250 \mu \mathrm{g} / \mathrm{kg}$, sin patrón interno, para FLD (c) y DAD (d), (e) blanco para la detección por MS al que se le adicionó el patrón interno en concentración de $150 \mu \mathrm{g} / \mathrm{kg}$ y (f) muestra adicionada para MS con analitos en concentración de 150 $\mu \mathrm{g} / \mathrm{kg} \cdot$ ( $^{*}$ Isómero Bromadiolona. 
Como se puede observar en las anteriores Figuras, el método desarrollado permite realizar la determinación de los 4 rodenticidas en los tres tipos de tejidos analizados.

\section{VII.2.- Validación de la metodología analítica}

La validación fue llevada a cabo siguiendo las mismas directrices que en las otras matrices estudiadas.

Los porcentajes de recuperación y eficacia del tratamiento de muestra para los rodenticidas estudiados se determinó realizando 6 réplicas a tres concentraciones diferentes (baja, media y alta) comparando las áreas de los analitos obtenidas en las muestras tratadas con las áreas que nos proporcionaban los patrones de los analitos.

Para el estudio del efecto matriz en el caso de la determinación de los compuestos por espectrometría de masas, se compararon las áreas obtenidas de los analitos de las muestras de tejidos a las que se adicionó la misma concentración de los compuestos y tratadas según el método desarrollado con las áreas de los extractos de las muestras blanco a las que se adicionó la misma concentración de rodenticidas y el patrón interno (FC) para la detección por MS al reconstituir el residuo seco. Para investigar el posible efecto matriz, el cual es particularmente importante para la detección ESI-MS, se compararon las áreas de los picos correspondientes a la inyección de mezcla de patrones de una determinada concentración con las áreas de los extractos de muestra blanco tratados y su residuo seco reconstituido con mezcla patrón de la misma concentración.

En las siguientes Tablas 42 y 43 se muestran los resultados obtenidos 


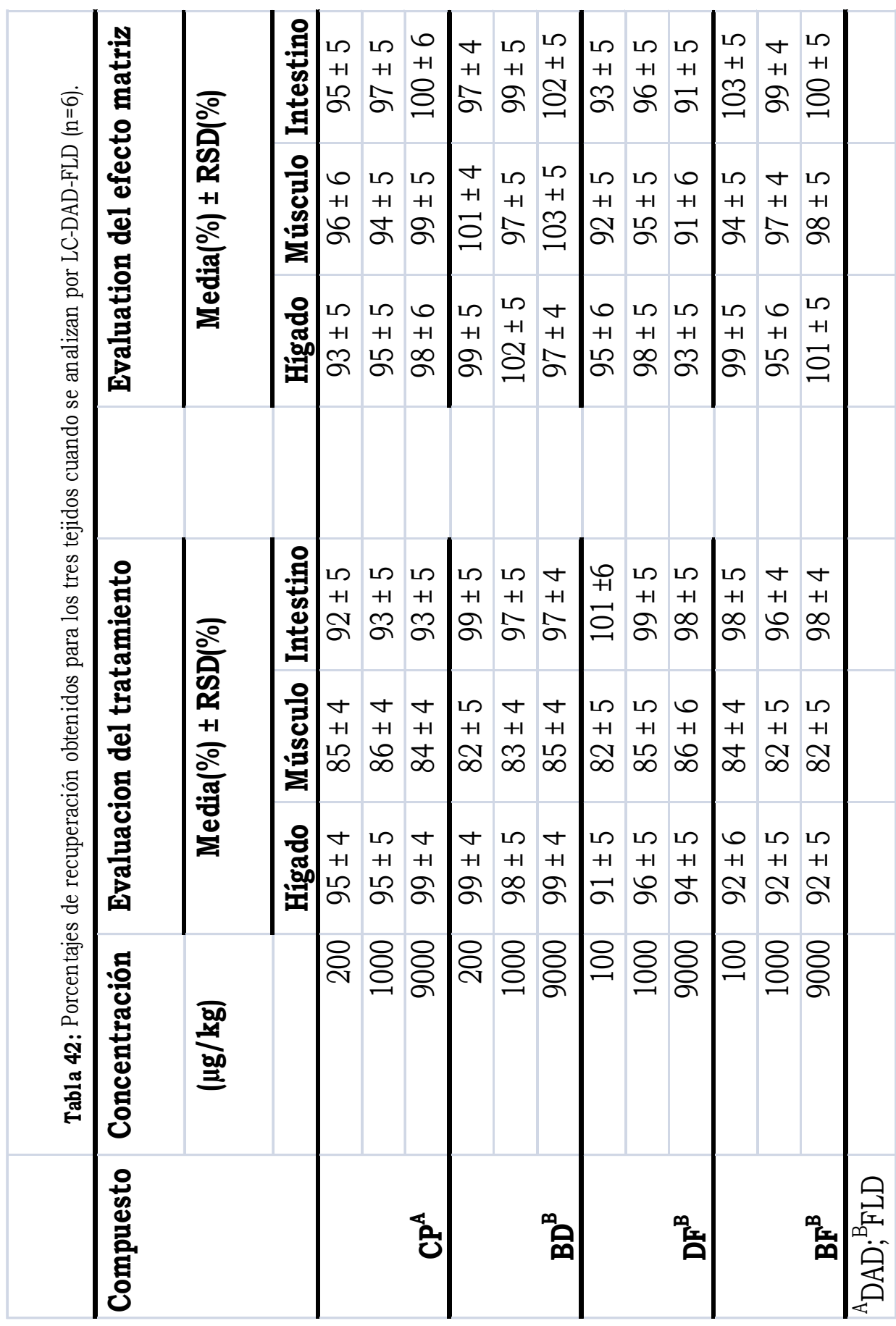




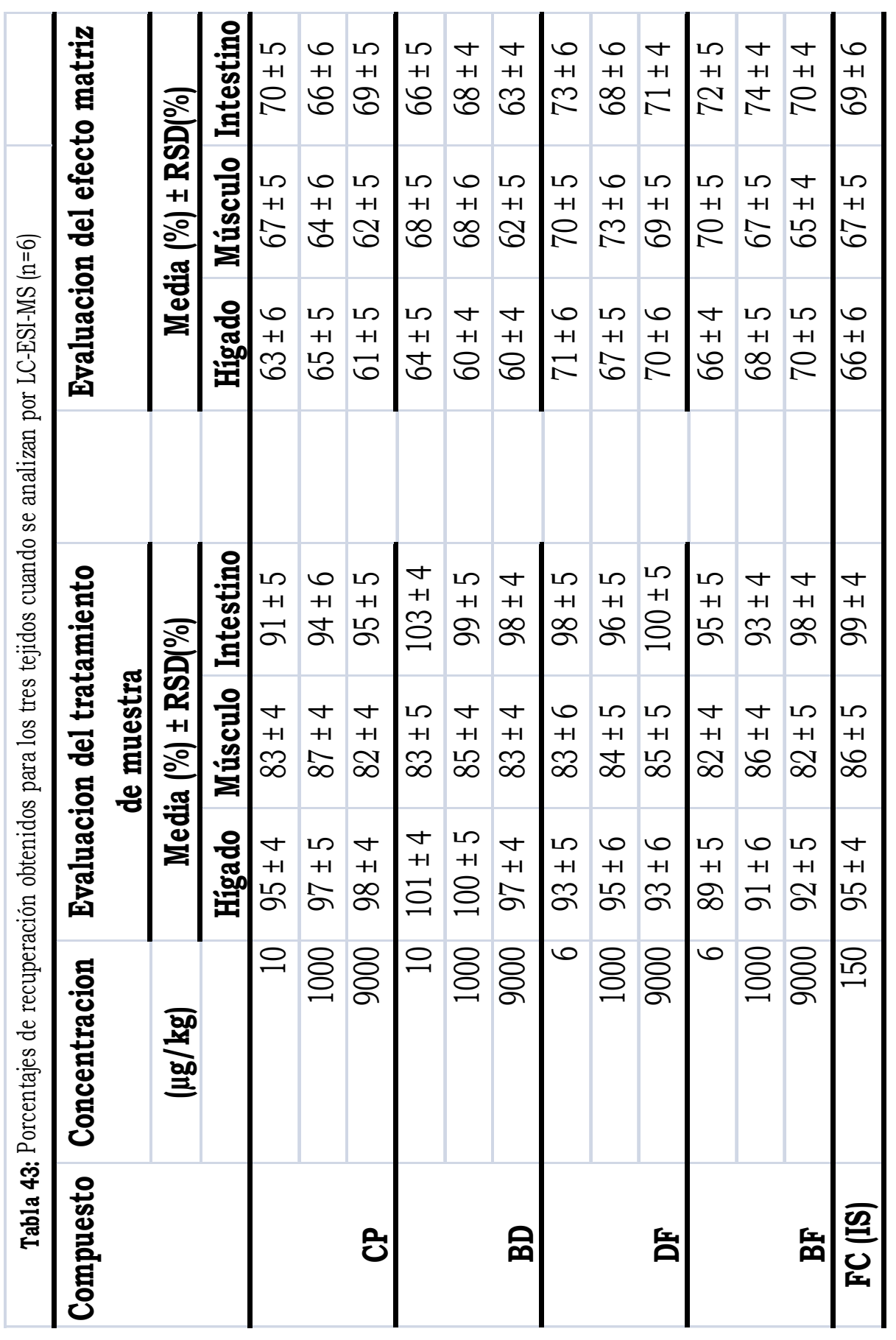


En las Tablas anteriores se compara la eficacia del método que se propone para la determinación de los 4 rodenticidas analizados en las diferentes matrices de tejido animal a los que se adicionó los compuestos antes y después del tratamiento. Los porcentajes de recuperación varian entre $82 \%$ y $103 \%$, lo que indica que el tratamiento que se propone es adecuado. No se aprecian diferencias significativas entre los diferentes detectores utilizados, aunque si se observa que los porcentajes que se obtienen en músculo son menores que los porcentajes obtenidos en hígado e intestino.

Sin embargo, también en las anteriores Tablas se puede observar la existencia de un efecto matriz importante, ya que los porcentajes de recuperación que se obtienen son inferiores al 75\% para todos los compuestos a los tres niveles de concentración estudiados para los extractos de las muestras blanco tratadas y reconstituidas con la mezcla patrón. Por lo que se puede concluir que la matriz afecta a la ionización por electrospray de los compuestos, provocando una supresión en la ionización.

\section{Selectividad}

La selectividad del método quedó demostrada al comparar los cromatogramas correspondientes a muestras blanco sin adicionar y adicionadas con una concentración conocida de los 4 compuestos y tratadas que se encuentran en las Figuras 33, 34 y 35 de esta memoria, donde no se observan interferencias para ninguno de los sistemas de detección empleado ni para ninguno de los tejidos estudiados, por lo que el método desarrollado es selectivo para la determinación de estos compuestos en muestras de tejido animal (hígado, intestino y músculo). 


\section{Linealidad}

Las soluciones para el calibrado se prepararon de distinta forma dependiendo del tipo de curva de calibración que se realizara, con patrones o en matriz. Para el calibrado con patrones se prepararon por dilución en metanol a partir de las disoluciones concentradas. Para la detección por DAD-FLD el intervalo de concentración utilizado fue de 25

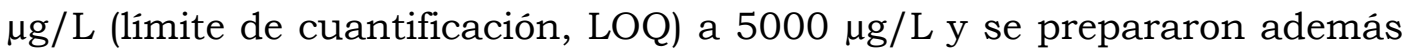
6 soluciones más dentro de este intervalo (100, 250, 500, 1000, 2000 y $4500 \mu \mathrm{g} / \mathrm{L}$ ). Para ESI-MS la linealidad fue estudiada entre $1.5 \mu \mathrm{g} / \mathrm{L}$ (LOQ) y $5000 \mu \mathrm{g} / \mathrm{L}$ preparando además otras 6 disoluciones dentro de este intervalo para obtener la curva de calibrado (10, 25, 100, 250, 500, 1000 y $2000 \mu \mathrm{g} / \mathrm{L}$ ). El patrón interno se añadió a todas las disoluciones patrón para que su concentración fuera de $75 \mu \mathrm{g} / \mathrm{L}$.

Para preparar el calibrado en matriz se pesaron $50 \mathrm{mg}$ de los tejidos blancos de topillo a los que se adicionaron $100 \mu \mathrm{L}$ de solución patrón en metanol de diferentes concentraciones antes de someterlas al tratamiento que se propone. Las concentraciones para la detección DAD-FLD fueron desde el LOQ ( 50 $\mu \mathrm{g} / \mathrm{kg}), 200,500,1000,2000,4000$ y $9000 \mu \mathrm{g} / \mathrm{kg}, \mathrm{y}$ para ESI-MS desde el LOQ ( 5 $\mu \mathrm{g} / \mathrm{kg}), 20,50,200,500,1000$ y 4000 $\mu \mathrm{g} / \mathrm{kg}$. Se utilizó además, como punto adicional, el blanco en cada caso del tejido tratado, con o sin adición del patrón interno, para los tres detectores utilizados. La concentración de patrón interno que se utilizó fue de $150 \mu \mathrm{g} / \mathrm{kg}$ para la detección ESI-MS y se añadió en los $100 \mu \mathrm{L}$ junto al resto de los compuestos que se adicionaban inicialmente a los $50 \mathrm{mg}$ de tejido.

También se prepararon muestras de control (QC) utilizando $50 \mathrm{mg}$ de blanco de tejido (hígado, intestino o músculo) al que se adicionó, antes del tratamiento, $100 \mu \mathrm{L}$ de patrones individuales de rodenticida (o con el patrón interno únicamente en el caso del análisis por ESI-MS). Las 
concentraciones de las muestras QC fueron las bajas para DAD-FLD de 100 y $200 \mu \mathrm{g} / \mathrm{kg}$, y de 6 y $10 \mu \mathrm{g} / \mathrm{kg}$ para ESI-MS. Las concentraciones medias fueron de $1000 \mu \mathrm{g} / \mathrm{kg}$ y las altas de $9000 \mu \mathrm{g} / \mathrm{kg}$ para todos 10 s compuestos y para ambos sistemas cromatográficos.

Una vez preparados los puntos de calibración se inyectaron en los equipos LC-DAD-FLD y LC-MS, utilizando para la cuantificación el método del patrón externo para la detección DAD-FLD y el del patrón interno para ESI-MS, representando el área o relación de áreas (analito/ patrón interno) para cada analito en función de la concentración y detector para la obtención de los calibrados tanto para los patrones como en matriz.

Todas las soluciones se inyectaron tres veces, de baja a alta concentración, y después de un calibrado completo, las muestras QC se inyectaron también de baja a alta concentración por triplicado. La linealidad se evaluó calculando los coeficientes de correlación $\left(R^{2}\right)$, recalculando las concentraciones de los patrones de calibración y el análisis de los factores de respuesta. Los datos del intervalo lineal y de los coeficientes de correlación se muestran en la Tablas 44 y 45 . La linealidad de los calibrados se confirmó por los gráficos de los factores de respuesta, valores $\mathrm{R}^{2}>0.99$ ) y desviaciones estándar (RSD) $<3 \%$ en todo el intervalo de concentraciones, para los tres detectores utilizados y matrices analizadas. La ausencia de bias se confirmó mediante un test t y a través del gráfico de residuales

De los resultados que se obtuvieron se estableció que la cuantificación de los compuestos en hígado e intestino con detección DAD-FLD se puede realizar con el calibrado de patrones. Los calibrados dieron líneas rectas en el intervalo de concentraciones estudiado. Además, las pendientes del calibrado con patrones y calibrados en matriz para cada tipo de tejido entran dentro del intervalo de confianza. 


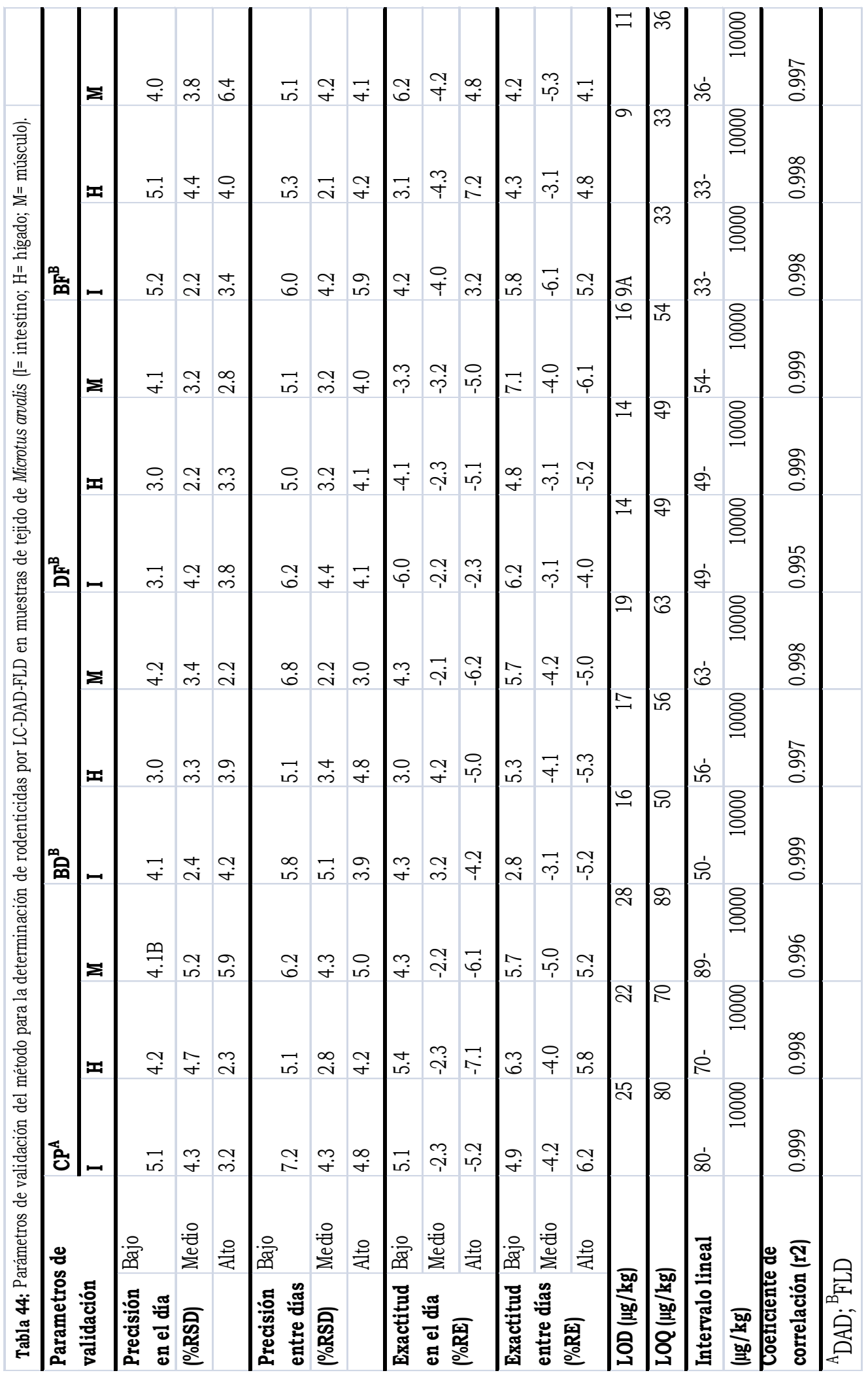




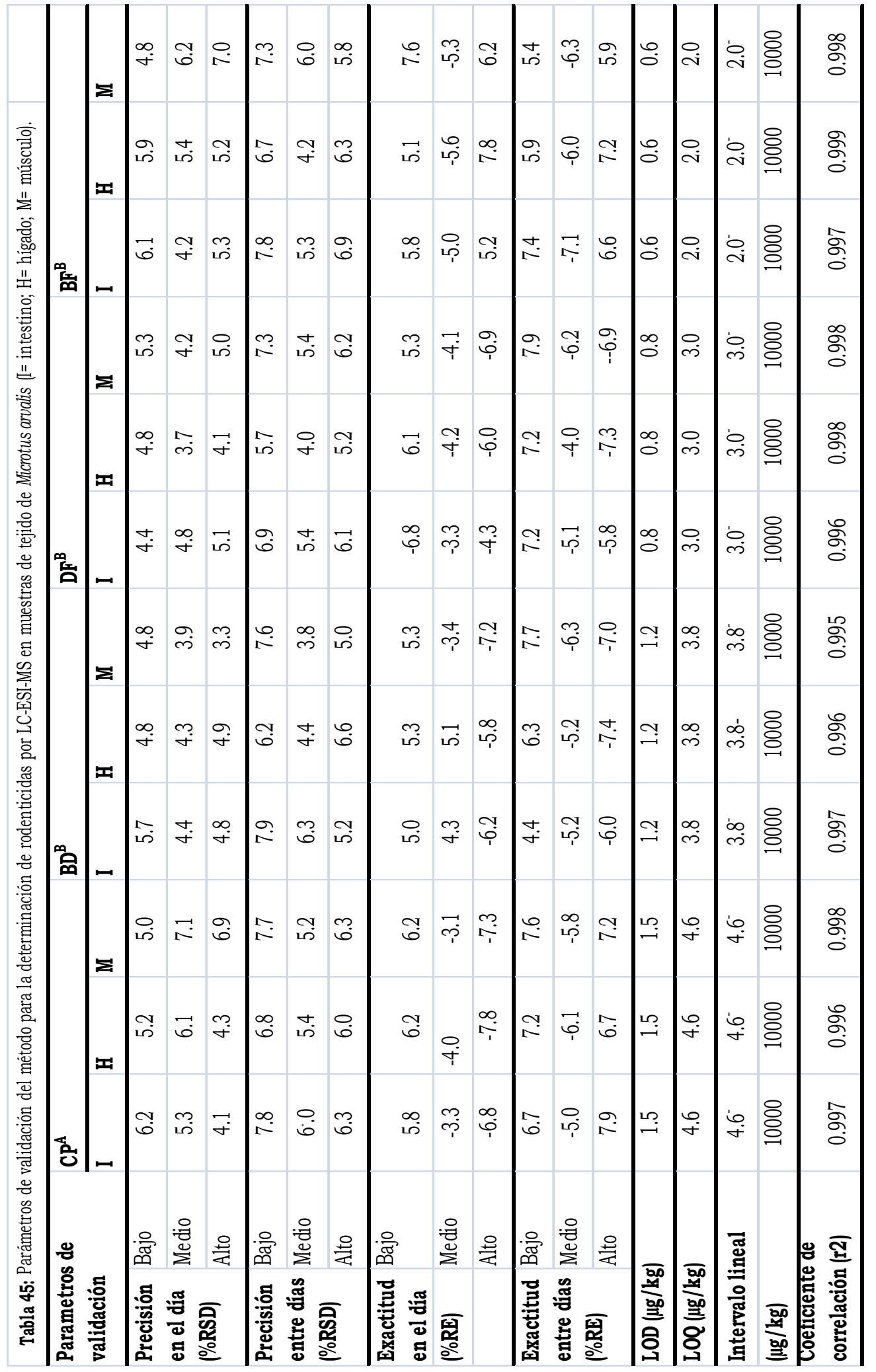


Sin embargo en músculo para realizar la correcta cuantificación es necesario utilizar el calibrado en matriz, debido a la pérdida de los compuestos durante el procedimiento de extracción y que no se puede compensar salvo con dicho calibrado. Por otro lado, como ya se ha indicado, se observó un fuerte efecto matriz que afectaba a la ionización de los analitos, por lo que no fue de extrañar que en la detección ESI-MS los intervalos de confianza para las pendientes de los calibrados con patrones y en matriz no se superpongan, por lo que para cuantificar los anticoagulantes en tejidos por LC-ESI-MS se debe de realizar con el calibrado en matriz.

El efecto de la contaminación por arrastre (carry-over) se evaluó para cada analito en cada matriz inyectando muestras de control con una elevada concentración de los compuestos o patrones de calibración, de 5 o 10 $\mathrm{mg} / \mathrm{kg}$, y determinando las respuestas a los tiempos de retención de los analitos y del patrón interno. Las Figuras 33, 34 y 35 que se han mostrado anteriormente, indican un inapreciable efecto de arrastre cuando se utiliza el método desarrollado para analizar los rodenticidas anticoagulantes en los tejidos de interés. Por otra parte, la evaluación de la reproducibilidad se determinó reinyectando patrones de concentración determinada 3 veces por día y muestras de control a dos niveles de concentración (bajo y alto) que habian sido almacenadas durante una semana proporcionando valores para los \%RSD inferiores al $1.5 \%$ en todos los casos, demostrando con ello que las muestras se pueden re-analizar en el intervalo de una semana.

La precisión y exactitud se determinaron por repetidos análisis de las muestras control $(\mathrm{QC})$ en el mismo día. Antes de cada análisis se realizó la linea de calibrado y después se inyectaron 6 réplicas de muestras QC con baja, media y alta concentración en los compuestos de interés, expresando la precisión por la desviación estándar relativa (\%RSD). Como se puede ver en las Tablas 44 y 45, la precisión para los compuestos 
estudiados se encuentra dentro del intervalo entre el 2 y el $7 \%$ para todos los sistemas de detección utilizados y tejidos estudiados. El estudio de la precisión intermedia y exactitud se realizó analizando 6 replicados de muestras control a los tres niveles de concentración de rodenticidas en tres días consecutivos, los valores que se obtuvieron se encuentran comprendidos entre el 2 y el $8 \%$ (\%RSD).

La exactitud expresada como \% de error relativo (\%RE) para cada compuesto, se determinó calculando la concentración de cada compuesto a partir del calibrado y comparándola con la que tenía la muestra, encontrándose (ver Tabla) que variaba entre el 2-8\% para los ensayos en el día y entre el 3-8\% para los resultados obtenidos en tres días consecutivos. Como se puede observar en las Tablas 44 y 45, la precisión y exactitud fueron algo superiores para la detección DAD-FLD que para la ESI-MS, aunque ambas fueron lo suficientemente altas, mostrando estos resultados que el método desarrollado es preciso y exacto. También estos valores justifican que aunque en la mayoría de las directrices para la validación se recomienda la utilización de un patrón interno y que se ha utilizado en este trabajo para mejorar la reproducibilidad de los análisis realizados con detección ESI-MS, no siendo necesaria su utilización para realizar análisis con detección DAD-FLD debido al elevado grado de precisión y exactitud de estos detectores.

Los límites de detección (LOD) y de cuantificación (LOQ) se determinaron de forma experimental (ver Tablas 44 y 45) inyectando un número ( $\mathrm{n}=6$ ) de extractos blancos de tejido y midiendo el ruido en el intervalo de tiempo al que eluian los analitos. Los LOD y LOQ se estimaron como 3 y 10 veces la relación señal/ruido, respectivamente. En todos los casos, los valores de LOD y LOQ que se obtuvieron fueron mejores cuando la detección se realiza con ESI-MS que con DAD-FLD, sin embargo esta última puede ser una buena alternativa para utilizarla en los casos que no se necesite una elevada sensibilidad. 


\section{VII.3.- Aplicación del método al análisis de muestras de hígado, músculo e intestino}

El Instituto Tecnológico de Castilla y León (ITACyL) nos proporcionó muestras de hígado, intestino y músculo de topillos, los cuales habian muerto desconociendo su causa. Fueron 30 muestras recolectadas por técnicos del ITACyL en provincias de Valladolid y Palencia.

Cada una de las muestras fue sometida al método de extracción que se propone para este tipo de matrices. No se encontraron residuos de DF ni de $\mathrm{BF}$ en concentraciones superiores a los límites de detección en ninguna de las muestras analizadas.

Sin embargo en algunas muestras se encontraron residuos de $\mathrm{CP}$ y $\mathrm{BD}$ a niveles de concentración muy inferiores a los valores de dosis letales $\left(\mathrm{LD}_{50}\right)$. Estos residuos se encontraron en hígado pero no en intestino ni en músculo y se detectaron con LC-ESI-MS debido a que el sistema LC-DADFLD no tiene sensibilidad suficiente. El hecho de encontrar residuos en el hígado está en concordancia con estudios previos en los que se establece que es el órgano donde se acumulan los anticoagulantes.

Las concentraciones de $\mathrm{BD}$ encontradas en tres de las muestras analizadas fueron de 10,15 y $25 \mu \mathrm{g} / \mathrm{kg}$ y las concentraciones de CP encontradas en cinco de las muestras fueron de 10, 15, 20, 30 y 45 $\mu \mathrm{g} / \mathrm{kg}$. En la Figura 36 se muestra el cromatograma obtenido por LC-ESIMS correspondiente a una de las muestras de hígado analizada con una concentración de $\mathrm{CP}$ de $30 \mu \mathrm{g} / \mathrm{kg}$. 


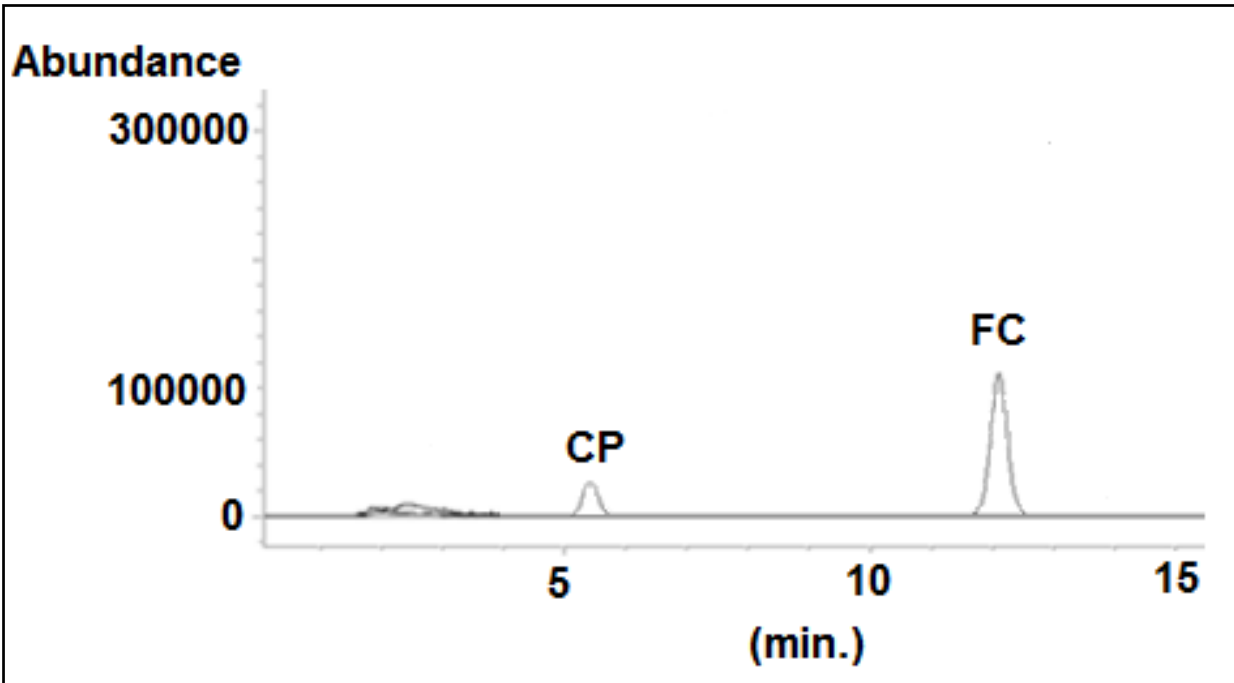

Figura 36: Cromatograma LC-ESI-MS (SIM) en modo negativo de una muestra de hígado, con el patrón interno FC en una concentración de $150 \mu \mathrm{g} / \mathrm{kg}$, en la que se detectó CP en una concentración de $30 \mu \mathrm{g} / \mathrm{kg}$

Hay que señalar que en ninguna de las muestras de hígado analizadas se detectaron a la vez los dos rodenticidas.

En definitiva, los residuos de rodenticidas detectados en alguna de las muestras analizadas son tan bajos que no parece que puedan afectar a otras especies animales. No obstante esto se debiera confirmar con posteriores análisis de un mayor número de muestras y a poder ser disponer de muestras recogidas después de la administración de estos compuestos. 


\section{VIII.- ANÁLISIS MULTIRRESIDUO DE 9 RODENTICIDAS}

EN MUESTRAS DE SUELO Y AGUA MEDIANTE HPLCFLD-DAD-MSD. 

Como ya se ha mencionado en esta memoria, las plagas de topillos aparecen en esta región de forma cíclica y para combatir la última plaga que fue muy intensa la Junta de Castilla y León no le quedó más remedio, como último recurso, que autorizar un intensivo tratamiento primero con clorofacinona y posteriormente con bromadiolona. Sin embargo, se observó que ciertos grupos de roedores eran capaces de resistir cantidades de estos compuestos muy superiores a la dosis letal. Este hecho indica la aparición de un fenómeno de resistencia lo que sugiere la necesidad de buscar otros compuestos alternativos para atacar futuras plagas, lo que justificó el plantearse ampliar el número de compuestos anticoagulantes, incorporando al estudio la warfarina (W), pindona (PD), difacinona (DP) y coumatetralilo $(\mathrm{CT})$, además de la $\mathrm{CP}, \mathrm{BD}, \mathrm{DF}, \mathrm{FC}$ y $\mathrm{BF}$.

Por tanto, el objetivo de este apartado fue desarrollar un método que fuera capaz de determinar nueve analitos en muestras de suelo y agua utilizando cromatografia de líquidos de alta resolución acoplado a los tres detectores (FLD, DAD, MSD), para posteriormente aplicarlo para realizar el análisis en muestras reales de agua y suelo.

\section{1.- Condiciones cromatográficas}

Las referencias bibliográficas consultadas, como ya se ha indicado, en su gran mayoria proponen como métodos para el análisis de anticoagulantes en distintas matrices el mecanismo de reparto en fase inversa, por lo que se pensó en utilizar la misma columna que en el resto del trabajo. Es de señalar el hecho que son muy pocos los trabajos en los que se aborda la separación y análisis de los 9 rodenticidas y ninguno en los que se aplique a aguas y suelos.

Inicialmente se utilizaron las condiciones cromatográficas establecidas para la separación de los 5 rodenticidas objeto de los anteriores apartados. 
Las soluciones patrón concentradas de los 9 rodenticidas se prepararon disolviendo aproximadamente $10 \mathrm{mg}$ de cada compuesto en $10 \mathrm{~mL}$ de metanol para obtener una concentración final de aproximadamente 1000 $\mathrm{mg} / \mathrm{L}$. Estas soluciones fueron después diluidas con metanol para preparar las soluciones de trabajo las cuales contenian todos los compuestos. Tanto las soluciones patrón concentradas como las de trabajo fueron almacenadas en viales topacio a $-20^{\circ} \mathrm{C}$ en la oscuridad para evitar su posible fotodegración. Los nuevos analitos incorporados al estudio, fueron estables en las condiciones indicadas, al menos durante un mes.

\section{VIII.1.1.- Condiciones para la detección}

En primer lugar fue necesario establecer las condiciones para realizar la detección de los 4 nuevos compuestos incorporados para los tres sistemas de detección.

Las pruebas se realizaron utilizando una columna Gemini $\mathrm{C}_{18}, 110 \AA$ $(150 \times 4.6 \mathrm{~mm}, 5 \mu \mathrm{m})$ y una fase móvil compuesta por metanol y formiato amónico $30 \mathrm{mM}$ a pH 6.5 en agua $(73: 27, \mathrm{v} / \mathrm{v})$, en régimen isocrático, con un flujo de fase móvil de $1 \mathrm{~mL} / \mathrm{min}$, salvo cuando se realizó el FIA para el MS donde no se empleó columna y el flujo fue de $0.3 \mathrm{~mL} / \mathrm{min}$, utilizando un volumen de inyección de $20 \mu \mathrm{L}$ y una temperatura de separación de $30^{\circ} \mathrm{C}$.

Es necesario señalar que los 4 nuevos rodenticidas incorporados en el estudio, no presentan fluorescencia por lo que su detección se realiza por DAD y MSD. 


\section{Absorción molecular}

Con las condiciones cromatográficas iniciales anteriormente indicadas e inyectando los patrones de $5 \mathrm{mg} / \mathrm{L}$ en metanol se obtuvo el espectro de absorción molecular en el intervalo de 200 a $400 \mathrm{~nm}$. Los espectros obtenidos se presentan en la siguiente Figura 37:

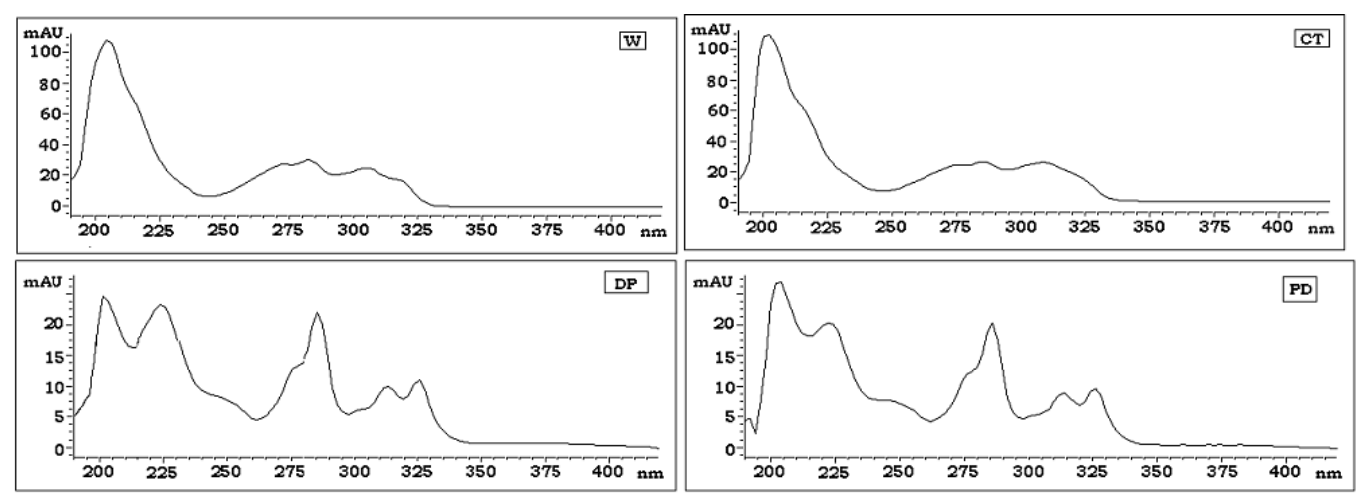

Figura 37: Espectros de absorción de los cuatro nuevos analitos de estudio.

A partir de los espectros de absorción que presentaban los analitos se seleccionó una longitud de onda de $285 \mathrm{~nm}$ para realizar su detección.

\section{Espectrometria de Masas}

Fue necesario establecer los parámetros del MSD para los 4 nuevos rodenticidas, para lo cual se siguió el mismo procedimiento que para los 5 compuestos iniciales y consistente en la realización de un FIA. Las condiciones más adecuadas para este tipo de detección se muestran, para los 9 analitos en la siguiente Tabla 46: 
Tabla 46: Parámetros para la detección por ESI-MS en modo negativo

\begin{tabular}{lc}
\hline \multicolumn{1}{c}{ Parámetro } & Valor \\
\hline Voltaje del fragmentador $(\mathrm{V})$ & $*$ \\
Voltaje del capilar $(\mathrm{V})$ & 3500 \\
Flujo gas secante $\left(\mathrm{N}_{2}, \mathrm{~mL} / \mathrm{min}\right)$ & 10 \\
Temperatura gas secante $\left(\mathrm{N}_{2},{ }^{\circ} \mathrm{C}\right)$ & 350 \\
Presión del nebulizador $(\mathrm{psig})$ & 50 \\
Ganancia & 10 \\
\hline
\end{tabular}

\begin{tabular}{lc}
\hline \multicolumn{1}{c}{ Compuesto } & *Voltaje del Fragmentador \\
\hline W, CT, DP, CP, & 180 \\
BD, DF & \\
PD & 140 \\
FC, BF & 220 \\
\hline
\end{tabular}

A continuación, en la siguiente Figura 38, se muestran los espectros de MS para los 4 anticoagulantes obtenidos con los parámetros indicados en la Tabla anterior

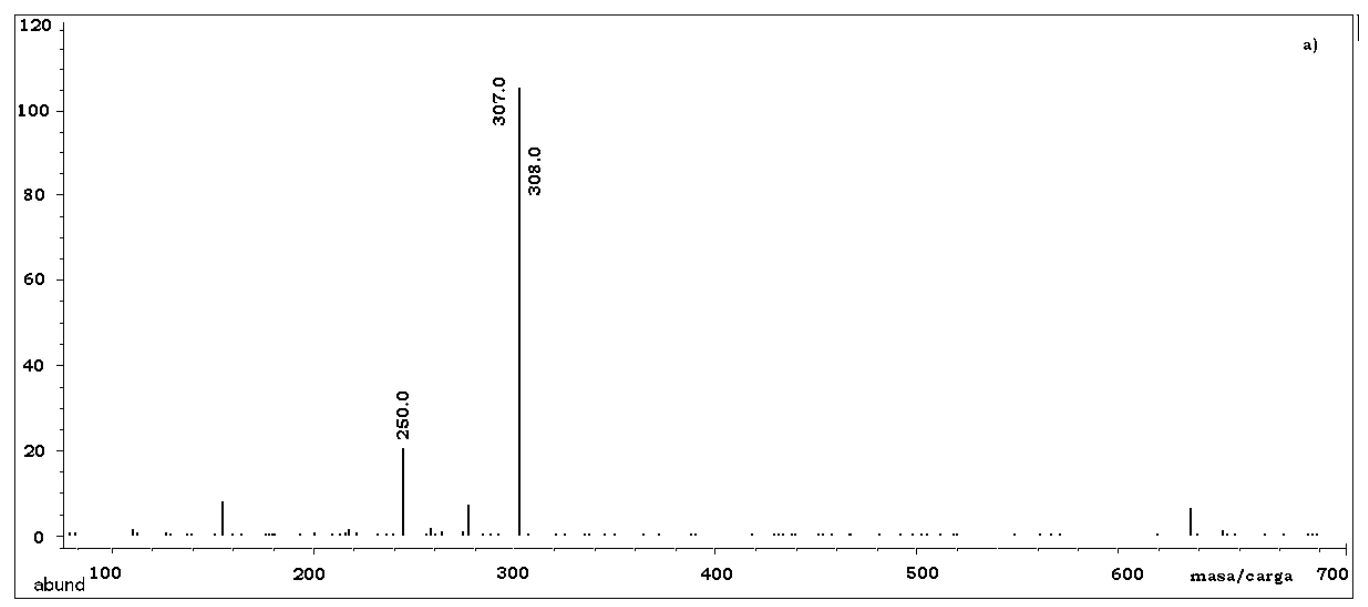



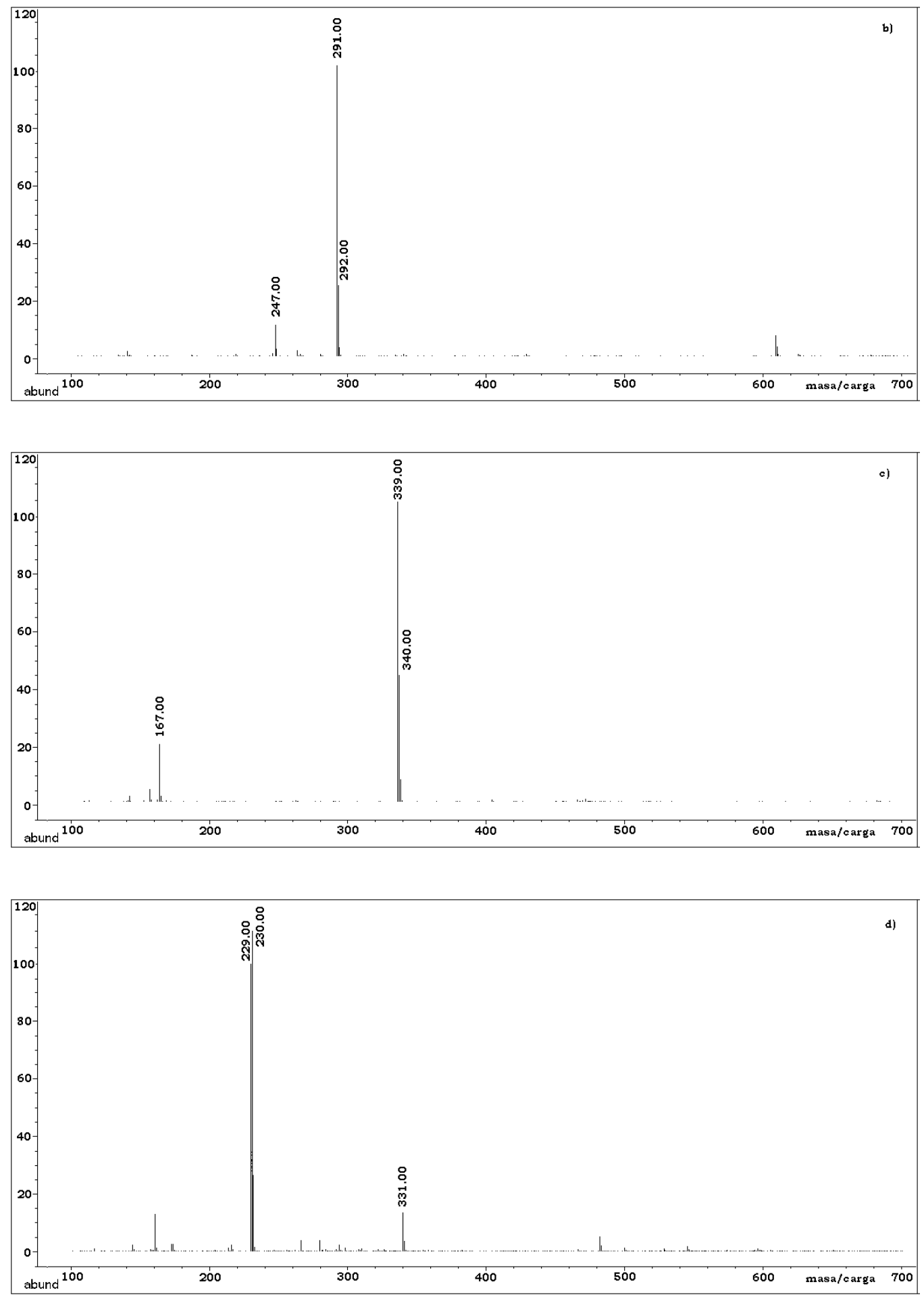

Figura 38: Espectros ESI-MS en modo negativo (SCAN) de a) Warfarina, b) Coumatetralil, c) Difacinona y d) Pindona. 
A la vista de los espectros de ESI- MS en modo negativo, se seleccionaron los iones para cuantificar en modo SIM, todos ellos correspondientes a los iones moleculares desprotonados $[\mathrm{M}-\mathrm{H}]-$, y los iones de confirmación para los compuestos, los cuales se muestran en la Tabla 47:

Tabla 47: Iones seleccionados para la cuantificación y confirmación para realizar la detección SIM por ESI-MS en modo negativo para cada rodenticida

\begin{tabular}{|c|c|c|}
\hline Compuesto & $\begin{array}{l}\text { Ion de cuantificación }{ }^{a} \\
(\mathrm{~m} / \mathrm{z})\end{array}$ & $\begin{array}{c}\text { Iones de confirmación } \\
(\mathrm{m} / \mathrm{z})\end{array}$ \\
\hline $\mathbf{W}$ & 307 & 250,308 \\
\hline CT & 291 & 292,247 \\
\hline DP & 339 & 340,167 \\
\hline PD & 230 & 229, 231 \\
\hline $\mathbf{C P}$ & 373 & 374,375 \\
\hline BD & 527 & 525,526 \\
\hline DF & 443 & 444,445 \\
\hline BF & 523 & 521,524 \\
\hline FC & 541 & 382,289 \\
\hline
\end{tabular}

a[M-H]- para todos los compuestos

\section{VIII.1.2.- Composición de la fase móvil}

Para comenzar con el estudio, se procedió a inyectar en el equipo cromatográfico en las condiciones anteriormente señaladas, $20 \mu \mathrm{L}$ de una solución patrón de cada nuevo analito individual en concentración de 5 $\mathrm{mg} / \mathrm{L}$. Los resultados que se obtuvieron mostraron que con la composición de fase móvil utilizada, los analitos incorporados eran poco retenidos, eluyendo los 4 a tiempos de retención inferiores a los 6 minutos y además la warfarina y coumatetralilo coeluian y tampoco se conseguía una buena separación de ellos con la pindona. Con el fin de aumentar la retención, se realizaron una serie de pruebas en las cuales se disminuía el porcentaje de metanol manteniendo el resto de las condiciones constantes. Los resultados que se obtuvieron se muestran en la siguiente Tabla 48: 
Tabla 48: Variación en los tiempos de retención para los compuestos con el porcentaje de metanol

\section{Tiempo de retención $(\min )$}

\begin{tabular}{ccccc}
\hline \% MeOH & W & CT & PD & DP \\
\hline $\mathbf{7 3}$ & 3.93 & 3.99 & 4.18 & 5.62 \\
$\mathbf{6 0}$ & 4.62 & 4.93 & 5.07 & 7.84 \\
$\mathbf{5 5}$ & 6.34 & 6.51 & 6.76 & 12.69 \\
\hline
\end{tabular}

De la observación de los datos de la Tabla 48 se deduce, como era de esperar, que al aumentar la polaridad de la fase móvil mediante la disminución del porcentaje de metanol se produce un aumento en la retención para los 4 compuestos, siendo este más acusado para la difacinona, no obstante la warfarina y el cumatetralilo siguen teniendo tiempos de retención muy próximos, aunque parece que la separación entre ellos aumenta a medida que disminuye el porcentaje del modificador orgánico. Se probó a disminuir más el porcentaje de metanol y además de no conseguir una separación adecuada entre ellos los otros 5 anticoagulantes presentaban retenciones muy elevadas.

Al no conseguirse mejorar la separación mediante ningún cambio en el porcentaje de modificador, se pensó en estudiar la influencia que el pH de la fase móvil ejercía sobre la retención de estos nuevos compuestos, variándose también, según los casos, el porcentaje de metanol, pero manteniendo constante la concentración de formiato amónico (30 mM) así como el flujo y temperatura de separación. Se realizaron una serie de experiencias en las cuales mediante la adición de ácido fórmico se modificaba el $\mathrm{pH}$ del formiato amónico $30 \mathrm{mM}$. Algunos de los resultados que se obtuvieron se recogen en la siguiente Tabla 49: 
Tabla 49: Variación de los tiempos de retención con el pH y porcentaje de modificador orgánico

Tiempo de retención (min)

\begin{tabular}{cccccc}
\hline $\mathbf{p H}$ & \% MeOH & $\mathbf{W}$ & $\mathbf{C T}$ & $\mathbf{P D}$ & $\mathbf{D P}$ \\
\hline \multirow{3}{*}{4.0} & 60 & 12.3 & 13.2 & - & - \\
& 70 & 10.9 & 12.2 & - & - \\
& 80 & 3.3 & 3.6 & 7.4 & 4.7 \\
\hline \multirow{3}{*}{3.0} & 60 & 12.4 & 18.3 & - & - \\
& 65 & 8.1 & 11.4 & - & - \\
& 70 & 5.5 & 7.5 & - & - \\
& 73 & 4.7 & 6.2 & - & - \\
\hline
\end{tabular}

Como se puede observar en los datos de la Tabla 49, a medida que disminuye el $\mathrm{pH}$ de la fase móvil aumenta la retención de forma significativa para todos los compuestos, mejorándose la separación entre la W y el CT y lográndose separaciones hasta línea de base, pero la retención para la $\mathrm{PD}$ y DP es excesiva ya que no se consiguen eluir a $\mathrm{pH} 4$ en un tiempo inferior a los 20 minutos y ni a los 25 minutos a $\mathrm{pH} 3$ incluso utilizando un $80 \%$ de metanol. También de los datos de la Tabla se deduce que se produce un cambio en la selectividad con el pH para la PD y DP, ya que al pH original de 6.5 eluía antes la PD que la DP cosa que se invierte a $\mathrm{pH} 4.0$.

También se realizaron experiencias utilizando como componente de la fase móvil formiato amónico $30 \mathrm{mM}$ llevado a $\mathrm{pH}$ básicos mediante la adición de amoniaco, observándose, en los cromatogramas que se obtuvieron, una pérdida de simetría acompañada de un ensanchamiento de los picos correspondientes a los compuestos por lo que se desestimó el trabajar a dichos $\mathrm{pH}$. 
Dado que a pH 3.0 se conseguía una buena separación entre warfarina y coumatetralilo y a $\mathrm{pH} 4.0$, con un porcentaje elevado de metanol, entre difacinona y pindona, se pensó en realizar un gradiente, tanto de $\mathrm{pH}$ como de modificador orgánico. Después de una serie de gradientes ensayados, el que proporcionó los mejores resultados, en cuanto a la resolución entre los compuestos, fue el que se muestra, a continuación, en la Tabla 50:

Tabla 50: Gradiente de pH y modificador orgánico.

\begin{tabular}{cccc}
\hline $\mathbf{t}_{\mathbf{r}}$ (min) & \%MeOH & pH 3.5 & pH 4.0 \\
\hline 0 & 65 & 35 & 0 \\
9.5 & 65 & 35 & 0 \\
10.0 & 70 & 0 & 30 \\
\hline
\end{tabular}

En la Figura 39 se muestra un cromatograma correspondiente a la inyección de una mezcla patrón de los 9 anticoagulantes en concentración de $5 \mathrm{mg} / \mathrm{L}$ con el gradiente anteriormente señalado.

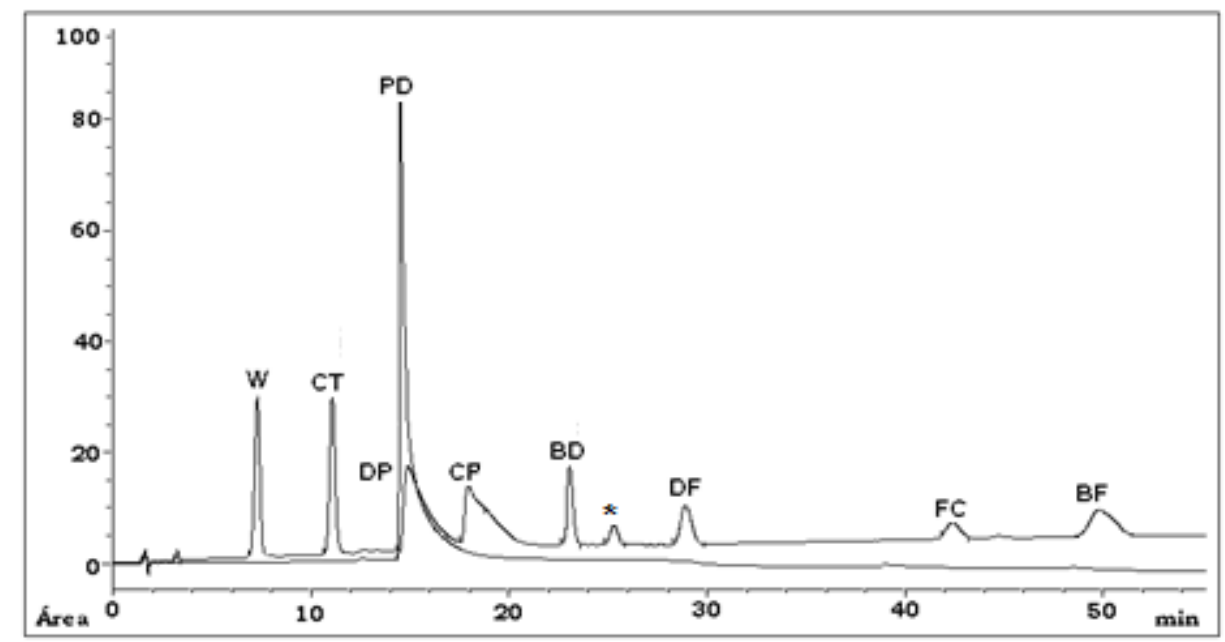

Figura 39: Cromatograma de un patrón de los 9 analitos en concentración $1.25 \mathrm{mg} / \mathrm{L}$ obtenido con el gradiente ensayado y DAD. $(*)$ isómero de la bromadiolona

Como se puede observar, con este gradiente se producía la coelución de pindona y difacinona, y los picos correspondientes a la difacinona y clorofacinona y en menor medida el de la pindona, presentaban una enorme cola. Por otra parte, el FC y BF con el porcentaje de modificador 
orgánico utilizado $(70 \%)$ eran excesivamente retenidos y además el tiempo entre la elución del DF y el FC era de más de 10 minutos. Por ello, se pensó en la necesidad de añadir algún aditivo a la fase móvil para mejorar la forma de los picos correspondientes a la DF, CP y PD y por otro lado aumentar el porcentaje de modificador orgánico, poco antes de la elución del DF.

En primer lugar se probó a utilizar como aditivo la trietilamina (TEA) ensayándose dos concentraciones 10 y $30 \mathrm{mM}$ adicionadas al formiato amónico, pero con ninguna de las concentraciones se logró ninguna mejora en la forma de los picos, por lo que se pensó en utilizar otro compuesto, en concreto se pensó en la di-n-butilamina (DBA), que había sido utilizada para mejorar la forma de los picos en algún trabajo encontrado en la revisión bibliográfica.

Se comenzó el estudio de este aditivo utilizando el gradiente, detallado en la Tabla 50, empleando distintas concentraciones con la finalidad de establecer el efecto que la concentración de este compuesto ejercía sobre la forma de los picos y si su presencia afectaba a la separación. Se probaron concentraciones de este compuesto, adicionado al formiato amónico, de 10, 20, 30 y $40 \mathrm{mM}$ variando también el $\mathrm{pH}$ del formiato, para cada concentración de este aditivo. Los $\mathrm{pH}$ estudiados fueron entre 3.0 y 6.5. El resultado de estas pruebas mostraron que la forma de los picos mejoraba para algunos compuestos con concentraciones $20 \mathrm{mM}$ de DBA mientras que para otros era más adecuada la $30 \mathrm{mM}$, y en cuanto al pH también resultaba crítico su valor pues de ello dependía lograr la resolución necesaria para poder realizar tanto la identificación como la cuantificación de los compuestos. En definitiva, se planteó que era necesario utilizar distintas concentraciones de DBA, $\mathrm{pH}$ y porcentajes de metanol dependiendo de los compuestos, lo que implicaba tener que establecer la composición de la fase móvil más adecuada para cada grupo de compuestos. 
Así, para la warfarina y el cumatetralilo se obtenía una buena resolución y forma de pico, con una composición de la fase móvil: $35 \%$ de formiato amónico $30 \mathrm{mM}(\mathrm{pH}$ 3.5) y $30 \mathrm{mM}$ en DBA/ 65\% de Metanol (v/v), mientras que para difacinona y pindona se obtenía separación hasta línea de base cuando el $\mathrm{pH}$ de la fracción acuosa de la fase móvil era de 4.4 y la forma de los picos mejoraba cuando se adicionaba al formiato DBA en concentración $20 \mathrm{mM}$, manteniendo el porcentaje de metanol constante en el $65 \%$. Sin embargo, la utilización de DBA como aditivo provocaba una deformación en la forma de los picos correspondientes a la bromadiolona, difenacum, flocumafen y brodifacum, posiblemente podria ser debida al inicio de la separación de los isómeros correspondientes a cada compuesto. Razón por la cual se optó por la eliminación de este aditivo en la fase móvil para la elución de estos compuestos y utilizar la misma composición de fase móvil que se había establecido para la separación de estos 5 analitos anteriormente en el trabajo.

En resumen, el gradiente que se propone para la separación de los 9 anticoagulantes se muestra en la Tabla 51, utilizando un flujo de fase móvil de $1 \mathrm{~mL} / \mathrm{min}$. 
Tabla 51:Programa del gradiente de elución para la separación de los 9 rodenticidas

\begin{tabular}{|c|c|c|c|c|}
\hline $\begin{array}{c}\text { Tiempo } \\
\text { (min) }\end{array}$ & $\begin{array}{c}\mathrm{NH}_{4} \mathrm{COO} 30 \mathrm{mM} \\
+ \\
\text { DBA } 30 \mathrm{mM}(\mathrm{pH} \\
3.5) \\
(\%)\end{array}$ & $\begin{array}{c}\mathrm{NH}_{4} \mathrm{COO} \\
30 \mathrm{mM}+ \\
\mathrm{DBA} 20 \mathrm{mM} \\
(\mathrm{pH} \mathrm{4.4)} \\
(\%)\end{array}$ & $\begin{array}{c}\mathrm{NH}_{4} \mathrm{COO} \\
30 \mathrm{mM} \\
(\mathrm{pH} 6.5) \\
(\%)\end{array}$ & $\begin{array}{c}\text { Metanol } \\
\text { (\%) }\end{array}$ \\
\hline 0.0 & 35 & 0 & 0 & 65 \\
\hline 6.0 & 35 & 0 & 0 & 65 \\
\hline 6.5 & 0 & 40 & 0 & 60 \\
\hline 9.0 & 0 & 45 & 0 & 55 \\
\hline 11.0 & 0 & 0 & 0 & 65 \\
\hline 14.0 & 0 & 0 & 35 & 70 \\
\hline 18.0 & 0 & 0 & 25 & 75 \\
\hline 20.0 & 0 & 0 & 25 & 75 \\
\hline 22.0 & 0 & 0 & 20 & 80 \\
\hline 26.0 & 0 & 0 & 20 & 80 \\
\hline 28.0 & 35 & 0 & 0 & 65 \\
\hline 33.0 & 35 & 0 & 0 & 0 \\
\hline
\end{tabular}

Se estudió la influencia que la temperatura de la columna y el volumen de inyección ejercian sobre la separación, para lo cual la temperatura se varió entre 25 y $50^{\circ} \mathrm{C}$ a intervalos de $5^{\circ} \mathrm{C}$ y el volumen de inyección entre 10 y $50 \mu \mathrm{L}$. Los mejores resultados en cuanto al tiempo de retención y relación señal/ruido $(\mathrm{S} / \mathrm{N})$ se obtuvieron con $25^{\circ} \mathrm{C}$ y $20 \mu \mathrm{L}$, respectivamente. Las condiciones cromatográficas que se proponen proporcionan picos estrechos y reproducibles, y permiten la separación de los 9 compuestos objeto de estudio en un tiempo inferior a los 30 minutos. Es de señalar, al igual que en los estudios anteriores, que el pico correspondiente al isómero de la $\mathrm{BD}$ aparece a un tiempo de retención próximo al del pico mayoritario del otro isómero.

En la siguiente Figura 40, se muestra el cromatograma correspondiente a la inyección de $20 \mu \mathrm{L}$ de una mezcla patrón de los 9 compuestos en concentración de $1.25 \mathrm{mg} / \mathrm{L}$. 


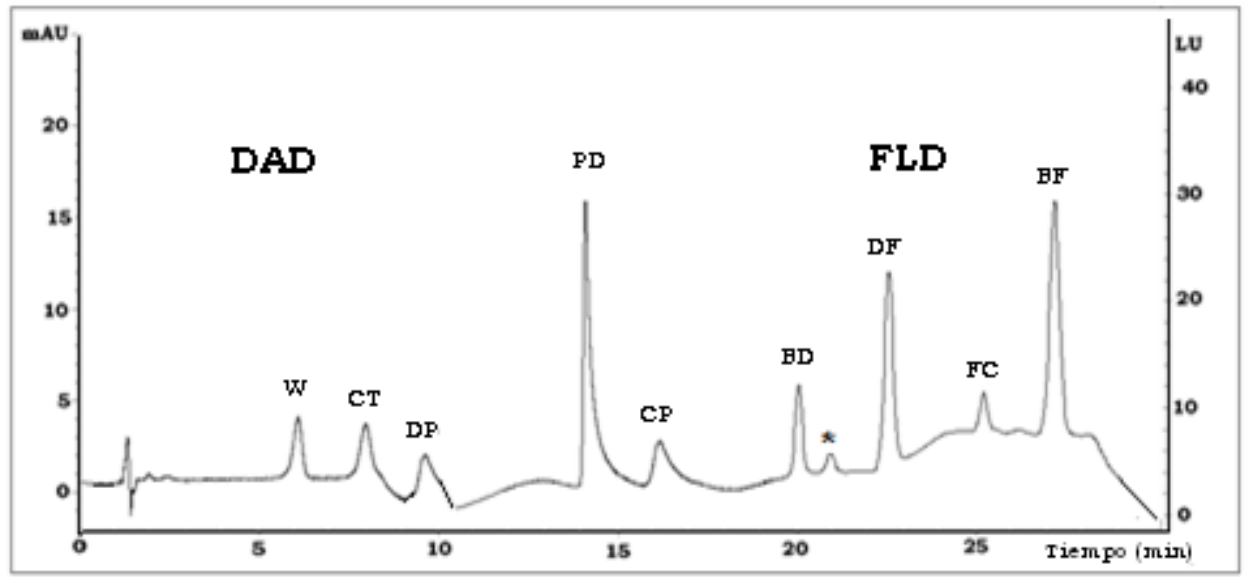

Figura.40: Cromatograma de una mezcla patrón de los nueve compuestos en concentración de 1.25 mg/1 obtenido con detección DAD-FLD.

\section{VIII.2.- Determinación de 9 rodenticidas en suelo}

Una vez establecidas las condiciones cromatográficas para la separación de los 9 rodenticidas, se abordó el desarrollo del método que permitiera su determinación en suelos. Para ello, inicialmente se pensó en utilizar el mismo procedimiento que el que se propone en este trabajo para extracción de los 4 anticoagulantes en la misma matriz. Para lo cual se pesaron 2 muestras de $1 \mathrm{~g}$; a una de las cuales se le adicionó $0.5 \mathrm{~mL}$ de una mezcla patrón de los nueve analitos en concentración conocida y a la otra muestra, que iba a actuar como blanco, $0.5 \mathrm{~mL}$ de metanol. A continuación, cada muestra fue trasvasada a tubos de centrífuga a los que se les añadió $15 \mathrm{~mL}$ de metanol y se agitaron mecánicamente durante 5 minutos, luego fueron centrifugadas otros 5 minutos a $9000 \mathrm{rpm}$, se decantó, se evaporó a sequedad en rotavapor a $40^{\circ} \mathrm{C}$ y los residuos secos se disolvieron en $1 \mathrm{~mL}$ de metanol. Por último, se filtraron con filtros de Nylon de $0,45 \mu \mathrm{m}$ en viales topacio, procediendo a inyectar $20 \mu \mathrm{L}$ de las muestras junto a un patrón de los 9 compuestos de la misma 
concentración que la adicionada en el cromatógrafo en las condiciones establecidas.

Los porcentajes de recuperación que se obtuvieron fueron bajos para los 4 nuevos compuestos, fundamentalmente para la difacinona y pindona con un $40 \%$ y un $50 \%$, respectivamente. Tratando de incrementar las recuperaciones se realizaron cambios empleando distintos volúmenes del extractante, así como se probaron extracciones sucesivas sin éxito en ninguno de los ensayos. En este punto se pensó en cambiar la naturaleza del extractante. Se realizaron una serie de pruebas con acetonitrilo en las cuales se obtuvo que además de no mejorar las recuperaciones, se producía una pérdida considerable en la simetría de los picos.

Se pensó en utilizar como extractante la propia fase móvil $(40 \%$ formiato

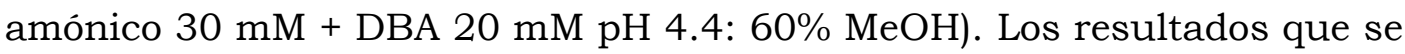
obtuvieron fueron prometedores ya que se observó un aumento en los porcentaje de recuperación, fundamentalmente para DP y PD, por lo que se probaron distintas proporciones de los componentes de la fase móvil. En la Tabla 52 se muestran los resultados obtenidos para los compuestos que presentaban recuperaciones más bajas.

Tabla 52: Porcentajes de recuperación en función de las distintas proporciones de extractante utilizado. A: Metanol. / B: Formiato amónico 30mM+DBA 20 mM pH 4.4.

\section{\% Recuperación}

\begin{tabular}{ccccc}
\hline Compuesto & $80 \% \mathrm{~A} / 20 \% \mathrm{~B}$ & $90 \% \mathrm{~A} / 10 \% \mathrm{~B}$ & $92 \% \mathrm{~A} / 8 \% \mathrm{~B}$ & $95 \% \mathrm{~A} / 5 \% \mathrm{~B}$ \\
\hline DP & 70 & 75 & 84 & 80 \\
PD & 43 & 72 & 79 & 75
\end{tabular}

Como se puede observar los mejores porcentajes de recuperación para ambos analitos se obtienen con una proporción de $92 \%$ de metanol y $8 \%$ de formiato $30 \mathrm{mM}+$ DBA $20 \mathrm{mM} \mathrm{pH}$ 4.4. Puesto que la presencia del DBA como aditivo en la fase móvil se debió a la necesidad de eliminar en lo más posible la cola de los picos correspondiente a la DP, PD y CP, se planteó 
en este momento si era necesaria su presencia en la solución a emplear como extractante. Para comprobarlo, se realizó una prueba utilizando como extractante la mezcla de metanol: formiato amónico $30 \mathrm{mM} \mathrm{pH} 4.4$ (92\%:8\%, v/v), comprobándose que los porcentajes de recuperación se mantenían, por los que no era necesario su uso en la mezcla extractante. Como los porcentajes de recuperación eran buenos para los 9 analitos se seleccionó esta mezcla para aislarlos y concentrarlos de las muestras de suelo.

Una vez establecida la mezcla extractante, el siguiente estudio que se realizó tuvo como finalidad establecer el volumen a emplear de la misma. Para ello, se realizaron una serie de experiencias en las que a la muestra adicionada y sin adicionar se le añadieron diferentes volúmenes de la mezcla seleccionada comprendidos entre 5 y $25 \mathrm{~mL}$. De los resultados que se obtuvieron permitieron establecer como volumen más adecuado el de $15 \mathrm{~mL}$, ya que con este volumen se obtuvieron los mayores porcentajes de recuperación, mientras que la utilización de volúmenes superiores no conducía a incrementarlos.

Por último, se realizó el estudio para establecer el volumen de metanol necesario para la solubilización del residuo seco. Se realizaron una serie análisis en las que se variaba dicho volumen entre 0,5 y $2 \mathrm{~mL}$. De los análisis realizados se pudo deducir que la utilización de $1 \mathrm{~mL}$ era lo más adecuado, pues era el volumen que permitía obtener los mejores resultados en términos de recuperaciones y sensibilidad.

El tratamiento de muestra que se propone para la determinación de 9 anticoagulantes en suelos se resume en el siguiente esquema (Figura 41): 


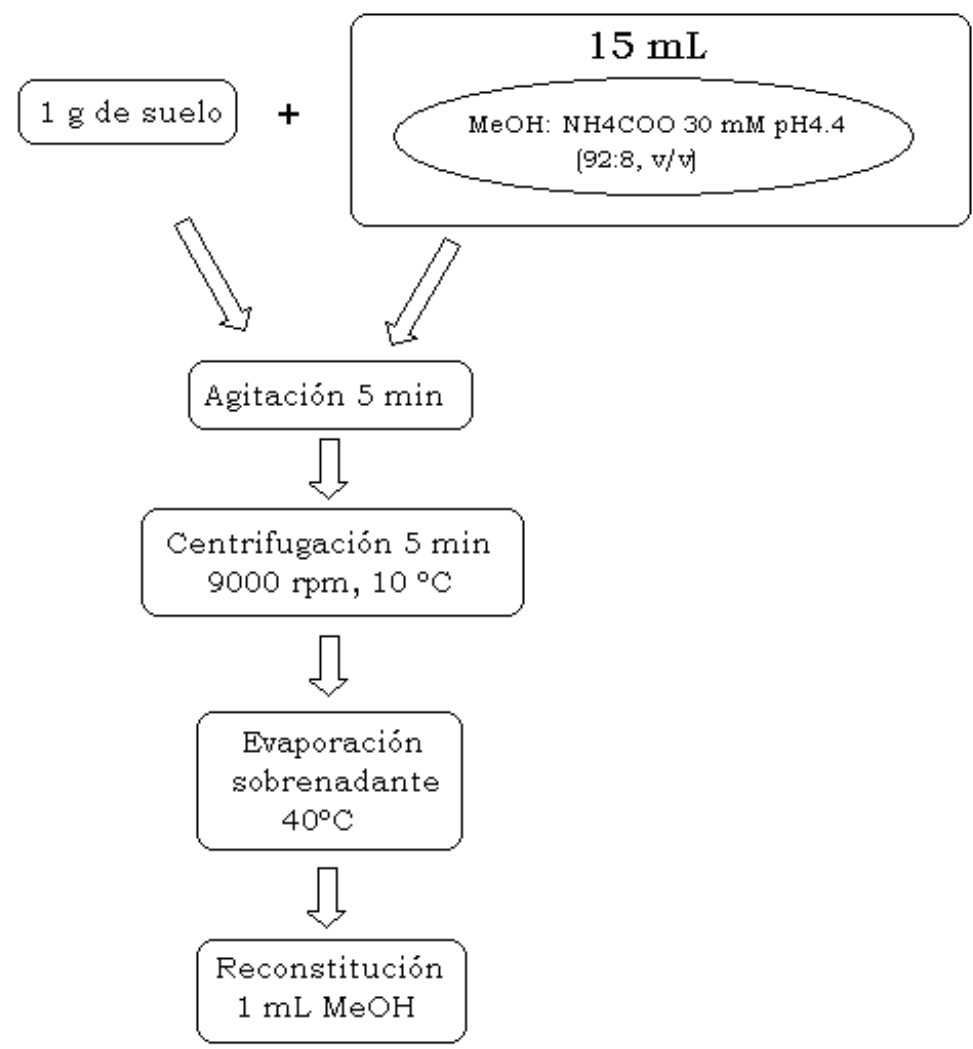

Figura 41: Esquema del tratamiento de muestra.

A continuación, en la Figura 42 se muestran los cromatogramas superpuestos correspondientes a la inyección de $20 \mu \mathrm{L}$ de un blanco y una muestra a la que se adicionó una mezcla patrón de los 9 compuestos en concentración conocida, en las condiciones cromatográficas establecidas en el equipo LC- DAD- FLD; y en la Figura 43, los cromatogramas correspondientes a la inyección de las mismas muestras en el equipo LCESI-MS en modo negativo. 


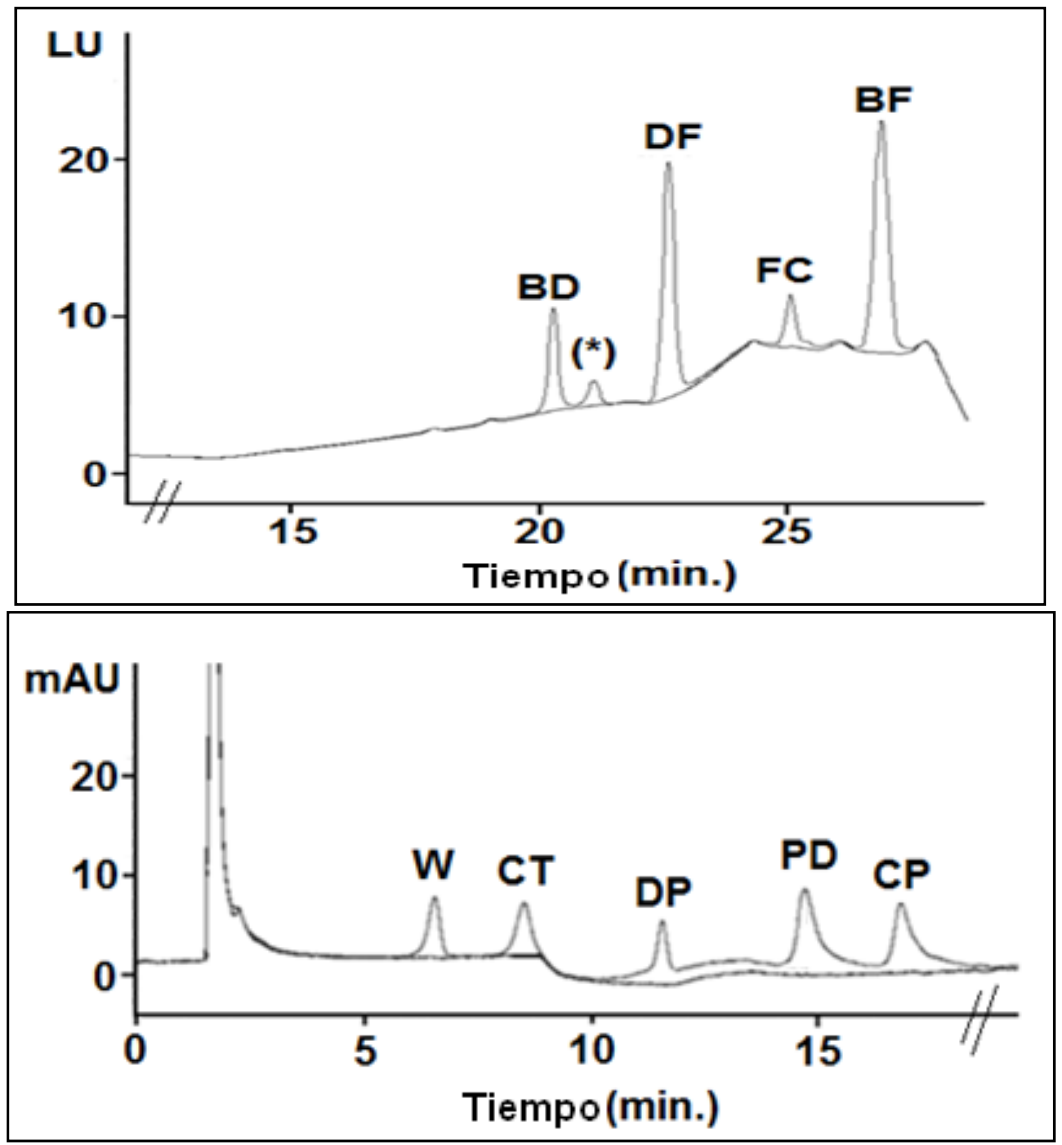

Figura 42: Cromatogramas superpuestos correspondientes a un blanco y una muestra a la que se le adicionaron los nueve analitos, con el equipo LC- FLD- DAD. 


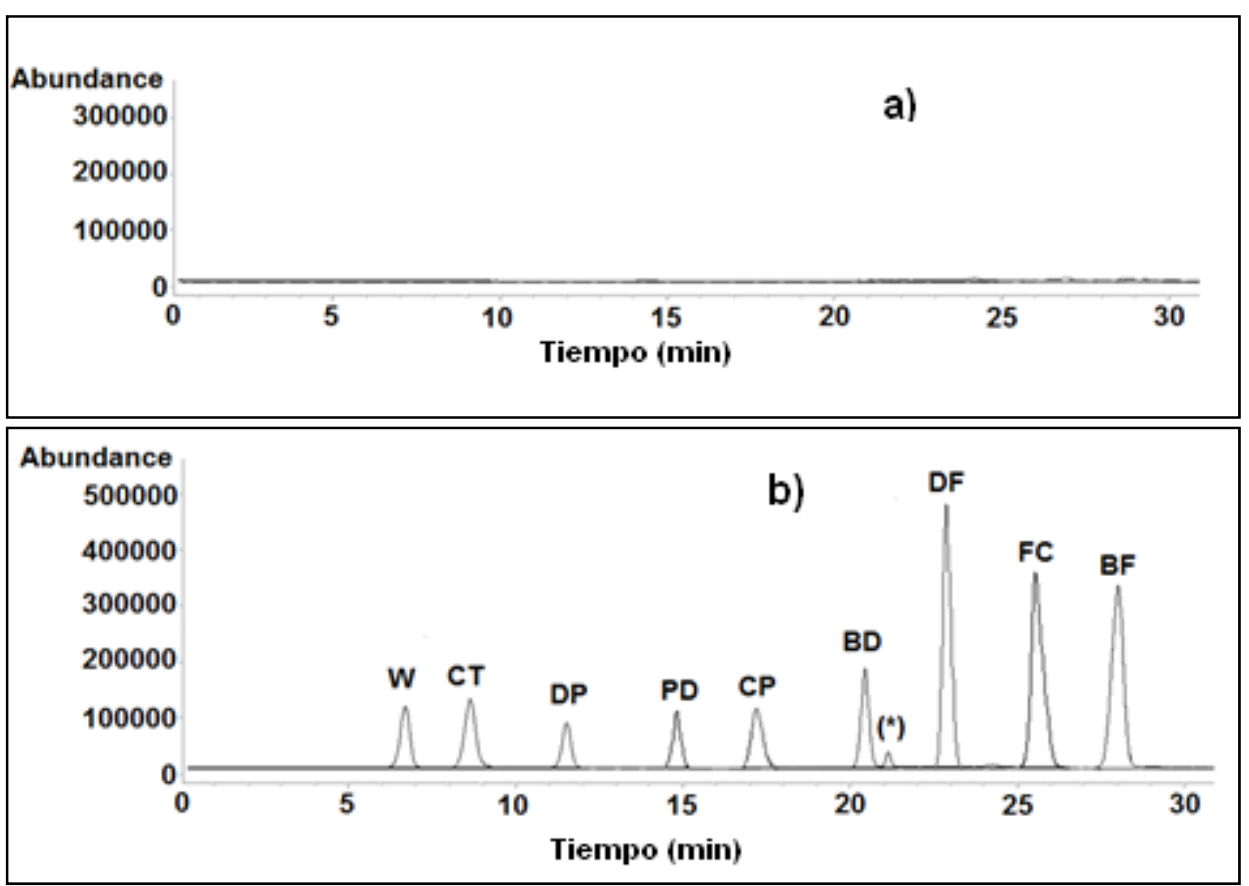

Figura 43: Cromatogramas correspondientes a ) un blanco y b) una muestra a la que se le adicionaron los nueve analitos, con el equipo LC- ESI-MS en modo negativo (SIM).

Como se puede ver en las Figuras anteriores, los picos correspondientes a todos los compuestos se encuentran separados hasta línea de base, no existiendo ninguna interferencia proveniente de la matriz que impidiera su correcto análisis.

La eficacia y recuperación del tratamiento de muestra para los rodenticidas estudiados se determinó por sextuplicado a tres niveles de concentración (bajo, medio y alto), comparando las áreas de los picos de los compuestos obtenidos en los blancos de suelo a los que se adicionó una concentración conocida de los compuestos y que posteriormente se trataron según el procedimiento que se propone, con las áreas de los picos que se obtuvieron cuando las muestras blanco de suelo se sometieron al tratamiento y en la etapa de solubilización del residuo seco se le adicionó la misma concentración de los compuestos. Los porcentajes de recuperación que se obtuvieron se muestran en la Tabla 53: 
Tabla 53:Porcentajes de recuperación obtenidos para blancos de suelo a los que se adicionó los la mezcla patrón antes y después de ser tratados según el procedimiento desarrollado $(n=6)$

\begin{tabular}{|c|c|c|c|}
\hline \multirow[t]{2}{*}{ Compuesto } & \multirow[t]{2}{*}{$\begin{array}{l}\text { Concentración } \\
\text { ( } \mu \mathrm{g} / \mathrm{kg}, \text { suelo) }\end{array}$} & $\begin{array}{c}\text { Evaluación del } \\
\text { tratamiento de } \\
\text { muestra }\end{array}$ & $\begin{array}{l}\text { Evaluación del } \\
\text { efecto matriz }\end{array}$ \\
\hline & & $\begin{array}{c}\text { Media (\%) } \pm \\
\text { RSD (\%) }\end{array}$ & $\begin{array}{c}\text { Media (\%) } \pm \text { RSD } \\
(\%)\end{array}$ \\
\hline \multirow{3}{*}{$\mathbf{W}$} & 3 & $90 \pm 5$ & $83 \pm 6$ \\
\hline & 250 & $92 \pm 5$ & $81 \pm 5$ \\
\hline & 1000 & $91 \pm 4$ & $82 \pm 5$ \\
\hline \multirow{3}{*}{ CT } & 3 & $92 \pm 4$ & $78 \pm 5$ \\
\hline & 250 & $91 \pm 4$ & $75 \pm 6$ \\
\hline & 1000 & $93 \pm 5$ & $74 \pm 6$ \\
\hline \multirow{3}{*}{ DP } & 3 & $93 \pm 5$ & $69 \pm 5$ \\
\hline & 250 & $90 \pm 5$ & $66 \pm 6$ \\
\hline & 1000 & $91 \pm 5$ & $67 \pm 5$ \\
\hline \multirow{3}{*}{ PD } & 3 & $92 \pm 5$ & $70 \pm 5$ \\
\hline & 250 & $90 \pm 5$ & $68 \pm 6$ \\
\hline & 1000 & $93 \pm 5$ & $72 \pm 5$ \\
\hline \multirow{3}{*}{$\mathbf{C P}$} & 3 & $92 \pm 5$ & $68 \pm 5$ \\
\hline & 250 & $94 \pm 5$ & $70 \pm 6$ \\
\hline & 1000 & $93 \pm 5$ & $71 \pm 5$ \\
\hline \multirow{3}{*}{ BD } & 2 & $90 \pm 6$ & $82 \pm 6$ \\
\hline & 250 & $92 \pm 5$ & $84 \pm 5$ \\
\hline & 1000 & $92 \pm 6$ & $81 \pm 5$ \\
\hline \multirow{3}{*}{ DF } & 0.7 & $97 \pm 6$ & $84 \pm 6$ \\
\hline & 250 & $99 \pm 5$ & $83 \pm 5$ \\
\hline & 1000 & $100 \pm 6$ & $80 \pm 5$ \\
\hline \multirow{3}{*}{ FC } & 0.7 & $95 \pm 5$ & $84 \pm 6$ \\
\hline & 250 & $93 \pm 5$ & $82 \pm 5$ \\
\hline & 1000 & $96 \pm 4$ & $83 \pm 5$ \\
\hline \multirow{3}{*}{ BF } & 0.7 & $95 \pm 6$ & $80 \pm 6$ \\
\hline & 250 & $97 \pm 6$ & $81 \pm 6$ \\
\hline & 1000 & $97 \pm 6$ & $84 \pm 6$ \\
\hline
\end{tabular}

Como se puede ver en los datos de la Tabla 53, los porcentajes de recuperación para todos los compuestos y niveles de concentración se encuentran en un intervalo entre el 90 y el 100\%, indicando estos valores que el tratamiento de muestra que se propone es adecuado. Por otra parte, cuando se comparó el área de los picos de los compuestos en metanol con el área de las muestras blanco tratadas y reconstituidas con la mezcla patrón en metanol, se pudo comprobar la existencia de un efecto matriz que provocaba una disminución en la señal para todos los compuestos debido a la influencia de la misma en la ionización por ESI, 


\section{VIII.2.1.- Validación del método}

La validación del método se realizó, como en todos los apartados de esta memoria, en términos de selectividad, limites de detección y cuantificación, linealidad, precisión y exactitud. En la memoria se presentan únicamente los datos de la validación del método para el sistema LC-ESI-MS debido a que proporciona mayor sensibilidad.

\section{Selectividad}

Para evaluar la selectividad del método, se inyectaron en el sistema cromatográfico los extractos de blancos de suelos y muestras de suelo a las que se había adicionado una concentración conocida de los 9 anticoagulantes, tratados según el método que se propone. En los cromatogramas que se obtuvieron y que se muestran en las Figuras 42 y 43, es evidente la ausencia de interferencias, para los sistemas de detección utilizados, lo que demuestra la selectividad del mismo.

\section{Limites de determinación y de cuantificación}

Los Límites de detección (LOD) y de cuantificación (LOQ) se determinaron de forma experimental inyectando extractos de blancos de suelo $(n=6)$ y midiendo la señal correspondiente al ruido, estableciéndose los límites para las concentraciones que proporcionaban una señal de 3 y 10 veces superiores al ruido respectivamente. En la Tabla 53 se muestran los valores que se obtuvieron.

\section{Linealidad}

Debido a que en las muestras de suelo se observó un efecto matriz acusado fue necesario para realizar la correcta cuantificación de los 9 compuestos realizar una calibración en matriz, para lo cual muestras blanco de suelo se trataron según el método desarrollado, y se les adicionó cantidades variables de los rodenticidas objeto de estudio, dentro del 
intervalo comprendido entre LOQ y $1000 \mu \mathrm{g} / \mathrm{kg}$, en el mL que se utiliza para reconstituir el residuo seco después de concentrar a sequedad. Las líneas de calibrado se realizaron representando el área del pico frente a la concentración con un peso de $1 / x$ del modelo de regresión lineal. La linearidad se evaluó de forma visual observando las curvas de calibrado y calculando la ecuación de regresión y el coeficiente de correlación, que en todos los casos es mayor de 0.99, como se observar en la Tabla 53.

\section{Exactitud y precisión}

Para evaluar la exactitud y la precisión, expresadas en \% de error relativo (\%RE) y \% de desviación estándar relativa (\%RSD) respectivamente, en el día se realizaron análisis repetidos $(n=6)$ de extractos blancos de suelo sometidos al tratamiento y reconstituyendo el residuo con $1 \mathrm{~mL}$ de solución patrón de concentración conocida, empleándose 3 niveles de concentración, en el mismo día; y para determinar la exactitud y precisión intermedia se hicieron los mismos análisis pero en tres días consecutivos. Los resultados que se obtuvieron y que se detallan en la Tabla 54 para el nivel intermedio de concentración y la detección por ESI-MS, se encontraron por debajo del $8 \%$ para la precisión en y intermedia, para todos los sistemas de detección. Los valores obtenidos tanto para la exactitud como la precisión se detallan en la Tabla 54, donde para un nivel de concentración intermedio los valores variaban entre el 2 y $8 \%$ para todos los compuestos en el día y entre 3\% y 8\% para la exactitud entre días. Estos resultados permiten establecer que el método desarrollado para el análisis de 9 rodenticidas es preciso y exacto. 


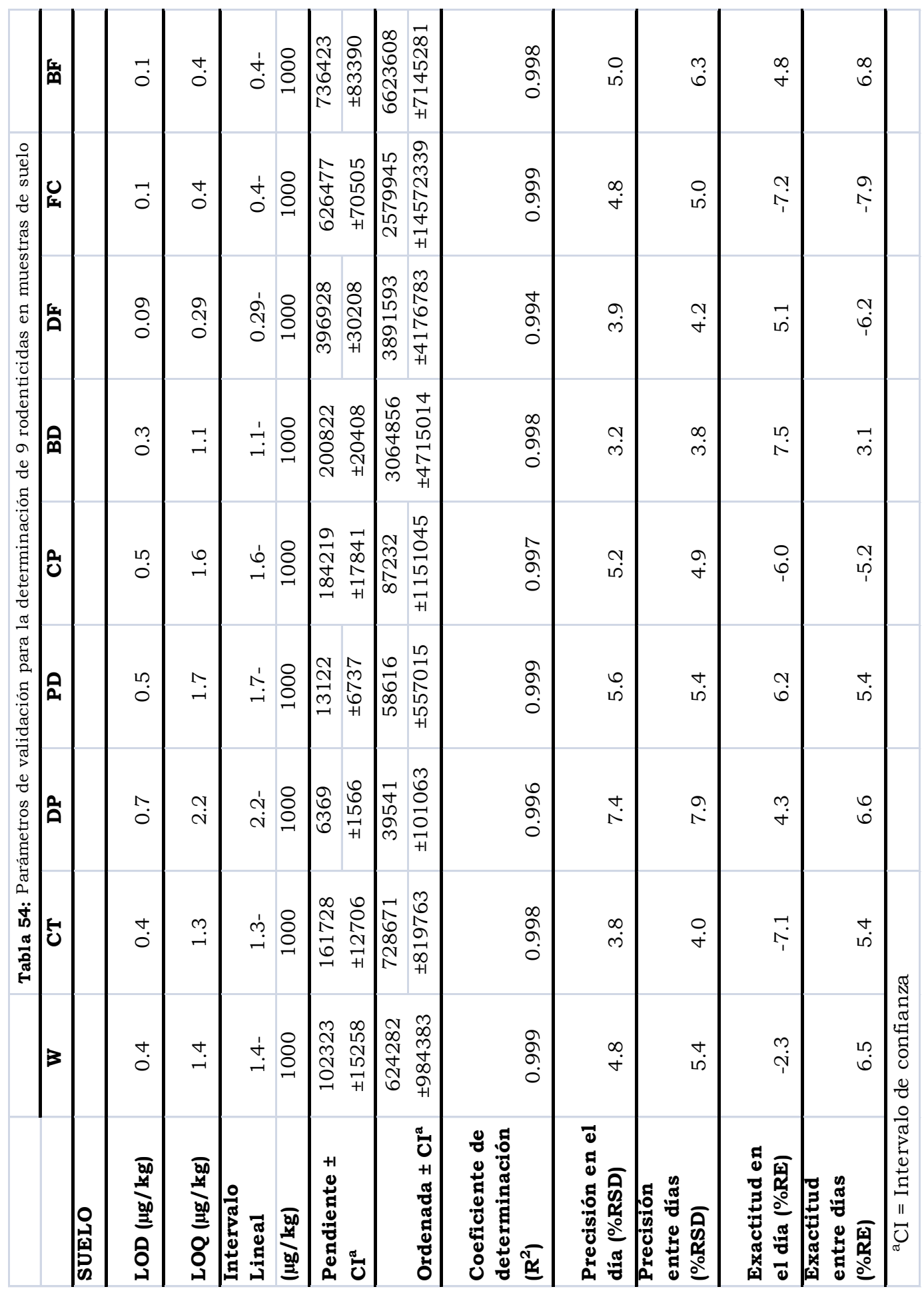




\section{VIII.2.2.- Aplicación del método al análisis de muestras de suelo}

Se aplicó el método a las 134 muestras de suelo proporcionadas por el ITACyL, y que ya habían sido analizadas por el método desarrollado para 4 rodenticidas $(\mathrm{CP}, \mathrm{BD}, \mathrm{DF} \mathrm{y} \mathrm{BF})$, no encontrando en ninguna de las muestras concentraciones superiores al LOD de los nuevos anticoagulantes incorporados. $\mathrm{Y}$ obviamente se obtuvieron los mismos resultados para las muestras en las que se habia detectado residuos de BD y CP.

\section{VIII.3.- Determinación de 9 rodenticidas en agua}

Una vez establecidas las condiciones cromatográficas para la separación de los 9 anticoagulantes con buena resolución, se pensó en desarrollar un método que permitiera la determinación de los 9 compuestos en agua. En un principio se aplicó el método desarrollado para realizar el análisis de los 4 rodenticidas $(\mathrm{CP}, \mathrm{BD}, \mathrm{DF} \mathrm{y} \mathrm{BF})$ en esta matriz, y descrito anteriormente en esta memoria, tomando inicialmente un volumen de 100 $\mathrm{mL}$ de agua.

Los resultados que se obtuvieron mostraron recuperaciones elevadas para la mayoría de los compuestos excepto para la DP que eran bajas, aproximadamente del $20 \%$.

Tratando de aumentar la recuperación de este compuesto se realizaron distintos ensayos en los que se adicionaron distintos reactivos utilizando siempre como disolvente extractante el acetato de etilo. Se probó la adición de la composición de la fase móvil a la cual se producía la elución de la DP con resultados negativos. Posteriormente, se adicionó ácido fórmico al $10 \%$ al acetato de etilo y aunque se obtuvieron recuperaciones elevadas para todos los compuestos, los resultados no eran reproducibles. Este problema era probablemente debido a que al no ser totalmente 
miscibles, cada vez se tenía una composición distinta del extractante. Se realizaron distintos ensayos consistentes en añadir el ácido fórmico al agua en distintas concentraciones con resultados no adecuados, ya que aunque las recuperaciones para los compuestos fluorescentes (BD, DF, FC y BF) eran adecuadas, de los compuestos absorbentes (W, CT, DP, PD y $\mathrm{CP})$ prácticamente no se recuperaba nada.

Los mejores resultados se obtuvieron cuando al agua llevada a un $\mathrm{pH}$ cercano a 10 se le añadía el ácido fórmico y posteriormente se realizaba la extracción con acetato de etilo.

Se realizaron distintos ensayos para establecer, en primer lugar, el volumen de ácido fórmico al 10\% que se debía añadir, para lo cual se varió entre 1 y $5 \mathrm{~mL}$. Las mayores recuperaciones se obtuvieron con la adición de $2 \mathrm{~mL}$ y la utilización de volúmenes mayores no las mejoraba, por lo que se seleccionó este volumen.

Se estudió también la influencia que ejercía el volumen de extractante en un intervalo entre 15 y $30 \mathrm{~mL}$, seleccionando un volumen de $25 \mathrm{~mL}$ ya que volúmenes superiores no mejoraban la eficacia de la extracción.

Se comprobó, que como en el método desarrollado para la determinación de 4 anticoagulantes, 10 minutos de agitación mecánica era el tiempo adecuado y que con $1 \mathrm{~mL}$ de metanol se disolvía completamente el extracto seco.

Por lo tanto el tratamiento de muestra que se propone aparece detallado en la siguiente Figura 44. 


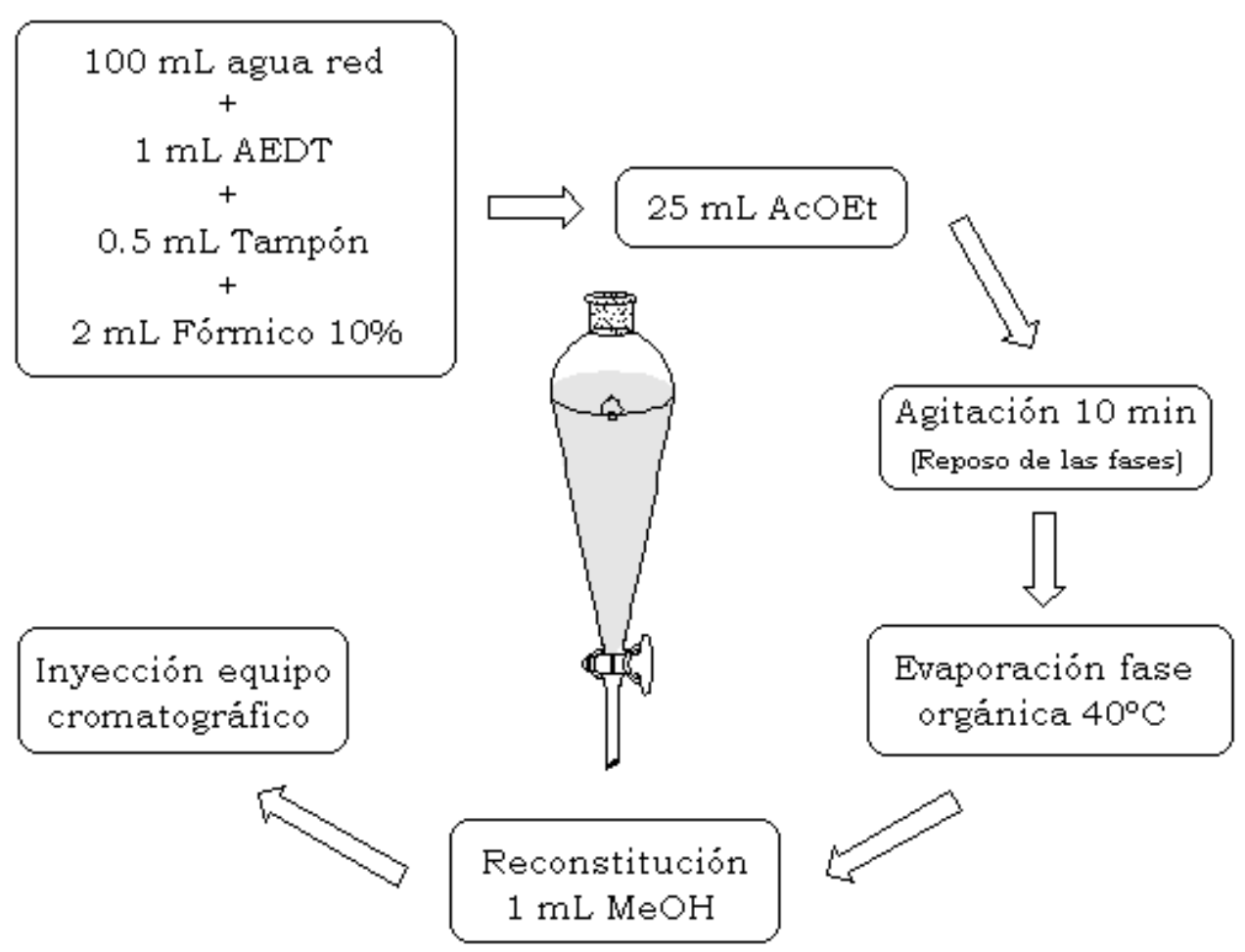

Figura 44: Esquema del tratamiento de muestra realizado.

En la Figura 45 se muestra los cromatogramas de un blanco y de una muestra de agua a la que se añadió una concentración de los 9 compuestos de $625 \mu \mathrm{g} / \mathrm{L}$ para la detección DAD-FLD y de $250 \mu \mathrm{g} / \mathrm{L}$ para ESI-MS modo SIM, ambas sometidas al tratamiento desarrollado.

En la Tabla 55 se detallan los porcentajes de recuperación obtenidos, los cuales se determinaron por sextuplicado a tres niveles de concentración (bajo, medio y alto), de la misma manera que en suelo. 

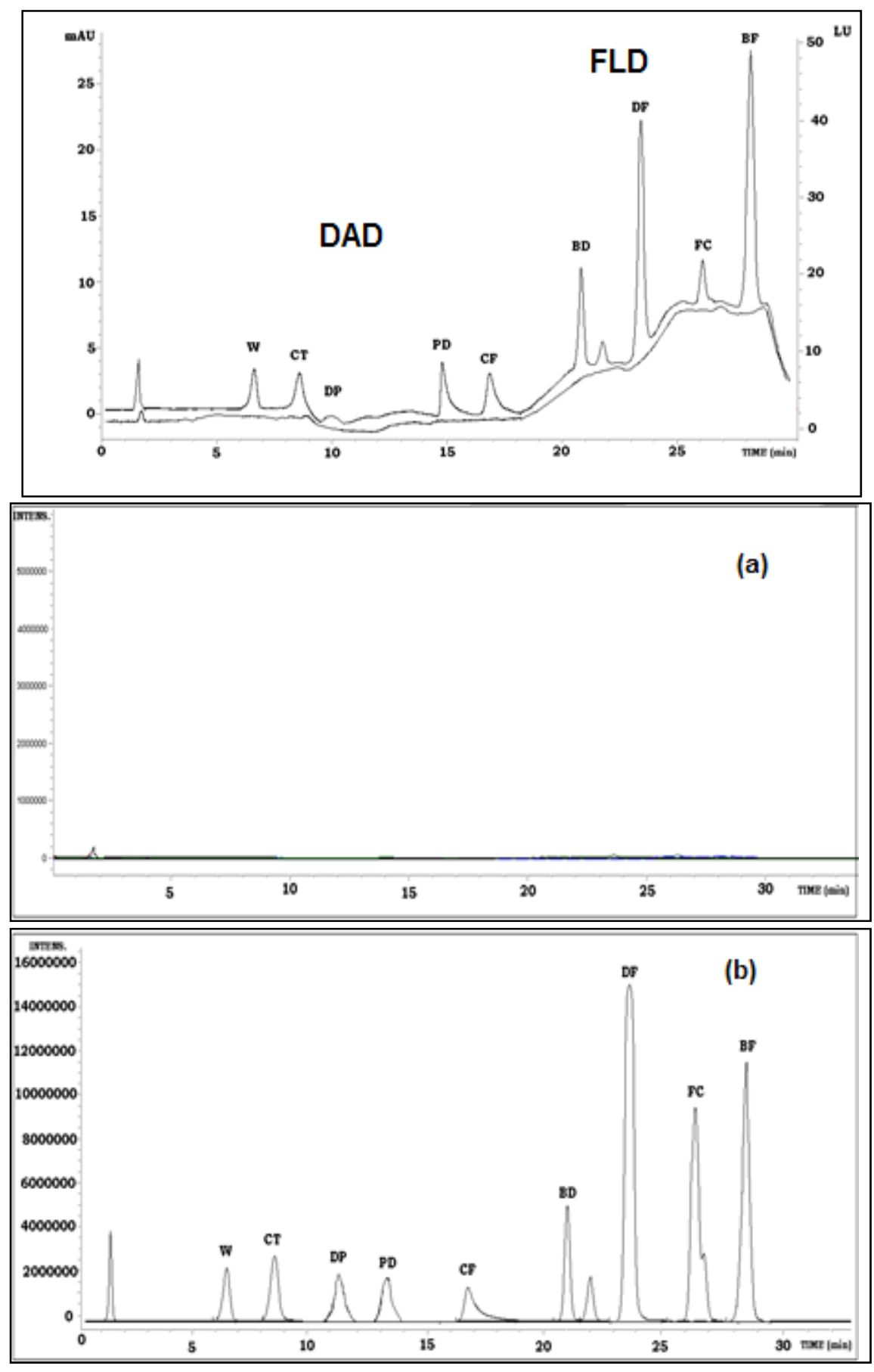

Figura 45: Cromatogramas superpuestos de un blanco de agua y muestra adicionada, tratadas, obtenidos con LC-DAD-FLC. Cromatogramas de blanco (a) y muestra adicionada tratadas (b), obtenidos con el sistema LC-ESI.MS en modo SIM. 
Tabla 55: Porcentajes de recuperación obtenidos para blancos de agua adicionados y después de ser tratados según el procedimiento desarrollado $(n=6)$

\begin{tabular}{|c|c|c|c|}
\hline \multirow[t]{2}{*}{ Compuesto } & \multirow[t]{2}{*}{$\begin{array}{c}\text { Concentración } \\
\text { ( } \mu \mathrm{g} / \mathrm{L}, \text { agua) }\end{array}$} & \multirow{2}{*}{$\begin{array}{c}\begin{array}{c}\text { Evaluación del } \\
\text { tratamiento de } \\
\text { muestra }\end{array} \\
\begin{array}{c}\text { Media }(\%) \pm \text { RSD } \\
(\%)\end{array} \\
\end{array}$} & \multirow{2}{*}{$\begin{array}{l}\begin{array}{l}\text { Evaluación del } \\
\text { efecto matriz }\end{array} \\
\begin{array}{l}\text { Media (\%) } \pm \text { RSD } \\
(\%)\end{array} \\
\end{array}$} \\
\hline & & & \\
\hline \multirow{3}{*}{$\mathbf{W}$} & 3 & $92 \pm 4$ & $95 \pm 5$ \\
\hline & 250 & $94 \pm 5$ & $97 \pm 6$ \\
\hline & 1000 & $96 \pm 5$ & $99 \pm 5$ \\
\hline \multirow{3}{*}{ CT } & 3 & $97 \pm 5$ & $92 \pm 5$ \\
\hline & 250 & $95 \pm 4$ & $98 \pm 5$ \\
\hline & 1000 & $99 \pm 5$ & $93 \pm 5$ \\
\hline \multirow{3}{*}{ DP } & 3 & $99 \pm 4$ & $103 \pm 5$ \\
\hline & 250 & $101 \pm 5$ & $101 \pm 6$ \\
\hline & 1000 & $98 \pm 5$ & $105 \pm 4$ \\
\hline \multirow{6}{*}{ PD } & 3 & $97 \pm 4$ & $100 \pm 5$ \\
\hline & 250 & $98 \pm 5$ & $102 \pm 6$ \\
\hline & 1000 & $100 \pm 5$ & $106 \pm 4$ \\
\hline & 3 & $95 \pm 4$ & $100 \pm 5$ \\
\hline & 250 & $98 \pm 5$ & $99 \pm 6$ \\
\hline & 1000 & $99 \pm 5$ & $102 \pm 4$ \\
\hline \multirow{3}{*}{ BD } & 2 & $95 \pm 6$ & $98 \pm 5$ \\
\hline & 250 & $97 \pm 5$ & $96 \pm 5$ \\
\hline & 1000 & $96 \pm 5$ & $97 \pm 6$ \\
\hline \multirow{3}{*}{ DF } & 0.7 & $99 \pm 6$ & $97 \pm 5$ \\
\hline & 250 & $101 \pm 5$ & $100 \pm 5$ \\
\hline & 1000 & $102 \pm 5$ & $98 \pm 6$ \\
\hline \multirow{3}{*}{ FC } & 0.7 & $102 \pm 4$ & $99 \pm 5$ \\
\hline & 250 & $100 \pm 5$ & $100 \pm 6$ \\
\hline & 1000 & $104 \pm 5$ & $101 \pm 5$ \\
\hline \multirow{3}{*}{ BF } & 0.7 & $99 \pm 6$ & $97 \pm 5$ \\
\hline & 250 & $102 \pm 5$ & $95 \pm 6$ \\
\hline & 1000 & $100 \pm 6$ & $97 \pm 5$ \\
\hline
\end{tabular}

Los datos de la Tabla muestran que los porcentajes de recuperación para todos los compuestos y niveles de concentración se encuentran en un intervalo entre el 92 y el 104\%, lo que indica que el tratamiento de muestra que se propone es adecuado. En este caso no se observó la existencia de efecto matriz, ya que se obtienen el mismo orden de recuperación para las muestras blanco a las que se adicionó antes del tratamiento la mezcla patrón, comparándolas con los extractos de los blancos que se reconstituyeron con la mezcla patrón. 


\section{VIII.3.1.- Validación de la metodología analítica}

Se realizó la validación del método de forma totalmente análoga a la del suelo. Demostrando la selectividad del método debido a que no existe ninguna interferencia que eluya a los tiempos de retención de los compuestos, como se puede apreciar en los cromatogramas que aparecen en la Figura 45.

En cuanto al resto de los parámetros de validación, se detallan para la detección ESI-MS en la siguiente Tabla 56.

Como se puede observar en la Tabla 56, los límites de detección y cuantificación que se obtienen son menores que los que se obtienen en suelo, estando los LOD, para todos los compuestos comprendidos entre 0.08 y $0.5 \mu \mathrm{g} / \mathrm{L}$ y $\operatorname{los}$ LOQ entre 0.26 y $1.7 \mu \mathrm{g} / \mathrm{L}$.

La curva de calibrado para la determinación de los compuestos, se realizó sin necesidad de realizar un calibrado en matriz, mostrando los resultados una buena linealidad en el intervalo de concentraciones estudiado, con coeficientes de correlación superiores en todos los casos al 0.99.

En cuanto a la precisión tanto en el día como entre días, los resultados que se obtuvieron fueron en todos los casos inferiores al $8 \%$ y los valores de la exactitud calculados variaban entre el 2.3 y 7.9 . 


\begin{tabular}{|c|c|c|c|c|c|c|c|c|c|c|c|c|c|c|}
\hline & 战 & $\begin{array}{l}0 \\
0 \\
0\end{array}$ & ले & อे & ঃ & 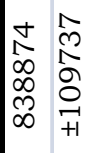 & $\begin{array}{l}0 \\
0 \\
o \\
⿱ 亠 乂 \\
m \\
n\end{array}$ & 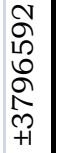 & $\begin{array}{l}\infty \\
\text { ळे } \\
0\end{array}$ & $\begin{array}{l}\dot{0} \\
\dot{10}\end{array}$ & $\stackrel{0}{\sim}$ & $\begin{array}{l}\infty \\
\dot{\sigma}\end{array}$ & $\begin{array}{l}\infty \\
\dot{+}\end{array}$ & \\
\hline 8 & $\bigcup_{\mid=1}$ & $\begin{array}{l}0 \\
0 \\
0\end{array}$ & ڤ̊ & $\stackrel{1}{m}$ & ঃ & 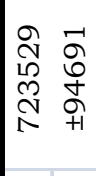 & 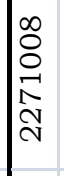 & 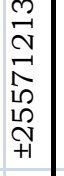 & बू & $\stackrel{\vec{r}}{\dot{H}}$ & $\stackrel{9}{0}$ & $\begin{array}{l}\text { Nִ } \\
\text { ip }\end{array}$ & 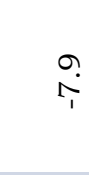 & \\
\hline 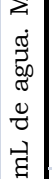 & 兵 & $\begin{array}{l}\infty \\
0 \\
0\end{array}$ & $\begin{array}{l}\text { ஸे } \\
0\end{array}$ & $\begin{array}{l}\dot{1} \\
\stackrel{1}{0} \\
0\end{array}$ & $\stackrel{8}{\circ}$ & $\begin{array}{ll}N & N \\
N & N \\
\sim & 0 \\
O & 0 \\
\wp & N \\
\forall & +1\end{array}$ & $\begin{array}{l}q \\
\stackrel{1}{1} \\
\hat{\alpha} \\
\hat{D} \\
\infty \\
\infty \\
-1\end{array}$ & 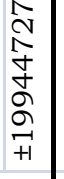 & $\begin{array}{l}\text { مू } \\
\text { बे }\end{array}$ & $\begin{array}{l}\stackrel{0}{\oplus} \\
\dot{m}\end{array}$ & $\stackrel{\mathscr{r}}{\dot{\gamma}}$ & $\stackrel{q}{r}$ & 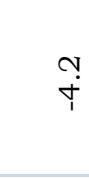 & \\
\hline 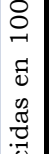 & คิ & 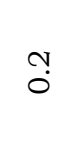 & $\hat{0}$ & $\stackrel{1}{\circ}$ & ঃ & 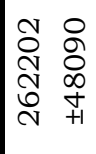 & $\begin{array}{l}\text { O } \\
\text { O } \\
\text { O } \\
\text { Oे } \\
\text { - }\end{array}$ & $\begin{array}{l}0 \\
N \\
\sigma \\
N \\
10 \\
-1 \\
0 \\
+1\end{array}$ & $\begin{array}{l}\text { बू } \\
\text { ல }\end{array}$ & $\stackrel{\sim}{\stackrel{\gamma}{*}}$ & $\begin{array}{l}\infty \\
\dot{10}\end{array}$ & ט? & $\vec{m}$ & \\
\hline $\begin{array}{l}\tilde{0} \\
0 \\
0 \\
0 \\
a \\
0 \\
0 \\
0 \\
0\end{array}$ & ठ̊ & $\stackrel{+}{\circ}$ & $\stackrel{?}{r}$ & ભे & ○ & 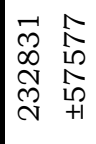 & 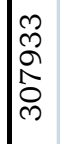 & \begin{tabular}{l}
$\infty$ \\
1 \\
$\Lambda$ \\
+ \\
\multirow{1}{N}{} \\
0 \\
+1
\end{tabular} & $\begin{array}{l}0 \\
\text { ूे } \\
\vdots\end{array}$ & $\stackrel{+}{\dot{H}}$ & $\begin{array}{l}G \\
\text { in }\end{array}$ & $\begin{array}{l}\infty \\
\stackrel{+}{+}\end{array}$ & 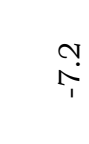 & \\
\hline 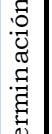 & Q & $\stackrel{+}{\circ}$ & $\stackrel{+}{-}$ & ले & $\underset{一}{8}$ & $\mid \begin{array}{cc}0 & \infty \\
O & \infty \\
0 & \infty \\
\infty & 0 \\
-1 & +1\end{array}$ & 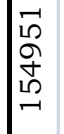 & $\begin{array}{l}\widehat{N} \\
\stackrel{-}{\sigma} \\
\infty \\
\infty \\
+1 \\
+1\end{array}$ & $\begin{array}{l}\infty \\
\text { ळू } \\
0 \\
0\end{array}$ & $\stackrel{\varphi}{\dot{\sigma}}$ & $\stackrel{\vec{t}}{\overrightarrow{0}}$ & $\stackrel{\leftrightarrow}{\sigma}$ & $\stackrel{\vec{t}}{\overrightarrow{0}}$ & \\
\hline 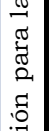 & 㞩 & in & $\stackrel{\sim}{\sim}$ & $\stackrel{1}{r}$ & 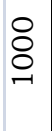 & $\mid \begin{array}{lll}0 & 2 \\
& 2 \\
& \infty \\
& +1\end{array}$ & 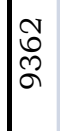 & 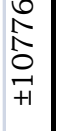 & $\begin{array}{l}\text { बे } \\
\text { ळे }\end{array}$ & ֻั & $\stackrel{?}{\sim}$ & Pִ & $\begin{array}{l}0 \\
\dot{\varphi} \\
\dot{\varphi}\end{array}$ & \\
\hline 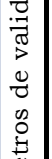 & U & $\overbrace{0}^{\infty}$ & نـ & ’ & ঃ & 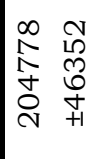 & $\begin{array}{l}\infty \\
10 \\
0 \\
10 \\
0 \\
-1\end{array}$ & 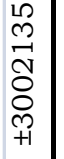 & $\begin{array}{l}\infty \\
\text { ळू } \\
0 \\
0\end{array}$ & $\begin{array}{l}\infty \\
\dot{m}\end{array}$ & $\stackrel{\infty}{\stackrel{\infty}{+}}$ & $\vec{p}$ & $\stackrel{+}{+}$ & \\
\hline 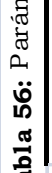 & $B$ & $\overbrace{0}^{\infty}$ & $\stackrel{\sim}{\sim}$ & $\stackrel{1}{-}$ & ঃ & 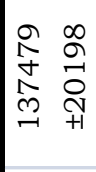 & 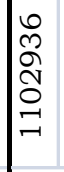 & $\begin{array}{l}0 \\
0 \\
-1 \\
0 \\
0 \\
m \\
+1 \\
+1\end{array}$ & बू & $\begin{array}{l}\stackrel{\varphi}{\oplus} \\
\dot{m}\end{array}$ & $\stackrel{+}{+}$ & $\begin{array}{l}n \\
\stackrel{N}{i}\end{array}$ & $\stackrel{\sim}{i}$ & 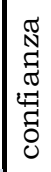 \\
\hline$\stackrel{\sigma \sigma}{\sigma}$ & & 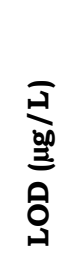 & 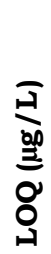 & 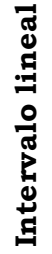 & 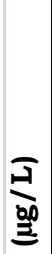 & 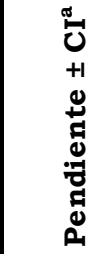 & & 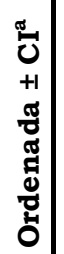 & 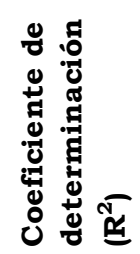 & 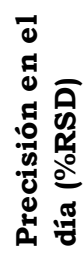 & 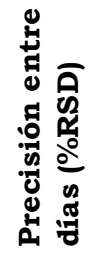 & 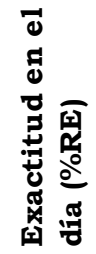 & 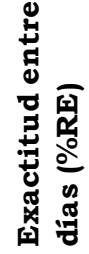 & 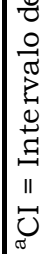 \\
\hline
\end{tabular}


Al igual que en el estudio anterior realizado para la determinación de cuatro rodenticidas en agua, se intentó disminuir los límites de detección y cuantificación aumentando el volumen de muestra a tratar a $250 \mathrm{~mL}$, lo que conllevaba modificar las distintas variables que influian en la extracción de los analitos.

Se realizaron ensayos variando tanto los volúmenes de extractante como los tiempos de agitación, seleccionándose $40 \mathrm{~mL}$ de volumen de extractante y 25 minutos de agitación, ya que la utilización de volúmenes y tiempos mayores no se mejoraba la recuperación de los analitos.

También para este caso, $1 \mathrm{~mL}$ de metanol fue el volumen elegido para la reconstitución, ya que es suficiente para la disolución del residuo seco.

Se validó el método para este volumen del método y los resultados se muestran en la Tabla 57. 


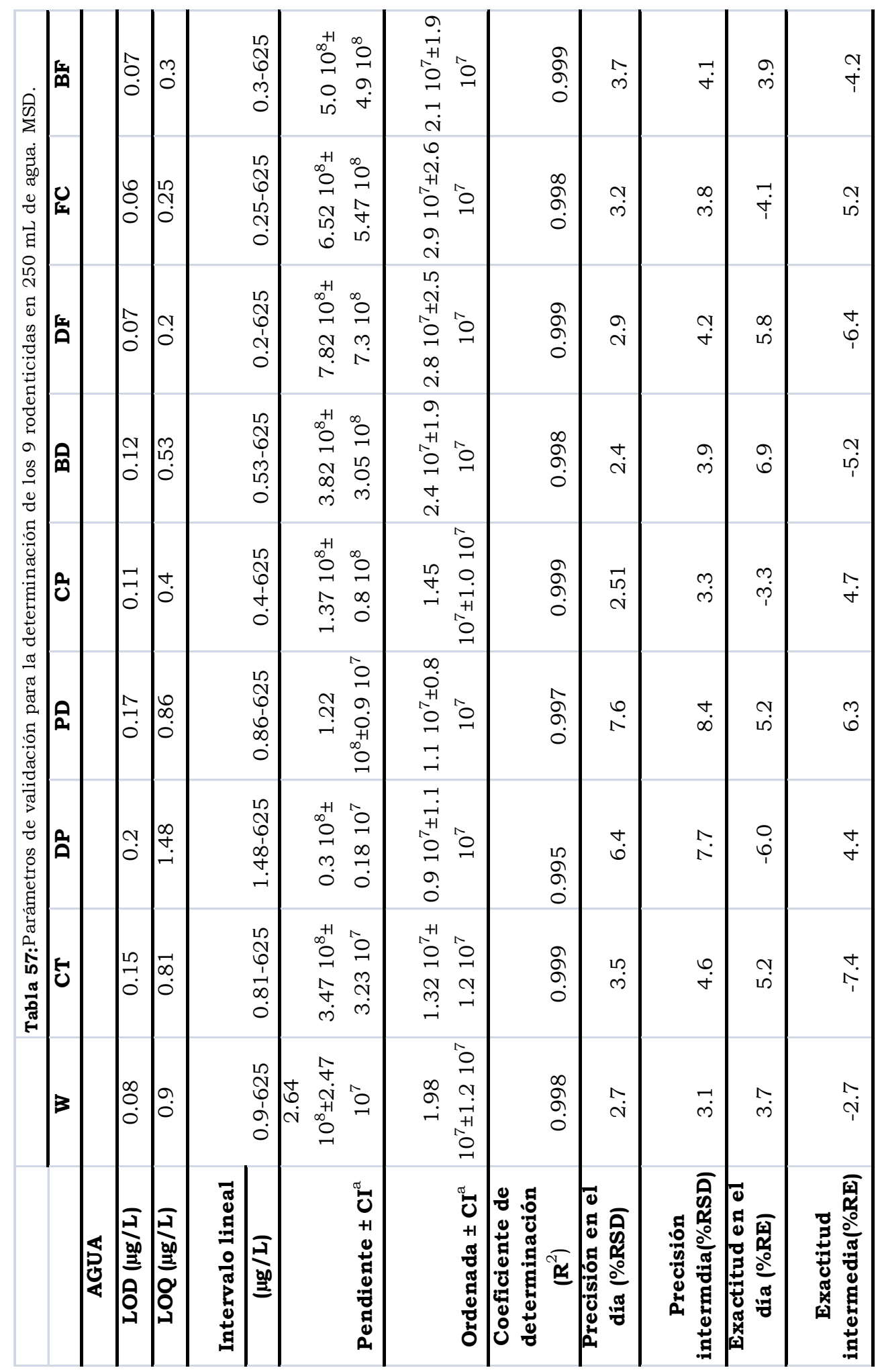




\section{VIII.3.2.- Aplicación del método}

Como en el caso de los suelos, el método se aplicó a 10 nuevas muestras de agua, no encontrándose residuos por encima de los LODs para ninguno de los rodenticidas estudiados. 


\section{IX.- CONCLUSIONES}



1. Se ha desarrollado un método cromatográfico para análisis de clorofacinona, bromadiolona, difenacum y brodifacum en suelo agrícola.

El tratamiento de muestra se realiza extrayendo con metanol y los porcentajes de recuperación superan el 90\%.

La separación se efectúa sobre una columna $\mathrm{C}_{18}$ con una fase móvil de metanol y formiato amónico $30 \mathrm{mM}(73: 27 \mathrm{v} / \mathrm{v})$ a $\mathrm{pH} 6,5$, en régimen isocrático, a $30^{\circ} \mathrm{C}$.

Para la detección se han empleado detectores de diodos en fila, de flurescencia y espectrométrico de masas con analizador cuadrupolar. Los límites de detección van desde $0,1 \mu \mathrm{g} / \mathrm{kg}$ en el detector de masas a los $50 \mu \mathrm{g} / \mathrm{kg}$ en los detectores de DAD y FLD.

2. Se ha desarrollado un método cromatográfico para análisis de clorofacinona, bromadiolona, difenacum y brodifacum en agua

Para el tratamiento de muestra se proponen dos opciones: una extracción sólido-líquido sobre relleno polimérico y una extracción líquido-líquido con acetato de etilo que proporciona porcentajes de recuperación más altos. Es de señalar la enorme influencia del $\mathrm{pH}$ sobre los porcentajes de recuperación, por lo que se propone efectuarla a $\mathrm{pH}$ 10, en presencia de AEDT.

Las condiciones cromatográficas fueron las mismas que para los suelos.

3. Se ha examinado la liberación de clorofacinona y bromadiolona en aguas y suelos, bien por el empleo de grano o pastillas que contenían el rodenticida.

En agua se observa una liberación más rápida a partir del cebo en grano, con un pico de mayor liberación antes de los 10 días. La pastilla, por el 
contrario, tiene una liberación más lenta pero obviamente más prolongada en el tiempo.

En los ensayos de lixiviación en suelos ha sido muy dificil reproducir en el laboratorio las condiciones reales en campo, lo que se observa es que en profundidad se mantienen mucho más tiempo que en superficie donde se produce una germinación de los granos y una disgregación de las pastillas. Por ello se recomienda introducir el cebo en las huras.

4. Se ha desarrollado metodología para la determinación de clorofacinona, bromadiolona, difenacum y brodifacum en muestras de hígado, intestino y músculo de topillo.

El tratamiento de muestra se realiza con metanol que se emplea para reconstituir el extracto evaporado proveniente del hígado, mientras que para intestino y músculo es preferible reconstituirlo con la fase móvil.

Las condiciones cromatográficas empleadas fueron las mismas que las propuestas para suelo y aguas.

5. Se ha estudiado la estabilidad en el laboratorio de los patrones de rodenticidas bajo distintas condiciones de luz y temperatura

Comprobándose que son estables al menos durante dos meses cuando se almacenan en recipientes ámbar y a una temperatura de $4^{\circ} \mathrm{C}$. La bromadiolona presenta una mayor velocidad de degradación.

6. Se ha desarrollado un método multirresiduo para análisis de clorofacinona, bromadiolona, difenacum, brodifacum, warfarina, pindona, cumatetralilo, difacinona y flocumafen en muestras de agua y suelo agrícola. 
Para la extracción en suelos hubieron de modificarse las condiciones iniciales pasando a una mezcla de metanol y formiato amónico $30 \mathrm{mM}$ a pH 4,4 (92:8,V/V) como más idónea.

La fase móvil ahora está constituida por $40 \%$ formiato amónico $30 \mathrm{mM}+$ DBA $20 \mathrm{mM}$ a pH 4,4 y $60 \%$ de metanol. Se propone un gradiente tanto de concentración como de $\mathrm{pH}$.

7. Los métodos puestos a punto se han aplicado al análisis de 134 muestras de suelo agricola recogidas en zonas con distinta intensidad del tratamiento rodenticida y 7 muestras de agua del entorno de los campos donde mayor aplicación se efectuó.

Los resultados no muestran una incidencia significativa del tratamiento sobre las muestras entregadas 

X.- BIBLIOGRAFÍA 

Addison, J. B.; Improved method for high pressure liquid chromatography determination of chlorophacinone in mouse tissue. J. Assoc. of Anal. Chem. 65 (1982)1299-1301.

Albert, C. A.; Wilson, L. K.; Mineau, P.; Trudeau, S.; Elliott, J. E.; Anticoagulant Rodenticides in Three Owl Species from Western Canada, 1988-2003. Archives of Environ Cont. and Toxicol. 58 (2) (2010) 451-459.

Anastassiades, M.; Lehotay, S. J.; Stajnbaher, D.; Schevick, I. J.; Fast and easy multiresidue method employing acetonitrile extraction/partition and dispersive solid phase extraction for the determination of pesticide residues in produce. J. AOAC. Int. 86 (2003) 412-431.

André, C.; Guyon, C.; Thomassin.; Barbier, A.; Richert, L.; Guillaume, Y.; Association mechanism between a series of rodenticide and humic acid: A frontal analysis to support the biological data. J. Chromatogr. B. 820 (2005) 9-14.

Armentano, A.; Iammarino, M.; Lo Magro, S.; Muscarella, M.; Validation and application of multi-residue analysis of eight anticoagulant rodenticides by high-performance liquid chromatography with fluorimetric detection. J. Vet. Diagnostic Invent. 24 (2) (2012) 307-311.

Askham, L. R.; Effectiveness of two anticoagulant rodenticides (Chlorophacinone and Bromadiolone) for Columbian ground squirrel (Spermophilus columbianus) control in eastern Washington. Crop Protection 4 (3) (1985) 365-371.

Berny, P. J.; Buronfosse, T.; Lorgue, G.; Anticoagulant poisoning in animals: a simple new high-performance thin-layer chromatographic (HPTLC) method for the simultaneous determination of eight anticoagulant rodenticides in liver samples. J. Anal. Toxicol. 19 (1995) 576-580. 
Berny, P.; Velardo, J.; Pulce, C.; Dámico, A.; Kammerer, M.; Lasseur, R.; Prevalence of anticoagulant rodenticide poisoning in humans and animals in France and substances involved. Clin. Toxicol. 48 (2010) 935-941.

Bland, P. D.; High pressure liquid chromatography determination of Brodifacum in formulations: collaborative study Rodenticides. J. Assoc. of Anal. Chem. 66 (1983) 993-999.

Brooks J.E. and Rowe F.P.; 1979. Control de Roedores Domésticos O.M.S / O.P.S. Publicación Científica $N^{\circ} 726$.

Buckle, A. P.; Smith, R. H.; Rodent Pest and their control. Exp. Agriculture. 31.03 (1994) 386-387.

Bullard, R. W.; Thompson, R. D.; Hulguin, G.; Diphendione residues in tissues of cattle. J. Agric. Food Chem. 24 (1976) 261-263.

Cai, M.; Dong, X.; Chen, X.; Jin, M.; An assay for identification and determination of toxic rodenticide valone in serum by ion chromatography-electrospray ionization tandem mass spectrometry with ion trap detector. Talanta 78 (1) (2009) 242-247.

Chen, X.; Cai, M.; Jin, M.; Analysis and Confirmation of Rodenticide Pindone in Human Plasma by IC-ESI-IT-MS. Chromatographia 70 (2009) 1201-1206.

Dunley, P. A.; Campbell, E. W.; Lindsey, G. D.; Broadcast application of a placebo rodenticide bait in a native Hawaiian forest. Int. J. Biodeter. Biodegrad. 45 (2000) 199-208.

Eason, C. T.; Murphy, E. C.; Wright; Spurr, E. B.; Assessment of risks of Brodifacum to non-target birds and mammals in New Zealand. Ecotoxicology, 11 (2002) 35-48. 
Ecobichon, D. J.; Toxic effects of pesticides, in Haasen. CD Editor. The basic science of Poisons, N. Y. McGraw Hill. 2001, 763-810.

Environmental Protection Agency. EPA`S final risk mitigation decision for ten rodenticides (May 28, 2008).

EVPMC9. European Vertebrate Pest Management Conference, Turku, Finland 22-27.9(2013). O1. Jens Jacobs: Common vole outbreaks in Germany: economic significance and management actions.

Fisher, P.; Funnell, E.; Fairweather, A.; Brown, L.; Campion, M.; Accidental discharge of Brodifacum baits into a freshwater lake: A case study. Bull. Environ. Contam. Toxicol. 88 (2012) 226-228.

Fournier-Chambrillon, C.; Berny, P. J.; Coiffier, O.; Barbedienne, P.; Dasse, B.; Delas, G.; Galineau, H.; Mazet, A.; Pouzenc, P.; Rosoux, R.; Fournier, P.; Evidence of secondary poisoning of free-ranging riparian mustelids by anticoagulant rodentticides in France: implications for conservation of European mink (Mustela lutreola). J. of Wildlife Diseases. 40 (4) (2004) 688-695.

Giorgi, M.; Mengozzi, G.; An HPLC Method for the Determination of Bromadiolone Plasma Kinetics and its Residues in Hen Eggs. J. Chromatogr. Sci. 48 (2010) 714-720.

Giradoux, P.; Tremollieres, C.; Barbier, B.; Defaut, R.; Rieffel, D.; Bernard, N.; Lucot, E.; Berny, P.; Persistence of bromadiolone anticoagulant rodenticide in Arvicola terrestris populations after field control. Environ. Res. 102 (2006) 291-298. 
Gray, A.; Eadsforth, C. V.; Dutton, A.; The toxicity of three secondgeneration rodenticides to barn owls. Pest. Sci. 42, 3 (1994) 179-181.

(b)Gray, A.; Eadsforth, C. V.; Dutton, A.; Vaughan, J. A.; Non invasive method for monitoring the exposure of barn owls to second generation rodenticides. Pest. Sci. 41, 4 (1994) 339-343.

Greaves, J.H.; La lucha contra los roedores en la agricultura. Estudio de la F.A.O. $\mathrm{N}^{\circ}$ 40. 1984. 88 pgs.

Groboscht, T.; Angelow, B.; Schouberg, L.; Lampe, D.; Acute bromadiolone intoxication. J. Anal. Toxicol 30 (2006) 281-286.

Guermouche, M. H.; Bensalah, K.; LC and SPE Determination of Chlorophacinone in Corn Grains, Soil and Rat Plasma. Chromatographia 67 (2008) 63-68.

Hao,Y., Dong,X., Liang,S., Sun,H., Analysis of four anticoagulants rodenticidas in foodstuff and body fluids by high performance liquid chromatography with photodiode array detector. Anal. Methods 6(7) (2014) 2356-2362

Hernández-Moreno,D., De la Casa Resino, I., López-Beceiro, A., Soler Pérez,M., Secondary poisoning of non-target animals in an ornithological zoo in Galicia (NW Spain) with anticoagulant rodenticides. A case report. Veterinary Med.58(10) (2013)553-559

Hunter, K.; High-performance liquid chromatographic strategies for the determination and confirmation of anticoagulant rodenticide residues in animal tissues. J. Chromatogr. 321 (1985) 255-272. 
Hunter, K.; Determination of coumarin anticoagulant rodenticide residues in animal tissue by high-performance liquid chromatography. J. Chromatogr. 270 (1983) 267-276.

Hunter, K. Sharp, E. A.; Newton, A.; Determination of diastereoisomers of bromadiolone, an anticoagulant rodenticide, in animal tissues by highperformance liquid chromatography. J. Chromatogr. 435 (1988) 83-95.

Hunter, K. Sharp, E. A.; Modification to procedures, J. Chromatogr. 437 (1)(1988) 301-305.

IUPAC.2002.Thompson, M., Ellison, S.L.R., Wood, R., Harmonized guidelines for single-laboratory validation of methods of analysis. Pure Appl. Chem. 74 (2002) 835-855

Ishizuka, M.; Tanikawa, T.; Tanaka, X. D.; Heewon, M.; Okajima, F.; Sakamoto, K. Q.; Pesticide resistance in wild mammals: Mechanisms of anticoagulant resistance in wild rodents. J. Toxicol. Sci. 33 (2008) 283291.

Jin, M.; Cai, M.; Chen X.; An yttrium-sensitized luminescence system and its application for the determination of trace chlorophacinone in serum. Anal. Biochem. 413 (2011) 142-147.

Jin, M.; Ouyang, X. K.; Chen X.; High-performance liquid chromatography coupled with electrospray ionization tandem mass spectrometry for the determination of Flocumafen and Brodifacum in whole blood. J. Appl. Toxicol. 27 (2007) 18-24. 
Jin, M.; Xu, G.; Ren, Y.; Chen X.; Xu, X.; Identification and determination of coumatetralyl and coumafuryl in animal tissues by high-performance liquid chromatography coupled with electrospray ionization tandem mass spectrometry. J. Appl.Toxicol. 28 (2008) 621-627.

Jin, M.; Chen X.; Zhu, Y.; Determination of five 4-hydroxycoumarin rodenticides in animal liver tissues by ion chromatography with fluorescence detection. J. Chromatogr. A. 1155 (2007) 57-61.

Jin, M.; Chen, X.; Ye, M.; Zhu, Y.; Analysis of indandione anticoagulant rodenticides in animal liver by eluent generator reagent free ion chromatography coupled with electrospray mass spectrometry. J. Chromatogr. A 1213 (2008) 77-82.

Jones, A.; HPLC determination of anticoagulant rodenticide residues in animal livers. Bull Environ. Contam. Toxicol. 56 (1996) 8-15.

Katona B. and Wason S.; Superwarfarin poisoning. J. Emerg. Med. 1989; 7: 627-631.

Kawano, Y.; Chang, W.; Spectrophotometric determination of Rozol in paraffinized formulations. J. Assoc. of Anal. Chem. 42 (1980) 996-998.

Kinsella, B.; Lehotay, S. J.; Mastovska, K.; Lightfield, A. R.; Furey, A.; Danaher, M.; New method for the analysis of flukicide and other anthelmintic residues in bovine milk and liver using liquid chromatography-tandem mass spectrometry. Anal. Chim. Acta 637 (2009) 196- 207.

Kohn, M. H:; Pelz, H. J.; Wayne, R. K.; A gene-anchored map position of the rat warfarin-resistance locus, $\mathrm{Rw}$, and its orthologs in mice and humans. Blood 96 (5) (2000) 1996-1998. 
Lakticova, K.; Hromada, R.; Oudrasovic, M.; Legath, J.; Dureko, R.; Oudrasovicova, O.; Nowakovic, B. Saba, L.; Occurrence of Residues of Warfarin after its Application to Cereal Corps. Polish J. of Environ. Stud. 18.3 (2009) 405-419.

Langford,K.H., Reid,M., Thomas,K.V., The occurrence of a second generation anticoagulant rodenticidas in non-target raptor species in Norway. Sci.Total Environ.450-451, (2013)205-208

Langseth, W.; Nymozu, U.; Fresenius.; Determination of coumarin anticoagulant rodenticide residues in animal liver by high-performance liquid chromatography. J. Anal. Chem. 339 (1991) 249-252.

Lao, W.; Gay, J.; Enantioselective degradation of warfarin in soils. Chirality 24 (1) (2012) 54-59.

Last, J. A. The missing link: The story of Karl Paul Link. Toxicol Sci 66(2002) 4-6.

Lawrence, J. F.; Chalermchaikit, T.; Michael, J. M.; Multicomponent determination of 4-hydroxycoumarin anticoagulant rodenticidas in blood serum by liquid chromatography with fluorescence detection, J. Anal. Toxicol. 15 (1991) 126-129.

Lemus, J. A.; Bravo, C.; García-Montijano, M.; Palacin, C.; Ponce, C.; Magana, M.; Alonso, J. C.; Side effects of rodent control on non-target species: Rodenticides increase parasite and pathogen burden in great bustards. Sci. Total Environ. 409, 22 (2011) 4729-4734. 
Letta, J. M.; Koskinen, W. C.; Multiresidue Analysis of Seven Anticoagulant Rodenticides by High-Performance Liquid Chromatography/Electrospray/Mass Spectrometry. J. Agric. Food Chem. 55 (2007) 571-576.

Locatelli, I.,Kmetec,V., Mrhar, A., Grabnar,I.; Determination of warfarin enantiomers and hydroxylated metabolites in human blood plasma by achiral and chiral separation. J. Chromatogr. B 818 (2005) 191-198.

Mack R. B.; Not all rats have four legs: Superwarfarin poisoning. N. C. Med. J. 1994; 55: 554-6.

Markussen, D. K.; Heiberg, A-C.; Fredholm, M.; Kristensen, M.; Differential expression of cytochrome P450 genes between bromadioloneresistant and anticoagulant-susceptible Norway rats: a possible role for pharmacokinetics in bromadiolone resistance, Pest Man. Sci. 64 (3) (2008) 239-248.

Medvedovici, A.; David, F.; Sandra, P.; Determination of the rodenticides warfarin, diphenadione and chlorophacinone in soil samples by HPLCDAD. Talanta 44 (1997) 1633-1640.

Mesmer, M. Z.; Flurer, R. A.; Determination of chlorophacinone and diphacinone in commercial rodenticides by liquid chromatography-UV detection and liquid chromatography- electrospray ionization mass spectrometry. J. Chromatogr. A. 891 (2000) 249-255.

Mura, P.; Piriou, A.; Papet, Y.; Lochon, D.; Reiss, D.; Rapid high performance liquid chromatography assay of chlorofacinone and diphacinone in human serum. J. Anal. Toxicol. 16 (1992) 179-181. 
Ogilvie, S. C.; Pierce, R. J.; Wright, G. R. G.; Booth, L. H.; Eason, C. T.; Brodifacum residue analysis in water, soil, invertebrates and birds after rat eradication on Lady Alice Island, New Zealand. J. of Ecology. 21,2 (1997). 195-197.

Olea, P. P.; Sanchez Barbudo, I. S.; Viñuela, J.; Barja, I.; Mateo-Tomás, P.; Piñeiro, A.; Lack of scientific evidence and precautionary principle in massive release of rodenticides threatens biodiversity: old lessons need new reflections. Environ. Conserv. 36 (2009) 1-4.

Opong-Wensah, K.; Porter, W. R.; Separation of some rodenticides and related compounds by thin-layer chromatography. J. Chromatogr. 455 (1988) 439-443.

Pelz, H-J.; Rost, S.; Huenerberg, M.; Fregin, A.; Heiberg, A.-C.; Baert, K.; MacNicoll, A. D.; Prescott, Colin V.; Walker, A-S.; Oldenburg, J.; Mueller, C. R.; The genetic basis of resistance to anticoagulants in rodents. Genetics 170 (4) (2005) 1839-1847.

Ploss1, F.; Giera, M.; Bracher, F.; Multiresidue analytical method using dispersive solid-phase extraction and gas chromatography-ion trap mass spectrometry to determine pharmaceuticals in whole blood. J. Chromatogr. B, 1135 (2006) 19-26.

Primus, T.; Kohler, D. J.; Johnston, J. J.; Determination of Diphacinone in Hawaiian invertebrates. J. Chromatogr. Sci. 44 (2006) 1-5.

Reynolds, J. D.; Extraction and identification of ten anticoagulant rodenticides from baits and stomach contents by high pressure liquid chromatography. Proc. Am. Assoc. Vet. Lab. Diagn. 23 (1980) 187-194. 
Ring, P. R.; Bostick, J. M.; Validation of a method for determination of (R)warfarin and (S)-warfarin in human plasma using LC with UV detection. J. Pharm. Biomed. Anal. 22 (2000) 573-581.

Sage, M.; Coeurdassier, M.; Defaut, R.; Lucot, R.; Barbier, B.; Rieffel, D.; Berny, P.; Giradoux, P.; How environment and vole behaviour may impact rodenticide bromadiolone persistence in wheat baits after field controls of Arvicola terrestris? Environ. Pollution 148 (2007) 372-379.

SANCO/12571/2013. Analytical method validation and performance criteria. Actualización de SANCO/ 12495/2011: Method validation \& Quality control procedure for pesticide residues analysis in Food\&Feed.

Semenza, J. C.; Menne, B.; Climate change and infectious diseases in Europe. Lancet Infest Dis. 9 (2009) 365-375.

Shore, R. F.; Malcom, H. M., Mclennan, D.; Turk, A; Walkor, L. A.; Wienburg, C. L. J.; Did foot-and-mouth disease control operations affect rodenticide exposure in raptors? Wild Manage. 70 (2006) 588-593.

Shore, R. F.; Birks, J. D. S.; Afsar, A.; Nienburg, C. L.; Kitcherner, A. L.; Spatial and temporal analysis of second-generation anticoagulant rodenticide residues in polecats (Mustela Putorius) from throughout their range in Britain 1992-1999. Environ. Pollution 122 (2003) 183-193.

Takahashi, H.; Kashima, T.; Kimura, S.; Muramoto, N.; Nakahata, H.; Kubo, S.; Echizen, H.; Determination of unbound warfarin enantiomers in human plasma and 7-hydroxywarafrin in human urine by chiral stationary-phase liquid chromatography with ultraviolet or fluorescence and on-line circular dichroism detection. J. Chromatogr. B 701 (1997) 7180. 
Thomas, P. J.; Mineau, P.; Shore, R. F.; Champoux, L.; Martin, P. A.; Wilson, L. K.; Second generation anticoagulant rodenticides in predatory birds: Probabilistic characterization of toxic liver concentrations and implications for predatory bird populations in Canada. Environ, Int.37 (2011) 914-920.

Tosh, D. G.; McDonald, R. A.; Bearhop, S.; Lilenellyn, N. R.; Fee, S., Sharp, E. A.; Does small mammal prey guild affect the exposure of predators to anticoagulant rodenticides?. Environ. Pollut. 159 (2011) 3106-3112.

Uno, T.; Niioka, T.; Hayabari, M.; Sugawara, K.; Tateishi, T.; Simultaneous detrmination of warfarin enantiomers and its metabolite in human plasma by column-switching high performance liquid chromatography with chiral separation. Ther.Drug Monit. 29 (2007) 333-339.

Vandenbrouke, V.; Desmet, N.; DeBacker, P. Croubels, S.; Multi-residue analysis of eight anticoagulant rodenticides in animal plasma and liver using liquid chromatography combined with heated electrospray ionization tandem mass spectroemtry. J. Chromatogr. B. 869 (2008) 101110.

Vidal, D.; Alzaga, V.; Luque-Larena, J. J.; Mateo, R.; Viñuela, J.; Possible interaction between a rodenticide treatment and a pathogen in common vole (Microtus arvalis) during a population peak. Sci. Total Environ. 408 (2009) 267-271.

Vien, J.; Grandemange, A; Cosson, J. F.; Benoit, E.; Berny, P. J.; Are water vole resistant to anticoagulant rodenticides following field treatments. Ecotoxicology 20 (2011) 1432-1441. 
Vigh, G.; Varga-Puchony, E.; Papp-Hites, E.; Hlavay, J.; Balogh, S.; Determination of chlorophacinone in formulations by reversed phase ionpair chromatography. J. Chromatogr. 214 (1981) 335-341.

Vudathala, D.; Cummings, M.; Murphy, L.; Analysis of Multiple Anticoagulant Rodenticides in Animal Blood and Liver Tissue Using Principles of QuEChERS Method. J. Anal. Toxicol. 34 (2010) 273-279.

Vyas,N.B., Huise,C.S.,Rice,C.P. Chlorophacinone residues in mammalian prey at a black-tailed praire dog colony. Environ.Toxicol and Chem. 31(11)(2012)2513-2516

Wallace, M.E.; Macswinney, F.J.; 1976. (cit. en Brooks y Rowe). Control de Roedores Domésticos. Doc.W.H.O/V.P.C/79.276/ O.M.S.

Witmer (2011) Final report of USFWS Project: Retention time of chlorophacinone in the tissues of black-tailed prairie dogs. Exposed to chlorophacinone bait. U.S. Fish and Wildlife Service. Region 6. South Dakota.2011

Wong,Y.C., Norsyamimi,N., Wan-Nurdiyana,W.A. Determination of Paraquat residue level in sandy clay loam soil using high performance liquid chromatography . J. Basic \& App.Sciences,9(2013)566-577

World Health Organization (1995). Antocoagulant rodenticides. Environmental Health Criteria 175. World Health Organization. Geneva.

World Health Organization (1996). Data Sheets on pesticides. No 88 Bromadiolone WHO Geneva.

http://www.inchem.org/documents/pds/pds/pest88_e.htm 
Yan, H.; Xiang, P.; Zhu, L., Shen, M.; Determination of bromadiolone and Brodifacum in human blood using LC-ESI/MS/MS and its application in four superwarfarin poisoning cases. Forensic Sci. International 222 (2012) 313-317.

Yuen, S. H.; Determination of the rodenticides Difenacum and Brodifacum in finished baits by reversed-phase liquid chromatography. Analyst 103 (1978) 842-849.

Zhou, Q.; Yau, W. P.; Chan, E.; Enantioseparation of warfarin and its metabolites by capillary zone electrophoresis. Electrophoresis 24 (2003) 2617-2626.

Zuo, Z.; Wo, S. K.; Lo, C., M. Y.; Zhou, L.; Cheng, G.; You, J. H. S.; Simultaneous measurement of S-warfarin, R-warfarin, S-7hydroxywarfarin and R-7-hydroxywarfarin in human plasma by liquid chromatography-tandem mass spectrometry. J. Pharm. Biomed. Anal. 52 (2010) 305-310. 